Simulação de escoamento de fluidos em superfícies definidas por pontos não organizados

Kémelli Campanharo Estacio 


\title{
Simulação de escoamento de fluidos em superfícies definidas por pontos não organizados
}

\author{
Kémelli Campanharo Estacio
}

Orientador: Prof. Dr. Luis Gustavo Nonato

Co-orientador: Prof. Dr. Norberto Mangiavacchi

Tese apresentada ao Instituto de Ciências Matemáticas e de Computação - ICMC-USP, como parte dos requisitos para obtenção do título de Doutor em Ciências - Ciências de Computação e Matemática Computacional. 
Dedico este trabalho à minha querida familia, com muito amor. 



\section{Agradecimentos}

Agradeço a Deus por conceder-me persistência, disposição, inteligência e saúde necessárias para a realização deste trabalho. Ele tem abençoado a minha vida de todas as formas possíveis (imagináveis ou não), tem-me dado forças nos momentos mais difíceis e tem-me ensinado o quanto é bom confiar Nele.

Agradeço a minha família por todo o suporte durante essa caminhada. Agradeço todo o amor, a paciência, a preocupação, o apoio, o interesse, e a confiança. Este trabalho não teria sido possível sem a presença deles em minha vida.

Agradeço ao meu orientador Luis Gustavo Nonato por dar-me a oportunidade de realizar um dos meus maiores sonhos. Agradeço também ao meu querido co-orientador Norberto Mangiavacchi, que, mesmo à distância, teve papel fundamental na realização deste trabalho. Sou grata também ao Dr. Graham F. Carey, meu orientador durante o estágio no exterior, por sua disponibilidade, amizade, contribuição e interesse no sucesso deste trabalho, tornando minha permanência no exterior muito agradável e proveitosa.

Agradeço a todos os professores do ICMC/USP, do GESAR/UERJ e do ICES/UT que, direta ou indiretamente, contribuíram para o sucesso deste trabalho.

Agradeço à FAPESP pelo suporte financeiro a esta pesquisa e à CAPES pelo suporte financeiro durante meu estágio na University of Texas at Austin por meio do projeto PDEE e também pelo suporte financeiro no início deste trabalho. Agradeço também a FURNAS Centrais Elétricas $\mathrm{S} / \mathrm{A}$ pelo auxílio financeiro às minhas viagens.

Agradeço aos meus colegas de trabalho do LCAD - Laboratório de Computação de Alto Desempenho, do GESAR - Grupo de Ensaios e Simulações Ambientais em Reservatórios e do CFDLab - Computational Fluid Dynamics Laboratory pelas agradáveis (muitas) horas que passamos juntos, pelas discussões e colaborações.

Agradeço, por fim, a todas pessoas que de alguma maneira se tornaram especiais para mim e são bênçãos vivas em minha vida.

Kémelli. 

"Finalmente, irmãos, tudo o que é verdadeiro, tudo o que é respeitável, tudo o que é justo, tudo o que é puro, tudo o que é amável, tudo o que é de boa fama, se alguma virtude há e se algum louvor existe, seja isso o que ocupe o vosso pensamento."

(Filipenses 4:8) 



\section{Resumo}

Atualmente diversos produtos são fabricados por meio de injeção de polímeros, num processo denominado moldagem por injeção: material fundido é injetado em um molde no qual resfria e endurece. Contudo, ao contrário de outros processos de produção, a qualidade da peça criada por meio de moldagem por injeção não depende apenas do material e da sua forma geométrica, mas também da maneira na qual o material é processado durante a moldagem. Por esse motivo, o uso de modelagem matemática e simulações numéricas tem aumentado consideravelmente como maneira de auxiliar o processo de produção e tem-se tornado uma ferramenta indispensável.

Desta forma, este projeto tem o propósito de simular o escoamento de fluidos durante a fase de preenchimento do processo de moldagem por injeção, utilizando o modelo

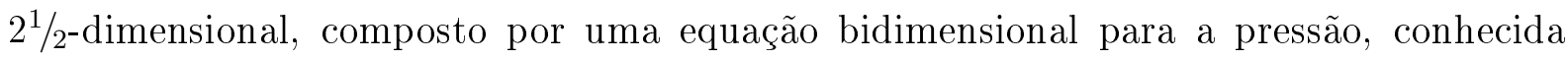
como equação de Hele-Shaw, e uma equação tridimensional para a temperatura do fluido. Um modelo bidimensional para a temperatura é também desenvolvido e apresentado.

Este projeto de doutorado propõe duas estratégias numéricas para a solução da equação de Hele-Shaw. A primeira delas é baseada em uma formulação euleriana do método Smoothed Particle Hydrodynamics, onde os pontos utilizados na discretização não se movem, e não há utilização de malhas. A segunda estratégia é baseada na criação de malhas dinamicamente construídas na região do molde que já encontra-se parcialmente cheio de fluido e subseqüente aplicação do método Control Volume Finite Element Method. Uma estratégia dinâmica do método semi lagrangeano é apresentada e aplicada à solução da equação bidimensional da temperatura. O projeto também pretende investigar três novas abordagens para o tratamento da superfície livre. Duas delas são baseadas na técnica Volume of Fluid e uma delas é uma adaptação meshless do método Front-Tracking.

O comportamento não newtoniano do fluido é caracterizado por uma família de modelos de viscosidade. Testes numéricos indicando a confiabilidade das metodologias propostas são conduzidos.

Palavras-chave: Equação de Hele-Shaw, superfície livre, fluidos não newtonianos, CVFEM, SPH, VOF, Front-Tracking, esquema semi-lagrangeano. 



\section{Abstract}

Currently, several plastic products are manufactured by polymer injection, in a process named injection molding: molten material is injected into a thin mold where it cools and solidifies. However, unlike other manufacturing processes, the quality of injection-molded parts depends not only on the material and shape of the part, but also on how the material is processed throughout the molding. For this reason, the use of mathematical modelling and numerical simulations has been increasing in order to assist in the manufacturing process, and it has become an essential tool.

Therefore, this Sc.D. project has the purpose of simulating the fluid flow during the filling stage of the injection molding process, using the $2^{1} / 2^{-}$dimensional model, compounded by a two-dimensional equation for the pressure field (also known as Hele-Shaw equation) and a three-dimensional equation for the temperature of the fluid. A simpler two-dimensional model for the temperature field is also derived and presented.

This project proposes two novel numerical strategies for the solution of Hele-Shaw equation. The first one is based on an Eulerian formulation of the Smoothed Particle Hydrodynamics method, where the particles used in the discretization do not move along as the simulation evolves, thereby avoing the use of meshes. In the second strategy, local active dual patches are constructed on-the-fly for each active point to form a dynamic virtual mesh of active elements that evolves with the moving interface, then the Control Volume Finite Element Method is applied for the pressure field approximation. A dynamic approach of the semi-Lagrangian scheme is applied to the solution of the two-dimensional temperature equation. The project also assesses three new approaches for the treatment of the free surface of the fluid flow. Two of them are based on the Volume of Fluid technique and one of them is a meshless adaptation of the Front-Tracking method.

The non-Newtonian behavior is characterized by a family of generalized viscosity models. Supporting numerical tests and performance studies, which assess the accuracy and the reliability of the proposed methodologies, are conducted.

Keywords: Hele-Shaw equation, free surface, non-Newtonian fluid, CVFEM, SPH, VOF, Front-Tracking, semi-Lagrangian. 



\section{Lista de Figuras}

2.1 Sistema de coordenadas locais para a cavidade de um molde. . . . . . . . 33

2.2 Escoamento em uma célula de Hele-Shaw. . . . . . . . . . . . . . . . . 37

2.3 Modelos de viscosidade generalizados. . . . . . . . . . . . . . . . 47

4.1 Modelo computacional para um método meshless mostrando a fronteira, as partículas e os suportes. . . . . . . . . . . . . . . 56

4.2 Seqüência de Gaussianas aproximando a distribuição Delta de Dirac con-

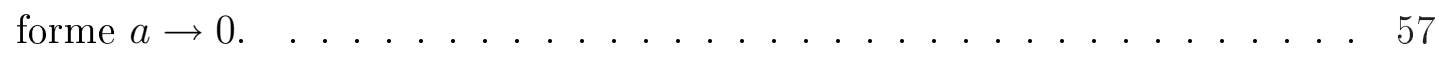

4.3 Exemplo de três funções peso comumente utilizadas: exponencial e splines de terceira e quarta ordem. . . . . . . . . . . . . . . . . . 59

4.4 Volume associado ao ponto $i$. . . . . . . . . . . . . 63

4.5 Norma $L_{2}$ do erro cometido na aproximação da equação de Laplace. . . . . 68

4.6 Ordem de convergência $q$ do método proposto. . . . . . . . . . . . . . . . . 69

4.7 Dimensões do canal e região de injeção (área hachurada) . . . . . . . . . . . 69

4.8 Molde retangular com um canal de entrada e diferentes espessuras. A região de injeção de fluido está representada pela área hachurada. . . . . . . . . . 71

4.9 Perfis de pressão na região de injeção de fluido ao longo da simulação. Valores obtidos pelo presente método são comparados com os resultados de Chang e Yang (2001) . . . . . . . . . . . . . . . . . 72

4.10 Diversos perfis da posição da superfície livre durante o preenchimento do molde. As posições preditas pelo método estão de acordo com os resultados obtidos por Chang e Yang (2001) . . . . . . . . . . . . . . . . . 73

4.11 Resultados de Chang e Yang (2001) para a posição da superfície livre. A linha tracejara representa o modelo $2^{1} / 2 \mathrm{D}$ e a malha representa um modelo

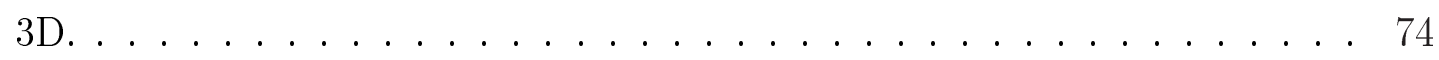

4.12 Dimensões do molde em formato de chave. . . . . . . . . . . . . . . . . 75

4.13 Malha não estruturada triangular utilizada na aproximação por volumes finitos, e pontos definindo a geometria do molde, utilizados na metodologia proposta. 
4.14 Perfil da velocidade na região de injeção de fluido. . . . . . . . . . . . . . 76

4.15 Seis estágios da distribuição de pressão durante o preenchimento do molde obtidos usando o método dinâmico implementado. A pressão na região de injeção aumenta no decorrer do enchimento do molde resultante da imposição de velocidade prescrita e constante na região de injeção de fluido. 77

4.16 Perfil da pressão na região de injeção de fluido durante a simulação. . . . . 78

4.17 Comparação da posição da superfície livre predita pelo presente método (azul) e o método de Estacio e Mangiavacchi (2007) (preto). A linha representa a superfície livre: a região à esquerda da linha encontra-se cheia de fluido enquanto a região à direita da linha encontra-se vazia. . . . . . . 78

4.18 Três diferentes vistas do conjunto de pontos definindo o molde do Piu-Piu. 79

4.19 Seis estágios da distribuição da pressão durante o preenchimento do molde. Os valores estão divididos por $p_{0}=10^{5} \mathrm{~N} / \mathrm{m}^{2}$. . . . . . . . . . . . 79

4.20 Seis estágios do campo de velocidade. . . . . . . . . . . . . . . 80

5.1 Malha não estruturada triangular e volumes de controle. . . . . . . . . . 82

5.2 Volume de controle associado ao vértice $i$. . . . . . . . . . . . . . . 83

5.3 Elemento triangular. . . . . . . . . . . . . . . . . . . 84

5.4 Os ângulos $N_{P} P N_{1}$ e $N_{P} P N_{1}$ são pequenos implicando na formação de um único cluster. . . . . . . . . . . . . . . . . . . . . . . . . . . . 92

5.5 Os ângulos $N_{P} P N_{1}$ e $N_{P} P N_{2}$ são pequenos, mas os ângulos $N_{P} P N_{3}$ e $N_{P} P N_{4}$ não são, implicando na formação de dois clusters. . . . . . . . . . 92

5.6 Procedimento de inserção para pontos de fronteira: o método tenta inserir um novo ponto $N_{O}$ na direção oposta à do vetor formado de $P$ a $N_{P}$. A inserção não é realizada porque o novo ponto está fora do domínio. ... . 93

5.7 Procedimento de inserção para pontos de fronteira: o método tenta inserir um novo ponto $N_{O}$ na direção oposta à do vetor formado de $P$ a $N_{P}$. A inserção não é realizada porque a distância entre $P$ e $N_{O}$ é menor que uma tolerância $\varepsilon$ pré-definida. . . . . . . . . . . . . . . . . . 93

5.8 Procedimento de inserção para pontos de fronteira: o método tenta inserir um novo ponto $N_{O}$ na direção oposta à do vetor formado de $P$ a $N_{P}$. A inserção é realizada com sucesso.

5.9 Procedimento de inserção de pontos no interior da superfície livre: se a distância entre $P$ e seu vizinho mais próximo $N_{P}$ é maior que metade do raio da circunferência centrada em $P$ e maior do que $\varepsilon$ então o método insere um novo ponto $N_{B}$ entre os pontos $P$ e $N_{P} \ldots \ldots$. . . . . . . 94 
5.10 Procedimento de inserção de pontos no interior da superfície livre: se a distância entre $P$ e seu vizinho mais próximo $N_{P}$ é maior que metade do raio da circunferência centrada em $P$ e do que $\varepsilon$ então o método insere um novo ponto $N_{B}$ entre os pontos $P$ e $N_{P}$. Inserção não realizada porque o segundo critério não é satisfeito. . . . . . . . . . . . . . . . . . . . . . . . . 94

5.11 Marcação dos vértices/volumes de controle durante o preenchimento de um molde. Vértices centros de volumes de controle cuja estrela (demais triângulos que compõem tal volume) apresentam vértices com $\phi=0 \mathrm{e}$ $\phi=1$ são marcados com $\phi=0,5 \ldots \ldots \ldots \ldots \ldots$

5.12 Norma $L_{2}$ do erro cometido na aproximação da equação de Laplace. . . . . 100

5.13 Ordem de convergência $q$ do método proposto. . . . . . . . . . . . . . . 101

5.14 Dimensões do canal e região de injeção (área hachurada) . . . . . . . . . . . 101

5.15 Comparação dos perfis da pressão na região de injeção durante o preenchimento do molde. Valores obtidos pelo método proposto e pelo método baseado em malhas de Estacio e Mangiavacchi (2007) considerando um fluido newtoniano com $\eta_{0}=4 \times 10^{6}$ Pa s. . . . . . . . . . . . . 102

5.16 Comparação dos perfis da pressão na região de injeção durante o preenchimento do molde. Valores obtidos pelo método proposto e pelo método baseado em malhas de Estacio e Mangiavacchi (2007) considerando um fluido de Cross com parâmetros descritos na Tabela 2.1 da Seção 2.9 . .. 102

5.17 Erro relativo cometido pelo método proposto ao predizer o tempo de preenchimento do molde descrito na Figura 5.14. . . . . . . . . . . . . . . . . 104

5.18 Ordem de convergência do método proposto. Valores ilustram que a ordem de convergência é aproximadamente linear. . . . . . . . . . . . . . . . . 104

5.19 Erro relativo cometido pelo método proposto ao predizer o campo bidimensional de temperatura ao final do preenchimento do molde descrito na Figura 5.14． . . . . . . . . . . . . . . . . 106

5.20 Ordem de convergência do método proposto. Valores ilustram que a ordem de convergência é aproximadamente linear. . . . . . . . . . . . . . . . . . . 107

5.21 Molde retangular com um canal de entrada. A região de injeção é representada como a área hachurada na figura. . . . . . . . . . . . . . . . . 107

5.22 Comparação do perfil da pressão na região de injeção de fluido obtido pelo método proposto com o resultado de Chang e Yang (2001) durante o preenchimento do molde descrito na Figura 5.21. . . . . . . . . . . 108

5.23 Diversas etapas do avanço da superfície livre durante o preenchimento do molde descrito na Figura 5.21. Os resultados obtidos via método proposto estão de acordo com aqueles apresentados no trabalho de Chang e Yang (2001) . . . . . . . . . . . . . . . . . . . 109 
5.24 Resultados de Chang e Yang (2001). A linha tracejada representa as posições da superfície livre durante o preenchimento utilizando um modelo $2^{1} / 2 \mathrm{D}$, enquanto a malha representa um modelo 3D. . . . . . . . . . . . . 109

5.25 Dimensões do molde e inserções (obstáculos interiores) . . . . . . . . . . . 110

5.26 Evolução da distribuição da pressão dentro do molde apresentado na Figura 5.25 representando uma régua de desenhar. . . . . . . . . . . . . . . . . . . 110

5.27 Evolução da distribuição bidimensional da temperatura durante o preenchimento do molde. . . . . . . . . . . . . . . . . . . . . . . . . . 111

5.28 Avanço da superfície livre do fluido. . . . . . . . . . . . . . . . . 111

6.1 Pontos utilizados em aproximações meshless e raios associados a cada ponto, cobrindo todo o domínio. . . . . . . . . . . . . . . . . . 114

6.2 Malha não estruturada triangular e volumes de controle associados. . . . . 114

6.3 Disco centrado no ponto $i$ contendo um subconjunto de pontos vizinhos a $i$, segundo um raio pré-determinado $R_{i}$. . . . . . . . . . . . . . . 115

6.4 Pontos vizinhos à $i$, ordenados. $t$ é um vetor de referência pertencente ao plano definido pelos pontos, e $n$ é o vetor normal a este plano. . . . . . . . 115

6.5 A triangulação define um caminho local e o volume de controle dinâmico é determinado pelo método das medianas. . . . . . . . . . . . . . . . . . 116

6.6 Determinação do volume local $V_{i}$ e fronteira $S_{i}$ associados ao ponto $i$ localizado na superfície livre do fluido. Somente pontos cheios de fluido, isto é, pontos apresentando $\phi=1$, são usados na aproximação da equação de

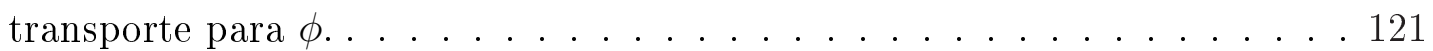

6.7 Dimensões do molde e região de injeção de fluido (área hachurada). . . 126

6.8 Erro relativo cometido pelo método proposto ao predizer o tempo de preenchimento do molde descrito na Figura 6.7 . . . . . . . . . . . . 128

6.9 Ordem de convergência do método proposto. Valores ilustram que a ordem de convergência é aproximadamente linear. . . . . . . . . . . . . . . . . . 128

6.10 Dimensões do molde em formato de canal e região de injeção de fluido (área hachurada). . . . . . . . . . . . . . . . . . . . . . . . . . . 129

6.11 Perfis de velocidade preditos para poliestireno usando vários modelos de viscosidade generalizada a dois valores médios da taxa de cisalhamento

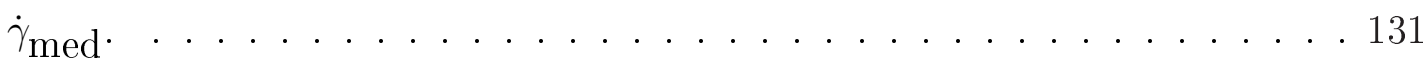

6.12 Perfis de viscosidade preditos pelos modelos generalizados de viscosidade para o caso de poliestireno a dois valores médios da taxa de cisalhamento

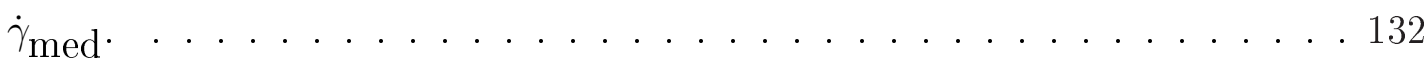

6.13 Norma $L_{2}$ do erro cometido pelo método proposto ao predizer o campo bidimensional de temperatura ao final do preenchimento do molde descrito na Figura 6.10. 
6.14 Molde retangular com um canal de entrada e uma inserção (buraco). A região de injeção é representada como a área hachurada na figura. . . . . . . 134

6.15 Comparação do perfil da pressão na região de injeção de fluido obtido pelo método proposto com o resultado de Chang e Yang (2001) . . . . . . . . . . 135

6.16 Diversas etapas do avanço da superfície livre durante o preenchimento do molde descrito na Figura 6.14. Os resultados obtidos via método proposto estão de acordo com aqueles apresentados no trabalho de Chang e Yang (2001) . . . . . . . . . . . . . . . . . . 136

6.17 Resultados de Chang e Yang (2001). A linha tracejada representa as posições da superfície livre durante o preenchimento utilizando um modelo $2^{1} / 2 \mathrm{D}$, enquanto a a malha representa um modelo 3D. . . . . . . . . . . . 136

6.18 Perfil da pressão na região de injeção de poliestireno durante o preenchimento de um molde retangular com um canal de entrada e uma inserção usando diversos modelos de viscosidade e velocidade de injeção prescrita $v_{\text {inj }}=3,7 \times 10^{-1} \mathrm{~m} / \mathrm{s} \ldots \ldots \ldots \ldots \ldots$. . . . . . . . . . . . . . . . .

6.19 Perfil da pressão na região de injeção durante o preenchimento do molde retangular com um canal de entrada e uma inserção de poliestireno representado por diversos modelos de viscosidade e usando $v_{\text {inj }}=2 \times 10^{-5} \mathrm{~m} / \mathrm{s} . \quad 138$

6.20 Visão do topo do molde e região de injeção de fluido representada por setas. A espessura do molde é constante e igual a $h=2 \times 10^{-3} \mathrm{~m}$. . . . . . . . . . 139

6.21 Comparação dos perfis da pressão na região de injeção durante o preenchimento do molde obtidos pelo método proposto e pelo método baseado em malhas de Estacio e Mangiavacchi (2007).

6.22 Evolução do campo de pressão para o caso do molde sendo preenchido com velocidade de injeção constante e igual a $v_{\text {inj }}=1,25 \times 10^{-2} \mathrm{~m} / \mathrm{s}$. . . . . . 140

6.23 Evolução do campo de temperatura bidimensional do fluido durante o preenchimento do molde. A temperatura do fluido no início da injeção é $T_{\text {inj }}=513$ K . . . . . . . . . . . . . . . . . . 140

6.24 Comparação entre a posição da superfície livre do fluido predita pelo método proposto (em branco) com a os resultados fornecidos por um método baseado em malhas. . . . . . . . . . . . . . . . . . . . . . . . . . . . . . . . 141

6.25 Detalhe do avanço da superfície livre do fluido ao redor de algumas das inserções presentes do molde da calculadora. . . . . . . . . . . . . . . . . . 142 



\section{Lista de Tabelas}

2.1 Parâmetros de modelos de viscosidade generalizados ajustados para representar poliestireno. . . . . . . . . . . . . . . . . . . . . 47

4.1 Erro cometido na solução da equação segundo a norma $L_{2}$, considerando-se pontos uniformemente e não uniformemente distribuídos em $\Omega$. . . . . . . 68

4.2 Velocidade do fluido ( $\mathrm{em} \mathrm{m} / \mathrm{s}$ ) quando o molde em formato de canal descrito na Figura 4.7 está parcialmente cheio $\left(\delta l=5 \times 10^{-2} \mathrm{~m}\right)$. Resultados obtidos usando distintos valores de pressão de injeção (em $P a$ ) imposta na região de entrada de fluido. Valores encontrados considerando-se o molde representado por 498 pontos ora com $N_{z}=5$ ora com $N_{z}=100$. . . . . . 70

4.3 Velocidade de fluido (em $\mathrm{m} / \mathrm{s}$ ) um molde em formato de canal obtida usando distintos valores de pressão de injeção (em $P a$ ) imposta na região de entrada de fluido. Valores encontrados considerando-se o molde descrito na Figura 4.7 parcialmente cheio e considerando se $N_{z}=5$ e $N_{z}=100$. . 71

5.1 Erro cometido na solução da Equação (5.30) segundo a norma $L_{2}$, considerando-se diversas malhas triangulares não estruturadas. . . . . . . . . . . 100

5.2 Erro relativo cometido na predição do tempo de preenchimento. Valores obtidos considerando-se diversas malhas triangulares não estruturadas. . 103

5.3 Erro cometido na solução da equação da temperatura segundo a norma $L_{2}$, considerando-se diversas malhas triangulares não estruturadas. . . . . . . . 106

6.1 Dados empregados no estudo da convergência do método e erro relativo

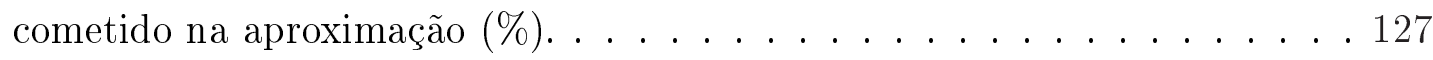

6.2 Pressão semi-analítica (em $P a$ ) na região de injeção do canal para vários modelos de viscosidades considerando quatro valores representativos da taxa de cisalhamento média do fluido $\dot{\gamma}_{\text {med }}$. Valores encontrados considerando o molde da Figura 6.10 preenchido pela metade e $N_{z}=1000$. . . . . 130 
6.3 Erro relativo (em \%) na estimativa do valor da pressão na região de injeção considerando quatro valores distintos da taxa de cisalhamento média $\dot{\gamma}_{\text {med }}=\frac{v_{\text {inj }}}{h}$. A integração numérica de $S_{2}$ é realizada considerando 5 e 100 camadas na direção transversal do molde. . . . . . . . . . . . . . . . . 131

6.4 Erro cometido na solução da equação da temperatura segundo a norma $L_{2}$, considerando-se diversos conjuntos de pontos. . . . . . . . . . . . . . . 133 


\section{Sumário}

\section{Lista de Figuras}

Lista de Tabelas

\section{Sumário}

1 Introdução 23

1.1 Proposta deste trabalho . . . . . . . . . . . . . . . . . . 25

1.2 Organização da tese . . . . . . . . . . . . . . . . . . 27

2 As equações governantes do escoamento de fluidos durante o preenchimento de moldes $\quad 29$

2.1 Considerações iniciais . . . . . . . . . . . . . . . . . . . . . . . . . . 29

2.2 O modelo matemático completo . . . . . . . . . . . . . . . . . 30

2.3 Suposições sobre o fluido . . . . . . . . . . . . . . . . . . . . . . 31

2.4 Suposições sobre a geometria do molde . . . . . . . . . . . . . . . . . . . . 32

2.5 Simplificação por análise matemática . . . . . . . . . . . . . . . 36

2.6 Simplificação devido à simetria . . . . . . . . . . . . . . . . . . . . 40

2.7 Simplificação adicional: modelo bidimensional para a temperatura . . . . . 41

2.8 Condições de contorno . . . . . . . . . . . . . . . . . . . . . . . . 45

2.9 Modelos de viscosidade . . . . . . . . . . . . . . . . . . . . . . . 46

2.10 Equações resultantes . . . . . . . . . . . . . . . . . . . . . . . 48

2.11 Considerações finais . . . . . . . . . . . . . . . . . . . . . 48

3 Desacoplamento iterativo das equações e discretização 49

3.1 Considerações iniciais . . . . . . . . . . . . . . . . . . . . . . 49

3.2 O modelo matemático . . . . . . . . . . . . . . . . . . . . 50

3.3 O processo iterativo de solução . . . . . . . . . . . . . . . . . . . 52

3.4 Considerações finais . . . . . . . . . . . . . . . . . . . . . . . 53

4 Métodos SPH euleriano e VOF dinâmico $\quad 55$

4.1 Considerações iniciais . . . . . . . . . . . . . . . . . . . 55 
4.2 Solução da equação de Hele-Shaw por SPH euleriano . . . . . . . . . . . 56

4.3 Avanço da superfície livre usando VOF dinâmico . . . . . . . . . . . . . . . 62

4.4 Algoritmo . . . . . . . . . . . . . . . . . . . 65

4.5 Verificações do método proposto . . . . . . . . . . . . . . 66

4.6 Resultados . . . . . . . . . . . . . . . . . . . . . 75

4.7 Comentários . . . . . . . . . . . . . . . . . . . 79

5 CVFEM, método semi lagrangeano e FT meshless 81

5.1 Considerações iniciais . . . . . . . . . . . . . . . . . . . . 81

5.2 Solução da equação de Hele-Shaw por CVFEM . . . . . . . . . . . . . 83

5.3 Solução da equação 2D da temperatura usando método semi lagrangeano . 88

5.4 Avanço da superfície livre usando meshless FT . . . . . . . . . . . . . . . . 91

5.5 Algoritmo . . . . . . . . . . . . . . . . . . . . . 96

5.6 Verificações do método proposto . . . . . . . . . . . . . . . . . . . . . . . 98

5.7 Resultados . . . . . . . . . . . . . . . . . . . . 108

5.8 Comentários . . . . . . . . . . . . . . . . . . . . . . . . 112

6 Métodos CVFEM, semi lagrangeano e VOF dinâmicos 113

6.1 Considerações iniciais . . . . . . . . . . . . . . . . . . . . . . . . . 113

6.2 Construção dinâmica dos volumes de controle . . . . . . . . . . . . . . . . 114

6.3 Solução da equação de Hele-Shaw por CVFEM dinâmico . . . . . . . . . . 116

6.4 Solução da equação 2D da temperatura via método semi lagrangeano dinâmico . . . . . . . . . . . . . . . . . . . . 118

6.5 Avanço da superfície livre usando VOF dinâmico . . . . . . . . . . . . . . 120

6.6 Algoritmo . . . . . . . . . . . . . . . . . . . . 123

6.7 Verificações do método proposto . . . . . . . . . . . . . . . . 126

6.8 Resultados . . . . . . . . . . . . . . . . . . . . . . 138

6.9 Comentários . . . . . . . . . . . . . . . . . . . . . 141

7 Comentários finais, contribuições e trabalhos futuros $\quad 145$

7.1 Publicações originadas da tese . . . . . . . . . . . . . . 147

7.2 Trabalhos futuros . . . . . . . . . . . . . . . . . . . 148

$\begin{array}{ll}\text { Referências Bibliográficas } & 149\end{array}$

A Análise dimensional das equações governantes $\quad 157$

A.1 Equação da continuidade . . . . . . . . . . . . . . . . . . . . 158

A.2 Equação da quantidade de movimento . . . . . . . . . . . . . . 158

A.3 Equação da temperatura . . . . . . . . . . . . . . . . . . . 163 


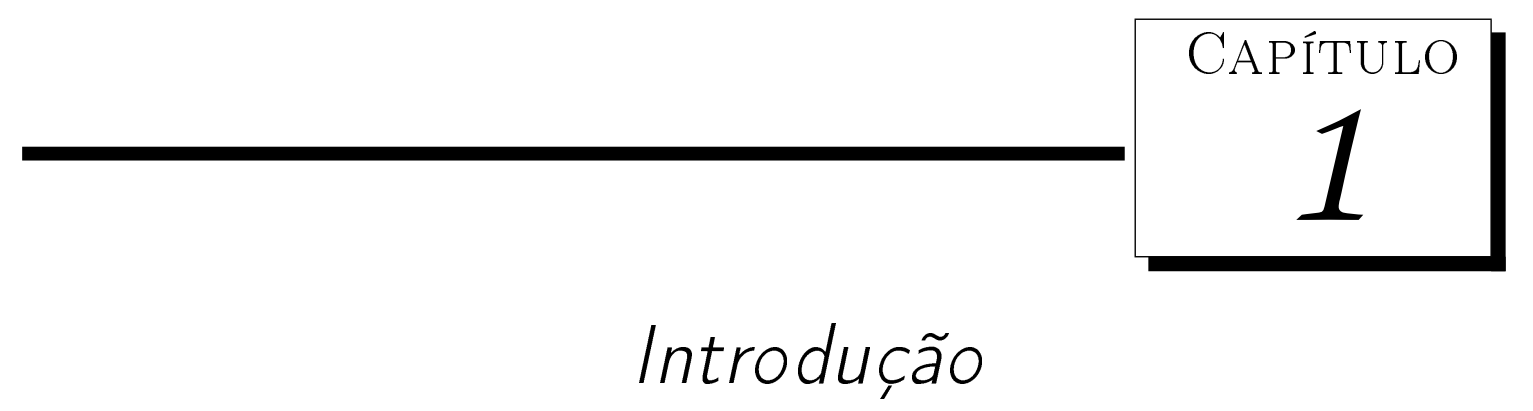

Moldagem por injeção é um dos processos industriais mais importantes de produção em massa de peças de plástico finas e complexas (Kim e Turng, 2004). No processo de produção, polímero fundido é injetado dentro da cavidade de um molde com alta velocidade ou pressão, em uma etapa denominada preenchimento. Em seguida, o molde é resfriado (etapa de empacotamento) e o produto é ejetado do molde assim que o polímero encontra-se completamente solidificado (etapa de solidificação). Em geral, o processo todo tem duração de poucos segundos (Holm e Langtangen, 1999).

Devido a sua alta produtividade, as aplicações de moldagem por injeção têm crescido rapidamente nos últimos anos em diversos setores industriais. Entretanto, ao contrário de outros processos de produção, a qualidade da peça criada por meio de moldagem por injeção não depende apenas do material e da sua forma geométrica, mas também da maneira na qual o material é processado durante a moldagem.

Por esse motivo, a necessidade de aumentar a qualidade dos produtos tem conduzido ao interesse na análise e na predição das propriedades físicas do produto, fazendo com que a antiga abordagem de produção, baseada em intuição, experiência dos engenheiros e tentativa-e-erro, seja cada vez menos utilizada (Zhou e Turing, 2006). Nesse sentido, o uso de modelagem matemática, iniciado nos anos 70 (Richardson, 1972, Kamal et. al., 1975, Hieber e Shen, 1980), tem aumentado consideravelmente e tem-se tornado uma ferramenta indispensável em tais processos de produção.

O modelo matemático completo para o processo de moldagem por injeção envolve conservação de massa, quantidade de movimento e energia, combinadas com uma equação constitutiva para fluidos não newtonianos. A localização da frente do fluido (superfície livre) deve também ser determinada como parte da solução, caracterizando este problema como sendo de fronteiras livres (Holm e Langtangen, 1999). 
Em geral, como característica intrínseca de um processo de moldagem por injeção, tem-se que a espessura da peça produzida (aproximadamente $10^{-3} \mathrm{~m}$ ) é muito menor que as outras dimensões (de vários centímetros a um metro). Além disso, polímeros fundidos são altamente viscosos, resultando em uma razão entre as forças inerciais e as forças viscosas (caracterizada pelo número de Reynolds) de ordem de $10^{-3}$ ou mesmo $10^{-4}$ (Kim e Turng, 2004).

Uma vez que as peças produzidas são bastante finas, e que as forças inerciais podem ser negligenciadas, a aproximação de Hele-Shaw pode ser usada para modelar o escoamento. Adicionalmente, este modelo também omite o cálculo da componente de velocidade na direção transversal do molde, isto é, ao longo da espessura, e negligencia parcialmente a convecção. Como resultado, a equação de conservação da quantidade de movimento é simplificada drasticamente e combinada com a equação de conservação de massa, resultando em uma equação de Poisson bidimensional em termos de pressão e fluidez: a equação de Hele-Shaw (Hieber e Shen, 1980).

Com relação ao problema de transferência de calor, a condução nas direções planares, quando comparada com a condução na direção transversal, é também desprezada por meio de análise dimensional. Outras simplificações comumente empregadas consideram desprezíveis a convecção na direção transversal do molde (efeito de chafariz) e a condução de calor nas paredes laterais do molde. Desta forma, a equação é simplificada, mas permanece tridimensional.

Por apresentar campos de pressão e velocidade bidimensionais e campo de temperatura tridimensional, o modelo de Hele-Shaw é também conhecido como modelo $2^{1} / 2^{\text {-dimensional. }}$

Como parte da solução do preenchimento do molde, além das equações da pressão e da temperatura, é necessário ainda o estabelecimento de uma estratégia para a identificação e o rastreamento da superfície livre do fluido. Se, por um lado, há uma variedade de métodos desenvolvidos com essa finalidade, apresentando características, vantagens e desvantagens distintas, por outro, não há regras simples para se escolher o melhor método para cada problema (Hyman, 1984). Alguns autores classificam tais métodos como métodos de acompanhamento de interface (interface tracking) e métodos de captura de interface (interface capturing) (Unverdi e Tryggvason, 1992).

Os métodos de acompanhamento de interface utilizam elementos computacionais, como partículas sem massa ou pontos conectados, para representar a interface. Tais elementos computacionais são movidos com a velocidade do fluido sobre uma malha geralmente fixa no espaço utilizada para a obtenção das demais variáveis do escoamento, como, por exemplo, a pressão e a velocidade do fluido. Os métodos de acompanhamento de interface podem ainda ser subdivididos em duas categorias: volume-tracking e front-tracking. Em métodos do tipo volume-tracking, partículas marcadoras são utilizadas para a reconstrução da interface. Estas partículas são transportadas juntamente com o fluido e sua presença em uma célula computacional da malha fixa no espaço indica a 
presença de fluido nesta célula. Exemplos desses métodos são o método MAC (Harlow e Welch, 1967) e seus sucessores (Amsden e Harlow, 1970, Tomé e McKee, 1994, McKee et. al., 2004).

Em métodos do tipo front-tracking, a interface é marcada e rastreada por um conjunto de pontos conectados formando uma malha de dimensão menor que se move sobre a malha fixa no espaço. A vantagem desse tipo de método é a capacidade de localizar exatamente a posição da superfície livre. Em contrapartida, dentre as desvantagens desse método podem ser citadas a necessidade de tratamento especial para lidar com divisão e coalescência da frente de fluidos (por exemplo, ao redor de obstáculos) e a necessidade de tratamento especial para manter a qualidade da frente em caso de expansões e contrações de escoamento (Unverdi e Tryggvason, 1992). Alguns exemplos de métodos dessa categoria são encontrados nos trabalhos de Glimm et. al. (1988), Unverdi e Tryggvason (1992), Glimm et. al. (1998), Tryggvason et. al. (2001) e Sousa et. al. (2004).

Em métodos de captura de interface não há necessidade de utilizar elementos computacionais explícitos para marcar a interface. Uma vantagem deste tipo de método é que a divisão e coalescência da frente de fluidos são tratadas automaticamente, mas, em contrapartida, a localização da interface não é bem definida. Nesta classe de métodos a interface é rastreada por uma função indicadora que pode representar uma fração de volume, ou por um conjunto de nível zero de uma função (level-set). Exemplos desse tipo de método são o método Volume of Fluid (VOF) (Hirt e Nichols, 1981) e level-set (Sussman et. al., 1994).

\subsection{Proposta deste trabalho}

Diversas estratégias têm sido desenvolvidas para a simulação numérica do preenchimento de moldes fazendo uso de malhas, estruturadas ou não, para a solução do modelo

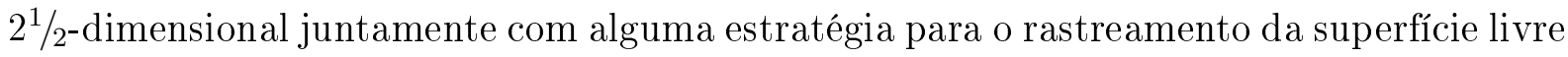
do escoamento.

Dentre os trabalhos que empregam o modelo de Hele-Shaw, Hieber e Shen (1980) apresentaram uma nova formulação não isotérmica para fluidos não newtonianos em cavidades finas de geometria arbitrária usando um método híbrido baseado em diferenças finitas e elementos finitos, sem incluir a característica tridimensional do campo de temperatura. Além disso, a estratégia adotada para o avanço da superfície livre do fluido é baseada em um procedimento de predição-correção da posição da frente.

Subbiah et. al. (1989) focaram seus estudos na geração de malhas e transformação de variáveis utilizando diferenças finitas e mapeamento de soluções. Holm e Langtangen (1999) propuseram a utilização de elementos finitos na aproximação do campo de pressão e a utilização de um método espectral para a aproximação do termo de condução da equação tridimensional da temperatura. A posição da superfície livre é predita por um método de level-set com refinamento local da malha de modo a aumentar qualidade da 
solução. Trabalhos de outros autores eliminam restrições no avanço temporal, na simetria e fazem uso de estratégias como processamento paralelo (Zhou e Li, 2001, Changyu et. al., 2005, Zhou e Turing, 2006).

Jiang et. al. (2007) utilizaram o método Control Volume Finite Element Method (CVFEM) implícito com controle de passo no tempo, durante a simulação do escoamento de Hele-Shaw, de modo que a superfície livre avance uma camada no domínio computacional a cada passo no tempo. Mais recentemente, Estacio e Mangiavacchi (2007) aplicaram o método CVFEM à solução da equação de Hele-Shaw, juntamente com a estratégia VOF para o avanço da superfície livre e uma técnica semi lagrangeana para o tratamento da equação da temperatura tridimensional.

Todos esses trabalhos, além de outros encontrados na literatura, apresentam a característica comum de serem baseados em malhas. Métodos numéricos que evitam o uso de malhas são chamados na literatura de métodos meshfree/meshless. Aqui, os termos meshfree e meshless são usados no sentido casual encontrado na literatura. Na verdade, não é tão comum encontrar um método puramente meshless que envolva alguma forma de discretização local sem que haja o uso de uma estrutura da dados e, conseqüentemente, um grafo, resultando na construção de uma malha implícita (Duarte, 1995, Chen e Liu, 2004, Fries e Matthies, 2004). Nesses casos, a malha não é gerada previamente à simulação numérica e este é o caso do trabalho proposto.

Neste trabalho, são apresentadas novas técnicas para a simulação do preenchimento de moldes que evitam, pelo menos em alguma instância da discretização, a construção e a manutenção explícita de malhas. Em uma das abordagens propostas, uma versão meshless do método Front-Tracking (FT) é utilizada para rastrear e avançar a posição da superfície livre, evitando os problemas normalmente encontrados na presença de mudança topológica da frente de fluido. Os campos de pressão, velocidade e temperatura, entretanto, continuam sendo obtidos por meio da utilização de malhas.

Uma outra abordagem proposta utiliza apenas pontos representando a fronteira e o interior do molde e uma adaptação euleriana do método Smoothed Partycle Hydrodynamics (SPH) é utilizada para avaliar o campo de pressão. Uma adaptação do método VOF é utilizada na vizinhança de cada ponto descrevendo o molde para predizer a posição da superfície livre.

Na última estratégia proposta, volumes de controle virtuais são construídos a partir do conjunto de pontos que representam o molde de modo a formar uma malha virtual dinâmica de elementos ativos. Em seguida, o método CVFEM pode ser aplicado localmente à solução da equação de Hele-Shaw. O avanço da superfície livre é realizado utilizando uma abordagem dinâmica semelhante aplicada ao método VOF e o campo de temperatura bidimensional é obtido por uma adaptação dinâmica de um esquema semi lagrangeano. 


\subsection{Organização da tese}

Este trabalho apresenta o desenvolvimento e a aplicação de três diferentes abordagens para a solução numérica da fase de preenchimento do processo de moldagem por injeção

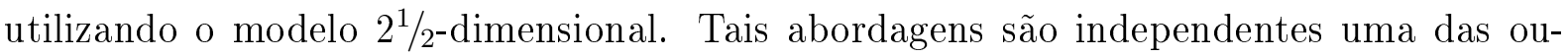
tras, mas apresentam como característica comum a utilização, em alguma instância, de conjuntos de pontos não organizados. As contribuições são apresentadas em capítulos auto-contidos e a tese é organizada da seguinte maneira:

Capítulo 2: Neste capítulo as equações de conservação tridimensionais são simplificadas convenientemente para o caso do escoamento de fluidos viscosos em cavidades finas de moldes, originando o modelo $2^{1} / 2^{-}$dimensional formado pela equação de Hele-Shaw e a equação tridimensional da temperatura. Um modelo simplificado bidimensional para a temperatura é proposto em seguida. Finalmente, condições iniciais e de contorno, e modelos de viscosidade são apresentados.

Capítulo 3: Este capítulo apresenta a estratégia adotada para o desacoplamento das equações governantes do escoamento de fluidos durante o preenchimento de moldes.

Capítulo 4: Neste capítulo, é apresentada a adaptação euleriana do método SPH aplicada para a solução da equação de Hele-Shaw, juntamente com uma abordagem dinâmica do método VOF utilizada para a predição e o rastreamento da superfície livre durante o preenchimento do molde. Na metodologia proposta, o fluido é considerado não newtoniano e o escoamento é considerado isotérmico.

Capítulo 5: A segunda abordagem apresentada utiliza as idéias propostas por Estacio e Mangiavacchi (2007) para a solução da equação de Hele-Shaw e da temperatura bidimensional, baseadas em malhas. Uma adaptação meshless do método FT é desenvolvida neste trabalho e utilizada para o avanço da superfície livre.

Capítulo 6: Este capítulo apresenta a estratégia adotada para a construção de volumes de controle virtuais e a construção de malhas dinâmicas. Uma adaptação local do método CVFEM é aplicada à solução da equação de Hele-Shaw, e o avanço da superfície livre e a determinação do campo bidimensional de temperatura são realizados utilizando abordagens analogamente dinâmicas, respectivamente, do método VOF e semi lagrangeano proposto por Estacio e Mangiavacchi (2007).

Capítulo 7: Este capítulo apresenta as conclusões, os comentários finais deste trabalho e algumas possibilidades de trabalhos futuros.

Conforme mencionado no início desta seção, os Capítulos 4, 5 e 6 são apresentados de maneira independente, contendo considerações iniciais, estratégias numéricas, algoritmo de solução, verificações do método numérico proposto, resultados e comentários finais, 
incluindo as publicações originadas de cada estudo. Finalmente, o Capítulo 7 apresenta comentários finais a respeito deste trabalho e sugere algumas possibilidades para a continuação da pesquisa realizada durante o doutorado. 


\section{$-2$ \\ As equações governantes do escoamento de fluidos durante o preenchimento de moldes}

Este capítulo descreve em detalhes os passos para a obtenção do modelo matemático que descreve o comportamento de um fluido viscoso em um escoamento desenvolvido no interior de geometrias estreitas: um problema comumente encontrado em processos de moldagem por injeção. Adicionalmente, as condições de contorno para as variáveis do escoamento e os modelos de viscosidade usualmente empregados são apresentados.

\subsection{Considerações iniciais}

O modelo matemático do processo de moldagem por injeção é um problema de superfície livre descrito pelas equações de conservação de massa, quantidade de movimento e energia. O fluido é assumido ser não newtoniano e seu comportamento reológico é comumente descrito por modelos de viscosidade newtonianos generalizados, como os modelos de Cross, Carreau, Ellis e Power-law Tucker III (1989).

As equações tridimensionais de conservação podem ser simplificadas drasticamente para este problema ao se impor a suposição de que o molde é tão fino que a aproximação de Hele-Shaw (Hele-Shaw, 1898, Hieber e Shen, 1980) pode ser utilizada. Neste caso a equação da quantidade de movimento é bidimensional, não linear e elíptica, cuja solução fornece a distribuição de pressão na região do molde que encontra-se preenchida de fluido e é comumente conhecida como equação de Hele-Shaw. O problema de transferência de calor é também simplificado, mas continua tridimensional, e uma formulação bidimensional para a equação da temperatura é encontrada considerando valores médios das variáveis do escoamento. A distribuição de velocidade é obtida como um pós-processamento do campo de pressão e a posição da superfície livre pode, em seguida, ser encontrada. Devido à característica bidimensional do campo de pressão e tridimensional do campo de temperatura, esta formulação é também conhecida como modelo $2^{1} / 2 \mathrm{D}$. 
Este capítulo descreve em detalhes os passos seguidos para a obtenção da equação de Hele-Shaw e as simplificações empregadas na equação tridimensional da temperatura baseados em suposições sobre o modelo do fluido, em considerações geométricas sobre o local onde se desenvolve o escoamento e na análise matemática das equações. Modelos de viscosidade não newtonianos e condições de contorno para o escoamento também são apresentados.

\subsection{O modelo matemático completo}

Durante a fase de preenchimento de um processo de moldagem por injeção, um polímero fundido é injetado adentro a cavidade de um molde até que a cavidade esteja completamente preenchida. Por este motivo, tal etapa do processo é um caso particular de escoamento de fluidos com superfície livre cujo movimento é governado pelas equações de conservação em três dimensões. O molde é então resfriado durante o processo de preenchimento e seguido do processo de empacotamento. O produto é ejetado do molde assim que o polímero se encontra completamente solidificado. Em geral o processo todo leva apenas alguns segundos.

O modelo matemático completo envolve as equações de conservação tridimensionais combinadas com uma relação constitutiva não newtoniana para modelar a viscosidade do polímero. As equações de conservação são:

$$
\begin{gathered}
\frac{\partial \rho}{\partial t}+(\nabla \cdot \rho \mathbf{v})=0 \\
\frac{\partial}{\partial t}(\rho \mathbf{v})=\rho \mathbf{g}+[\nabla \cdot \underline{\sigma}]-[\nabla \cdot \rho \mathbf{v v}] \quad \text { (massa) } \\
\rho c_{p}\left(\frac{\partial T}{\partial t}+\mathbf{v} \cdot \nabla T\right)=\beta T\left(\frac{\partial p}{\partial t}+\mathbf{v} \cdot \nabla p\right)+p \nabla \cdot \mathbf{v}+(\underline{\sigma}: \nabla \mathbf{v})+\nabla \cdot(k \nabla T) \quad \text { (energia) },
\end{gathered}
$$

onde $\rho$ é a densidade do fluido, $t$ é o tempo, $\mathbf{v}=\left(v_{x}, v_{y}, v_{z}\right)$ é a velocidade, $\mathbf{g}$ é a aceleração da gravidade e $\underline{\sigma}$ é o tensor tensão, $c_{p}$ é o calor específico, $\beta$ é o coeficiente de expansividade térmica, $k$ é a condutividade térmica do fluido, $T$ é a temperatura e $p$ é a pressão.

Contudo, devido a diversas características intrínsecas ao processo de preenchimento, as equações de conservação em três dimensões podem ser simplificadas, originando a aproximação de Hele-Shaw (Hele-Shaw, 1898, Hieber e Shen, 1980, Kennedy, 1995, Subbiah et. al., 1989, Zhou e Li, 2001, Estacio e Mangiavacchi, 2007).

Por exemplo, o fato da geometria da cavidade ser estreita permite análise dimensional das equações, resultando em um escoamento bidimensional. Além disso, o fato do aquecimento viscoso desempenhar um papel importante no equilíbrio global de energia em moldes finos, enquanto elasticidade tem pouca influência sobre injeção de fluido tanto por pressão quanto por vazão prescritas, torna modelos de viscosidade generalizados como 
o modelo de Cross (Cross, 1970) convenientes. Estas e outras características do problema fornecem várias simplificações aplicáveis ao processo multifísico acoplado 3D que conduzem a um modelo menos complexo, descrito nas seções seguintes.

\subsection{Suposições sobre o fluido}

Fazendo algumas considerações a respeito do fluido, é possível realizar simplificações nas equações de conservação. As suposições serão listadas a seguir:

Suposição 1: O fluido é considerado incompressível.

Essa suposição significa que a densidade é constante e, portanto, da Equação (2.1), tem-se:

$$
\nabla \cdot \mathbf{v}=0
$$

A Equação (2.4) permite simplificações na equação da quantidade de movimento. Considere o termo envolvendo o produto vv na Equação (2.2). Usando a identidade $(\nabla \cdot \mathbf{a s})=\mathbf{a} \cdot(\nabla \mathbf{s})+\mathbf{s}(\nabla \cdot \mathbf{a})$, tem-se:

$$
[\nabla \cdot \rho \mathbf{v} \mathbf{v}]=\rho[\nabla \cdot \mathbf{v} \mathbf{v}]=\rho[\mathbf{v} \cdot \nabla \mathbf{v}]+\rho \mathbf{v}(\nabla \cdot \mathbf{v})=\rho[\mathbf{v} \cdot \nabla \mathbf{v}]
$$

Suposição 2: O fluido pode ser representado como um fluido newtoniano generalizado.

Esta suposição implica que os efeitos viscoelásticos serão ignorados, ou seja, que a viscosidade $\eta$ depende somente da taxa de cisalhamento $\dot{\gamma}$, ou seja $\eta=\eta(\dot{\gamma})$, e, portanto, o tensor extra tensão $\underline{\tau}$ e o tensor tensão total $\underline{\sigma}$ podem ser escritos como:

$$
\underline{\tau}=\eta(\dot{\gamma}) \underline{\dot{\gamma}} \quad \text { e } \quad \underline{\sigma}=-p \underline{I}+\eta(\dot{\gamma}) \underline{\dot{\gamma}}
$$

onde $\underline{I}$ é o tensor identidade e $\underline{\dot{\gamma}}=\nabla \mathbf{v}+(\nabla \mathbf{v})^{\dagger}$ é o tensor taxa de deformação, $\dagger$ indicando a transposta. Essa suposição altera as expressões $(\nabla \cdot \underline{\sigma})$ e $\underline{\sigma}:(\nabla \mathbf{v})$ nas Equações (2.2) e (2.3), respectivamente. Desta forma, tem-se:

$$
[\nabla \cdot \underline{\sigma}]=-\nabla p+[\nabla \cdot \eta \underline{\dot{\gamma}}]
$$

e

$$
\underline{\sigma}:\{\nabla \mathbf{v}\}=\eta \dot{\gamma}^{2}
$$

onde a taxa de cisalhamento $\dot{\gamma}$ é definida pela equação $\dot{\gamma}=\sqrt{\frac{1}{2} \dot{\dot{\gamma}}:} \dot{\dot{\gamma}}$.

Suposição 3: A condutividade térmica do material é assumida constante.

Apesar do fato da condutividade térmica, $k$, depender da temperatura, essa suposição é imposta por causa da dificuldade na obtenção de dados materiais. 
Usando a suposição, o termo envolvendo $k$ na Equação (2.3) pode ser escrito como:

$$
\nabla \cdot(k \nabla T)=k \nabla^{2} T
$$

\subsubsection{Equações resultantes}

Impondo as suposições anteriores (2.4)-(2.7), as seguintes equações são obtidas:

$$
\begin{gathered}
\nabla \cdot \mathbf{v}=0 \quad \text { (massa) } \\
\rho \frac{\partial \mathbf{v}}{\partial t}=\rho \mathbf{g}-\nabla p+[\nabla \cdot \eta \underline{\gamma}]-\rho[\mathbf{v} \cdot \nabla \mathbf{v}] \quad \text { (quantidade de movimento) } \\
\rho c_{p}\left(\frac{\partial T}{\partial t}+\mathbf{v} \cdot \nabla T\right)=\beta T\left(\frac{\partial p}{\partial t}+\mathbf{v} \cdot \nabla p\right)+\eta \dot{\gamma}^{2}+k \nabla^{2} T \quad \text { (energia) }
\end{gathered}
$$

\subsection{Suposições sobre a geometria do molde}

Apesar das Equações (2.8) a (2.10) já terem sido simplificadas, resolvê-las nesta forma é considerado um grande desafio em Mecânica de Fluidos Computacional, devido ao forte acoplamento das equações e à presença de não-linearidades. Contudo, a injeção de fluidos é realizada em moldes essencialmente de cavidades estreitas e essa característica permite simplificações adicionais nas equações de conservação.

\subsubsection{Análise dimensional}

Como as peças geradas por moldagem por injeção são finas, o escoamento na cavidade é, portanto, similar ao escoamento em um canal bidimensional estreito.

A Figura 2.1 mostra a geometria de uma cavidade simples. Por conveniência, um sistema de coordenadas cartesianas é adotado para descrever a cavidade. Os eixos são organizados de tal forma que, em qualquer ponto na cavidade o plano $x y$ coincide com o plano médio da parte a ser moldada, e os pontos do eixo- $z$ se encontram na direção da espessura (também referenciada, neste trabalho, como direção transversal do molde).

Para simplificar as equações utiliza-se então análise dimensional com o objetivo de obter estimativas da ordem de magnitude de cada termo nas equações governantes. Para tanto, valores característicos são associados às variáveis e após a análise, termos de ordem suficientemente baixa são desconsiderados por terem pequena influência quando comparados com os demais. Os valores característicos são (Kennedy, 1995):

- Espessura da cavidade: $H=10^{-3} \mathrm{~m}$;

- Comprimento da cavidade: $L=H / \delta m$ onde $\delta=H / L<<1$;

- Velocidade do fluido: $\mathrm{v}_{0}=10^{-1} \mathrm{~m} / \mathrm{s}$; 


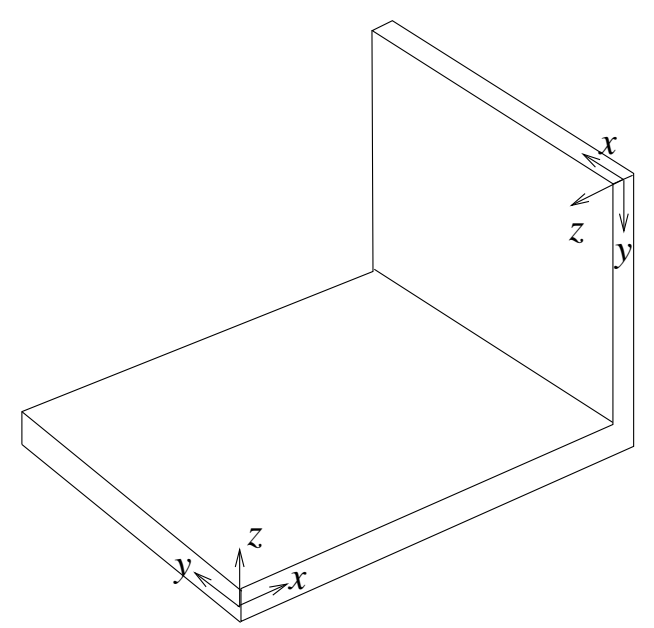

Figura 2.1: Sistema de coordenadas locais para a cavidade de um molde.

- Pressão na cavidade: $p_{0}=10^{7} \mathrm{~N} / \mathrm{m}^{2}(\mathrm{~Pa})$;

- Viscosidade do fluido: $\eta_{0}=10^{4} \mathrm{Ns} / \mathrm{m}^{2}$ (Pas);

- Coeficiente de expansão térmica: $\beta=10^{-3} 1 / K$;

- Condutividade térmica do fluido: $k=10^{-1} \mathrm{~W} / \mathrm{mK}$;

- Densidade do fluido: $\rho=10^{3} \mathrm{~kg} / \mathrm{m}^{3}$;

- Diferença de temperatura entre o molde e o fluido: $T_{0}=10^{2} \mathrm{~K}$.

Usando esses valores típicos, as variáveis relevantes nas equações podem ser definidas em termos de variáveis adimensionais, como segue:

- Coordenada- $x: x=L x^{*}=H / \delta x^{*}$;

- Coordenada-y: $y=L y^{*}=H / \delta y^{*}$;

- Coordenada- $z: z=H z^{*}$;

- Tempo: $t=\left[L / \mathrm{v}_{0}\right] t^{*}=\left[H / \delta \mathrm{v}_{0}\right] t^{*}$

- Componente $x$ da velocidade: $v_{x}=[L / T] v_{x}^{*}=\mathrm{v}_{0} v_{x}^{*}$;

- Componente $y$ da velocidade: $v_{y}=[L / T] v_{y}^{*}=\mathrm{v}_{0} v_{y}^{*}$;

- Componente $z$ da velocidade: $v_{z}=[H / T] v_{z}^{*}=\delta \mathrm{v}_{0} v_{z}^{*}$;

- Pressão: $p=p_{0} p^{*}$;

- Viscosidade: $\eta=\eta_{0} \eta^{*}$

- Diferença de temperatura: $\Delta T=T_{0} \Delta T^{*}$; 
onde as quantidades marcadas com o asterisco $(*)$ são adimensionais e de ordem um.

A aproximação envolverá, portanto, a substituição de variáveis adimensionais em cada equação, para, então, estimar a ordem de magnitude de cada termo. Por exemplo,

$$
\frac{\partial v_{x}}{\partial x}=\frac{\mathrm{v}_{0}}{L} \frac{\partial v_{x}^{*}}{\partial x^{*}}
$$

Como as variáveis adimensionais são de ordem um, a ordem de magnitude de $\frac{\partial v_{x}}{\partial x}$ é igual à ordem de magnitude de $\frac{\mathrm{v}_{0}}{L}$. Por simplicidade, escreve-se:

$$
O\left[\frac{\partial v_{x}}{\partial x}\right]=O\left[\frac{\mathrm{v}_{0}}{L}\right] .
$$

Usando os valores característicos dados por $\mathrm{v}_{0}$ e $L$ tem-se:

$$
O\left[\frac{\partial v_{x}}{\partial x}\right]=O\left[\frac{\mathrm{v}_{0}}{L}\right]=O\left[\frac{\delta \mathrm{v}_{0}}{H}\right]=O\left[\frac{10^{-1} \delta}{10^{-3}}\right]=O\left[10^{2} \delta\right] .
$$

Detalhes da análise dimensional são apresentados no Apêndice A.

\subsubsection{A equação da continuidade para a cavidade}

A equação da continuidade (2.8) para um fluido não newtoniano generalizado incompressível pode ser escrita em coordenadas cartesianas como segue:

$$
\frac{\partial v_{x}}{\partial x}+\frac{\partial v_{y}}{\partial y}+\frac{\partial v_{z}}{\partial z}=0
$$

Usando os valores característicos e as variáveis não adimensionais descritos na seção anterior, todos os termos têm ordem de magnitude similar, dados por $O\left[10^{2} \delta\right]$, e portanto não é possível simplificar mais a equação.

\subsubsection{A equação da quantidade de movimento para a cavidade}

As três componentes da equação da quantidade de movimento (2.9), quando expressa em coordenadas cartesianas, e as respectivas ordens de magnitude de cada termo nas equações são apresentadas a seguir.

Componente- $x$ :

$$
\begin{aligned}
\underbrace{\rho \frac{\partial v_{x}}{\partial t}}_{10^{4} \delta} & =\underbrace{\rho f_{x}}_{10^{4}}-\underbrace{\frac{\partial p}{\partial x}}_{10^{10} \delta}+\underbrace{\frac{\partial}{\partial x}\left(2 \eta \frac{\partial v_{x}}{\partial x}\right)}_{10^{9} \delta^{2}}+\underbrace{\frac{\partial}{\partial y}\left(\eta \frac{\partial v_{y}}{\partial x}\right)}_{10^{9} \delta^{2}}+\underbrace{\frac{\partial}{\partial y}\left(\eta \frac{\partial v_{x}}{\partial y}\right)}_{10^{9} \delta^{2}} \\
& +\underbrace{\frac{\partial}{\partial z}\left(\eta \frac{\partial v_{x}}{\partial z}\right)}_{10^{9}}+\underbrace{\frac{\partial}{\partial z}\left(\eta \frac{\partial v_{z}}{\partial x}\right)}_{10^{9} \delta^{2}}-\underbrace{\rho\left(v_{x} \frac{\partial v_{x}}{\partial x}\right)}_{10^{4} \delta}-\underbrace{\rho\left(v_{y} \frac{\partial v_{x}}{\partial y}\right)}_{10^{4} \delta}-\underbrace{\rho\left(v_{z} \frac{\partial v_{x}}{\partial z}\right)}_{10^{4} \delta} .
\end{aligned}
$$


Componente- $y$ :

$$
\begin{aligned}
\underbrace{\rho \frac{\partial v_{y}}{\partial t}}_{10^{4} \delta} & =\underbrace{\rho f_{y}}_{10^{4}}-\underbrace{\frac{\partial p}{\partial y}}_{10^{10} \delta}+\underbrace{\frac{\partial}{\partial x}\left(\eta \frac{\partial v_{x}}{\partial y}\right)}_{10^{9} \delta^{2}}+\underbrace{\frac{\partial}{\partial x}\left(\eta \frac{\partial v_{y}}{\partial x}\right)}_{10^{9} \delta^{2}}+\underbrace{\frac{\partial}{\partial y}\left(2 \eta \frac{\partial v_{y}}{\partial y}\right)}_{10^{9} \delta^{2}} \\
& +\underbrace{\frac{\partial}{\partial z}\left(\eta \frac{\partial v_{z}}{\partial y}\right)}_{10^{9} \delta^{2}}+\underbrace{\frac{\partial}{\partial z}\left(\eta \frac{\partial v_{y}}{\partial z}\right)}_{10^{9}}-\underbrace{\rho\left(v_{x} \frac{\partial v_{y}}{\partial x}\right)}_{10^{4} \delta}-\underbrace{\rho\left(v_{y} \frac{\partial v_{y}}{\partial y}\right)}_{10^{4} \delta}-\underbrace{\rho\left(v_{z} \frac{\partial v_{y}}{\partial z}\right)}_{10^{4} \delta} .
\end{aligned}
$$

Componente- $z$ :

$$
\begin{aligned}
\underbrace{\frac{\partial v_{z}}{\partial t}}_{10^{4} \delta} & =\underbrace{\rho f_{z}}_{10^{4}}-\underbrace{\frac{\partial p}{\partial z}}_{10^{10} \delta}+\underbrace{\frac{\partial}{\partial x}\left(\eta \frac{\partial v_{x}}{\partial z}\right)}_{10^{9} \delta^{2}}+\underbrace{\frac{\partial}{\partial y}\left(\eta \frac{\partial v_{z}}{\partial x}\right)}_{10^{9} \delta^{2}}+\underbrace{\frac{\partial}{\partial y}\left(\eta \frac{\partial v_{y}}{\partial z}\right)}_{10^{9} \delta^{2}} \\
& +\underbrace{\frac{\partial}{\partial z}\left(\eta \frac{\partial v_{z}}{\partial y}\right)}_{10^{9} \delta^{2}}+\underbrace{\frac{\partial}{\partial z}\left(2 \eta \frac{\partial v_{z}}{\partial z}\right)}_{10^{9} \delta^{2}}-\underbrace{\rho\left(v_{x} \frac{\partial v_{z}}{\partial x}\right)}_{10^{4} \delta}-\underbrace{\rho\left(v_{y} \frac{\partial v_{z}}{\partial y}\right)}_{10^{4} \delta}-\underbrace{\rho\left(v_{z} \frac{\partial v_{z}}{\partial z}\right)}_{10^{4} \delta} .
\end{aligned}
$$

Como a maioria das peças moldadas por injeção são constituídas por paredes finas, espera-se $\delta$ muito menor do que um. Tipicamente, $\delta$ varia no intervalo $0,001<\delta<0,1$ (Kennedy, 1995). Conhecendo os valores prováveis de $\delta$, os termos mais dominantes são o gradiente de pressão e as forças viscosas resultantes das derivadas na direção- $z$. Em particular, para $\delta=0,1$, forças gravitacionais e inerciais são, respectivamente, cinco e seis ordens de magnitude menores dos que os termos de ordens mais altas. Desta forma, ignora-se todos os termos menores ou iguais a $10^{9} \delta$, e então, as equações para as componentes $x, y$ e $z$ da equação quantidade de movimento tornam-se, respectivamente:

$$
\frac{\partial p}{\partial x}=\frac{\partial}{\partial z}\left(\eta \frac{\partial v_{x}}{\partial z}\right), \quad \frac{\partial p}{\partial y}=\frac{\partial}{\partial z}\left(\eta \frac{\partial v_{y}}{\partial z}\right), \quad \frac{\partial p}{\partial z}=0 .
$$

\subsubsection{Equação da temperatura para a cavidade}

A equação da temperatura (2.10) escrita em coordenadas cartesianas e as respectivas ordens de magnitude de cada termo são dadas por:

$$
\begin{gathered}
\underbrace{\rho c_{p} \frac{\partial T}{\partial t}}_{\left(10^{10} \delta\right)}+\underbrace{\rho c_{p} v_{x} \frac{\partial T}{\partial x}}_{\left(10^{10} \delta\right)}+\underbrace{\rho c_{p} v_{y} \frac{\partial T}{\partial y}}_{\left(10^{10} \delta\right)}+\underbrace{\rho c_{p} v_{z} \frac{\partial T}{\partial z}}_{\left(10^{10} \delta\right)}= \\
=\underbrace{\beta T \frac{\partial p}{\partial t}}_{\left(10^{8} \delta\right)}+\underbrace{\beta T v_{x} \frac{\partial p}{\partial x}}_{\left(10^{8} \delta\right)}+\underbrace{\beta T v_{y} \frac{\partial p}{\partial y}}_{\left(10^{8} \delta\right)}+\underbrace{\beta T v_{z} \frac{\partial p}{\partial z}}_{\left(10^{8} \delta\right)}+\underbrace{\eta \dot{\gamma}^{2}}_{\left(10^{8}\right)}+\underbrace{k \frac{\partial^{2} T}{\partial x^{2}}}_{\left(10^{7} \delta^{2}\right)}+\underbrace{k \frac{\partial^{2} T}{\partial y^{2}}}_{\left(10^{7} \delta^{2}\right)}+\underbrace{k \frac{\partial^{2} T}{\partial z^{2}}}_{\left(10^{7}\right)} .
\end{gathered}
$$

Pode-se observar a partir desta equação que os termos envolvendo variação de temperatura devido à compressão e/ou à expansão e à condução nas direções $x$ e $y$ são de ordem de magnitude significativamente menor, sendo, portanto, ignorados. 
O termo convectivo na direção- $z, v_{z} \frac{\partial T}{\partial z}$, é também ignorado. Apesar do efeito resultante da conveç̧ão na direção- $z$ fazer o fluido dividir-se e comportar-se como um chafariz na vizinhança da superfície livre, esse efeito ocorre em uma região de dimensão da ordem da espessura da cavidade, ou seja, muito pequena, e comumente é desprezado (Kennedy, 1995).

A equação de energia em termos de temperatura fica:

$$
\rho c_{p}\left(\frac{\partial T}{\partial t}+v_{x} \frac{\partial T}{\partial x}+v_{y} \frac{\partial T}{\partial y}\right)=\eta \dot{\gamma^{2}}+k \frac{\partial^{2} T}{\partial z^{2}},
$$

onde a taxa de cisalhamento é definida por

$$
\dot{\gamma}=\sqrt{\left(\frac{\partial v_{x}}{\partial z}\right)^{2}+\left(\frac{\partial v_{y}}{\partial z}\right)^{2}}
$$

\subsubsection{Equações resultantes}

Usando as suposições sobre o comportamento do material e a análise dimensional para estimar a magnitude dos termos em cada equação, as Equações (2.8) a (2.10) se reduzem a (Hieber e Shen, 1980, Subbiah et. al., 1989, Kennedy, 1995, Estacio, 2004):

Equação da continuidade:

$$
\frac{\partial v_{x}}{\partial x}+\frac{\partial v_{y}}{\partial y}+\frac{\partial v_{z}}{\partial z}=0
$$

Equações da quantidade de movimento:

$$
\begin{gathered}
\frac{\partial p}{\partial x}=\frac{\partial}{\partial z}\left(\eta \frac{\partial v_{x}}{\partial z}\right) \\
\frac{\partial p}{\partial y}=\frac{\partial}{\partial z}\left(\eta \frac{\partial v_{y}}{\partial z}\right) \\
\frac{\partial p}{\partial z}=0
\end{gathered}
$$

Equação da energia em termos da temperatura:

$$
\rho c_{p}\left(\frac{\partial T}{\partial t}+v_{x} \frac{\partial T}{\partial x}+v_{y} \frac{\partial T}{\partial y}\right)=\eta \dot{\gamma^{2}}+k \frac{\partial^{2} T}{\partial z^{2}} .
$$

\subsection{Simplificação por análise matemática}

Até agora, foram usadas as propriedades do material e a geometria da cavidade para simplificar as equações para a fase de preenchimento. Contudo, é possível simplificá-las ainda mais, por meio da integração das equações da continuidade e da quantidade de movimento. 


\subsubsection{Integração das equações da quantidade de movimento}

Das últimas equações da quantidade de movimento (2.12)-(2.14) tem-se que a pressão é uma função somente de $x$ e de $y$. Por essa razão, é conveniente integrar as equações da quantidade de movimento ao longo da espessura com o propósito de obter expressões para as velocidades $v_{x}$ e $v_{y}$.

A Figura 2.2 define a notação que será utilizada: a linha central da cavidade está em $z=0$ e as paredes da cavidade do molde estão localizadas em $z=h^{+}(x, y)$ e $z=h^{-}(x, y)$. A espessura da cavidade é $H=h^{+}-h^{-}$.

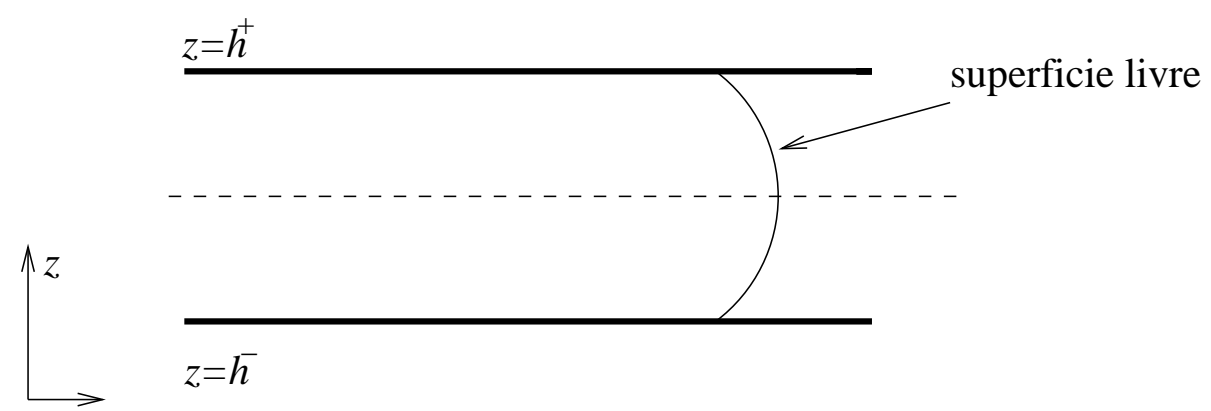

Figura 2.2: Escoamento em uma célula de Hele-Shaw.

Para começar, integra-se a Equação (2.12) com relação a $z$ de $h^{-}$a $z$ e obtém-se:

$$
\begin{aligned}
\int_{h^{-}}^{z} \frac{\partial p}{\partial x} d z^{\prime} & =\int_{h^{-}}^{z} \frac{\partial}{\partial z^{\prime}}\left(\eta \frac{\partial v_{x}}{\partial z^{\prime}}\right) \partial z^{\prime} \\
\frac{\partial p}{\partial x} z & =\eta \frac{\partial v_{x}}{\partial z}-\left[\eta \frac{\partial v_{x}}{\partial z}\right]_{z=h^{-}}+\left[\frac{\partial p}{\partial x} z\right]_{z=h^{-}}=\eta \frac{\partial v_{x}}{\partial z}-A(x, y),
\end{aligned}
$$

onde $A(x, y)=\left[\eta \partial v_{x} / \partial z\right]_{z=h^{-}}-[z \partial p / \partial x]_{z=h^{-}}$é constante para $(x, y)$ dados.

Dividindo ambos os lados da Equação (2.16) por $\eta$ e integrando de $h^{-}$a $z$ e obtém-se:

$$
\begin{aligned}
\frac{\partial p}{\partial x} \int_{h^{-}}^{z} \frac{z^{\prime}}{\eta} d z^{\prime} & =\int_{h^{-}}^{z} \frac{\partial v_{x}}{\partial z^{\prime}} d z^{\prime}-A(x, y) \int_{h^{-}}^{z} \frac{d z^{\prime}}{\eta} \\
& =v_{x}(z)-v_{x}\left(h^{-}\right)-A(x, y) \int_{h^{-}}^{z} \frac{d z^{\prime}}{\eta}
\end{aligned}
$$

Na parede da cavidade do molde, onde $z=h^{-}$ou $z=h^{+}$, tem-se $v_{x}=0$. Esta condição é chamada não escorregamento (no-slip). Aplicando a condição de não escorregamento na Equação (2.17) e rearranjando-a, obtém-se:

$$
v_{x}(z)=\frac{\partial p}{\partial x} \int_{h^{-}}^{z} \frac{z^{\prime}}{\eta} d z^{\prime}+A(x, y) \int_{h^{-}}^{z} \frac{d z^{\prime}}{\eta} .
$$

Utilizando as operações acima na Equação (2.13), é obtida uma expressão semelhante para a componente $y$ da velocidade:

$$
v_{y}(z)=\frac{\partial p}{\partial y} \int_{h^{-}}^{z} \frac{z^{\prime}}{\eta} d z^{\prime}+B(x, y) \int_{h^{-}}^{z} \frac{d z^{\prime}}{\eta}
$$


onde $B(x, y)=\left[\eta \partial v_{y} / \partial z\right]_{z=h^{-}}-[z \partial p / \partial y]_{z=h^{-}}$é constante para $(x, y)$ dados.

Aplicando a condição de não escorregamento na Equação (2.18) tem-se:

$$
0=\frac{\partial p}{\partial x} \int_{h^{-}}^{h^{+}} \frac{z^{\prime}}{\eta} d z^{\prime}+A(x, y) \int_{h^{-}}^{h^{+}} \frac{d z^{\prime}}{\eta}
$$

e então

$$
A(x, y)=-\frac{\partial p}{\partial x}\left\{\frac{\int_{h^{-}}^{h^{+}} \frac{z^{\prime}}{\eta} d z^{\prime}}{\int_{h^{-}}^{h^{+}} \frac{d z^{\prime}}{\eta}}\right\}=-\frac{\partial p}{\partial x} C(x, y)
$$

onde constante $C$ é definida por:

$$
C(x, y)=\frac{\int_{h^{-}}^{h^{+}} \frac{z^{\prime}}{\eta} d z^{\prime}}{\int_{h^{-}}^{h^{+}} \frac{d z^{\prime}}{\eta}}
$$

Do mesmo modo, usando a Equação (2.19), obtém-se:

$$
B(x, y)=-\frac{\partial p}{\partial y}\left\{\frac{\int_{h^{-}}^{h^{+}} \frac{z^{\prime}}{\eta} d z^{\prime}}{\int_{h^{-}}^{h^{+}} \frac{d z^{\prime}}{\eta}}\right\}=-\frac{\partial p}{\partial y} C(x, y)
$$

Usando esses resultados, as Equações (2.18) e (2.19) podem ser escritas, respectivamente, como:

$$
v_{x}=\frac{\partial p}{\partial x}\left\{\int_{h^{-}}^{z} \frac{z^{\prime}}{\eta} d z^{\prime}-C(x, y) \int_{h^{-}}^{z} \frac{d z^{\prime}}{\eta}\right\},
$$

$\mathrm{e}$

$$
v_{y}=\frac{\partial p}{\partial y}\left\{\int_{h^{-}}^{z} \frac{z^{\prime}}{\eta} d z^{\prime}-C(x, y) \int_{h^{-}}^{z} \frac{d z^{\prime}}{\eta}\right\} .
$$

A partir das Equações (2.21) e (2.22) estabelece-se uma das condições de contorno para a pressão. Nas paredes laterais do molde e inserções (buracos) impõe-se que a velocidade na direção n, normal a essas faces e restrita ao plano $x y$, é nula, ou seja,

$$
\frac{\partial p}{\partial \mathbf{n}}=0
$$

Em seguida as velocidades médias $\bar{v}_{x}$ e $\bar{v}_{y}$ são definidas como:

$$
\bar{v}_{x}=\frac{1}{h^{+}-h^{-}} \int_{h^{-}}^{h^{+}} v_{x}(z) d z
$$

$\mathrm{e}$

$$
\bar{v}_{y}=\frac{1}{h^{+}-h^{-}} \int_{h^{-}}^{h^{+}} v_{y}(z) d z .
$$

Substituindo a Equação (2.21) em (2.23) tem-se:

$$
\bar{v}_{x}=\frac{1}{h^{+}-h^{-}} \frac{\partial p}{\partial x}\left[\int_{h^{-}}^{h^{+}} \int_{h^{-}}^{z} \frac{z^{\prime}}{\eta} d z^{\prime} d z-C(x, y) \int_{h^{-}}^{h^{+}} \int_{h^{-}}^{z} \frac{d z^{\prime}}{\eta} d z\right]
$$


Essa integral pode ser avaliada usando integração por partes. Para avaliar a primeira integral em (2.25) faz-se $u=z$ e $v=\int_{h^{-}}^{z} \frac{z^{\prime}}{\eta} d z^{\prime}$, então

$$
\begin{aligned}
\int_{h^{-}}^{h^{+}} \int_{h^{-}}^{z} \frac{z^{\prime}}{\eta} d z^{\prime} d z & =\int_{h^{-}}^{h^{+}} v \frac{d u}{d z} d z=[v u]_{z=h^{-}}^{z=h^{+}}-\int_{h^{-}}^{h^{+}} u \frac{d v}{d z} d z \\
& =\left[z \int_{h^{-}}^{h^{+}} \frac{z^{\prime}}{\eta} d z^{\prime}\right]_{z=h^{-}}^{z=h^{+}}-\int_{h^{-}}^{h^{+}} \frac{z^{\prime 2}}{\eta} d z^{\prime}=h^{+} \int_{h^{-}}^{h^{+}} \frac{z^{\prime}}{\eta} d z^{\prime}-\int_{h^{-}}^{h^{+}} \frac{z^{\prime 2}}{\eta} d z^{\prime}
\end{aligned}
$$

De maneira análoga, para avaliar a segunda integral em (2.25) são usados $u=z$ e $v=\int_{h^{-}}^{z} \frac{d z^{\prime}}{\eta}$, então:

$$
\begin{aligned}
\int_{h^{-}}^{h^{+}} \int_{h^{-}}^{z} \frac{d z^{\prime}}{\eta} d z & =\int_{h^{-}}^{h^{+}} v \frac{d u}{d z} d z=[v u]_{z=h^{-}}^{z=h^{+}}-\int_{h^{-}}^{h^{+}} u \frac{d v}{d z} d z \\
& =\left[z \int_{h^{-}}^{h^{+}} \frac{d z^{\prime}}{\eta}\right]_{z=h^{-}}^{z=h^{+}}-\int_{h^{-}}^{h^{+}} \frac{z^{\prime}}{\eta} d z^{\prime}=h^{+} \int_{h^{-}}^{h^{+}} \frac{d z^{\prime}}{\eta}-\int_{h^{-}}^{h^{+}} \frac{z^{\prime}}{\eta} d z^{\prime}
\end{aligned}
$$

Substituindo as Equações (2.26) e (2.27) na Equação (2.25) e usando a Equação (2.20), tem-se:

$$
\begin{aligned}
\bar{v}_{x} & =\frac{1}{h^{+}-h^{-}} \frac{\partial p}{\partial x}\left[h^{+} \int_{h^{-}}^{h^{+}} \frac{z^{\prime}}{\eta} d z^{\prime}-\int_{h^{-}}^{h^{+}} \frac{z^{\prime 2}}{\eta} d z^{\prime}-C(x, y)\left\{h^{+} \int_{h^{-}}^{h^{+}} \frac{d z^{\prime}}{\eta}-\int_{h^{-}}^{h^{+}} \frac{z^{\prime}}{\eta} d z^{\prime}\right\}\right] \\
& =\frac{1}{h^{+}-h^{-}} \frac{\partial p}{\partial x}\left[h^{+} \int_{h^{-}}^{h^{+}} \frac{z^{\prime}}{\eta} d z^{\prime}-\int_{h^{-}}^{h^{+}} \frac{z^{\prime 2}}{\eta} d z^{\prime}-h^{+} \int_{h^{-}}^{h^{+}} \frac{z^{\prime}}{\eta} d z^{\prime}+\frac{\left(\int_{h^{-}}^{h^{+}} \frac{z^{\prime}}{\eta} d z^{\prime}\right)^{2}}{\int_{h^{-}}^{h^{+}} \frac{d z^{\prime}}{\eta}}\right] \\
& =\frac{1}{h^{+}-h^{-}} \frac{\partial p}{\partial x}\left[-\int_{h^{-}}^{h^{+}} \frac{z^{\prime 2}}{\eta} d z^{\prime}+\frac{\left(\int_{h^{-}}^{h^{+}} \frac{z^{\prime}}{\eta} d z^{\prime}\right)^{2}}{\int_{h^{-}}^{h^{+}} \frac{d z^{\prime}}{\eta}}\right]=\frac{-2 S_{2}}{h^{+}-h^{-}} \frac{\partial p}{\partial x}
\end{aligned}
$$

onde

$$
S_{2}=\frac{1}{2}\left\{\int_{h^{-}}^{h^{+}} \frac{z^{\prime 2}}{\eta} d z^{\prime}-\frac{\left(\int_{h^{-}}^{h^{+}} \frac{z^{\prime}}{\eta} d z^{\prime}\right)^{2}}{\int_{h^{-}}^{h^{+}} \frac{d z^{\prime}}{\eta}}\right\} .
$$

A quantidade $S_{2}$ é chamada fluidez. Usa-se o subscrito para indicar que está associada com o fluxo num canal que é essencialmente bidimensional.

A componente- $y$ da velocidade média pode ser encontrada de maneira análoga substituindo a Equação (2.22) na Equação (2.24). Desta forma,

$$
\bar{v}_{y}=\frac{-2 S_{2}}{h^{+}-h^{-}} \frac{\partial p}{\partial y} .
$$




\subsubsection{Integração da equação da continuidade}

Durante a fase de preenchimento a equação da continuidade é:

$$
\frac{\partial v_{x}}{\partial x}+\frac{\partial v_{y}}{\partial y}+\frac{\partial v_{z}}{\partial z}=0
$$

Integrando o lado esquerdo da equação com relação a $z$, entre $z=h^{-} \mathrm{e} z=h^{+}$, tem-se:

$$
\begin{aligned}
\int_{h^{-}}^{h^{+}} \frac{\partial v_{x}}{\partial x} d z+\int_{h^{-}}^{h^{+}} \frac{\partial v_{y}}{\partial y} d z & +\int_{h^{-}}^{h^{+}} \frac{\partial v_{z}}{\partial z} d z= \\
= & \int_{h^{-}}^{h^{+}} \frac{\partial v_{x}}{\partial x} d z+\int_{h^{-}}^{h^{+}} \frac{\partial v_{y}}{\partial y} d z+\left[v_{z}\right]_{z=h^{-}}^{z=h^{+}} \\
= & \text {como } v_{x}=v_{y}=v_{z}=0 \text { quando } z=h^{-} \text {ou } z=h^{+} \\
& \frac{\partial}{\partial x} \int_{h^{-}}^{h^{+}} v_{x} d z+\frac{\partial}{\partial y} \int_{h^{-}}^{h^{+}} v_{y} d z \\
\stackrel{(2.25) e}{=} \stackrel{(2.24)}{=} & \frac{\partial}{\partial x}\left(\left(h^{+}-h^{-}\right) \bar{v}_{x}\right)+\frac{\partial}{\partial y}\left(\left(h^{+}-h^{-}\right) \bar{v}_{y}\right) \\
& -\frac{\partial}{\partial x}\left(2 S_{2} \frac{\partial p}{\partial x}\right)-\frac{\partial}{\partial y}\left(2 S_{2} \frac{\partial p}{\partial y}\right) .
\end{aligned}
$$

Substituindo a equação acima em (2.31), obtém-se a seguinte equação:

$$
\frac{\partial}{\partial x}\left(S_{2} \frac{\partial p}{\partial x}\right)+\frac{\partial}{\partial y}\left(S_{2} \frac{\partial p}{\partial y}\right)=0
$$

Essa equação é uma equação simplificada para a pressão que combina as equações da continuidade e quantidade de movimento e é conhecida como equação de Hele-Shaw.

\subsection{Simplificação devido à simetria}

A Equação (2.32) pode ser simplificada ainda mais se for assumido que o campo de fluido é simétrico com relação à linha central da cavidade do molde. Além disso, a simetria no campo de fluido também significa que os cálculos precisam somente ser feitos para uma metade da espessura da cavidade, possibilitando um ganho na velocidade de processamento e redução dos requisitos de armazenagem de memória computacional. Fluxo assimétrico próximo a cantos felizmente é um efeito local e um pequeno erro é introduzido por essa suposição.

Suposição 5: O campo de fluido é assumido ser simétrico com relação à linha central da cavidade.

Como resultado dessa suposição, tem-se:

1. $\left|h^{+}\right|=\left|h^{-}\right|=h$. 
2. O perfil da velocidade ao longo da cavidade é simétrico sobre a linha central da cavidade, então $\frac{\partial v_{x}}{\partial z}=\frac{\partial v_{y}}{\partial z}=0 \quad$ em $\quad z=0$.

3. O campo de temperatura é simétrico com relação a linha central da cavidade, então $\frac{\partial T}{\partial z}=0 \quad$ em $\quad z=0$.

4. O campo de viscosidade é simétrico com relação a linha central da cavidade $z=0$. Isto significa que,

$$
\int_{h^{-}}^{h^{+}} \frac{z^{\prime}}{\eta} d z^{\prime}=\int_{-h}^{h} \frac{z^{\prime}}{\eta} d z^{\prime}=\int_{0}^{h} \frac{z^{\prime}}{\eta} d z^{\prime}+\int_{-h}^{0} \frac{z^{\prime}}{\eta} d z^{\prime}=\int_{0}^{h} \frac{z^{\prime}}{\eta} d z^{\prime}-\int_{0}^{h} \frac{z^{\prime}}{\eta} d z^{\prime}=0
$$

e, por (2.29) tem-se:

$$
\begin{aligned}
S_{2} & =\frac{1}{2} \int_{h^{-}}^{h^{+}} \frac{z^{\prime 2}}{\eta} d z^{\prime}=\frac{1}{2} \int_{-h}^{h} \frac{z^{\prime 2}}{\eta} d z^{\prime}=\frac{1}{2}\left[\int_{-h}^{0} \frac{z^{\prime 2}}{\eta} d z^{\prime}+\int_{0}^{h} \frac{z^{\prime 2}}{\eta} d z^{\prime}\right] \\
& =\frac{1}{2}\left[\int_{0}^{h} \frac{z^{\prime 2}}{\eta} d z^{\prime}+\int_{0}^{h} \frac{z^{\prime 2}}{\eta} d z^{\prime}\right]=\int_{0}^{h} \frac{z^{\prime 2}}{\eta} d z^{\prime} .
\end{aligned}
$$

Por outro lado, substituindo a expressão (2.33) na Equação (2.20) da constante $C(x, y)$, obtém-se que as componentes $v_{x}$ e $v_{y}$ da velocidade, definidas pelas Equações (2.21) e (2.22) respectivamente, também são simplificadas, resultando em:

$$
v_{x}=-\frac{\partial p}{\partial x}\left(\int_{0}^{z} \frac{z^{\prime}}{\eta} d z^{\prime}-\int_{0}^{h} \frac{z^{\prime}}{\eta} d z^{\prime}\right)
$$

$\mathrm{e}$

$$
v_{y}=-\frac{\partial p}{\partial y}\left(\int_{0}^{z} \frac{z^{\prime}}{\eta} d z^{\prime}-\int_{0}^{h} \frac{z^{\prime}}{\eta} d z^{\prime}\right)
$$

\subsection{Simplificação adicional: modelo bidimensional para a temperatura}

Analisando a equação da temperatura (2.15) pode-se observar que o campo de distribuição de temperatura é tridimensional, uma vez que os termos de dissipação viscosa e de condução dependem de $z$. Um modelo bidimensional para a temperatura, desenvolvido em um trabalho anterior (Estacio (2004), Estacio e Mangiavacchi (2007)), é apresentado e utilizado neste trabalho.

Tal modelo é baseado no emprego de perfis parabólicos para as variáveis do escoamento e no uso de valores médios de tais variáveis. Esses valores médios são calculados usando a seguinte definição:

Definição 1 O valor médio de uma variável $\varphi$, em um molde simétrico, é definido por:

$$
\bar{\varphi}=\frac{1}{h} \int_{0}^{h} \varphi d z
$$

onde $h$ é o valor da espessura do molde. 
Escrevendo a Equação (2.15) em termos de derivada material e aplicando a Definição 1, uma expressão para a equação da temperatura em termos de valores médios é dada por:

$$
\overline{\frac{D T}{D t}}=\frac{1}{\rho c_{p}}\left[\overline{\eta \dot{\gamma}^{2}}+\overline{k \frac{\partial^{2} T}{\partial z^{2}}}\right]
$$

Após o cálculo dos valores médios dos termos presentes na Equação (2.37), tem se que a equação bidimensional da temperatura média é dada por:

$$
\frac{\partial \bar{T}}{\partial t}=-\frac{6}{5}(\overline{\mathbf{v}} \cdot \nabla \bar{T})+\frac{1}{\rho c_{p}}\left[\frac{3}{5 h^{2}}\|\overline{\mathbf{v}}\|^{2}\left(2 \eta_{c}+3 \eta_{w}\right)-\frac{3 k}{h^{2}}\left(\bar{T}-T_{w}\right)\right],
$$

onde a barra denota valores médios para as variáveis, $\eta_{c}$ é a viscosidade na linha central da cavidade do molde, $\eta_{w}$ e $T_{w}$ são os valores da viscosidade e da temperatura na parede do molde, respectivamente. Detalhes do desenvolvimento deste modelo são encontrados nas subseções seguintes.

\subsubsection{Estabelecimento de perfis parabólicos para as variáveis}

De modo a obter o modelo bidimensional médio para a equação da temperatura, simplificações são realizadas levando-se em conta perfis parabólicos para a velocidade, a temperatura e a viscosidade do fluido, apresentados a seguir.

Perfil parabólico para a velocidade:

$$
\mathbf{v}=\mathbf{v}_{\max } f(z)
$$

Perfil parabólico para a viscosidade:

$$
\eta=\left(\eta_{c}-\eta_{w}\right) f(z)+\eta_{w}
$$

Perfil parabólico para a temperatura:

$$
T=\left(T_{\max }-T_{w}\right) f(z)+T_{w}
$$

onde $f(z)=-(z-h)(z+h) / h^{2}, h$ é a espessura do molde, $\mathbf{v}_{\max }, \eta_{c}$ e $T_{\max }$ são os valores da velocidade, da viscosidade e da temperatura na linha central da cavidade do molde $(z=0)$, e $\eta_{w}$ e $T_{w}$ são a viscosidade do fluido e a temperatura do fluido na parede da cavidade do molde $(z=h)$. Note que, neste último caso, como há condição de não escorregamento, a velocidade do fluido na parede do molde é assumida $\mathbf{v}=0$.

As simplificações são iniciadas considerando a espessura do molde, $h$, constante e aplicando a Definição 1 nas Equações (2.38) e (2.40). Tem-se:

$$
\overline{\mathbf{v}}=\frac{1}{h} \int_{0}^{h} \mathbf{v}_{\max } f(z) d z=\frac{2}{3} \mathbf{v}_{\max }
$$




$$
\bar{T}=\frac{1}{h} \int_{0}^{h}\left(T_{\max }-T_{w}\right) f(z) d z=\frac{2}{3} T_{\max }+\frac{1}{3} T_{w}
$$

Substituindo essas duas expressões nas Equações (2.38) e (2.40), tem-se que os perfis parabólicos para a velocidade e temperatura, escritos em termos de valores médios destas variáveis, são dados por:

$$
\mathbf{v}=\frac{3}{2} \overline{\mathbf{v}} f(z)
$$

$\mathrm{e}$

$$
T=\frac{3}{2}\left(\bar{T}-T_{w}\right) f(z)+T_{w}
$$

\subsubsection{Cálculo da derivada material média}

Aplicando a Definição 1 ao termo que representa a derivada material na equação da temperatura, temos:

$$
\begin{aligned}
\frac{\overline{D T}}{D t} & =\frac{1}{h} \int_{0}^{h} \frac{D T}{D t} d z=\frac{1}{h} \int_{0}^{h}\left[\frac{\partial T}{\partial t}+\mathbf{v} \cdot \nabla T\right] d z= \\
& =\frac{1}{h} \int_{0}^{h} \frac{\partial T}{\partial t} d z+\frac{1}{h} \int_{0}^{h} \mathbf{v} \cdot \nabla T d z=\frac{\overline{\partial T}}{\partial t}+\overline{\mathbf{v} \cdot \nabla T} .
\end{aligned}
$$

Serão necessários, portanto, os cálculos dos valores médios da derivada temporal de $T$ e do termo convectivo. Considerando o perfil parabólico para a temperatura (2.42), tem-se que o valor médio da derivada temporal é dado por:

$$
\begin{aligned}
\overline{\frac{\partial T}{\partial t}} & =\frac{1}{h} \int_{0}^{h} \frac{\partial T}{\partial t} d z=\frac{1}{h} \int_{0}^{h} \frac{\partial}{\partial t}\left[\frac{3}{2}\left(\bar{T}-T_{w}\right) f(z)+T_{w}\right] d z= \\
& =\frac{1}{h} \int_{0}^{h} \frac{3}{2} \frac{\partial \bar{T}}{\partial t} f(z) d z=\frac{3}{2 h} \frac{\partial \bar{T}}{\partial t} \int_{0}^{h} f(z) d z=\frac{\partial \bar{T}}{\partial t} .
\end{aligned}
$$

Da mesma maneira como procedido no cálculo da derivada temporal média, o termo convectivo médio será avaliado considerando-se os perfis parabólicos para a velocidade (2.41) e a temperatura (2.42). Tem-se

$$
\begin{aligned}
\overline{\mathbf{v} \cdot \nabla T} & =\frac{1}{h} \int_{0}^{h} \mathbf{v} \cdot \nabla T d z=\frac{1}{h} \int_{0}^{h}\left[\frac{3}{2} \overline{\mathbf{v}} f(z)\right] \cdot \nabla\left[\frac{3}{2}\left(\bar{T}-T_{w}\right) f(z)+T_{w}\right] d z \\
& =\frac{1}{h} \int_{0}^{h}\left[\frac{3}{2} \overline{\mathbf{v}} f(z)\right] \cdot\left[\nabla\left(\frac{3}{2} \bar{T} f(z)\right)-\nabla\left(\frac{3}{2} T_{w} f(z)\right)+\nabla\left(T_{w}\right)\right] d z \\
& =\frac{1}{h} \int_{0}^{h}\left[\frac{3}{2} \overline{\mathbf{v}} f(z)\right] \cdot\left[\frac{3}{2} f(z) \nabla \bar{T}\right] d z=\frac{9}{4 h}(\overline{\mathbf{v}} \cdot \nabla \bar{T}) \int_{0}^{h} f^{2}(z) d z=\frac{6}{5}(\overline{\mathbf{v}} \cdot \nabla \bar{T}) .
\end{aligned}
$$

Finalmente, tem-se que o valor médio da derivada material é dado por:

$$
\frac{\overline{D T}}{D t}=\frac{\partial \bar{T}}{\partial t}+\frac{6}{5}(\overline{\mathbf{v}} \cdot \nabla \bar{T})
$$




\subsubsection{Cálculo da dissipação viscosa média}

Aplicando a Definição 1 ao termo que representa a dissipação viscosa na equação da temperatura, tem-se:

$$
\overline{\eta \dot{\gamma^{2}}}=\frac{1}{h} \int_{0}^{h} \eta \dot{\gamma^{2}} d z=\frac{1}{h} \int_{0}^{h} \eta\left[\left(\frac{\partial v_{x}}{\partial z}\right)^{2}+\left(\frac{\partial v_{y}}{\partial z}\right)^{2}\right] d z .
$$

Utilizando o perfil de velocidade definido na Equação (2.38), os valores das derivadas parciais da velocidade com relação a $z$ podem ser calculados:

$$
\begin{aligned}
& \frac{\partial v_{x}}{\partial z}=-\frac{3 z}{h^{2}} \bar{v}_{x}, \\
& \frac{\partial v_{y}}{\partial z}=-\frac{3 z}{h^{2}} \bar{v}_{y} .
\end{aligned}
$$

Agora, utilizando o perfil parabólico para a viscosidade (2.39) e as expressões dadas em (2.45) e (2.46) na Equação (2.44), tem-se que:

$$
\begin{aligned}
\overline{\eta \gamma^{2}} & =\frac{1}{h} \int_{0}^{h} \eta\left[\left(\frac{\partial v_{x}}{\partial z}\right)^{2}+\left(\frac{\partial v_{y}}{\partial z}\right)^{2}\right] d z \\
& =\frac{1}{h} \int_{0}^{h}\left[\left(\eta_{c}-\eta_{w}\right) f(z)+\eta_{w}\right]\left(\frac{9 z^{2}}{h^{4}} \bar{v}_{x}^{2}+\frac{9 z^{2}}{h^{4}} \bar{v}_{y}^{2}\right) d z \\
& =\frac{3}{5 h^{2}}\left(\bar{v}_{x}^{2}+\bar{v}_{y}^{2}\right)\left(2 \eta_{c}+3 \eta_{w}\right) .
\end{aligned}
$$

\subsubsection{Cálculo da condução média}

Analogamente aos casos anteriores, tem-se que a condução média é dada por:

$$
\overline{k \frac{\partial^{2} T}{\partial z^{2}}}=\frac{1}{h} \int_{0}^{h} k \frac{\partial^{2} T}{\partial z^{2}} d z=k \frac{1}{h}\left(\left.\frac{\partial T}{\partial z}\right|_{h}-\left.\frac{\partial T}{\partial z}\right|_{0}\right)
$$

Assim, para o cálculo da condução média serão necessários os cálculos das derivadas parciais de $T$ com relação a $z$ em $z=0$ e em $z=h$. Para isso, assume-se o perfil parabólico para a temperatura (2.42), a calcula-se a derivada parcial em questão, dada por:

$$
\frac{\partial T}{\partial z}=-\frac{3 z}{h^{2}}\left(\bar{T}-T_{w}\right)
$$

Note que esta última derivada indica que o perfil assumido para a temperatura está de acordo com as condições de contorno do escoamento, que afirmam que a derivada de $T$ com relação a $z$ na linha central da cavidade, isto é, quando $z=0$, é nula.

Substituindo a expressão (2.49) na Equação (2.48), tem-se que a condução média pode ser escrita em termos de valores médios da temperatura:

$$
\overline{k \frac{\partial^{2} T}{\partial z^{2}}}=-\frac{3 k}{h^{2}}\left(\bar{T}-T_{w}\right)
$$




\subsubsection{O modelo $2 \mathrm{D}$ resultante}

Finalmente, a expressão para a distribuição média bidimensional de temperatura, em termos de valores médios das variáveis, é obtida substituindo as expressões (2.43), (2.47) e (2.50) na Equação (2.37):

$$
\frac{\partial \bar{T}}{\partial t}=-\frac{6}{5}(\overline{\mathbf{v}} \cdot \nabla \bar{T})+\frac{1}{\rho c_{p}}\left(\frac{3}{5 h^{2}}\|\overline{\mathbf{v}}\|^{2}\left(2 \eta_{c}+3 \eta_{w}\right)-\frac{3 k}{h^{2}}\left(\bar{T}-T_{w}\right)\right) .
$$

\subsection{Condições de contorno}

Para o problema de moldagem por injeção, condições de contorno relacionam a solução da pressão e distribuições térmicas na cavidade. Na verdade, a equação da pressão, resultante do acoplamento das equações da continuidade e da quantidade de movimento, é acoplada à equação da energia porque a viscosidade do material, que afeta a pressão, é determinada pela taxa de cisalhamento e, em alguns casos, também pela temperatura. A solução do problema de moldagem por injeção requer, portanto, a solução das equações da pressão e da temperatura.

\section{Condições de Contorno para a Pressão:}

- Em qualquer fronteira impermeável, o gradiente de pressão na direção normal à fronteira é zero. As fronteiras impermeáveis são as faces laterais, as paredes e quaisquer inserções (buracos) na cavidade do molde. Portanto, $\frac{\partial p}{\partial \mathbf{n}}=0$ no contorno rígido. Fisicamente isso quer dizer que o material não pode escoar através das faces laterais e paredes do canal, como foi mostrado na Seção 2.5.1.

- A vazão $q$ do fluido, ou a pressão $p$, é especificada na superfície na qual o fluido adentra na cavidade, ou seja, $q=q_{\text {inj }}$ ou $p=p_{\text {inj }}$.

- Assumindo que a pressão na superfície livre é a pressão relativa atmosférica (pressão manométrica), ela é assuminda como sendo zero.

\section{Condições de Contorno para a Temperatura:}

- O perfil da temperatura ao longo da espessura da cavidade, $T(z)$, é prescrito, isto é, $T(z)=T_{i n j}(z)$.

Embora haja a possibilidade de prescrever um perfil para a temperatura, é comum assumir que a temperatura é uniforme no(s) ponto(s) de injeção.

- A temperatura $T$ é prescrita sobre todo o contorno rígido. Temperaturas diferentes podem ser prescritas em cada fronteira. 


\subsection{Modelos de viscosidade}

Os fluidos nos quais a tensão de cisalhamento não é diretamente proporcional à taxa de deformação são chamados de fluidos não newtonianos. Numerosas equações empíricas têm sido propostas para definir o modelo matemático das relações observadas entre a tensão de cisalhamento e a taxa de deformação no caso de fluidos não newtonianos.

Para muitas aplicações práticas de engenharia essas relações entre a tensão de cisalhamento e a taxa de deformação podem ser adequadamente representadas por modelos amplamente difundidos, como os modelos de Carreau, de Cross, de Ellis e o Power-law, apresentados a seguir. Dentre os modelos generalizados de viscosidade, as leis de Carreau e a de Cross exibem excelente conformidade com o comportamento observado por certos polímeros de interesse industrial (Verhoyen e Dupret, 1998). Ambos modelos apresentam o platô newtoniano a baixas taxas de cisalhamento e a assíntota power-law a altas taxas de cisalhamento, quando utilizado um gráfico em escala logarítmica. Estes dois modelos, juntamente com os modelos de Ellis e Power-law são definidos como (Myers, 2005, Chen et. al., 1998):

Power-law (lei de potência): O modelo de Power-law descreve a viscosidade por

$$
\eta=K \dot{\gamma}^{n-1}
$$

onde $\dot{\gamma}$ é a taxa de cisalhamento. O índice de escoamento $n$ e o parâmetro de consistência $K$ dependem do fluido a ser modelado. Este modelo não é capaz de prever o platô newtoniano e portanto não é considerado apropriado para fluidos com tal comportamento a baixas taxas de cisalhamento (Tucker III, 1989).

Cross: O modelo proposto por Cross (1970) é dado por:

$$
\eta(\dot{\gamma})=\frac{\eta_{0}}{1+\left(\eta_{0} \frac{\dot{\gamma}}{\tau^{*}}\right)^{1-n}}
$$

onde $n$ é o índice da lei de potência, $\eta_{0}$ é viscosidade para taxa de cisalhamento nula, $\tau^{*}$ é o parâmetro que descreve a região de transição entre a taxa de cisalhamento nula, também conhecida como platô newtoniano, e a região da lei de potência da curva da viscosidade.

Carreau: O modelo de Carreau (1972) é comumente escrito em termos de quatro parâmetros:

$$
\eta=\eta_{\infty}+\left(\eta_{0}-\eta_{\infty}\right)\left[1+\lambda^{2} \dot{\gamma}^{2}\right]^{\frac{n-1}{2}}
$$

onde $\eta_{\infty}$ e $\eta_{0}$ são as viscosidades limitantes a baixas e altas taxas de cisalhamento. A alta taxa de cisalhamento $\eta_{\infty}$ é freqüentemente tomada como zero (Myers, 2005). O expoente $\frac{n-1}{2}$ está relacionado com a lei de potência (no intervalo de $\dot{\gamma}$ em que 
o fluido se comporta segundo a tal lei), e o parâmetro $\lambda$ é igual ao inverso de $\dot{\gamma}$ no ponto onde o prolongamento da reta da área da lei de potência encontra com $\eta=\eta_{0}$.

Ellis: O modelo de Ellis é escrito em termos da tensão de cisalhamento $\tau$ :

$$
\frac{1}{\eta}=\frac{1}{\eta_{0}}\left(1+\left|\frac{\tau}{\tau_{1 / 2}}\right|^{n-1}\right)
$$

onde $\eta_{0}$ é a viscosidade a taxa de cisalhamento nula, $\tau_{1 / 2}$ é a tensão de cisalhamento na qual a viscosidade é $\eta_{0} / 2$ e $(n-1)$ é a inclinação da curva $\log \left[\left(\eta_{0} / \eta\right)-1\right] \times$ $\log \left(\tau / \tau_{1 / 2}\right)$ (Reiner, 1969).

Normalmente, os parâmetros de um determinado modelo para um fluido específico são determinados experimentalmente. A Tabela 2.1 fornece os parâmetros que caracterizam o comportamento de poliestireno para cada um dos modelos descritos (Myers, 2005, Chen et. al., 1998).

Tabela 2.1: Parâmetros de modelos de viscosidade generalizados ajustados para representar poliestireno.

\begin{tabular}{ccccccc}
\hline \hline \multirow{2}{*}{ Modelo } & \multicolumn{5}{c}{ Parâmetros para poliestireno } \\
\cline { 2 - 6 } & $\eta_{0}$ & $n$ & $\lambda$ & $\tau_{1 / 2}$ & $\tau^{*}$ & $K$ \\
\hline Carreau & $4 \times 10^{6}$ & 0.4 & 46.4 & & & \\
Ellis & $4 \times 10^{6}$ & 3.2 & & $1.26 \times 10^{5}$ & & \\
Cross & $4 \times 10^{6}$ & 0.2838 & & & $1.791 \times 10^{5}$ & \\
Power-law & & 0.39 & & & $3.5 \times 10^{5}$ \\
\hline
\end{tabular}

Na Figura 2.3 a viscosidade $\eta(\dot{\gamma})$ é plotada contra a taxa de cisalhamento $\dot{\gamma}$ para os quatro diferentes modelos de viscosidade generalizada para poliestireno, em escala logaritmica. Pode-se observar que, com exceção de modelo Power-law, os demais modelos incluem o comportamento newtoniano $\eta(\dot{\gamma})=\eta_{0}$ no caso de baixas taxas de cisalhamento.

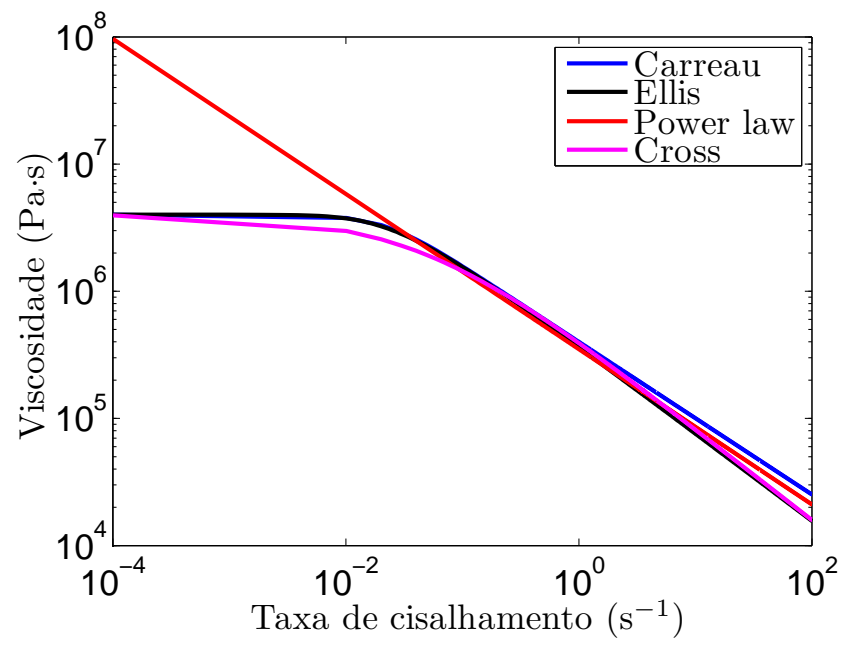

Figura 2.3: Modelos de viscosidade generalizados. 
Outros modelos de viscosidade, bem como seus diferentes parâmetros ajustados para outros materiais podem ser encontrados nos trabalhos de Hieber e Chiang (1989) (poliestireno), Zhou e Turing (2006) (polipropileno) e Carey e Chow (2003).

\subsection{Equações resultantes}

Como resultado das simplificações descritas nas seções anteriores e aplicadas às equações de conservação (2.1)-(2.3), tem-se finalmente que as equações que modelam o comportamento de um fluido durante o preenchimento de moldes são (Hieber e Shen, 1980, Subbiah et. al., 1989, Zhou e Li, 2001, Kennedy, 1995, Estacio, 2004):

Equação de Hele-Shaw:

$$
\frac{\partial}{\partial x}\left(S_{2} \frac{\partial p}{\partial x}\right)+\frac{\partial}{\partial y}\left(S_{2} \frac{\partial p}{\partial y}\right)=0, \quad S_{2}=\int_{0}^{h} \frac{z^{\prime 2}}{\eta} d z^{\prime}
$$

Equação da temperatura em três dimensões:

$$
\rho c_{p}\left(\frac{\partial T}{\partial t}+\mathbf{v} \cdot \nabla T\right)=\eta \dot{\gamma^{2}}+k \frac{\partial^{2} T}{\partial z^{2}}
$$

e em duas dimensões, a equação da temperatura média local é:

$$
\frac{\partial \bar{T}}{\partial t}=-\frac{6}{5}(\overline{\mathbf{v}} \cdot \nabla \bar{T})+\frac{1}{\rho c_{p}}\left(\frac{3}{5 h^{2}}\|\overline{\mathbf{v}}\|^{2}\left(2 \eta_{c}+3 \eta_{w}\right)-\frac{3 k}{h^{2}}\left(\bar{T}-T_{w}\right)\right) .
$$

As Equações (2.55)-(2.56) ou (2.55)-(2.57) devem ser resolvidas considerando uma estratégia para o avanço da superfície livre juntamente com as condições de contorno descritas na Seção 2.8, e considerando um dos modelos de viscosidade newtoniano generalizado descritos na Seção 2.9 .

\subsection{Considerações finais}

Neste capítulo, as equações que governam o escoamento não isotérmico de um fluido viscoso em um canal estreito foram derivadas, considerando simplificações a respeito do modelo do fluido, da geometria onde o escoamento é desenvolvido e, por fim, realizando uma análise dimensional e matemática das equações governantes.

Todas essas suposições resultaram no acoplamento das equações da continuidade e da quantidade de movimento em uma equação bidimensional para a pressão conhecida como equação de Hele-Shaw. As simplificações realizadas na equação tridimensional da temperatura também são descritas e um novo modelo simplificado bidimensional é também apresentado. Devido a essas simplificações, a validade das simulações torna-se restrita a moldes com pequena espessura e pouca curvatura. Considerando o polímero como sendo um fluido newtoniano generalizado, alguns modelos para a viscosidade foram apresentados juntamente com parâmetros ajustados de modo a representar poliestireno, um polímero que de fato é utilizado em processos de moldagem por injeção. 


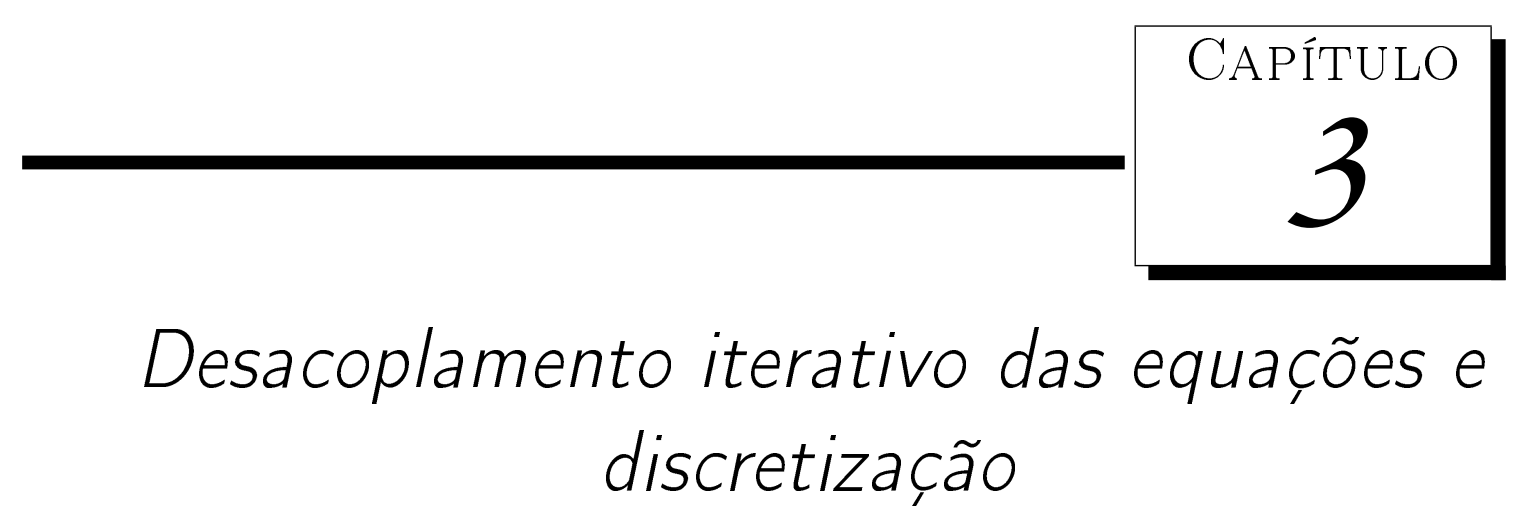

Neste capítulo, uma estratégia para o desacoplamento das equações governantes do preenchimento da cavidade de um molde fino por fluidos viscosos é apresentada. Tal estratégia é necessária devido ao acoplamento do campo de pressão ao campo de temperatura e também à presença de não-linearidade nas relações constitutivas, e baseia-se no uso de pequenos incrementos no tempo e linearizações das equações.

\subsection{Considerações iniciais}

Uma abordagem do tratamento numérico de escoamento de fluidos é começar com as leis de conservação em questão e relações constitutivas e construir um modelo matématico que é então adequado ao problema em questão. Conforme descrito no Capítulo 2, um modelo matemático amplamente aplicado ao processo de moldagem por injeção é o modelo de Hele-Shaw, proposto inicialmente por Hieber e Shen (1980). Este modelo é conhecido como modelo $2^{1} / 2^{-}$dimensional por apresentar uma equação bidimensional para o campo de pressão, conhecida como equação de Hele-Shaw, e uma equação tridimensional para o campo de temperatura.

Diversas estratégias têm sido desenvolvidas para a simulação numérica do preenchimento de moldes fazendo uso de malhas, estruturadas ou não, ou, equivalentemente, de alguma estrutura de dados (conectividade entre as entidades da malha). Dentre os trabalhos que empregam o modelo de Hele-Shaw, Hieber e Shen (1980), seus criadores, apresentaram uma nova formulação não-isotérmica para fluidos não newtonianos em cavidades finas de geometria arbitrária usando um método híbrido baseado em diferenças finitas e elementos finitos, sem incluir a característica tridimensional do campo de temperatura. Holm e Langtangen (1999) propuseram a utilização de elementos finitos na aproximação do campo de pressão e a utilização de um método espectral para a aproximação do termo 
de condução da equação tridimensional da temperatura. A posição da superfície livre é predita por um método de level-set com refinamento local da malha de modo a aumentar qualidade da solução. Subbiah et. al. (1989) focaram seus estudos na geração de malhas e transformação de variáveis utilizando diferenças finitas e mapeamento de soluções. Jiang et. al. (2007) utilizaram o método CVFEM implícito com controle de passo no tempo, durante a simulação do escoamento de Hele-Shaw, e Bernal e Kindelan (2007) utilizaram um método meshless do tipo Radial Basis Function para a solução da equação da pressão e estratégia level-set utilizando malhas cartesianas para o avanço da superfície livre.

Independentemente da estratégia numérica adotada para a solução numérica das equações, todos os trabalhos citados anteriormente, e vários outros encontrados na literatura, apresentam a característica comum de resolver as equações em questão de maneira desacoplada. A formulação inicial fornece um conjunto de equações acopladas por causa da dependência da fluidez da viscosidade, que por sua vez depende da velocidade e, em alguns modelos, da temperatura do fluido. Mesmo em escoamentos isotérmicos, o conjunto de equações continua acoplado e com presença de não-linearidades: a velocidade depende da pressão que depende da fluidez. A solução numérica das equações desacopladas requer menos tempo computacional do que a solução das equações em sua forma acoplada (Tucker III, 1989) e é preferível para a classe de problemas em questão.

\subsection{O modelo matemático}

Como resultado das simplificações descritas no Capítulo 2, tem-se finalmente que as equações que modelam o comportamento de um fluido viscoso durante o preenchimento de moldes são (Hieber e Shen, 1980, Subbiah et. al., 1989, Kennedy, 1995, Zhou e Li, 2001, Estacio, 2004, Estacio e Mangiavacchi, 2007):

Equação de Hele-Shaw:

$$
\frac{\partial}{\partial x}\left(S_{2} \frac{\partial p}{\partial x}\right)+\frac{\partial}{\partial y}\left(S_{2} \frac{\partial p}{\partial y}\right)=0
$$

Equação da temperatura em três dimensões:

$$
\rho c_{p}\left(\frac{\partial T}{\partial t}+\mathbf{v} \cdot \nabla T\right)=\eta \dot{\gamma^{2}}+k \frac{\partial^{2} T}{\partial z^{2}},
$$

e em duas dimensões:

$$
\frac{\partial \bar{T}}{\partial t}=-\frac{6}{5}(\overline{\mathbf{v}} \cdot \nabla \bar{T})+\frac{1}{\rho c_{p}}\left(\frac{3}{5 h^{2}}\|\overline{\mathbf{v}}\|^{2}\left(2 \eta_{c}+3 \eta_{w}\right)-\frac{3 k}{h^{2}}\left(\bar{T}-T_{w}\right)\right),
$$

onde a fluidez e as componentes $x$ e $y$ velocidade, considerando o escoamento simétrico, e a taxa de cisalhamento são dadas, respectivamente pelas equações:

$$
S_{2}=\int_{0}^{h} \frac{z^{\prime 2}}{\eta} d z^{\prime}
$$




$$
\begin{aligned}
& v_{x}=-\frac{\partial p}{\partial x}\left(\int_{0}^{z} \frac{z^{\prime}}{\eta} d z^{\prime}-\int_{0}^{h} \frac{z^{\prime}}{\eta} d z^{\prime}\right), \\
& v_{y}=-\frac{\partial p}{\partial y}\left(\int_{0}^{z} \frac{z^{\prime}}{\eta} d z^{\prime}-\int_{0}^{h} \frac{z^{\prime}}{\eta} d z^{\prime}\right),
\end{aligned}
$$

$\mathrm{e}$

$$
\dot{\gamma}=\sqrt{\left(\frac{\partial v_{x}}{\partial z}\right)^{2}+\left(\frac{\partial v_{y}}{\partial z}\right)^{2}}=\frac{z}{\eta}\|\nabla p\|,
$$

e a barra no modelo bidimensional indica valores médios, conforme descrito na Seção 2.7. Como a velocidade é proporcional ao gradiente de pressão e, ao mesmo tempo, o campo de pressão não varia na direção- $z$, é conveniente escrever as expressões para $v_{x}$ e $v_{y}$ em termos de valores médios:

$$
\bar{v}_{x}=\frac{1}{h} \int_{0}^{h} v_{x} d z=-\frac{S_{2}}{h} \frac{\partial p}{\partial x}
$$

$$
\bar{v}_{y}=\frac{1}{h} \int_{0}^{h} v_{y} d z=-\frac{S_{2}}{h} \frac{\partial p}{\partial y},
$$

e usar esses valores médios para avançar a posição da superfície livre durante o preenchimento do molde.

As Equações (3.1)-(3.2) ou (3.1)-(3.3) devem ser resolvidas considerando uma estratégia para o avanço da superfície livre, considerando um dos modelos de viscosidade newtoniano generalizado descritos na Seção 2.9 (modelo Power-law, de Cross, de Carreau ou de Ellis), juntamente com condições de contorno descritas na Seção 2.8:

i. A pressão é zero na superfície livre, ou seja: $p=0$ na superfície livre.

ii. A pressão ou a velocidade é definida nas regiões de injeção de fluido, isto é: $p=p_{\text {inj }}$ ou $v=v_{\text {inj }}$ sobre o(s) ponto(s) de injeção.

iii. O gradiente de pressão na direção normal é zero em qualquer parede do molde, ou seja, na fronteira, tem-se: $\frac{\partial p}{\partial \mathbf{n}}=0$.

iv. A temperatura na parede da cavidade ou em algum ponto interior à parede do molde é definida, isto é: $T=T_{w}$ em $z=h$ ou $z=h+\delta$.

v. O gradiente de temperatura na direção- $z$ é zero na linha central da cavidade, isto é: $\frac{\partial T}{\partial z}=0 \quad$ em $\quad z=0$.

vi. A temperatura do fluido é definida nas regiões de injeção: $T=T_{\text {inj }}$ sobre o(s) ponto(s) de injeção. 


\subsection{O processo iterativo de solução}

A simulação numérica de um processo de moldagem por injeção envolve a aproximação quase estacionária da Equação (3.1) para o campo de pressão em conjunto com o avanço da superfície livre (Kennedy, 1995). Como a fluidez $S_{2}$ depende da viscosidade, que, por sua vez, depende tanto da temperatura quanto da taxa de cisalhamento, as Equações (3.1) e (3.2) devem ser resolvidas simultaneamente. Nos estudos subseqüentes, uma estratégia de desacoplamento iterativo é implementada utilizando um incremento pequeno no avanço temporal. Em um tempo particular, a temperatura é assumida constante e o campo de pressão é calculado assumindo um valor para a viscosidade àquela temperatura. Assegurando-se que os passos no tempo são suficientemente pequenos, este desacoplamento garante resultados satisfatórios (Tucker III, 1989, Changyu et. al., 2005).

Os principais passos do desacoplamento iterativo, e as linearizações associadas, para um passo no tempo típico utilizado na simulação da fase de preenchimento do processo de moldagem por injeção são descritos a seguir.

1. Resolva iterativamente a equação da pressão linearizada (3.1) no domínio atual:

(a) Cálculo de $S_{2}$ :

$S_{2}$ é calculado a partir da viscosidade na iteração atual. No caso da primeira iteração, a viscosidade newtoniana é utilizada, caso contrário, a viscosidade é calculada na iteração atual fazendo-se uso dos valores da taxa de cisalhamento e da temperatura de um passo anterior.

(b) Cálculo do campo de pressão:

O uso do valor atual de $S_{2}$ lineariza a equação da pressão, e a aproximação do campo de pressão é obtida resolvendo-se o sistema linear resultante da discretização da Equação (3.1) sujeita a condições de contorno (Seção 2.8).

(c) Determinação do campo de velocidade:

Depois de calcular o campo de pressão, é possível determinar a velocidade usando as Equações (3.5) e (3.6), as velocidades médias dadas pelas Equações (3.8) e (3.9) e o valor atual da viscosidade.

(d) Determinação da taxa de cisalhamento:

Um novo valor para a taxa de cisalhamento pode então ser calculado usando os atuais valores da velocidade e do campo de pressão, via Equação (3.7);

(e) Cálculo da viscosidade:

Assumindo a temperatura constante, a viscosidade é atualizada usando esse valor da taxa de cisalhamento de acordo com os modelos de viscosidade generalizado descritos na Seção 2.9 . 
Os passos de (a) a (e) são repetidos até que em duas iterações consecutivas, a variação da pressão seja menor do que uma tolerância permitida, numa estratégia denominada aproximações sucessivas.

2. Solução da equação da temperatura:

- Modelo tridimensional

(a) Cálculo dos termos convectivos e de dissipação viscosa:

Após a convergência do cálculo da pressão, os valores atuais das velocidades $v_{x}$ e $v_{y}$, a taxa de cisalhamento $\dot{\gamma}$ e viscosidade $\eta$ são usados na Equação (3.2) para calcular os termos convectivos e de dissipação viscosa.

(b) Cálculo da condução:

Tendo sido calculados os termos convectivos e de dissipação viscosa, a solução de (3.2) fica reduzida a um problema de condução com estes termos tratados como termos fonte. Os cálculos da condução são realizados por métodos de diferenças finitas na direção transversal do molde, isto é, ao longo da espessura, e fornecem o campo de temperatura.

- Modelo bidimensional

(a) Cálculo dos termos convectivos, de dissipação viscosa e de condução:

Após a convergência do cálculo da pressão, os valores atuais das velocidades médias $\bar{v}_{x}$ e $\bar{v}_{y}$, da viscosidade $\eta$, e da própria temperatura são usados na Equação (3.3) para calcular os termos convectivos, de dissipação viscosa e de condução. A solução de (3.3) fica reduzida a um problema de transporte com estes termos tratados como termo fonte.

3. Avanço da superfície livre:

(a) Os valores médios da velocidade descritos pelas Equações (3.8) e (3.9) são usados para atualizar a localização da superfície livre de acordo com a estratégia adotada.

Os passos da solução descritos devem ser repetidos até que o molde esteja completamente cheio de fluido. Considerando-se que os passos de tempo empregados sejam suficientemente pequenos, esta estratégia desacoplada para a solução das equações governantes da fase de preenchimento do processo de moldagem por injeção fornece resultados satisfatórios (Tucker III, 1989, Subbiah et. al., 1989, Kennedy, 1995).

\subsection{Considerações finais}

Neste capítulo foram apresentadas as equações governantes da fase de preenchimento do processo de moldagem por injeção, juntamente com as condições iniciais e/ou de contorno para essas equações, e o processo de solução dessas equações. O processo de solução 
foi apresentado de maneira detalhada com o intuito de apresentar claramente os passos necessários para a solução numérica desacoplada desse problema.

Os próximos capítulos apresentam três diferentes esquemas de solução das equações da pressão e temperatura e também para o avanço da superfície livre. Tais esquemas são independentes e fazem o uso de técnicas numéricas distintas para a solução das equações em questão, mas apresentam como característica comum a estratégia de desacoplamento descrita no presente capítulo.

O Capítulo 4 apresenta uma estratégia dinâmica combinando idéias dos métodos Smoothed Particle Hydrodynamics (SPH) e Volume of Fluid (VOF) aplicadas na obtenção da solução numérica das equações governantes da fase de preenchimento no caso do escoamento isotérmico: a equação de Hele-Shaw é resolvida aplicando-se uma adaptação Euleriana do método SPH e a posição da superfície livre do fluido é predita utilizando uma adaptação dinâmica do método VOF. No Capítulo 5, o método de volumes finitos conhecido como Control Volume Finite Element Method (CVFEM) é apresentado e aplicado à solução da equação de Hele-Shaw; uma adaptação meshless do método Front-Tracking é empregada na predição da superfície livre do escoamento e a equação bidimensional da temperatura é resolvida segundo o esquema semi larangeano proposto por Estacio (2004), Estacio e Mangiavacchi (2007). Finalmente, o Capítulo 6 apresenta a estratégia para a construção de volumes de controle virtuais de modo a formar uma malha virtual dinâmica de elementos ativos e em seguida apresenta a adaptação local do método CVFEM aplicado à solução da equação de Hele-Shaw, o avanço da superfície livre utilizando uma abordagem dinâmica semelhante aplicada ao método VOF e o campo de temperatura bidimensional é obtido por uma adaptação dinâmica do esquema semi larangeano proposto por Estacio e Mangiavacchi (2007). 


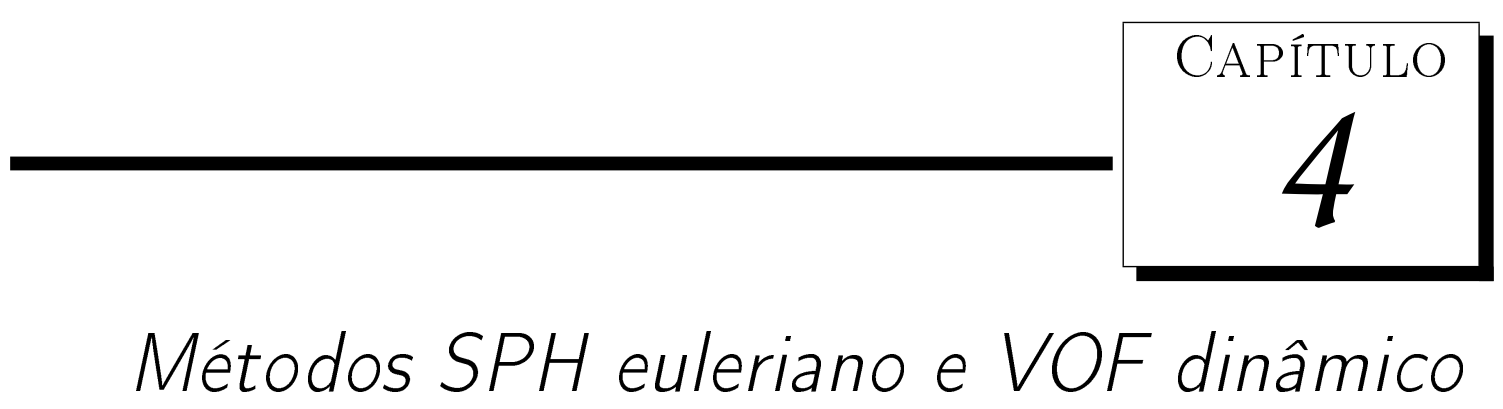

Neste capítulo, uma estratégia dinâmica combinando idéias dos métodos Smoothed Particle Hydrodynamics e Volume of Fluid é aplicada na obtenção da solução numérica das equações governantes da fase de preenchimento de um molde. A equação de Hele-Shaw é resolvida aplicando-se uma adaptação euleriana do método SPH e posição da superfície livre do fluido é predita utilizando uma adaptação dinâmica do método VOF. Testes são realizados de modo a ilustrar a confiabilidade dos resultados obtidos pelo método, e em seguida alguns exemplos de simulação empregando-se esta abordagem também serão apresentados.

\subsection{Considerações iniciais}

As formulações iniciais do método Smoothed Particle Hydrodynamics (SPH) foram desenvolvidas por Lucy (1977), Gingold e Monaghan (1977) e utilizam interpolações em conjuntos de pontos possivelmente não ordenados. Esta técnica foi originalmente desenvolvida para simular fenômenos de astrofísica, sendo estendida para modelar uma série de outros problemas. O método SPH é considerado puramente lagrangeano e não requer uma malha para calcular as derivadas espaciais: a idéia básica utiliza partículas, representações integrais e interpolação.

A interpolação é baseada na teoria de integrais interpolantes usando funções núcleos aproximando a distribuição delta de Dirac. As interpolantes são funções analíticas que podem ser derivadas sem a necessidade do uso de uma malha. Em outras palavras, as derivadas das variáveis são obtidas por meio de derivação analítica das funções núcleo. Se os pontos estão fixos, as equações se reduzem a equações de diferenças finitas apresentando formas distintas dependendo da função núcleo escolhida (Shao e Lo, 2003, Ellero, 2004).

Com relação à representação e o rastreamento da interface presente entre dois fluidos distintos, que no caso líquido-ar é comumente denominada superfície livre, diversas 
estratégias podem ser empregadas. No método Volume of Fluid (VOF), primeiramente introduzido por Hirt et. al. (1970) e Hirt e Nichols (1981), são utilizadas funções marcadoras para reconstrução da superfície livre, que assumem valores entre 0 e 1, dependendo da quantidade de fluido em cada célula utilizada na discretização. A cada passo no tempo, a superfície livre é então reconstruída a partir das funções marcadoras e movida com a velocidade normal do fluido, para a atualização de tais funções.

Neste capítulo, as equações governantes da fase de preenchimento de moldes por fluidos viscosos são resolvidas numericamente utilizando-se uma adaptação do método SPH para o caso em que as partículas que representam o domínio estão fixas no espaço, isto é, segundo o referencial euleriano, juntamente com uma versão dinâmica do método VOF, fazendo uso do raio do suporte compacto ao invés de células. Detalhes das técnicas empregadas são descritos nas seções subseqüentes.

\subsection{Solução da equação de Hele-Shaw por SPH eule- riano}

O método SPH utiliza a forma integral de funções: qualquer função $f$ definida sobre um domínio de interesse e representando alguma variável física pode ser expressa em termos de seus valores em um conjunto discreto de pontos não organizados - as partículas - por meio de uma definição apropriada de núcleo de interpolação (Lucy, 1977, Gingold e Monaghan, 1977, Monaghan, 1992, Ellero, 2004).

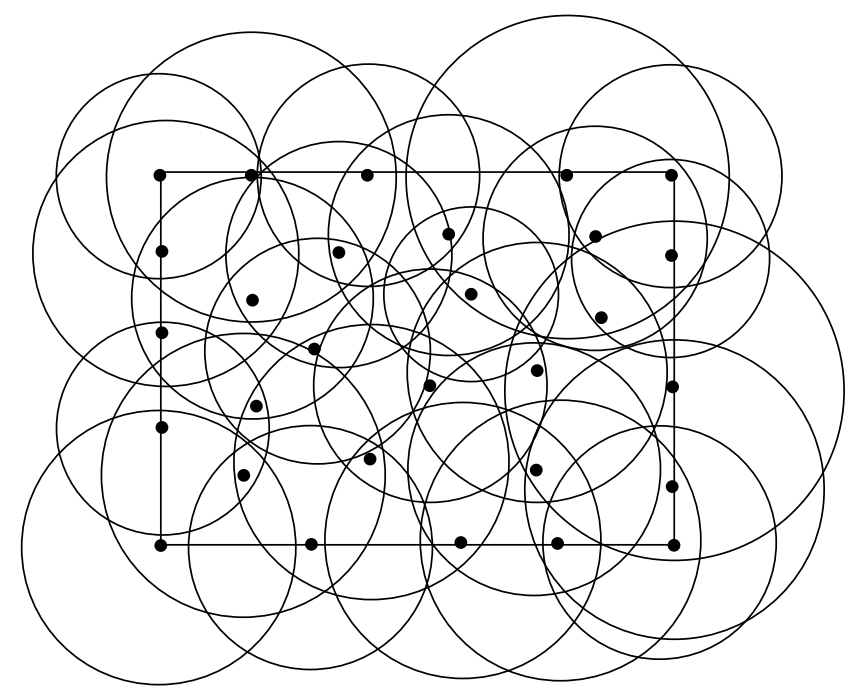

Figura 4.1: Modelo computacional para um método meshless mostrando a fronteira, as partículas e os suportes.

O método SPH baseia-se no conceito de representação integral de uma função $f(\mathbf{x})$, dado pela seguinte identidade:

$$
f(\mathbf{x})=\int_{\Omega} f\left(\mathbf{x}^{\prime}\right) \delta\left(\mathbf{x}-\mathbf{x}^{\prime}\right) d \mathbf{x}^{\prime}
$$

onde $f$ é uma função do vetor de posição x e $\delta$ é a distribuição Delta de Dirac, que possui 
as seguintes propriedades:

$$
\delta(x)=\left\{\begin{array}{lll}
\infty & \text { se } & x=0 \\
0 & \text { se } & x \neq 0
\end{array}\right.
$$

$\mathrm{e}$

$$
\int_{-\infty}^{\infty} \delta(x) d x=1
$$

A distribuição Delta de Dirac é análoga ao Delta de Kronecker no domínio discreto e pode ser pensada como uma "função" quase sempre nula, com um impulso infinito na origem do sistema. A rigor, $\delta$ não é uma função no senso ordinário de finção, pois assume o valor $\infty$ no ponto $x=0$ e a integral mencionada anteriormente deveria ser nula.

A Figura 4.2 ilustra uma definição da distribuição Delta de Dirac pelo limite de uma seqüência de Gaussianas:

$$
\delta(x)=\lim _{a \rightarrow 0} \frac{1}{a \sqrt{\pi}} \mathrm{e}^{-x^{2} / a^{2}} .
$$

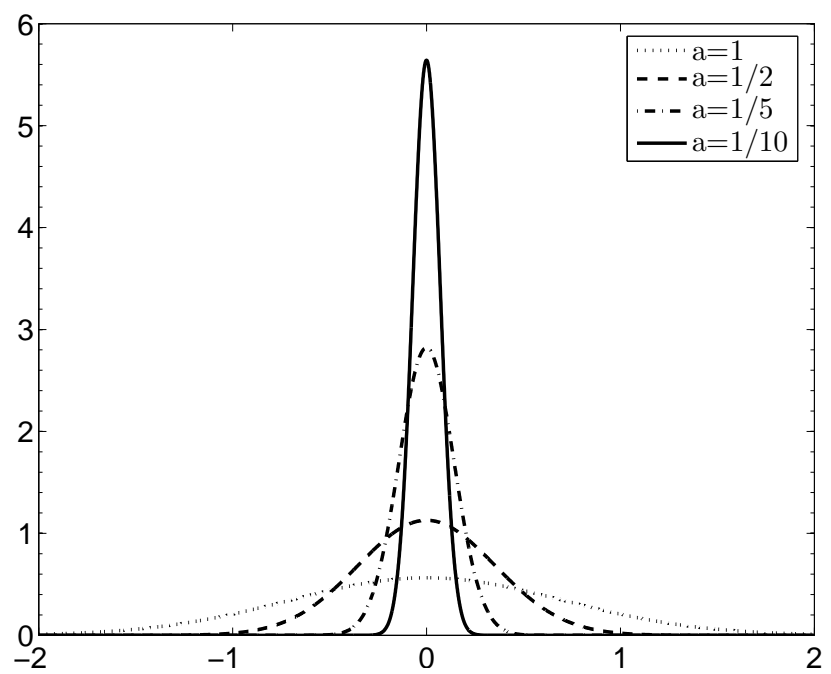

Figura 4.2: Seqüência de Gaussianas aproximando a distribuição Delta de Dirac conforme $a \rightarrow 0$.

Quando utilizada a distribuição Delta de Dirac, a representação integral da Equação (4.1) é exata desde que a função $f(\mathbf{x})$ seja contínua no domínio $\Omega$. Contudo, a integral na Equação (4.1) não é computável, visto que $\delta$ não é uma função, e portanto faz-se necessário substituir tal distribuição por alguma função que apresente comportamento semelhante. Tais funções são chamadas núcleos de interpolação.

Substituindo a distribuição delta de Dirac por uma função núcleo de interpolação $W\left(\mathbf{x}-\mathbf{x}^{\prime}, r\right)$, obtemos:

$$
<f(\mathbf{x})>=\int_{\Omega} f\left(\mathbf{x}^{\prime}\right) W\left(\mathbf{x}-\mathbf{x}^{\prime}, r\right) d \mathbf{x}^{\prime}
$$

onde $<>$ é uma aproximação finita para a propriedade e $r$ representa o raio do núcleo 
interpolante, ou seja, o raio de influência deste núcleo.

A representação integral finita é válida e converge quando a função peso satisfaz as seguintes condições (Belytschko et. al., 1996, Ellero, 2004):

$$
\begin{gathered}
W(\mathbf{x}, r)>0 \text { em um subdomínio } \Omega_{I} \text { de } \Omega, \\
W(\mathbf{x}, r)=0 \text { fora do subdomínio } \Omega_{I}, \\
\int_{\Omega} W(\mathbf{x}, r) d \Omega=1 \text { (propriedade de normalidade) } \\
W(\mathbf{x}, r) \text { é uma função monotonicamente decrescente, } \\
W(\mathbf{x}, r) \rightarrow \delta(\mathbf{x}) \text { quando } r \rightarrow 0 .
\end{gathered}
$$

Estas características asseguram a normalização e a consistência apropriadas no limite do contínuo. A representação integral contínua dada pela equação (4.2) pode ser convertida na forma discreta por meio de uma soma feita sobre todas as partículas no suporte definido pelo raio $r$ (Liu e Liu, 2003). Para tanto, o volume infinitesimal $d \mathbf{x}^{\prime}$ de uma partícula $j$ de densidade $\rho_{j}$ na integral em (4.2) é substituído pelo volume finito da partícula $\Delta V_{j}$, levando em conta que:

$$
\rho_{j}=\frac{m_{j}}{\Delta V_{j}} \Rightarrow \Delta V_{j}=\frac{m_{j}}{\rho_{j}}
$$

onde $m_{j}$ é a massa da partícula $j$.

A integral em (4.2), pode então ser aproximada por:

$$
\begin{aligned}
<f(\mathbf{x})> & =\int_{\Omega} f\left(\mathbf{x}^{\prime}\right) W\left(\mathbf{x}-\mathbf{x}^{\prime}, r\right) d \mathbf{x}^{\prime} \\
& \approx \sum_{j}^{n_{p}} f\left(\mathbf{x}_{j}\right) W\left(\mathbf{x}-\mathbf{x}_{j}, r\right) \Delta V_{j} \\
& =\sum_{j}^{n_{p}} \frac{m_{j}}{\rho_{j}} f\left(\mathbf{x}_{j}\right) W\left(\mathbf{x}-\mathbf{x}_{j}, r\right)
\end{aligned}
$$

onde a soma é feita sobre todos os $n_{p}$ pontos no suporte compacto do ponto $j$.

Por exemplo, a aproximação da função $f$ para um ponto $i$ no domínio $\Omega$ é dada por:

$$
<f_{i}>=\sum_{j}^{n_{j}} \frac{m_{j}}{\rho_{j}} f_{j} W\left(\mathbf{x}_{i}-\mathbf{x}_{j}, r_{i}\right)
$$

onde $n_{j}$ é a quantidade de pontos $j$ vizinhos a $i$ segundo o raio de suporte $r_{i}$. O valor de $f$ em $\mathbf{x}_{i}$ é denotado por $f_{i}$. Esta expressão indica que o valor da função no ponto $i$ é aproximado pela média dos valores da função nos pontos vizinhos a $i$ ponderada pela função peso.

Portanto, é possível construir uma aproximação diferenciável de uma função a partir dos valores nos pontos de interpolação usando uma função peso, também denominada 
interpolante, que é diferenciável e não é necessário usar diferenças finitas, elementos finitos, nem malhas. Três funções amplamente empregadas como interpolantes são: a exponencial, a spline cúbica, ou de terceira ordem, e a spline de quarta ordem, exemplificadas a seguir e ilustradas na Figura 4.3. Neste trabalho, a função exponencial (4.4) com $\alpha=0,3$ (Liu, 2003) é empregada como interpolante.

Exponencial:

$$
W(u)=\left\{\begin{array}{lll}
e^{-\frac{u^{2}}{\alpha}} & \text { se } & u \leq 1 \\
0 & \text { se } & u>1
\end{array} .\right.
$$

Spline cúbica:

$$
W(u)=\left\{\begin{array}{lll}
\frac{2}{3}-4 u^{2}+4 u^{3} & \text { se } & u \leq \frac{1}{2} \\
\frac{4}{3}-4 u+u^{2}-\frac{4}{3} u^{3} & \text { se } & \frac{1}{2}<u \leq 1 \\
0 & \text { se } & u>1
\end{array}\right.
$$

Spline de quarta ordem:

$$
W(u)=\left\{\begin{array}{lll}
1-6 u^{2}+8 u^{3}-3 u^{4} & \text { se } & u \leq 1 \\
0 & \text { se } & u>1
\end{array} .\right.
$$

onde o argumento de $W(u)$ é $u=\left\|\mathbf{x}-\mathbf{x}^{\prime}\right\| / r$, sendo $r$ o raio do suporte compacto.

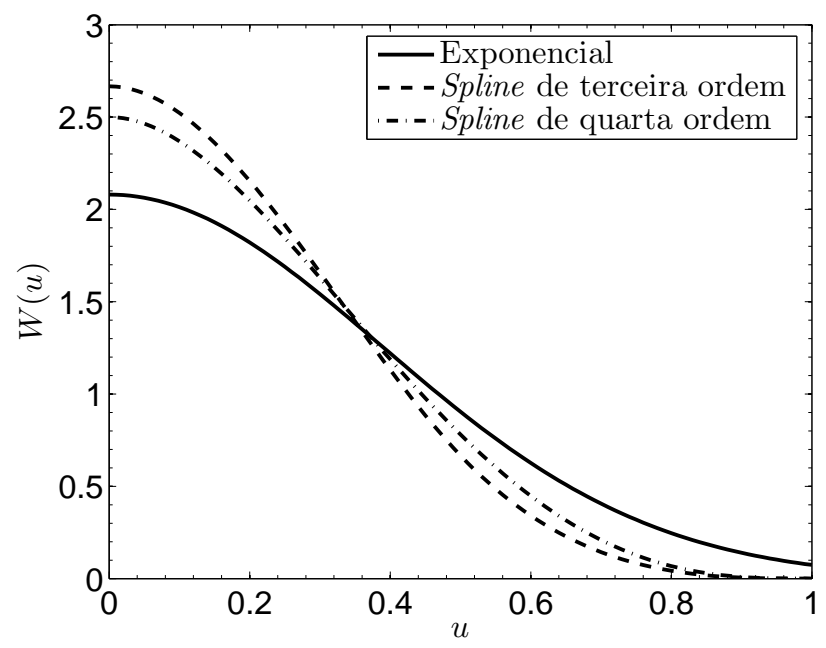

Figura 4.3: Exemplo de três funções peso comumente utilizadas: exponencial e splines de terceira e quarta ordem.

Finalmente, lembrando que a Equação (3.1) pode ser escrita como:

$$
\nabla \cdot S_{2} \nabla p=0
$$


sua aproximação por SPH é, portanto:

$$
\sum_{i=1}^{n_{p}} p_{i} \nabla \cdot S_{2_{i j}} \nabla W\left(u_{i j}, r\right)=0 .
$$

onde $p_{i}$ representa a pressão $p$ no ponto $i$ do domínio em questão e a fluidez $S_{2}$ é tomada como a média:

$$
S_{2_{i j}}=\frac{2}{\frac{1}{S_{2_{i}}}+\frac{1}{S_{2_{j}}}},
$$

e $u_{i j}$ é a distância entre o ponto $i$ e cada um dos seus vizinhos $j$ segundo o raio do suporte $r$. Como está sendo usado o referencial euleriano, a massa e a densidade do fluido se tornam constantes, podendo ser incorporadas em $W$. O cálculo de $S_{2_{i j}}$ realizado por meio de média harmônica é preferível por produzir a solução exata em caso de uma variação brusca de $S_{2}$ localizada exatamente entre os pontos $i$ e $j$.

A Equação (4.6) pode ser expressa como o seguinte sistema linear:

$$
K p=f,
$$

onde $K$ é uma matriz esparsa e simétrica de dimensão $N \times N$, sendo $N$ a quantidade de pontos que descrevem o domínio. Cada elemento da diagonal da matriz é associado a um ponto $i$, e os elementos não nulos das linhas da matriz são associados aos pontos $j$ vizinhos ao ponto $i$ segundo o raio do suporte.

\subsubsection{Cálculo da fluidez}

De acordo com a Equação (3.4), a fluidez $S_{2}$ depende explicitamente da viscosidade do fluido e implicitamente da velocidade com a qual o fluido se move adentro da cavidade do molde, por meio da taxa de cisalhamento, e varia ao longo da simulação. Desta forma, de modo a atualizar os valores da fluidez nos pontos que definem o molde, é necessário o conhecimento dos valores da viscosidade e da velocidade nestes pontos.

\subsubsection{Cálculo da viscosidade e da taxa de cisalhamento}

Os diferentes modelos de viscosidade empregados neste trabalho foram descritos de maneira geral na Seção 2.9, juntamente com uma descrição específica para o caso da modelagem do comportamento de poliestireno fundido. Nesta seção, os passos necessários para a aproximação numérica da viscosidade do fluido são apresentados.

Para o primeiro passo do avanço temporal da simulação, a fluidez $S_{2}$ é calculada a partir da viscosidade newtoniana para cada ponto $i$ do conjunto de pontos que define o molde. Neste caso, a viscosidade é independente da taxa de cisalhamento do escoamento e dada por $\eta=\eta_{0}$, constante. Tem-se:

$$
S_{2_{i}}=\int_{0}^{h} \frac{z^{\prime 2}}{\eta_{0}} d z^{\prime}=\frac{h_{i}^{3}}{3 \eta_{0}} .
$$


Nos passos subseqüentes da simulação, a viscosidade é calculada fazendo-se uso dos valores da taxa de cisalhamento de um passo anterior.

Lembrando que, para cada ponto $i$, a taxa de cisalhamento é dada por:

$$
\dot{\gamma}_{i}=\left.\sqrt{\left(\frac{\partial v_{x}}{\partial z}\right)^{2}+\left(\frac{\partial v_{y}}{\partial z}\right)^{2}}\right|_{i},
$$

temos que as derivadas $\left.\frac{\partial v_{x}}{\partial z}\right|_{i}$ e $\left.\frac{\partial v_{y}}{\partial z}\right|_{i}$ podem ser obtidas analiticamente por derivação das expressões (3.5) e (3.6) para $v_{x}$ e $v_{y}$. Simplificando,

$$
\dot{\gamma}_{i}=\left.\frac{z}{\eta}\|\nabla p\|\right|_{i}
$$

O cálculo do gradiente de pressão presente na Equação (4.8) é realizado por mínimos quadrados para cada ponto $i$. Para tanto, a pressão, conhecida em cada ponto $j$ na vizinhança de $i$, é aproximada como sendo linear nessa vizinhança:

$$
p=A_{i} x+B_{i} y+C_{i} z+D_{i}
$$

e calcula-se as derivadas de $p$ no ponto $i$ analiticamente por meio desta expressão, donde:

$$
\|\nabla p\|_{i}=\sqrt{A_{i}^{2}+B_{i}^{2}}
$$

O campo médio de velocidade é obtido por meio da derivação da expressão (4.9). Para cada ponto $i$ discretizando o domínio, tem-se:

$$
\left.\bar{v}_{x}\right|_{i}=-\left.\frac{S_{2}}{h} \frac{\partial p}{\partial x}\right|_{i}=-\frac{S_{2_{i}}}{h_{i}} A_{i}
$$

$\mathrm{e}$

$$
\left.\bar{v}_{y}\right|_{i}=-\left.\frac{S_{2}}{h} \frac{\partial p}{\partial y}\right|_{i}=-\frac{S_{2_{i}}}{h_{i}} B_{i} .
$$

Voltando à Equação (4.8), tem-se que a taxa de cisalhamento varia inversamente com a viscosidade que, por sua vez, depende da taxa de cisalhamento para os modelos de viscosidade generalizada discutidos anteriormente. A equação não-linear resultante é resolvida iterativamente pelo método de Newton conforme descrito a seguir.

Substituindo a relação constitutiva escolhida para a viscosidade do fluido (modelo Power-law, de Carreau, Cross ou Ellis) na Equação (4.8) para definir a função $G$, tem-se:

$$
G(\dot{\gamma})=\dot{\gamma}-\frac{z}{\eta(\dot{\gamma})}\|\nabla p\|
$$

A função de iteração correspondente para o método de Newton é:

$$
\dot{\gamma}^{k+1}=\dot{\gamma}^{k}-\frac{G\left(\dot{\gamma}^{k}\right)}{G^{\prime}\left(\dot{\gamma}^{k}\right)},
$$


onde $G^{\prime}\left(\dot{\gamma}^{k}\right)$ é a derivada de $G\left(\dot{\gamma}^{k}\right)$ com relação a $\dot{\gamma}^{k}$ (Isaacson e Keller, 1966).

Por exemplo, as expressões para $G(\dot{\gamma})$ e $G^{\prime}(\dot{\gamma})$ para o modelo de Carreau são dadas, respectivamente, por:

$$
G(\dot{\gamma})=\dot{\gamma}-\frac{z}{\eta_{0}}\|\nabla p\|\left[1+(\lambda \dot{\gamma})^{2}\right]^{\frac{1-n}{2}}
$$

$\mathrm{e}$

$$
G^{\prime}(\dot{\gamma})=1+\frac{z\|\nabla p\|(n-1) \lambda^{2} \dot{\gamma}}{\eta_{0}\left[1+(\lambda \dot{\gamma})^{2}\right]^{\frac{n+1}{2}}}
$$

Enquanto a distribuição de pressão é constante na direção transversal, ambas taxa de cisalhamento e viscosidade variam nessa direção e devem ser aproximadas ao longo da espessura do molde. Com este objetivo, a direção transversal do molde é dividida em $N_{z}$ camadas e ambas taxa de cisalhamento e viscosidade são aproximadas para cada uma destas camadas: conhecendo o valor da taxa de cisalhamento em uma determinada espessura $z$, um novo valor da viscosidade do fluido nesta mesma espessura é determinado de acordo com o modelo de viscosidade escolhido. Assim, para cada ponto $i$ na discretização, o valor da fluidez é determinado por meio de integração numérica ao longo da espessura do molde, conhecendo-se os valores da viscosidade e da taxa de cisalhamento em cada uma das camadas que discretizam a direção transversal neste ponto.

\subsection{Avanço da superfície livre usando VOF dinâmico}

De modo a representar a posição da superfície livre de um escoamento de fluido, o método VOF utiliza uma função $\phi$ cujo valor é $\phi=1$ em qualquer ponto ocupado por fluido e $\phi=0$ caso contrário. Valor de $\phi$ entre 0 e 1 em uma célula representa a fração de volume da célula ocupada pelo fluido. Em particular $\phi=1$ corresponde às células cheias de fluido, $\phi=0$ às células vazias e $0<\phi<1$ às células contendo a superfície livre (Hirt e Nichols, 1981, Shin e Lee, 2000).

A dependência temporal de $\phi$ é governada pela seguinte equação de transporte:

$$
\frac{\partial \phi h}{\partial t}+\nabla \cdot(\overline{\mathbf{v}} \phi h)=0
$$

onde $\overline{\mathbf{v}}$ é a velocidade média do fluido e $h$ é a espessura do molde. Diversas técnicas podem ser utilizadas para resolver a Equação (4.12), e uma delas consiste em resolver a sua forma integral

$$
\int_{V}\left(\frac{\partial \phi h}{\partial t}+\nabla \cdot(\overline{\mathbf{v}} \phi h)\right) d V=0
$$

Aplicando o teorema de Gauss, tem-se:

$$
\frac{\partial}{\partial t} \int_{V} \phi h d V+\int_{S} \phi h \overline{\mathbf{v}} \cdot \mathbf{n} d S=0
$$

No caso de métodos meshless o conceito de célula, volume ou elemento não está definido, já que apenas pontos são utilizados na aproximação. Desta forma é necessário 
associar um volume de controle fictício a cada ponto $i$ da discretização. Por exemplo, considere um volume de controle fictício parcialmente cheio $V_{i}$ associado ao ponto $i$, isto é, $0<\phi_{i}<1$, com partículas vizinhas $j$, conforme ilustrado na Figura 4.4.

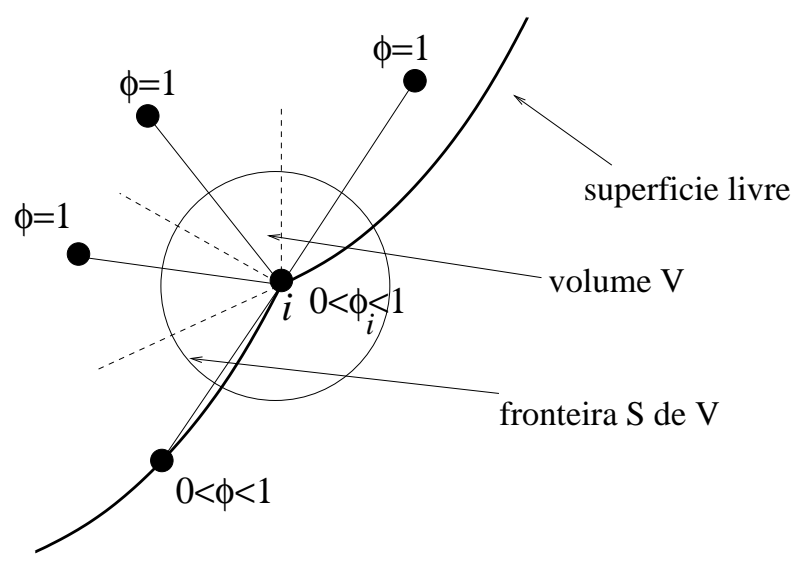

Figura 4.4: Volume associado ao ponto $i$.

Além disso, para o volume $V_{i}$ tem-se que a taxa de variação do volume do fluido em $i$ é igual à soma das contribuições provenientes das partículas vizinhas $j$ em que $\phi_{j}=1$. Desta forma, a Equação (4.13) fica:

$$
\frac{\partial}{\partial t} \int_{V_{i}} \phi_{i} h_{i} d V=-\int_{S} \phi_{j} h_{j} \overline{\mathbf{v}} \cdot \mathbf{n} d S
$$

Matematicamente, considerando que $\phi$ e $h$ são uniformes no volume do ponto $i$, é possível simplificar o lado esquerdo, obtendo:

$$
V_{i} h_{i} \frac{\partial \phi_{i}}{\partial t}=-\int_{S} \phi_{j} h_{j} \overline{\mathbf{v}} \cdot \mathbf{n} d S
$$

onde a integral da superfície da direita deve incluir a contribuição de todos os volumes associados a pontos $j$ cheios, isto é se $\phi_{j}=1$.

Com relação ao ponto $i$, de volume $V_{i}$, fronteira $S_{i}$ e $n_{p}$ pontos vizinhos $j$, a velocidade média (3.8) e (3.9) na direção $j i$ é dada por:

$$
\overline{\mathbf{v}}=-k \nabla p \cdot \mathbf{n}=k_{i j} \frac{p_{j}-p_{i}}{\left\|\mathbf{x}_{j}-\mathbf{x}_{i}\right\|}
$$

onde $\mathbf{x}_{i}$ e $\mathbf{x}_{j}$ são as posições do ponto $i$ e de seus vizinhos $j$, respectivamente e $k_{i j}=$ $S_{2_{i j}} / h_{i j}$. Para o cálculo de $k_{i j}$, a média harmônica é preferível à média aritmética por produzir a solução exata em caso de uma variação brusca de $S_{2} / h$ localizada na metade da distância entre os pontos $i$ e $j$.

A Equação (4.14) pode então ser escrita como:

$$
V_{i} h_{i} \frac{\partial \phi_{i}}{\partial t}=-\int_{S} \phi_{j} h_{j} k_{i j} \frac{p_{j}-p_{i}}{\left\|\mathbf{x}_{j}-\mathbf{x}_{i}\right\|} d S
$$


onde a integral de superfície pode ser numericamente aproximada, fornecendo:

$$
V_{i} h_{i} \frac{\partial \phi_{i}}{\partial t}=-\sum_{j=1, j \neq i}^{n_{p}} h_{j} k_{i j} \frac{p_{j}-p_{i}}{\left\|\mathbf{x}_{j}-\mathbf{x}_{\mathbf{i}}\right\|} A_{i j}
$$

onde $n_{p}$ é o número de partículas na vizinhança da partícula $i, A_{i j}$ é a superfície do volume $V_{i}$ e $k_{i j}$ é um valor médio dado por:

$$
k_{i j}=\left\{\begin{array}{ccc}
\frac{2}{\frac{h_{i}}{S_{2_{i}}}+\frac{h_{j}}{S_{2_{j}}}} & \text { se } \phi_{j}=1 \\
0 & \text { se } \quad \phi_{j} \neq 1
\end{array}\right.
$$

Assumindo uma distribuição aleatória isotrópica das partículas, podemos definir o raio médio, o volume médio e a área média da partícula $i$ como sendo, respectivamente:

$$
R_{i}=\frac{1}{2 n_{\mathrm{viz}}} \sum_{j=1, j \neq i}^{n_{v i z}}\left\|\mathbf{x}_{i}-\mathbf{x}_{j}\right\|
$$

onde $n_{\text {viz }}$ é o número de vizinhos $j$ de $i$,

$$
V_{i}=\pi R_{i}^{2}
$$

e

$$
A_{i j}=2 \pi R_{i}
$$

Substituindo essas últimas expressões em (4.15), e avaliando a derivada temporal usando Euler explícito, tem-se:

$$
\phi_{i}^{n+1}=\phi_{i}^{n}-\frac{2 \delta t}{h_{i} R_{i}} \sum_{j=1, j \neq i}^{n_{p}} h_{j} k_{i j} \frac{p_{j}-p_{i}}{\left\|\mathbf{x}_{j}-\mathbf{x}_{\mathbf{i}}\right\|} .
$$

Na estratégia adotada, deseja-se que, a cada passo no tempo $\delta t$, apenas um volume de controle fictício seja preenchido. Para tanto, calcula-se o passo de tempo $\delta t$ necessário para o preenchimento do volume associado a cada ponto $i$ pertencente à superfície livre $\left(0<\phi_{i}<1\right)$, impondo $\phi_{i}^{n+1}=1$ na Equação (4.16) e então escolhe-se o menor valor encontrado para $\delta t_{\text {preench: }}$

$$
\delta t_{\text {preench }}=\frac{R_{i} h_{i}\left(1-\phi^{n}\right)}{2 \sum_{j} h_{j} k_{i j} \frac{p_{j}-p_{i}}{\left\|\mathbf{x}_{j}-\mathbf{x}_{\mathbf{i}}\right\|}}
$$

A utilização de um passo no tempo que a cada iteração preencha apenas um volume de controle fictício resulta em um esquema com baixa difusão numérica, uma das maiores desvantagens presentes em métodos do tipo VOF (Ransau, 2002, Hirt e Nichols, 1981). 


\subsection{Algoritmo}

O algoritmo 1 calcula a solução do modelo matemático para a fase de preenchimento do processo de moldagem por injeção fornecendo uma aproximação para o campo de pressão, o campo de velocidades e o avanço da superfície livre do fluido conforme o preenchimento é realizado, utilizando a estratégia de desacoplamento descrita no Capítulo 3 e as abordagens SPH e VOF descritas no início deste capítulo. Os principais passos do algoritmo são identificados linha a linha e sua ação é descrita em seguida.

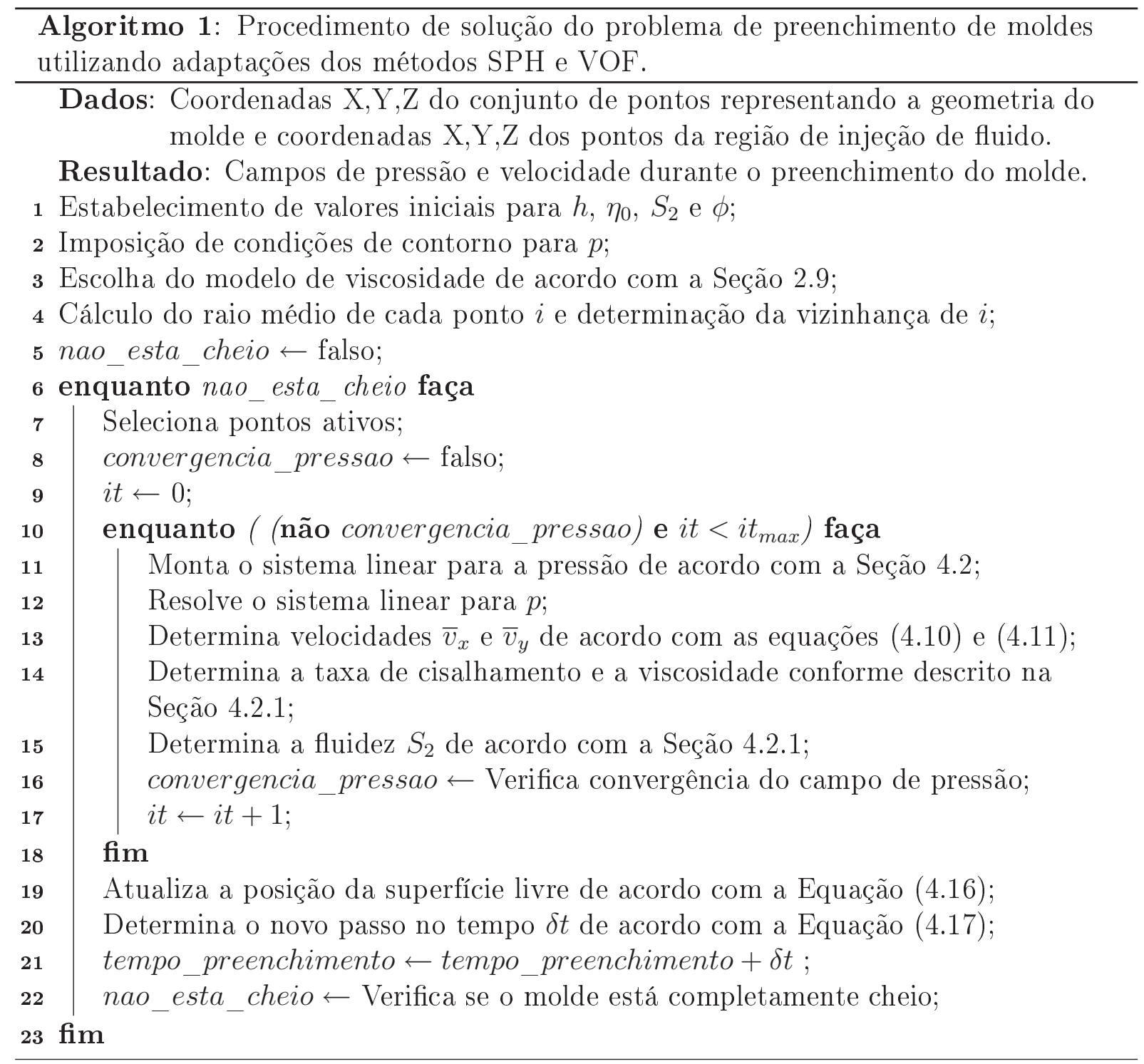

Na linha 2 a estratégia de injeção de fluido é escolhida: pressão ou velocidade prescrita. $\mathrm{Na}$ linha 4, um raio é associado a cada ponto $i$ na discretização, definindo os vizinhos de $i$. A linha 6 define o bloco de repetição responsável pelo avanço temporal da simulação: como a abordagem proposta utiliza o método VOF com uma restrição no passo de tempo de modo que apenas um volume associado a um ponto discretizando o domínio seja preenchido a cada passo no tempo, o bloco de repetição é realizado enquanto houver pelo 
menos um ponto $j$ tendo $\phi_{j}<1$. A linha 7 atualiza o subconjunto de pontos ativos conforme a superfície livre do escoamento se move: pontos inativos são ou vazios de fluido ou pontos da região de injeção no caso do preenchimento utilizando pressão prescrita, e não participam dos cálculos. A linha 10 ilustra o bloco de repetição para a convergência da pressão utilizando o método das aproximações sucessivas. A linha 11 realiza a montagem do sistema linear para a equação de Hele-Shaw utilizando as Equações (4.6) e (4.4). Finalmente as linhas 13-15 chamam procedimentos para calcular, respectivamente, as velocidades médias, segundo as equações (4.10) e (4.11), a viscosidade do fluido de acordo com a descrição apresentada na Seção 4.2.1 e utilizando um dos modelos apresentados na Seção 2.9, e a fluidez, por meio de integração numérica ao longo da espessura do molde, cuja aproximação também está descrita na Seção 4.2.1.

\subsection{Verificações do método proposto}

Condições de contorno típicas para o problema isotérmico são velocidade de injeção prescrita ou pressão de injeção prescrita. Como resultado da injeção de fluido adentro da cavidade de um molde com pressão prescrita, é esperado uma diminuição do valor da velocidade na região de injeção com o decorrer do preenchimento. Por outro lado, como resultado da injeção de fluido usando velocidade de injeção prescrita, espera-se que a pressão na região de injeção aumente ao decorrer do escoamento.

Qualquer que seja a estratégia de preenchimento do molde, os resultados da simulação são intimamente relacionados com a discretização da equação de Hele-Shaw. Na próxima seção, a equação de Hele-Shaw é discretizada utilizando a estratégia euleriana do método SPH, conforme descrito na Seção 4.2, e uma estimativa da ordem de convergência do método é analisada em duas condições distintas de distribuição de pontos no domínio representando a cavidade do molde.

Nas duas seções subseqüentes dois testes são realizados de modo a verificar a capacidade do método em fornecer simulações numéricas corretas. No primeiro deles, uma expressão analítica da velocidade do fluido durante o escoamento é apresentada no caso do preenchimento de um molde retangular com pressão de injeção prescrita utilizando um fluido newtoniano. A velocidade predita no injetor para o caso de um fluido de Cross é comparada com a velocidade obtida por meio de um método baseado em malhas.

No segundo teste, os resultados fornecidos pelo presente método são comparados com resultados encontrados na literatura, em caso do preenchimento de um molde retangular com um canal de entrada e dois valores distintos de espessura, utilizando um fluido newtoniano considerando-se velocidade de injeção prescrita.

\subsubsection{Estratégia euleriana do método SPH}

Este caso teste tem por objetivo estimar a qualidade dos resultados obtidos utilizando-se a adaptação euleriana do método SPH juntamente com a função núcleo do tipo exponen- 
cial escolhida (4.4). Para tanto, uma solução numérica obtida pelo método proposto é comparada com uma solução analítica. Distribuições uniformes e não uniformes de pontos no domínio representando o molde serão utilizadas com o intuito de ilustrar como o conjunto de pontos utilizado pode afetar a qualidade da solução obtida.

Nesse contexto, considere a equação de Hele-Shaw com a fluidez $S_{2}$ constante (esse seria o caso, por exemplo, do escoamento de um fluido newtoniano), definida em um domínio $\Omega=[-1,1] \times[-1,1]$ :

$$
\nabla^{2} p=0 \quad \text { em } \quad \Omega
$$

sujeita à seguintes condições de contorno:

$$
\begin{aligned}
& p(-1, y)=p(1, y)=1-y^{2}, \quad-1 \leq y \leq 1 \\
& p(x,-1)=p(x, 1)=x^{2}-1, \quad-1 \leq x \leq 1
\end{aligned}
$$

A solução analítica da Equação (4.18) sujeita a condições (4.19) é denotada por $u(x, y)$ e dada por:

$$
u(x, y)=x^{2}-y^{2} .
$$

A diferença entre a solução analítica e as soluções calculadas pelo método implementado para um dado conjunto de pontos é o erro cometido pela aproximação. Uma medida deste erro, como por exemplo, a norma $L_{2}$, pode ser comparada para conjunto de pontos sucessivamente refinados de modo a estimar com que taxa o erro cometido pela aproximação decresce. Em escala logarítmica, a inclinação da reta do erro cometido como função da quantidade de pontos utilizada na discretização é análoga à taxa de convergência do método numérico (Roy, 2005).

Nesse sentido, para estimar a ordem de convergência $q$ do método numérico apresentado em termos da norma $L_{2}$, faz-se:

$$
q=\frac{\log \left(\frac{L_{k+1}}{L_{k}}\right)}{\log \left(\frac{h_{k+1}}{h_{k}}\right)},
$$

onde $L_{k}$ refere-se ao erro cometido no conjunto com maior quantidade de pontos (refinado) e $L_{k+1}$ no conjunto com menor quantidade de pontos. Similarmente, $h_{k}$ e $h_{k+1}$ são diâmetros médios locais calculados nos respectivos conjuntos de pontos. O diâmetro médio local de um conjunto de $N$ pontos relativamente bem distribuídos em um domínio $\Omega$ de comprimento característico $l$ é definido por:

$$
h=\frac{l}{\sqrt{N}}
$$

Neste caso teste, a solução exata é dada pela Equação (4.20) e os erros cometidos considerando-se quantidades distintas de partículas são listados na Tabela 4.1: a terceira 
coluna da tabela refere-se às partículas não uniformemente distribuídas em $\Omega$ enquanto a quarta coluna refere-se às partículas distribuidas uniformemente, como se fossem os vértices de uma malha cartesiana regular. De modo a calcular os diâmetros locais para cada um dos conjuntos de pontos, o comprimento característico do molde é escolhido como sendo $l=2$, que é o comprimento de um dos contornos do domínio $\Omega$.

Tabela 4.1: Erro cometido na solução da equação segundo a norma $L_{2}$, considerando-se pontos uniformemente e não uniformemente distribuídos em $\Omega$.

\begin{tabular}{cccc}
\hline \hline Pontos & $h(\mathrm{~m})$ & $L_{2}$ (não uniform.) & $L_{2}$ (uniformemente) \\
\hline 100 & $2,00 \times 10^{-1}$ & $1,4191 \times 10^{-2}$ & $9,1108 \times 10^{-3}$ \\
200 & $1,41 \times 10^{-1}$ & $1,1981 \times 10^{-2}$ & $3,8884 \times 10^{-3}$ \\
400 & $1,00 \times 10^{-1}$ & $1,0762 \times 10^{-2}$ & $1,4262 \times 10^{-3}$ \\
800 & $7,07 \times 10^{-2}$ & $9,8306 \times 10^{-3}$ & $5,3444 \times 10^{-4}$ \\
1600 & $5,00 \times 10^{-2}$ & $8,3496 \times 10^{-3}$ & $1,8585 \times 10^{-4}$ \\
3200 & $3,53 \times 10^{-2}$ & $5,9087 \times 10^{-3}$ & $6,8150 \times 10^{-5}$ \\
\hline
\end{tabular}

Observa-se que no caso de conjuntos de pontos uniformemente espaçados o erro numérico é menor do que em conjuntos de pontos não uniformemente distribuídos, demonstrando que a qualidade da solução depende da regularidade dos dados (Li et. al., 2000).

A Figura 4.5 ilustra que a ordem de convergência do método é aproximadamente cúbica no caso de pontos uniformemente espaçados e sub-linear no caso de pontos não uniformemente espaçados em $\Omega$, já que em escala logarítmica um esquema de primeira ordem apresenta inclinação igual a um, esquemas de segunda ordem apresentam inclinação dois, e assim por diante. A variação da ordem de convergência para ambos os casos de distribuição de partículas no domínio $\Omega$ é ilustrada na Figura 4.6.

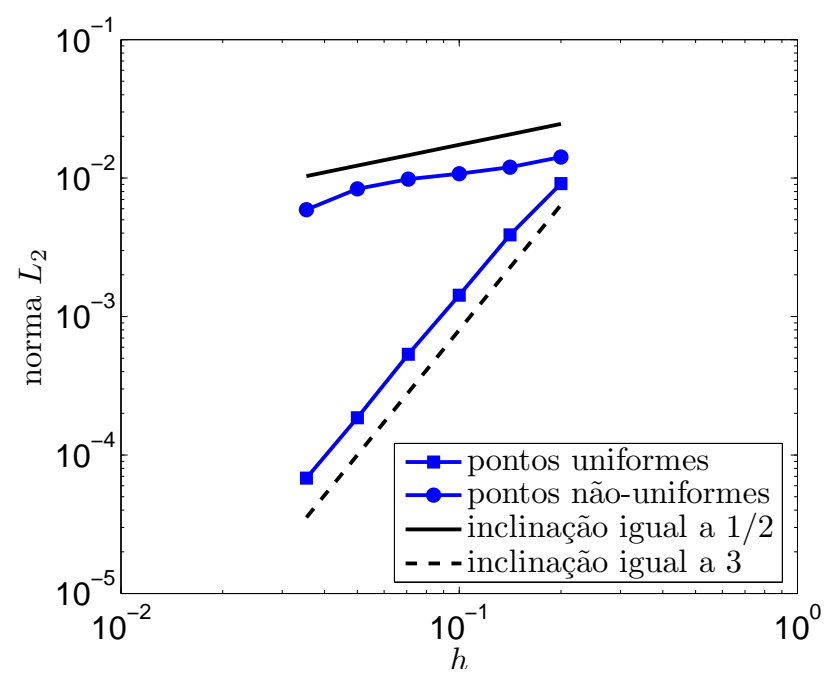

Figura 4.5: Norma $L_{2}$ do erro cometido na aproximação da equação de Laplace. 


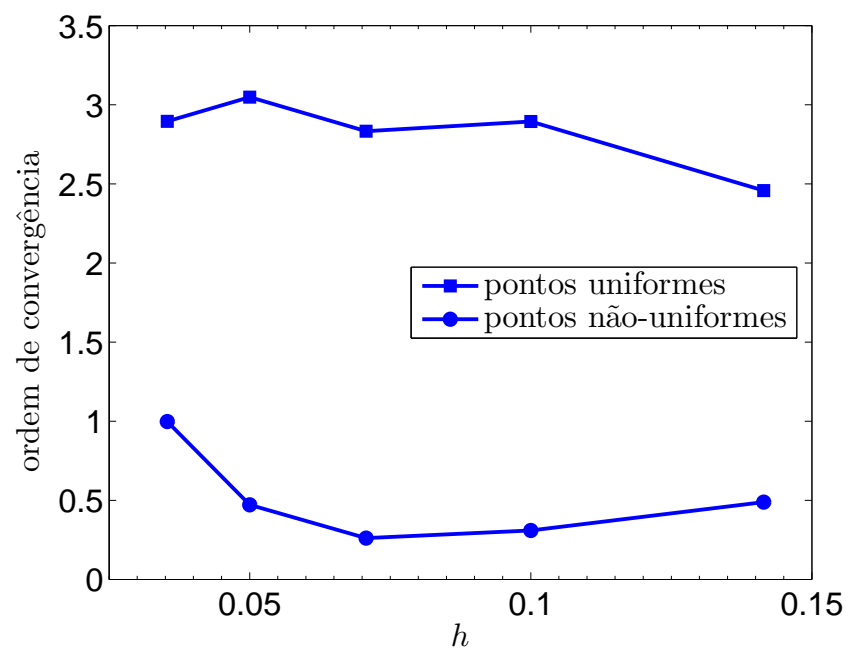

Figura 4.6: Ordem de convergência $q$ do método proposto.

\subsubsection{Escoamento em um canal retangular}

Nesta seção, a velocidade na região de injeção é comparada com uma solução analítica no caso do preenchimento de um molde retangular simples (ilustrado na Figura 4.7) considerando valores distintos de pressão de injeção prescrita $p_{\text {inj }}$ quando o molde está preenchido até a metade, considerando ainda um fluido newtoniano. O conjunto de pontos representando o contorno e o interior do molde tem 498 pontos.

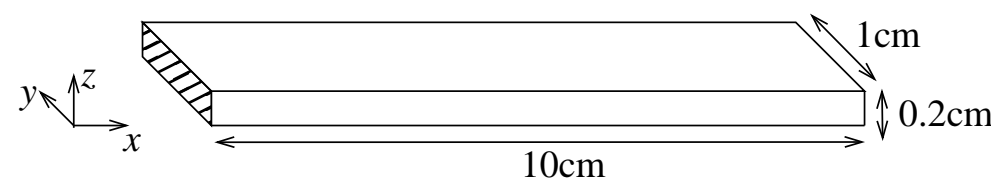

Figura 4.7: Dimensões do canal e região de injeção (área hachurada).

Como as dimensões do molde não variam na direção- $x$, e como as condições de contorno nas paredes estreitas da Figura 4.7 são do tipo escorregamento tem-se:

$$
\frac{\partial \bar{v}_{x}}{\partial y}=0 \quad \text { e } \quad \bar{v}_{y}=0
$$

e a solução para este problema é simplesmente dada por:

$$
\bar{v}_{x}=v_{0} \quad \text { e } \quad \bar{v}_{y}=0
$$

para todo o canal, onde a frente de fluido avança como um plano perpendicular ao eixo- $x$ movendo com velocidade $v_{0}$ resultante do pós-processamento do campo de pressão. $\mathrm{O}$ campo médio de velocidade, por outro lado, é obtido por meio das equações (3.8) e (3.9), resultando em:

$$
v_{0}=-\frac{S_{2}}{h} \frac{p-p_{\text {inj }}}{x}
$$

Lembrando que, na superfície livre, $x=\delta l$ e $p=p_{0}$, onde $\delta l$ é o deslocamento da 
superfície livre e $p_{0}$ é a pressão atmosférica, tem-se:

$$
v_{0}=\frac{S_{2}}{\delta l h} p_{\text {inj }}
$$

A Equação (4.24) é uma expressão analítica para a velocidade do fluido no canal e permite a verificação da credibilidade dos resultados fornecidos pelo método proposto.

No caso de um fluido newtoniano, a viscosidade é independente da taxa de cisalhamento, e portanto, a expressão para a fluidez $S_{2}$ reduz-se a:

$$
S_{2}=\frac{h^{3}}{3 \eta_{0}}
$$

onde $h$ é a espessura do molde e $\eta_{0}$ é a viscosidade do fluido. Substituindo esta expressão em (4.24), tem-se:

$$
v_{0}=\frac{h^{2}}{3 \eta_{0} \delta l} p_{\text {inj }}
$$

De acordo com a Equação (4.25) a velocidade $v_{0}$ do fluido ao longo do canal depende linearmente da pressão de injeção $p_{i n j}$ no caso de fluidos newtonianos.

Vários testes foram conduzidos considerando diversos valores de pressão de injeção no caso do enchimento do molde por um fluido newtoniano de viscosidade $\eta_{0}=4 \times 10^{6} \mathrm{Pas}$ no momento em que o molde está cheio pela metade, isto é, quando $\delta l=5 \times 10^{-2} \mathrm{~m}$. Estes resultados estão ilustrados na Tabela 4.2.

Tabela 4.2: Velocidade do fluido (em $\mathrm{m} / \mathrm{s}$ ) quando o molde em formato de canal descrito na Figura 4.7 está parcialmente cheio $\left(\delta l=5 \times 10^{-2} \mathrm{~m}\right)$. Resultados obtidos usando distintos valores de pressão de injeção (em $\mathrm{Pa}$ ) imposta na região de entrada de fluido. Valores encontrados considerando-se o molde representado por 498 pontos ora $\operatorname{com} N_{z}=5$ ora com $N_{z}=100$.

\begin{tabular}{ccccc}
\hline \hline Pressão de injeção & Sol. Analítica & Camadas & Sol. Numérica & Erro Relativo (\%) \\
\hline \multirow{2}{*}{$10^{5}$} & $6,6666 \times 10^{-7}$ & 5 & $6,7224 \times 10^{-7}$ & 0,8370 \\
& & 100 & $6,6191 \times 10^{-7}$ & 0,7125 \\
\multirow{2}{*}{$10^{7}$} & $6,6666 \times 10^{-5}$ & 5 & $6,7224 \times 10^{-5}$ & 0,8370 \\
\multirow{2}{*}{$10^{9}$} & & 100 & $6,6191 \times 10^{-5}$ & 0,7125 \\
& \multirow{2}{*}{$6,6666 \times 10^{-3}$} & 5 & $6,7224 \times 10^{-3}$ & 0,8370 \\
& & 100 & $6,6191 \times 10^{-3}$ & 0,7125 \\
\hline
\end{tabular}

No caso de fluidos não newtonianos como os descritos na Seção 2.9 e também empregados neste estudo, não é possível estabelecer uma equação do tipo (4.25) devido à dependência da viscosidade com relação à taxa de cisalhamento do fluido que, por sua vez, torna o cálculo de $S_{2}$ não linear.

No caso do fluidos de Cross (2.52), diversos testes foram realizados comparando o campo de velocidade obtido por meio do método proposto com o obtido empregando-se o método baseado em malhas de Estacio e Mangiavacchi (2007). Neste caso, considera-se 
poliestireno cujos parâmetros ajustados para o modelo de Cross estão descritos na Seção 2.9. Os resultados obtidos são apresentados na Tabela 4.3.

Tabela 4.3: Velocidade de fluido (em $\mathrm{m} / \mathrm{s}$ ) um molde em formato de canal obtida usando distintos valores de pressão de injeção (em $P a$ ) imposta na região de entrada de fluido. Valores encontrados considerando-se o molde descrito na Figura 4.7 parcialmente cheio e considerando se $N_{z}=5$ e $N_{z}=100$.

\begin{tabular}{cccc}
\hline \hline Pressão de injeção & Camadas & Método Proposto & (Estacio e Mangiavacchi, 2007) \\
\hline \multirow{2}{*}{$10^{5}$} & 5 & $6,9146 \times 10^{-7}$ & $6,9634 \times 10^{-7}$ \\
& 100 & $6,8016 \times 10^{-7}$ & $6,8496 \times 10^{-7}$ \\
$10^{6}$ & 5 & $8,5775 \times 10^{-6}$ & $8,9540 \times 10^{-6}$ \\
& 100 & $8,3222 \times 10^{-6}$ & $8,6549 \times 10^{-6}$ \\
$10^{7}$ & 5 & $4,9311 \times 10^{-4}$ & $4,8977 \times 10^{-4}$ \\
& 100 & $4,5191 \times 10^{-4}$ & $4,4906 \times 10^{-4}$ \\
\hline
\end{tabular}

Os resultados apresentados nas Tabelas 4.2 e 4.3 mostram que o método proposto produz soluções numéricas com erro inferior a $1 \%$ para o caso de fluidos newtonianos e resultados muito similares aos obtidos por um método baseado em malhas no caso de um fluido de Cross. Este fato demonstra a capacidade do presente método em fornecer resultados numericamente coerentes para o campo de velocidade no caso do preenchimento de moldes utilizando-se pressão de injeção prescrita.

\subsubsection{Escoamento em um molde retangular com um canal de en- trada}

O objetivo desta seção é verificar a capacidade do método em predizer corretamente perfis de pressão na região de injeção e posição da superfície livre durante o preenchimento do molde utilizando-se velocidade de injeção prescrita. A solução fornecida pelo presente método é comparada com os resultados apresentados no trabalho de Chang e Yang (2001) durante o preenchimento de um molde retangular com um canal de entrada e com um dos lados significativamente mais espesso do que o outro.

As dimensões do molde estão descritas na Figura 4.8. Há 639 pontos definindo ambos a fronteira e o interior do molde, e a sua direção vertical é dividida em $N_{z}=16$ camadas.

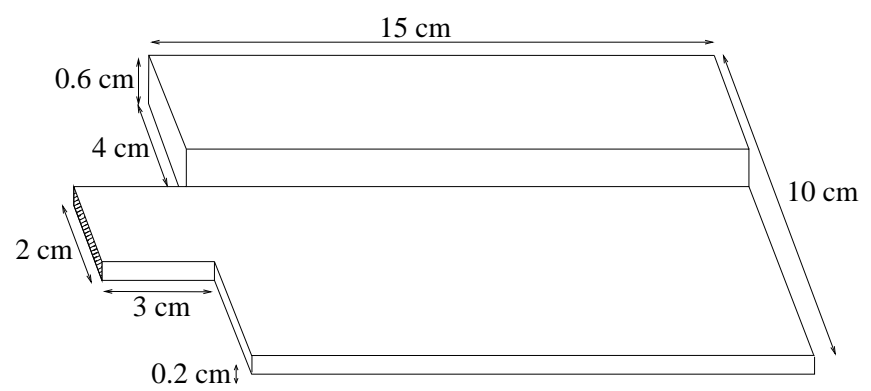

Figura 4.8: Molde retangular com um canal de entrada e diferentes espessuras. A região de injeção de fluido está representada pela área hachurada. 
Nesta simulação estipula-se que o molde deve estar completamente preenchido de fluido passados 2 segundos do início da injeção. O tempo necessário para o preenchimento de um molde de volume $V$ a uma dada velocidade de injeção fixa $v_{\text {inj }}$ pode ser calculado por meio de conservação de massa da seguinte maneira:

$$
t=\frac{V}{A v_{\text {inj }}},
$$

onde $A$ é a área da região de injeção de fluido. Nestas condições, tem-se que a velocidade de injeção necessária para o preenchimento do molde descrito na Figura 4.8 é de $v_{\text {inj }}=0,69 \mathrm{~m} / \mathrm{s}$.

A Figura 4.9 compara os perfis de pressão na região de injeção de fluido obtidas pelo método proposto com os resultados apresentados no trabalho de Chang e Yang (2001) para o caso de um fluido newtoniano $\left(\eta_{0}=10^{4} \mathrm{Pas}\right)$ e velocidade de injeção prescrita.

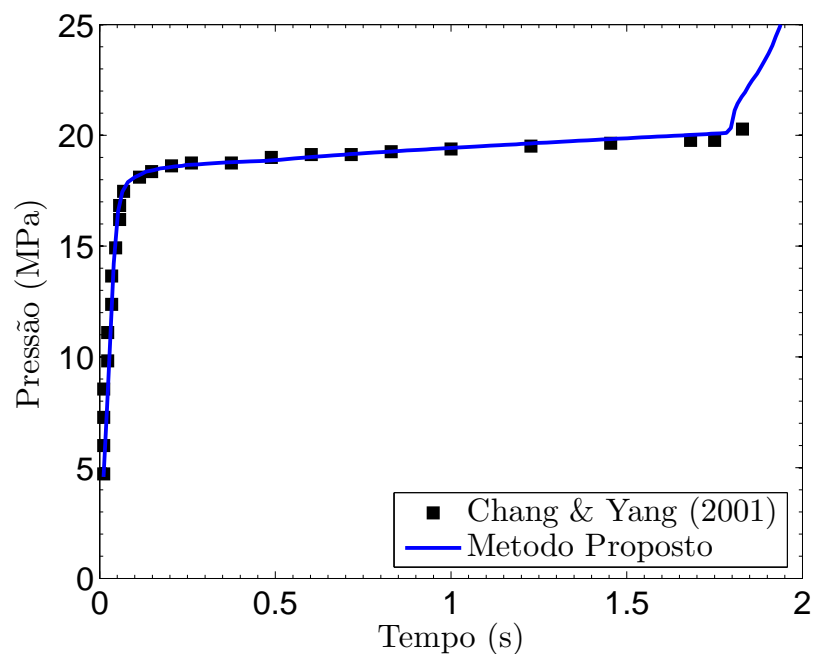

Figura 4.9: Perfis de pressão na região de injeção de fluido ao longo da simulação. Valores obtidos pelo presente método são comparados com os resultados de Chang e Yang (2001).

A Figura 4.10 ilustra a posição da superfície livre em oito diferentes estágios do preenchimento do molde. A linha preta representa a superfície livre do fluido; o volume do molde localizado à esquerda da linha está preenchido enquanto o volume do molde localizado à direita da linha ainda encontra-se vazio. A posição da superfície livre predita pelo método está consistente com os resultados de Chang e Yang (2001), apresentados na Figura 4.11.

O teste realizado nesta seção mostra a capacidade do método em prever pressão de injeção e posição da superfície livre corretas ao decorrer do preenchimento de um molde de geometria relativamente complexa utilizando-se velocidade de injeção prescrita. Este teste conclui os estudos realizados referentes à verificação do método implementado, explicitando a capacidade de fornecer resultados satisfatórios em ambas estratégias de injeção de fluido (pressão ou velocidade prescrita) e pode, portanto, ser utilizado com boa confiabilidade para a simulação numérica do problema físico em questão. 


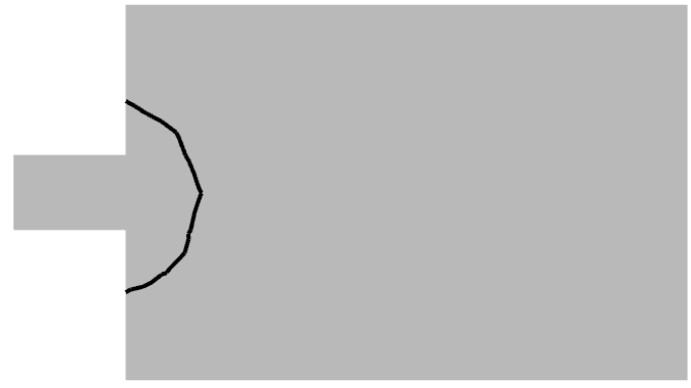

(a) $5 \%$ preenchido

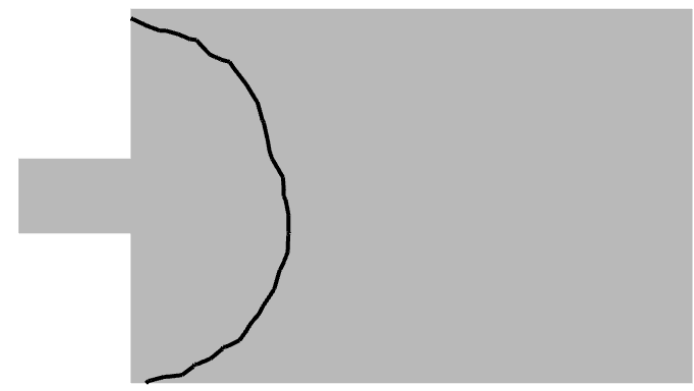

(c) $20 \%$ preenchido

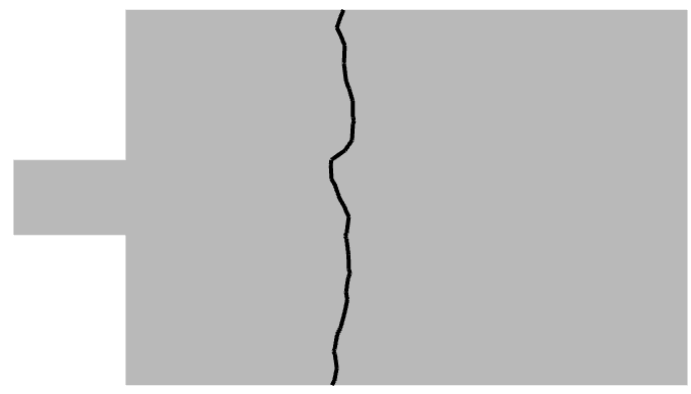

(e) $40 \%$ preenchido

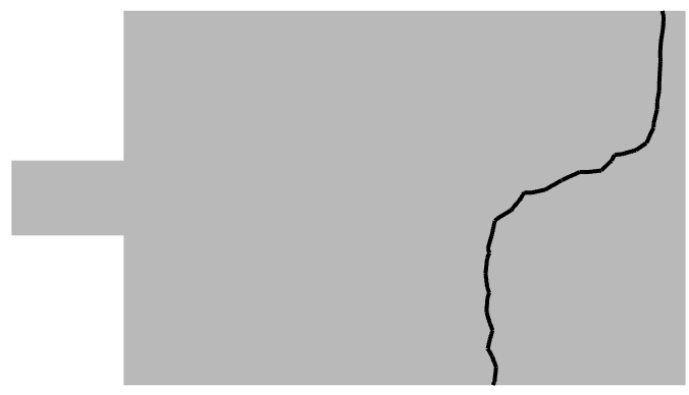

(g) $85 \%$ preenchido

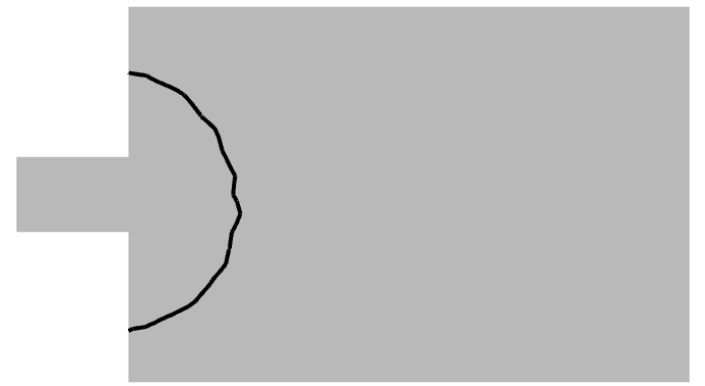

(b) $10 \%$ preenchido

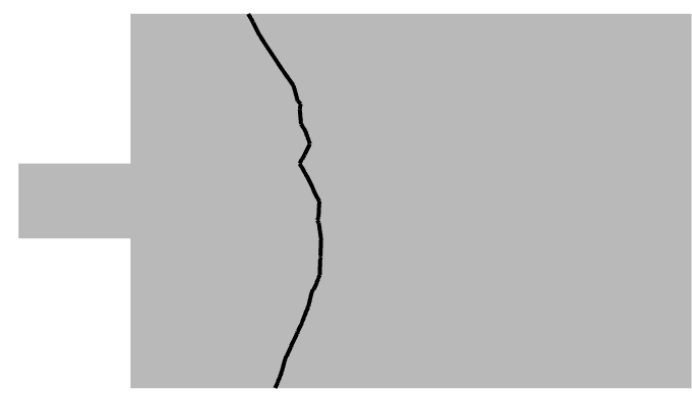

(d) $30 \%$ preenchido

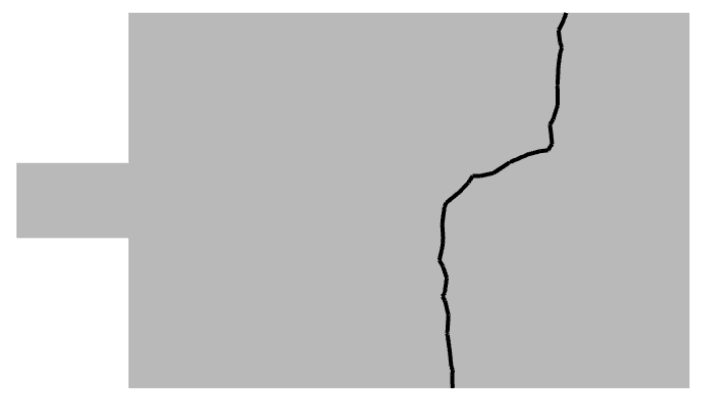

(f) $70 \%$ preenchido

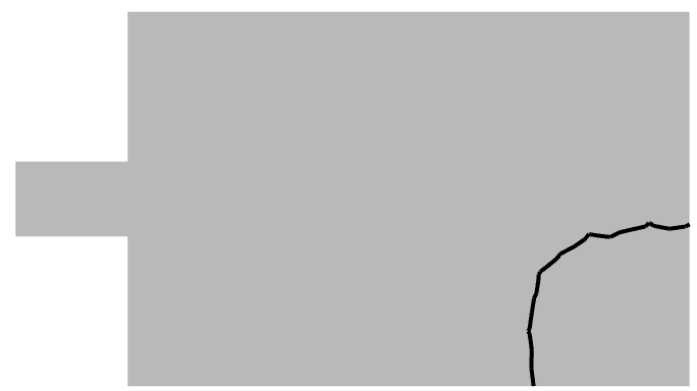

(h) $95 \%$ preenchido

Figura 4.10: Diversos perfis da posição da superfície livre durante o preenchimento do molde. As posições preditas pelo método estão de acordo com os resultados obtidos por Chang e Yang (2001). 


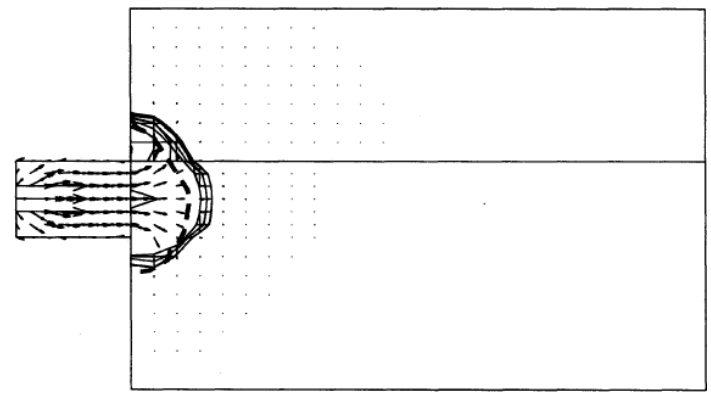

(a) $5 \%$ preenchido

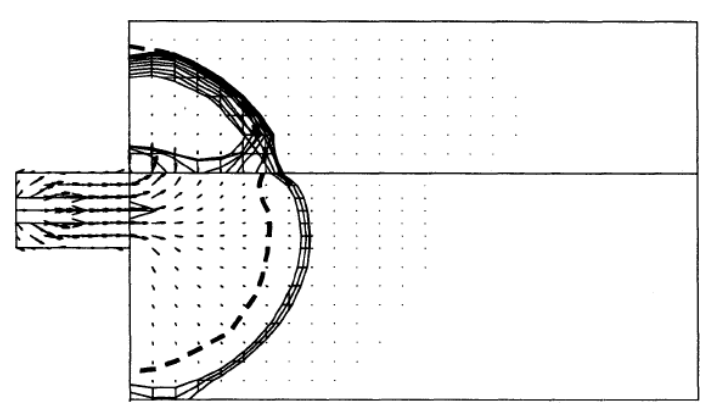

(c) $20 \%$ preenchido

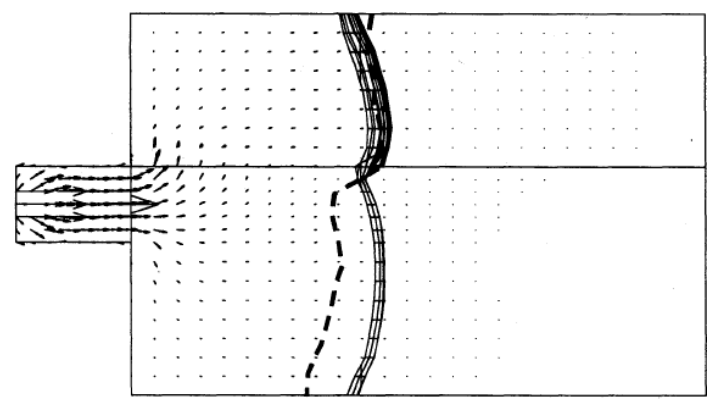

(e) $40 \%$ preenchido

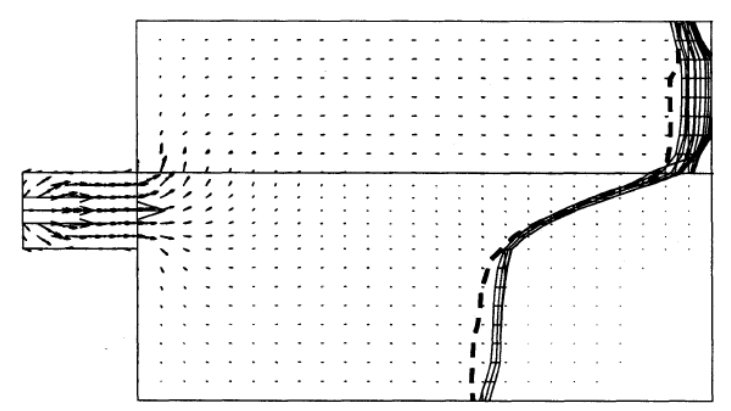

(g) $85 \%$ preenchido

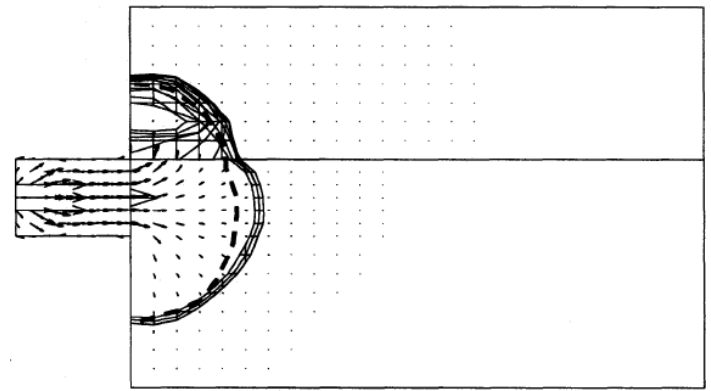

(b) $10 \%$ preenchido

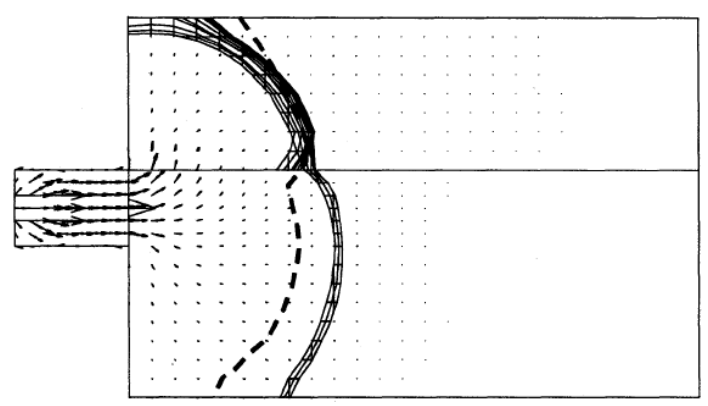

(d) $30 \%$ preenchido

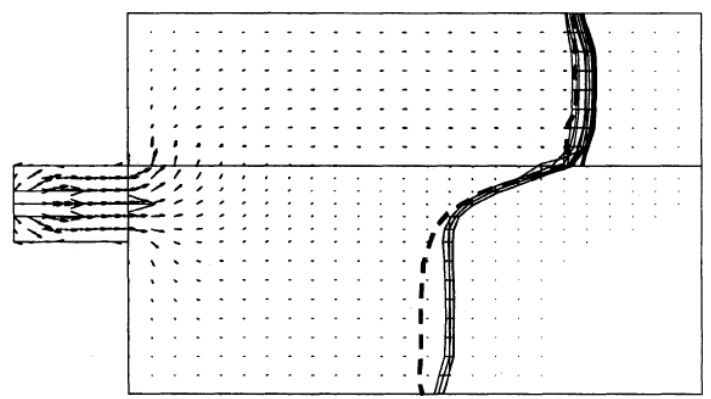

(f) $70 \%$ preenchido

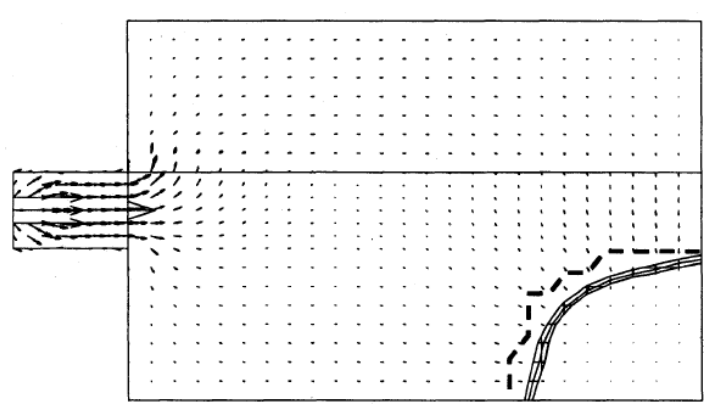

(h) $95 \%$ preenchido

Figura 4.11: Resultados de Chang e Yang (2001) para a posição da superfície livre. A linha tracejara representa o modelo $2^{1} / 2 \mathrm{D}$ e a malha representa um modelo 3D. 


\subsection{Resultados}

Nesta seção serão apresentados alguns resultados obtidos pela solução numérica das equações (4.5) e (4.12) para situações gerais, considerando um fluido newtoniano e o escoamento isotérmico.

$\mathrm{Na}$ primeira simulação, é apresentada uma comparação entre os resultados obtidos pelo método proposto com aqueles obtidos pelo método baseado em malhas de Estacio e Mangiavacchi (2007) durante o preenchimento de um molde em formato de chave com uma inserção circular (obstáculo).

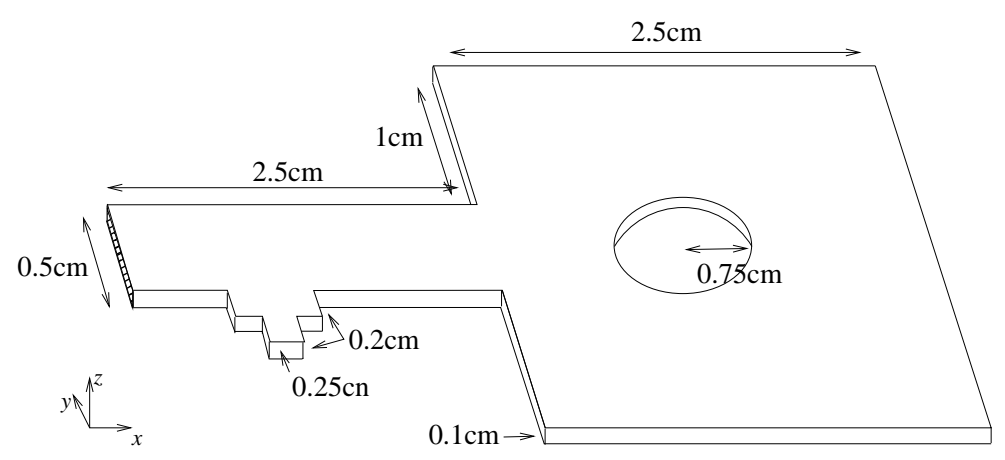

Figura 4.12: Dimensões do molde em formato de chave.

A Figura 4.12 mostra as dimensões do molde, e a Figura 4.13(a) ilustra a malha triangular não estruturada utilizada na aproximação de Estacio e Mangiavacchi (2007). A malha não estruturada triangular, construída utilizando o gerador de malhas Delaunay livre Easymesh (Niceno, 2001), apresenta 1713 triângulos de 942 volumes de controle. De modo a tornar a comparação dos resultados possível, os pontos utilizados na discretização das equações pelo método proposto são os vértices dos triângulos da malha ilustrada na Figura 4.13(a) e estão ilustrados na Figura 4.13(b).

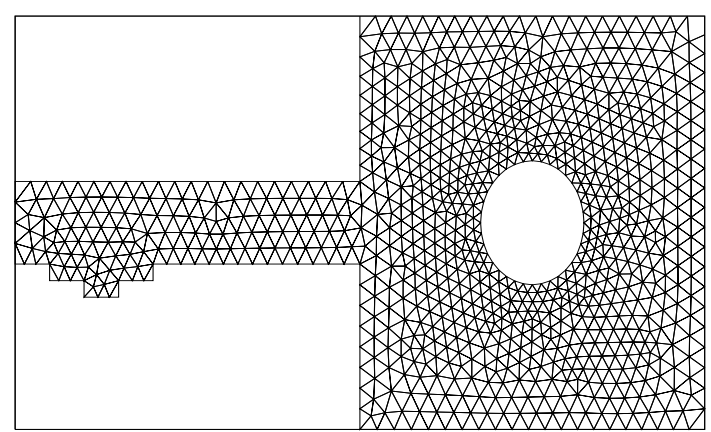

(a) Malha triangular

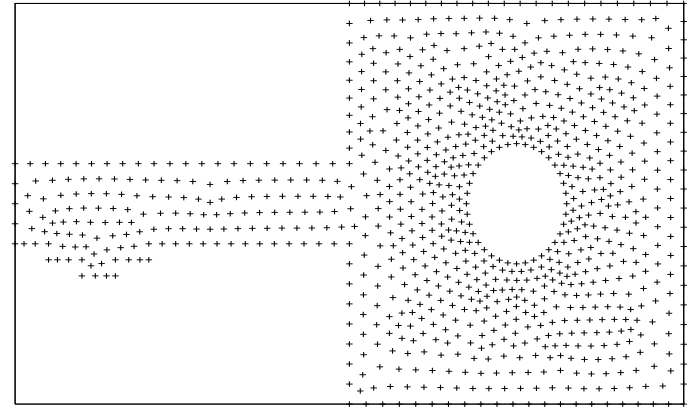

(b) Vértices da malha

Figura 4.13: Malha não estruturada triangular utilizada na aproximação por volumes finitos, e pontos definindo a geometria do molde, utilizados na metodologia proposta.

Nesta simulação, um fluido newtoniano de viscosidade $\eta_{0}=10^{4} \mathrm{~Pa}$ s é injetado adentro do molde com velocidade constante $v_{\text {inj }}=10^{-1} \mathrm{~m} / \mathrm{s}$ imposta na região de injeção. Nestas condições, o tempo esperado para o completo preenchimento do molde é 1,46 segundos. 
O perfil de velocidade ao longo da espessura obtido por ambos os métodos é ilustrado na Figura 4.14.

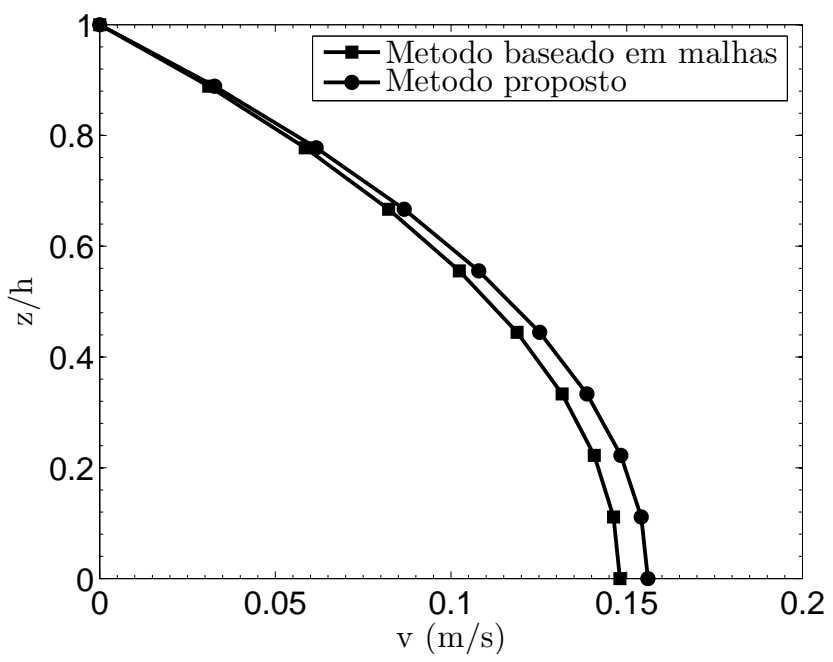

Figura 4.14: Perfil da velocidade na região de injeção de fluido.

A Figura 4.15 ilustra seis estágios do campo de pressão obtidos ao empregar o método dinâmico proposto e a Figura 4.16 ilustra os perfis da pressão na região de injeção obtidos por ambos os métodos durante o preenchimento do molde. A Figura 4.17 ilustra a posição da superfície livre do fluido obtida via ambos os métodos. Pode-se notar a boa concordância entre os resultados, tanto com relação à pressão dentro da cavidade do molde, resultante da imposição de velocidade de injeção prescrita, quanto com relação à posição da superfície livre do fluido durante o preenchimento do molde.

Esta simulação mostra a capacidade do método proposto em lidar com a divisão e posterior coalescência da frente de fluido, durante o preenchimento de um molde. A semelhança entre resultados obtidos pelo o presente método e aqueles obtidos pelo método que utiliza malhas mostra a validade da abordagem proposta.

Na segunda simulação é apresentado o preenchimento de um molde que imita o formato de um personagem de desenho animado (o Piu-Piu) com o propósito de ilustrar a capacidade de lidar com geometrias complexas e não planares. O conjunto de pontos representa o Piu-Piu, é tridimensional, e apresenta amplitude variando de 0,2355 m na direção- $x, 0,3675 m$ na direção- $y$ e $0,0180 m$ na direção- $z$, conforme ilustrado na Figura 4.18. Neste caso, a região de injeção de fluido é escolhida como sendo o cabelo do Piu-Piu.

As Figuras 4.19 e 4.20 mostram os campos de pressão e velocidade, respectivamente, em seis diferentes momentos: logo após o início do preenchimento, em quatro tempos intermediários e ao final do preenchimento. O tempo total de preenchimento predito pelo método é 0,12 segundos. Uma malha tridimensional foi construída utilizando o iMesh (Cuadros-Vargas e Nonato, 2006) de modo a permitir a visualização dos resultados. Vale ressaltar que as informações da malha não são utilizadas durante a simulação, sendo apenas utilizadas as coordenadas $x, y$ e $z$ dos pontos definindo o molde. 


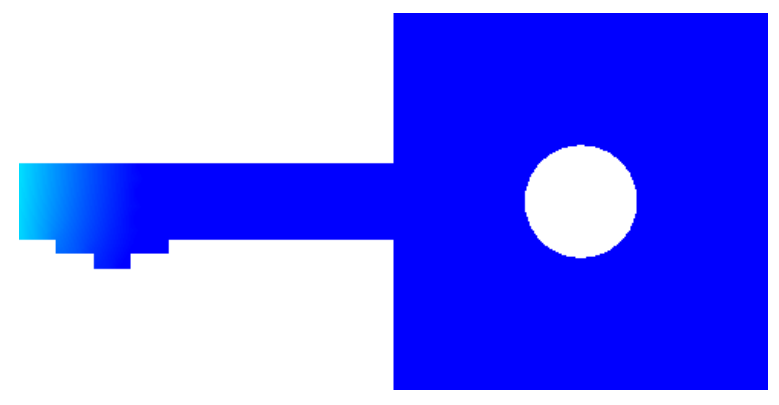

(a) $5 \%$ preenchido

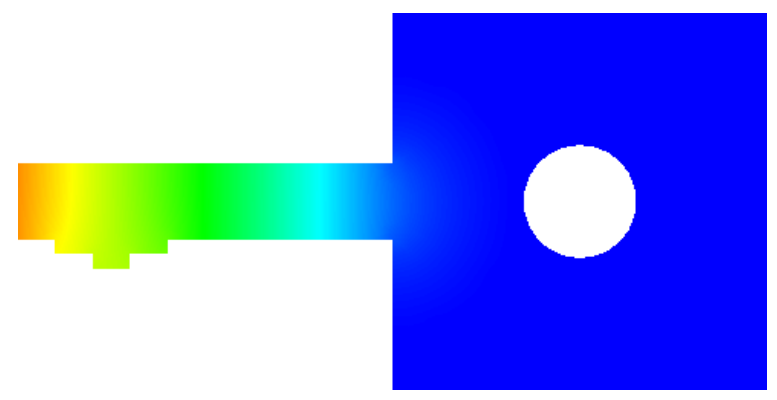

(c) $35 \%$ preenchido

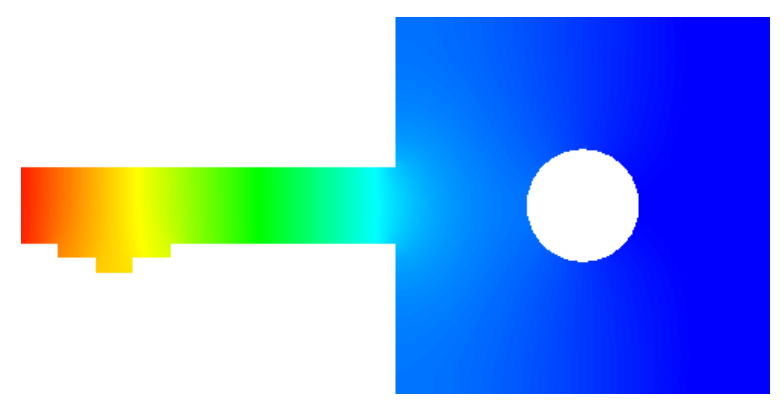

(e) $80 \%$ preenchido

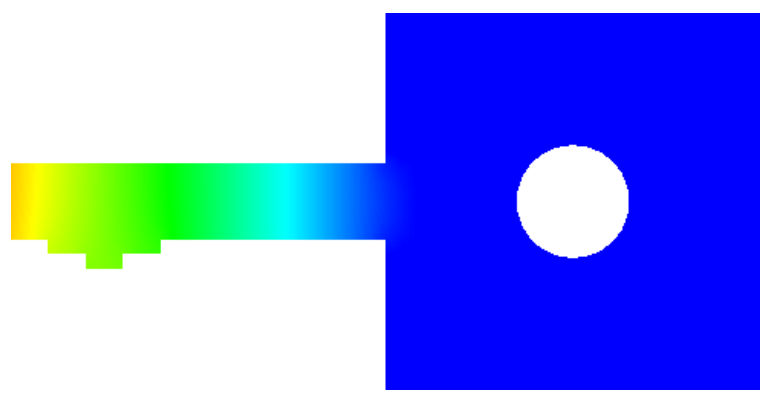

(b) $20 \%$ preenchido

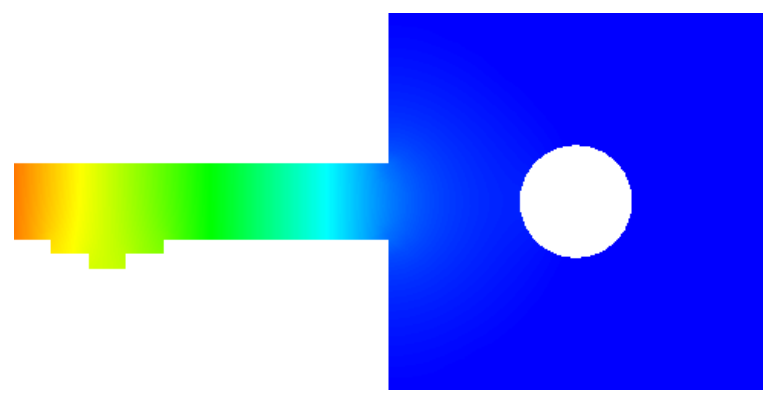

(d) $50 \%$ preenchido

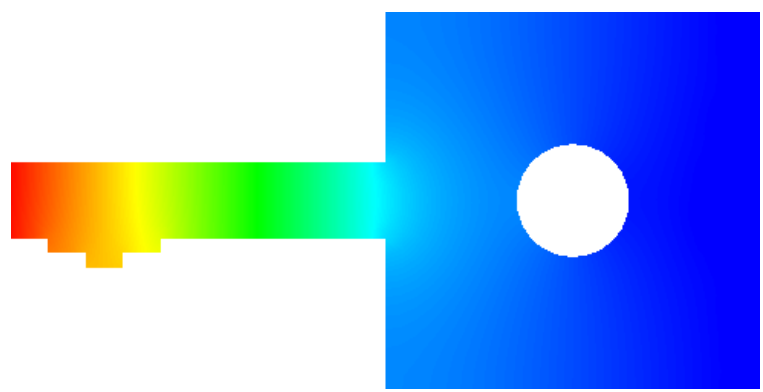

(f) $90 \%$ preenchido

\subsection{0}

$4.68 \mathrm{e}+005$

$9.35 e+005$

Figura 4.15: Seis estágios da distribuição de pressão durante o preenchimento do molde obtidos usando o método dinâmico implementado. A pressão na região de injeção aumenta no decorrer do enchimento do molde resultante da imposição de velocidade prescrita e constante na região de injeção de fluido. 


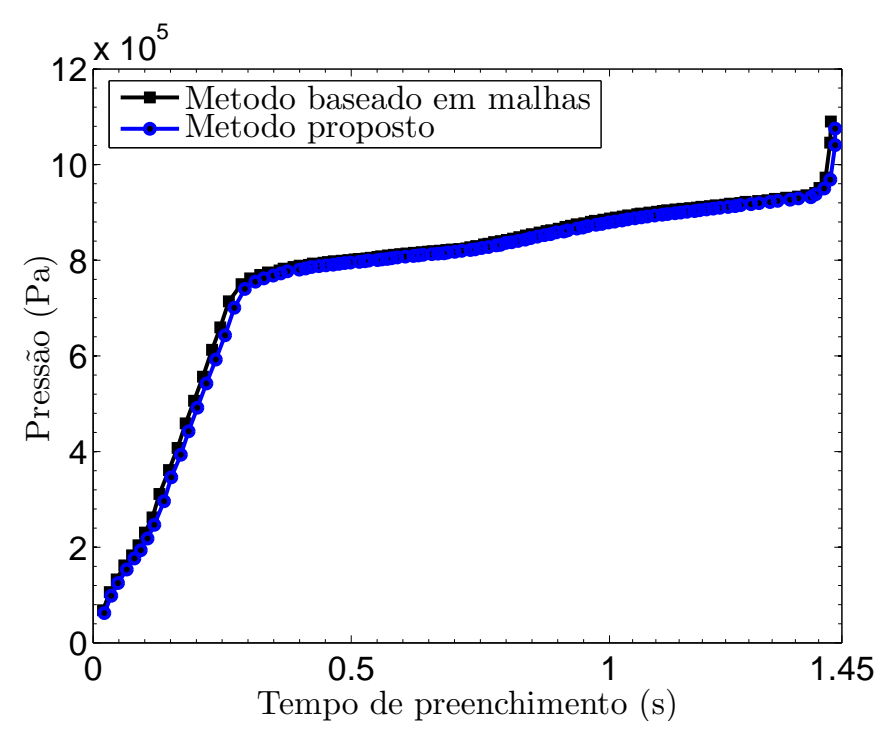

Figura 4.16: Perfil da pressão na região de injeção de fluido durante a simulação.

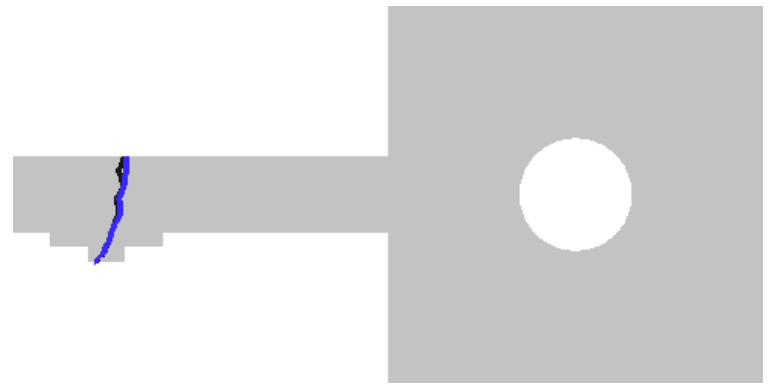

(a) $5 \%$ preenchido

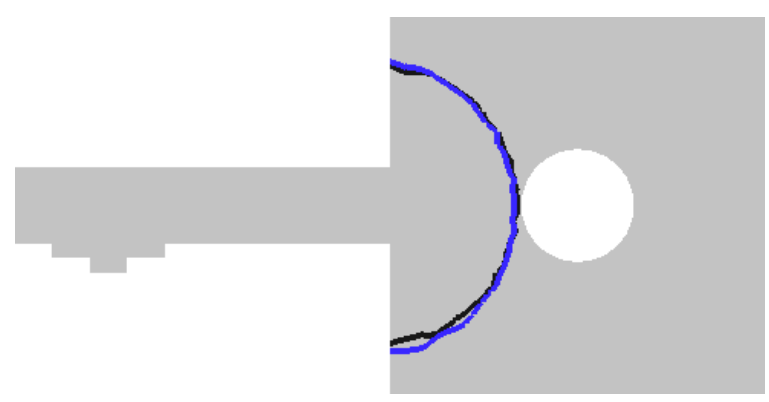

(c) $35 \%$ preenchido

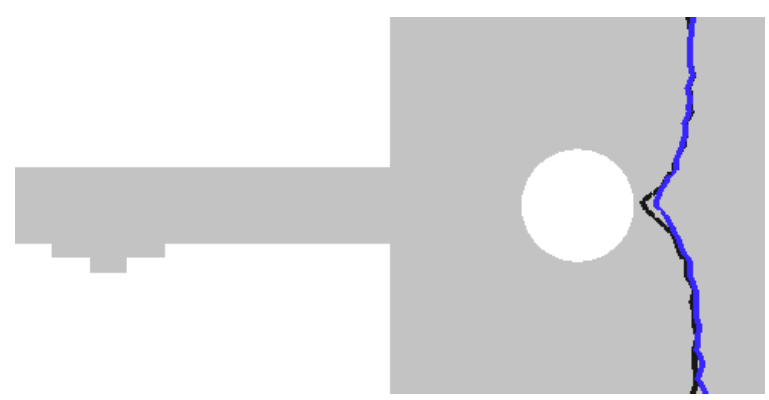

(e) $80 \%$ preenchido

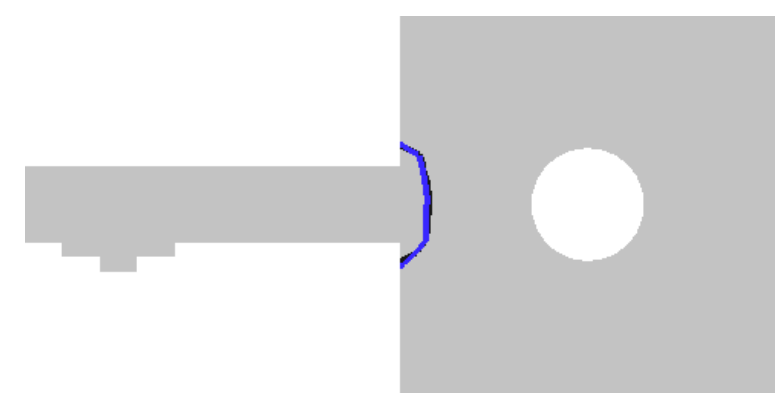

(b) $20 \%$ preenchido

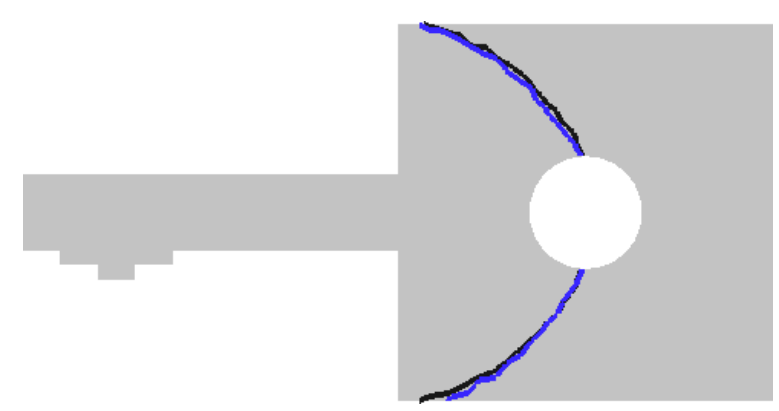

(d) $50 \%$ preenchido

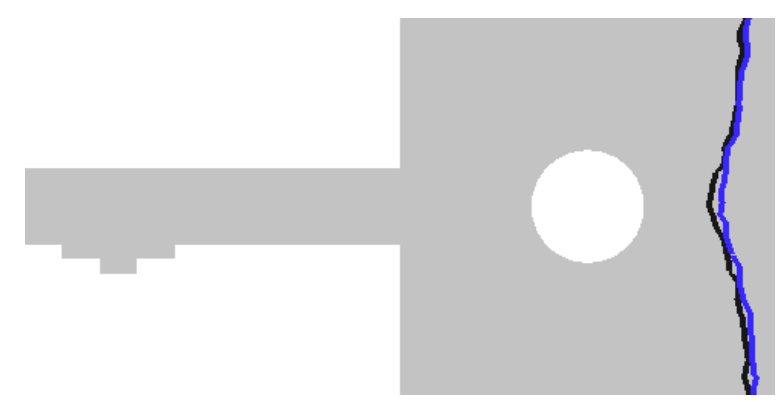

(f) $90 \%$ preenchido

Figura 4.17: Comparação da posição da superfície livre predita pelo presente método (azul) e o método de Estacio e Mangiavacchi (2007) (preto). A linha representa a superfície livre: a região à esquerda da linha encontra-se cheia de fluido enquanto a região à direita da linha encontra-se vazia. 

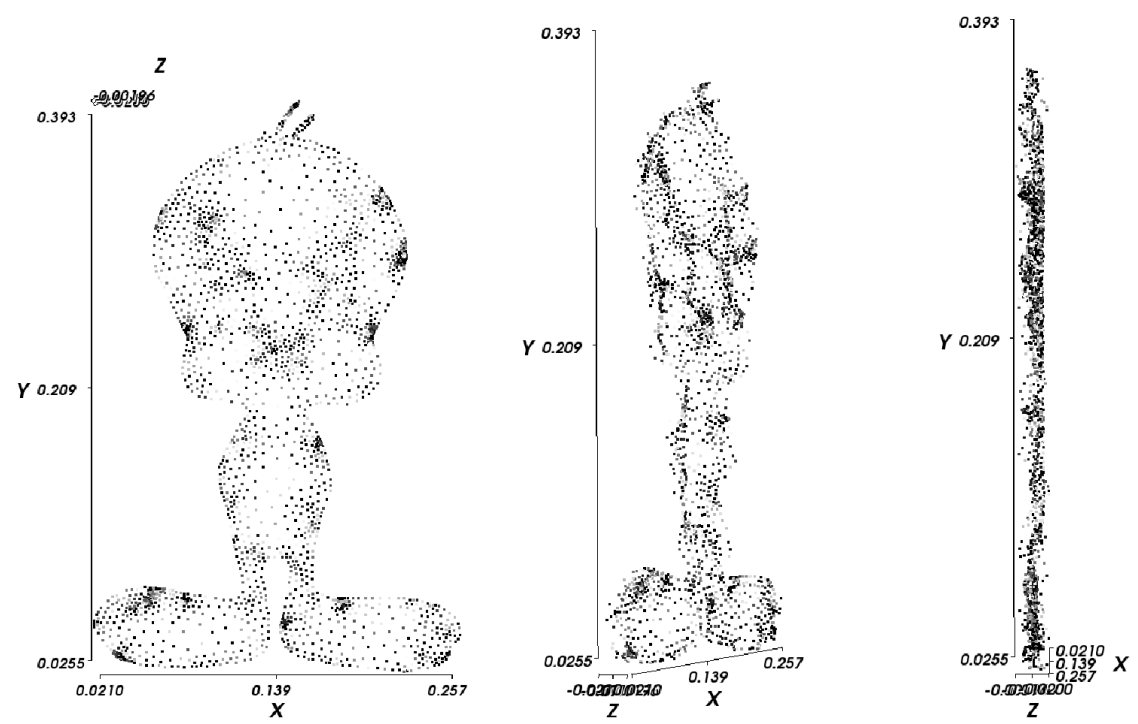

Figura 4.18: Três diferentes vistas do conjunto de pontos definindo o molde do Piu-Piu.
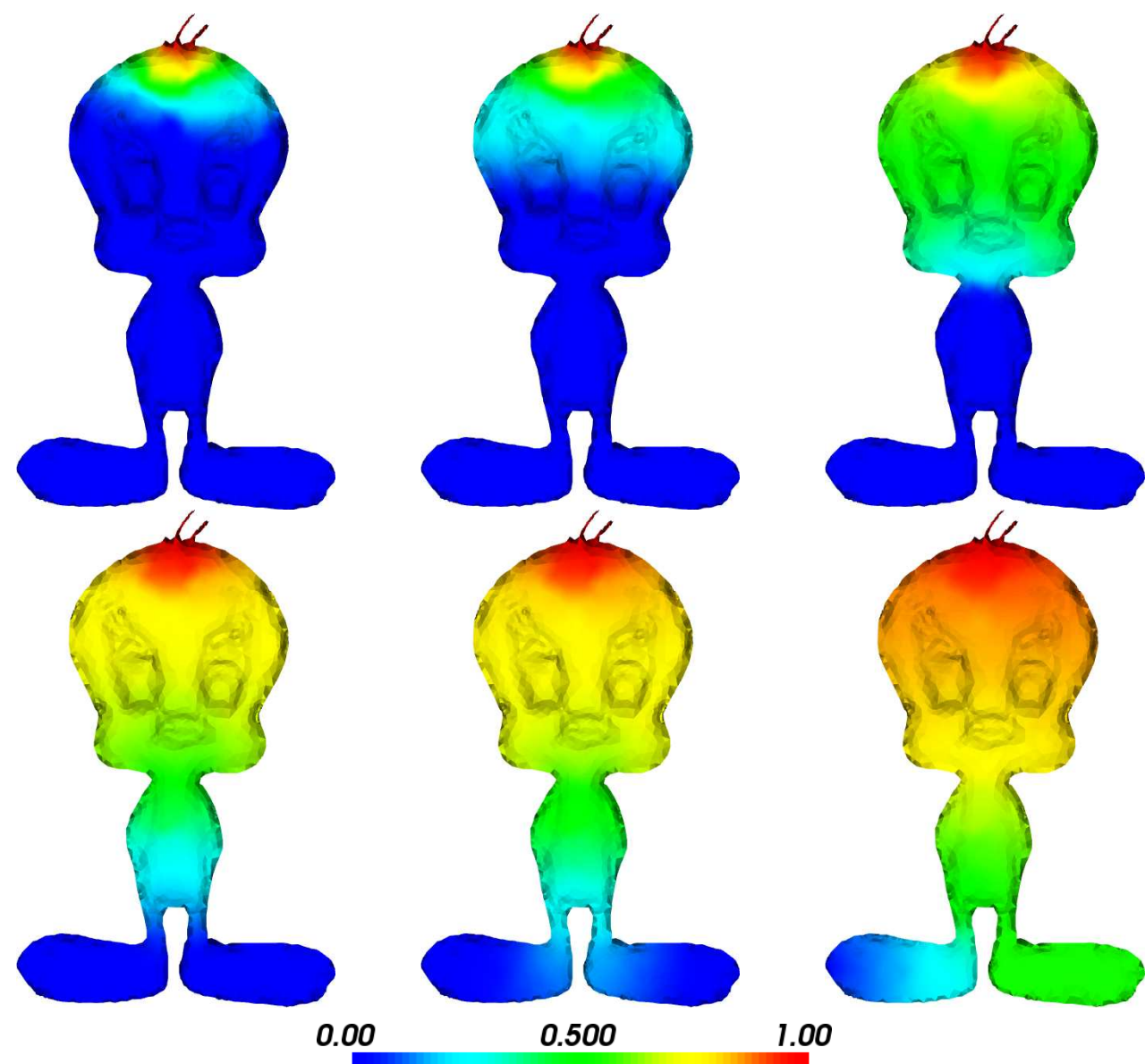

0.00

0.500

1.00

Figura 4.19: Seis estágios da distribuição da pressão durante o preenchimento do molde. Os valores estão divididos por $p_{0}=10^{5} \mathrm{~N} / \mathrm{m}^{2}$.

\subsection{Comentários}

Este capítulo apresentou uma adaptação euleriana do método SPH juntamente com uma abordagem dinâmica do método VOF para resolver as equações governantes do 

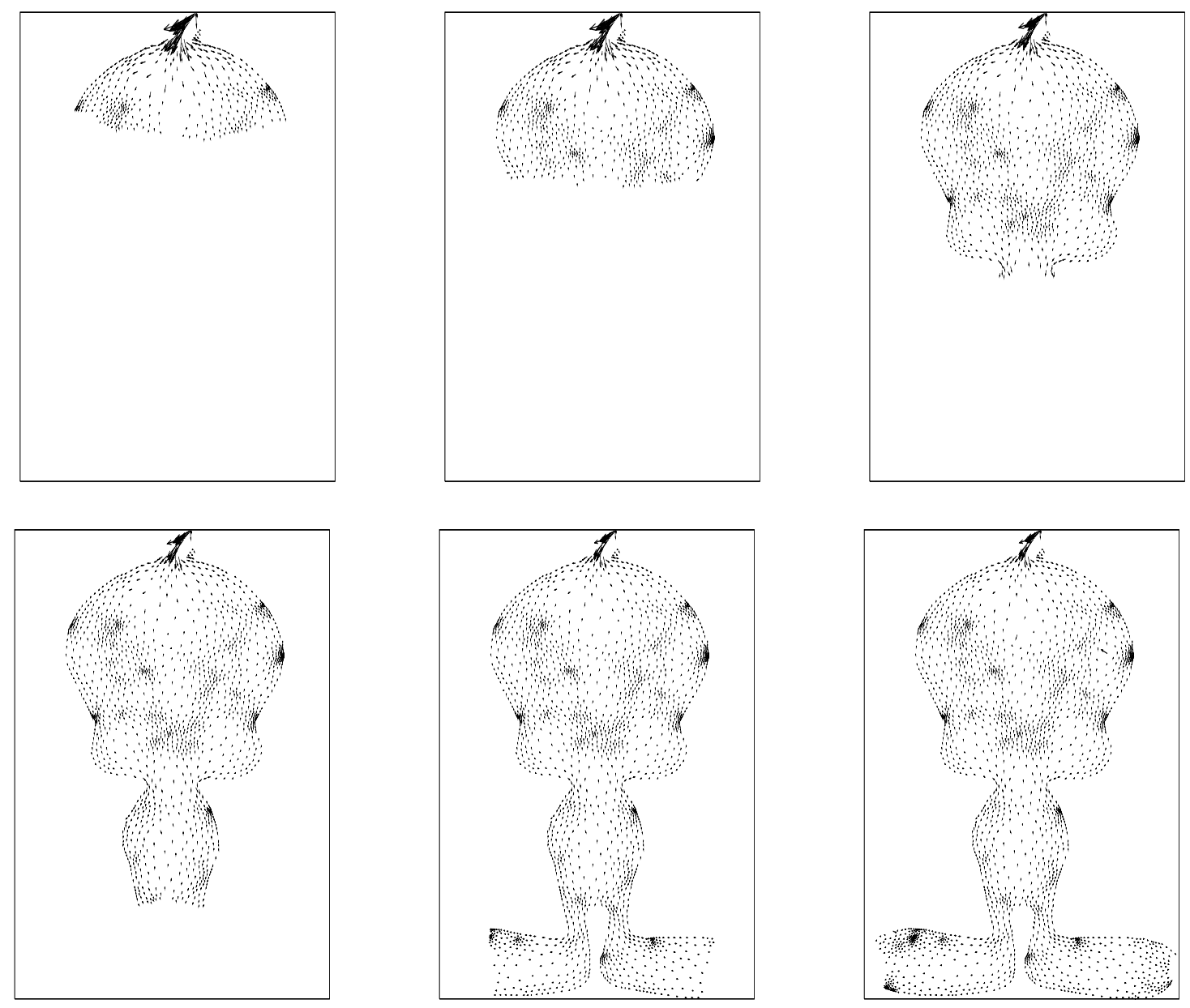

Figura 4.20: Seis estágios do campo de velocidade.

escoamento de fluidos durante a fase de preenchimento do processo de moldagem por injeção.

Alguns testes de verificação foram realizados de modo a ilustrar a confiabilidade do método quanto à discretização da equação de Hele-Shaw via adaptação euleriana do método SPH, e quanto à corretude dos campos de velocidade e pressão durante o escoamento de fluidos viscosos adentro da cavidade de moldes.

O método mostrou-se capaz de lidar com a divisão e coalescência de fluidos e de simular o preenchimento em moldes cuja espessura varia e em moldes de geometrias complexas não planares. A estratégia adotada para predizer a posição da superfície livre, que é baseada somente nas partículas, demonstrou-se ser consistente e precisa. Esta metodologia permite, portanto, simular o escoamento em diversas situações, sem o esforço computacional referente à construção e à manutenção de malhas.

Os estudos referentes a essa abordagem de solução das equações governantes da fase de preenchimento de um molde resultaram em dois artigos: um publicado em conferência internacional (Estacio et. al., 2006) e outro publicado em periódico nacional (Estacio et. al., 2007a). 


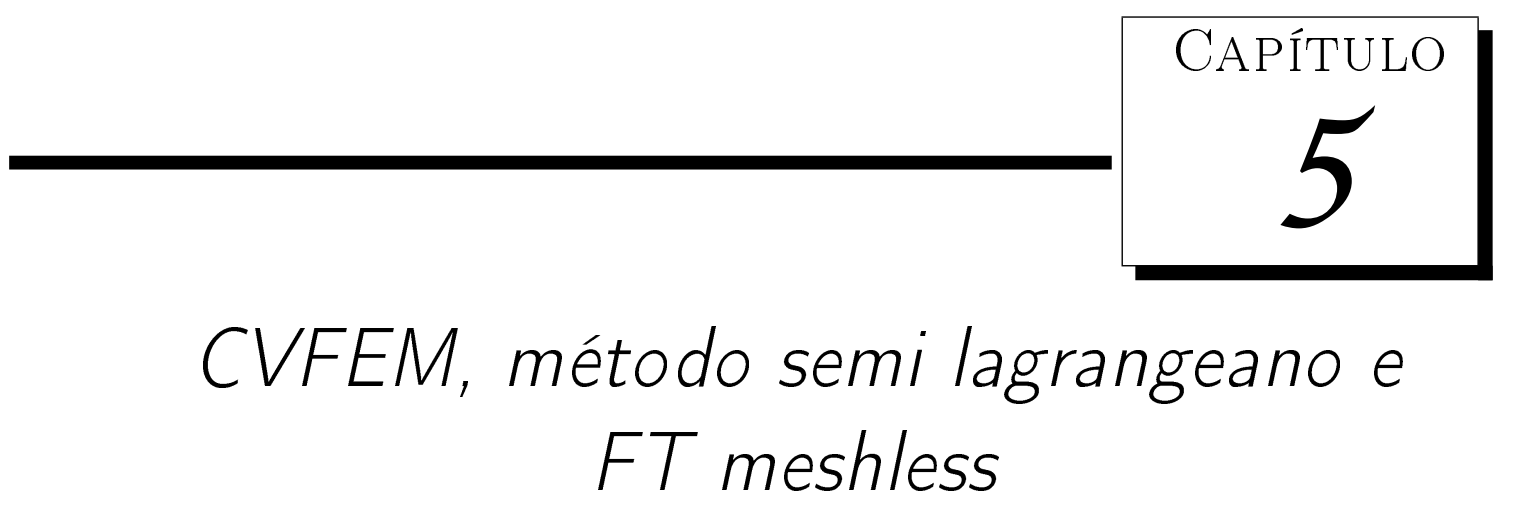

Este capítulo apresenta três técnicas aplicadas à solução das equações governantes do escoamento não isotérmico de fluidos durante o preenchimento de moldes. O método de volumes finitos conhecido como Control Volume Finite Element Method (CVFEM) é apresentado e aplicado à solução da equação de Hele-Shaw. Esse método é baseado em malhas, estruturadas ou não, e neste capítulo é considerado o seu uso em malhas não estruturadas triangulares. Em seguida, uma estratégia semi lagrangeana é utilizada para a solução da equação bidimensional da temperatura do fluido. Finalmente, uma breve descrição do método Front-Tracking (FT) será realizada e sua adaptação meshless será empregada na predição da posição da superfície livre do escoamento. Testes numéricos referentes à confiabilidade do método numérico proposto e resultados obtidos empregando-se esta abordagem também são apresentados.

\subsection{Considerações iniciais}

A técnica conhecida como CVFEM foi originalmente desenvolvida para a solução da equação de convecção-difusão em duas dimensões, por Baliga e Patankar (1980). Esta técnica combina as vantagens dos métodos de elementos finitos e volumes finitos, sendo baseada em uma interpretação física cuja solução satisfaz ambas conservação local e global (Abbassi et. al., 2003). Além disso, CVFEM utiliza volumes de controle não necessariamente regulares, que podem representar domínios complexos mais facilmente (Silva e Moura, 2001).

Esta técnica é aplicada à solução da equação de Hele-Shaw utilizando volumes de controle que são formados por polígonos resultantes da união dos pontos médios das arestas dos triângulos com o centróide dos triângulos. Um exemplo de malha não estruturada triangular e os volumes de controle associados é ilustrado na Figura 5.1. 

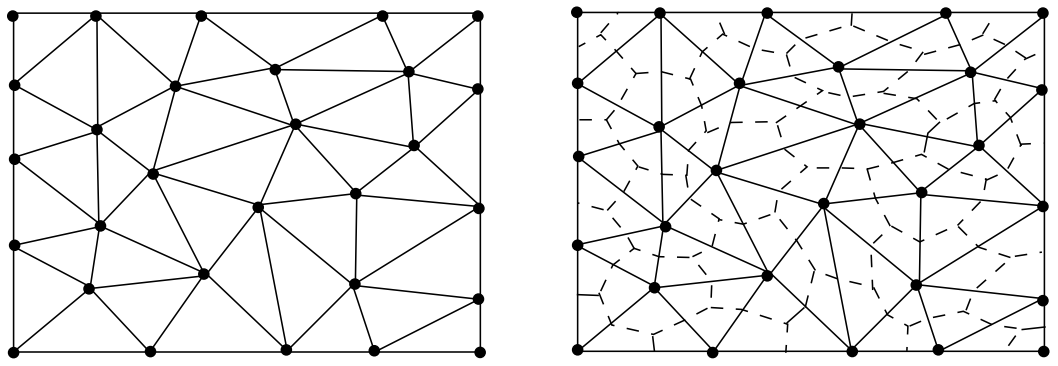

Figura 5.1: Malha não estruturada triangular e volumes de controle.

Uma vantagem de se utilizar esta abordagem para construir os volumes de controle é a garantia da não existência de volumes de controle exteriores à malha. E mais, a área de cada volume de controle interior a um determinado elemento triangular é exatamente igual à um terço da área do elemento, o que permite simplificações adicionais nos cálculos (Ammara e Masson, 2004, Estacio, 2004). Adicionalmente, o uso do referencial semi lagrangeano para a obtenção da solução do campo bidimensional de temperatura proporciona uma maneira de avaliar o termo convectivo presente na equação de modo a manter a estabilidade da solução numérica (Phillips e Williams, 2001a).

Neste capítulo, as equações governantes da fase de preenchimento de moldes por fluidos viscosos são resolvidas numericamente utilizando-se os passos seguidos por Estacio (2004) para a solução da equação da pressão e da temperatura bidimensional, juntamente com uma versão meshless do método FT utilizada para modelar o avanço da superfície livre do fluido durante o escoamento.

Na abordagem FT descrita por Esmaeeli e Tryggvason (1998) e Tryggvason et. al. (2001), para a representação e o rastreamento da superfície livre de fluidos, uma malha fixa é usada para a determinação das variáveis do escoamento, enquanto a interface (ou superfície livre) é rastreada por uma outra malha de dimensão inferior. Por exemplo, no caso bidimensional, a interface é considerada como sendo um conjunto de pontos conectados formando uma linha que se move com velocidade interpolada a partir das velocidades calculadas na malha fixa bidimensional. Devido à utilização de tais elementos computacionais explícitos para rastrear a posição da superfície livre, estratégias FT são mais complicadas de se implementar, uma vez que a presença de várias interfaces, a coalescência e a divisão das frentes devem ser explicitamente tratadas nesse método (Sousa et. al., 2004).

Neste trabalho, uma adaptação meshless do método tradicional FT é apresentada. A posição da superfície livre é predita usando um nova abordagem puramente baseada em pontos cuja principal vantagem é evitar o tratamento explícito das mudanças topológicas da superfície (coalescência e divisão da frente de fluido). Essa abordagem meshless, que se baseia principalmente em pesquisa espacial e marcação de células, proporciona uma implementação particularmente simples, enquanto continua apresentando bons resultados.

Ao contrário da técnica de Volume of Fluid descrita no trabalho de Estacio (2004) 
e Estacio e Mangiavacchi (2007), a estratégia FT meshless para representar a posição da superfície livre durante o preenchimento de moldes não apresenta difusão numérica e permite que mais do que um volume de controle seja preenchido a cada passo no tempo. Por este motivo, a simulação é finalizada com uma quantidade menor de iterações no avanço temporal.

\subsection{Solução da equação de Hele-Shaw por CVFEM}

Considere a equação de Hele-Shaw para a pressão (3.1) escrita na forma conservativa:

$$
\nabla \cdot \mathbf{J}=0
$$

onde o fluxo $\mathbf{J}$ é dado por $\mathbf{J}=-S_{2} \nabla p$. O procedimento do método de volumes finitos consiste na integração da equação diferencial na forma conservativa em um volume de controle arbitrário (Maliska, 1995). Do teorema de Gauss, tem-se:

$$
\int_{V} \nabla \cdot \mathbf{J} d V=\int_{S} \mathbf{J} \cdot \mathbf{n} d S=0
$$

onde $S$ é a fronteira fechada do volume de controle $V$ e $\mathbf{n}$ é um vetor unitário normal a $S$ que aponta para fora. No caso da aproximação discreta, essa relação válida em um volume de controle arbitrário é substituída pela aproximação dimensional finita obtida ao restringir $V$ ao conjunto finito de volumes de controle utilizados na discretização do domínio em questão.

Cada volume de controle é composto por contribuições de diversos triângulos da malha. Seja $V_{i}$ o volume finito associado ao ponto $i$, e $j$ os vértices dos $N$ triângulos do tipo $i$ - $j-j$ * que compõem o volume $V_{i}, \operatorname{com} j=1, \ldots, N+1$ e $j^{*}=(j+1) \bmod N$, onde o termo mod é usado para representar o resto da divisão inteira. Por exemplo, na Figura 5.2, $V_{i}$ é composto por contribuições dos triângulos $i-1-2, i-2-3, \ldots, i-9-1$. Os pontos $a$ e $c$ são os valores médios das distâncias $i j$ e $i j^{*}$, respectivamente, e o ponto 0 é o centróide do triângulo $i-j-j^{*}$.

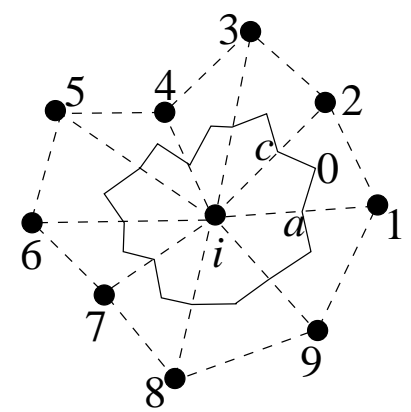

Figura 5.2: Volume de controle associado ao vértice $i$.

Desta forma, a contribuição do segmento $a 0 c$ para a integral de superfície ao redor do 
vértice $i$ e interior ao triângulo $i-j-j^{*}$ na Figura 5.2 tem a forma:

$$
\int_{a}^{0} \mathbf{J} \cdot \mathbf{n} d S+\int_{0}^{c} \mathbf{J} \cdot \mathbf{n} d S+[\text { contribuições de outros elementos associados a } i]=0
$$

A aproximação da equação de Hele-Shaw requer uma função de interpolação que descreva a variação da pressão no interior do elemento triangular, uma vez que o fluxo $\mathbf{J}$ depende das derivadas parciais de $p$ e a integração dada pela Equação (5.1) requer o valor dessas derivadas ao longo dos segmentos $a 0$ e $0 c$. Como os valores de $p$ são armazenados nos vértices dos triângulos, emprega-se uma função de interpolação para $p$, dentro do triângulo $i-j-j^{*}$, como ilustrado na Figura 5.3.

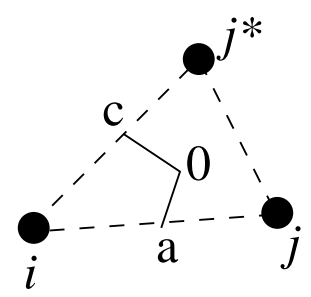

Figura 5.3: Elemento triangular.

Normalmente utiliza-se interpolação linear para a pressão (Abbassi et. al., 2003):

$$
p=A x+B y+C
$$

Sendo conhecidos os valores de $p$ e os valores das coordenadas $(x, y)$ nos vértices $i, j$ e $j^{*}$ é possível encontrar os valores das constantes $A, B$ e $C$ trivialmente, resolvendo-se o seguinte sistema linear:

$$
\begin{aligned}
p_{i} & =A x_{i}+B y_{i}+C, \\
p_{j} & =A x_{j}+B y_{j}+C, \\
p_{j^{*}} & =A x_{j^{*}}+B y_{j^{*}}+C,
\end{aligned}
$$

cuja solução resulta nos valores para as constantes $A, B$ e $C$, apresentados a seguir:

$$
\begin{gathered}
A=\frac{\left[\left(y_{j}-y_{j^{*}}\right) p_{i}+\left(y_{j^{*}}-y_{i}\right) p_{j}+\left(y_{i}-y_{j}\right) p_{j^{*}}\right]}{D}, \\
B=\frac{\left[\left(x_{j^{*}}-x_{j}\right) p_{i}+\left(x_{i}-x_{j^{*}}\right) p_{j}+\left(x_{j}-x_{i}\right) p_{j^{*}}\right]}{D}, \\
C=\frac{\left[\left(x_{j} y_{j^{*}}-x_{j^{*}} y_{j}\right) p_{i}+\left(x_{j^{*}} y_{i}-x_{i} y_{j^{*}}\right) p_{j}+\left(x_{i} y_{j}-x_{j} y_{i}\right) p_{j^{*}}\right]}{D},
\end{gathered}
$$

$\operatorname{com} D=\left(x_{i} y_{j}+x_{j} y_{j^{*}}+x_{j^{*}} y_{i}-y_{i} x_{j}-y_{j} x_{j^{*}}-y_{j^{*}} x_{i}\right)$.

Lembrando que o vetor fluxo é dado por $\mathbf{J}=\left(-S_{2} \frac{\partial p}{\partial x},-S_{2} \frac{\partial p}{\partial y}\right)$, é possível obter as derivadas de $p$ com relação a $x$ e a $y$ usando a função de interpolação (5.2). Assim, as componentes $J_{x}$ e $J_{y}$ resultam em: 


$$
J_{x}=-A S_{2} \quad \text { e } \quad J_{y}=-B S_{2}
$$

Os vetores $\mathbf{n}_{a 0}$ e $\mathbf{n}_{0 c}$ ortogonais aos segmento $a 0$ e $0 c$, respectivamente, são dados por

$$
\mathbf{n}_{a 0}=\left(\frac{y_{0}-y_{a}}{\Delta S_{a 0}},-\frac{x_{0}-x_{a}}{\Delta S_{a 0}}\right) \quad \text { e } \quad \mathbf{n}_{0 c}=\left(\frac{y_{c}-y_{0}}{\Delta S_{0 c}},-\frac{x_{c}-x_{0}}{\Delta S_{0 c}}\right),
$$

$\operatorname{com} \Delta S_{a 0}=\sqrt{\left(x_{0}-x_{a}\right)^{2}+\left(y_{0}-y_{a}\right)^{2}}$ e $\Delta S_{0 c}=\sqrt{\left(x_{c}-x_{0}\right)^{2}+\left(y_{c}-y_{0}\right)^{2}}$.

Substituindo as expressões da Equação (5.5) na Equação (5.1), é possível calcular as integrações ao longo de $a 0$ e $0 c$ :

$$
\begin{aligned}
\int_{a}^{0} \mathbf{J} \cdot \mathbf{n}_{a 0} d S & =\int_{a}^{0} J_{x} n_{x}+J_{y} n_{y} d S=\left(J_{x} \frac{y_{0}-y_{a}}{\Delta S_{a 0}}-J_{y} \frac{x_{0}-x_{a}}{\Delta S_{a 0}}\right) \Delta S_{a 0} \\
& =A S_{2}\left(y_{a}-y_{0}\right)+B S_{2}\left(x_{0}-x_{a}\right)
\end{aligned}
$$

e

$$
\begin{aligned}
\int_{0}^{c} \mathbf{J} \cdot \mathbf{n}_{0 c} d S & =\int_{0}^{c} J_{x} n_{x}+J_{y} n_{y} d S=\left(J_{x} \frac{y_{c}-y_{0}}{\Delta S_{0 c}}-J_{y} \frac{x_{c}-x_{0}}{\Delta S_{0 c}}\right) \Delta S_{0 c} \\
& =A S_{2}\left(y_{0}-y_{c}\right)+B S_{2}\left(x_{c}-x_{0}\right) .
\end{aligned}
$$

Além disso, como $\mathbf{J}$ é constante no interior do elemento $i-j-j^{*}$, tem-se:

$$
\int_{S} \mathbf{J} \cdot \mathbf{n} d S=A S_{2}\left(y_{a}-y_{c}\right)+B S_{2}\left(x_{c}-x_{a}\right) .
$$

Substituindo as expressões para as constantes $A$ e $B$ na Equação (5.6), tem-se que a integração ao longo da superfície $S$ pertencente ao elemento triangular $i-j-j^{*}$ relativa ao volume de controle associado ao vértice $i$ resulta, em:

$$
\int_{a}^{0} \mathbf{J} \cdot \mathbf{n} d S+\int_{0}^{c} \mathbf{J} \cdot \mathbf{n} d S=C_{i} p_{i}+C_{j} p_{j}+C_{j^{*}} p_{j^{*}},
$$

onde os coeficientes são dados por:

$$
\begin{aligned}
C_{i} & =\frac{S_{2}}{D}\left[\left(y_{a}-y_{c}\right)\left(y_{j}-y_{j^{*}}\right)+\left(x_{a}-x_{c}\right)\left(x_{j}-x_{j^{*}}\right)\right], \\
C_{j} & =\frac{S_{2}}{D}\left[\left(y_{a}-y_{c}\right)\left(y_{j^{*}}-y_{i}\right)+\left(x_{a}-x_{c}\right)\left(x_{j^{*}}-x_{i}\right)\right], \\
C_{j^{*}} & =\frac{S_{2}}{D}\left[\left(y_{a}-y_{c}\right)\left(y_{i}-y_{j}\right)+\left(x_{a}-x_{c}\right)\left(x_{i}-x_{j}\right)\right] .
\end{aligned}
$$

Esse cálculo é realizado para cada triângulo $i-j-j^{*}$ que compõe o volume de controle ao redor do vértice $i$, e para todos os $N_{V}$ vértices dos triângulos da malha usada na discretização do domínio. Desta forma, é necessário adicionar todas as contribuições devidas a todos os $N_{V}$ vértices dos triângulos da malha. Como tais triângulos e seus vértices são enumerados, um procedimento para somar estas contribuições consiste em calcular as contribuições $C$ de cada triângulo que compõe o volume de controle ao redor 
de cada vértice e montar (assemble) uma matriz esparsa $K$, de dimensão $N_{V} \times N_{V}$. As contribuições para o vetor independente resultam de valores prescritos para a pressão e são montados no vetor $F$, resultando no sistema:

$$
K p=F
$$

$\mathrm{Na}$ discretização usual por volumes finitos, esse sistema linear é simétrico e pode ser resolvido por um método iterativo eficiente, como por exemplo, pelo método dos Gradientes Conjugados (Shewchuk, 1994). Após obtida a solução, são encontrados os valores de $p$ determinados nos vértices dos triângulos, definindo a malha que representa o molde, ou seja, no centro dos volumes de controle nos quais foram realizados os balanços de conservação da pressão $p$.

\subsubsection{Aplicação das Condições de Contorno}

No método de discretização adotado, os volumes que se encontram na fronteira do domínio têm seus centros localizados sobre essa fronteira. Portanto, para valores de pressão prescrita, a equação do volume de fronteira passa assumir a forma $p=p_{\text {prescrito }}$. Em caso de fluxo ou velocidade prescritos, a equação associada a este volume de fronteira é empregada e o fluxo conhecido é utilizado.

Por exemplo, considerando que o segmento ij na Figura 5.3 seja um segmento da fronteira do domínio, a contribuição do segmento $i a$ para o volume de controle centrado em $i$ é dado por:

$$
\int_{i}^{a} \mathbf{J} \cdot \mathbf{n} d S
$$

Lembrando que $\mathbf{J}=-S_{2} \nabla p$ então:

$$
\mathbf{J} \cdot \mathbf{n}=-S_{2} \frac{\partial p}{\partial \mathbf{n}}
$$

Por outro lado, temos que a velocidade média (Equações (3.8) e (3.9)) na direção normal é dada por:

$$
\bar{v}_{n}=-\frac{S_{2}}{h} \frac{\partial p}{\partial \mathbf{n}} .
$$

Substituindo convenientemente a Equação (5.11) na Equação (5.10) obtém-se que $\mathbf{J} \cdot \mathbf{n}=\bar{v}_{n} h$, e a integração da Equação (5.9) pode ser avaliada como:

$$
\int_{i}^{a} \mathbf{J} \cdot \mathbf{n} d S=\bar{v}_{n} h \Delta S
$$

onde $\bar{v}_{n}$ é a velocidade prescrita na região de injeção e $\Delta S=\sqrt{\left(x_{i}-x_{a}\right)^{2}+\left(y_{i}-y_{a}\right)^{2}}$.

No caso de condições de fluxo nulo, a contribuição é nula e, portanto, esta condição é satisfeita automaticamente. Assim, a aplicação das condições de contorno consiste basicamente em fazer o balanço da propriedade considerada no volume de fronteira, obtendo-se 
a equação discretizada já contendo a informação da condição de contorno.

\subsubsection{Cálculo da fluidez}

De acordo com a Equação (3.4), a fluidez $S_{2}$ depende explicitamente da viscosidade do fluido e implicitamente da velocidade com a qual o fluido se move, por meio da taxa de cisalhamento, e varia ao longo da simulação. Desta forma, de modo a atualizar os valores da fluidez nos triângulos da malha que define o molde, é necessário o conhecimento dos valores da viscosidade e da velocidade nestes triângulos. A estratégia adotada para a aproximação da taxa de cisalhamento na abordagem proposta no presente capítulo é semelhante àquela apresentada no Capítulo 4 e será descrita a seguir.

\subsubsection{Cálculo da viscosidade e da taxa de cisalhamento}

Para o primeiro passo do avanço temporal da simulação, a fluidez $S_{2}$ é calculada a partir da viscosidade newtoniana para cada triângulo da malha. Neste caso, a viscosidade é independente da taxa de cisalhamento do escoamento e dada por $\eta=\eta_{0}$, constante. $\mathrm{Ou}$ seja,

$$
S_{2}=\int_{0}^{h} \frac{z^{\prime 2}}{\eta_{0}} d z^{\prime}=\frac{h^{3}}{3 \eta_{0}} .
$$

Nos passos subseqüentes da simulação, a viscosidade é calculada fazendo-se uso dos valores da taxa de cisalhamento de um passo anterior. Como a taxa de cisalhamento depende explicitamente da velocidade do fluido e implicitamente da pressão e da viscosidade, são necessárias aproximações para estes termos.

$\mathrm{Na}$ abordagem proposta, tem-se que a pressão é conhecida em cada um dos centros dos volumes de controle que discretizam o domínio computacional representado a geometria do molde, isto é, nos vértices dos triângulos da malha. Logo as velocidades $v_{x}$ e $v_{y}$ dadas pelas equações (3.5) e (3.6), dependentes do gradiente de pressão, são obtidas naturalmente para cada triângulo da malha. A pressão é, por sua vez, linearmente aproximada dentro de cada triângulo, segundo a expressão (5.2), fornecendo:

$$
\frac{\partial p}{\partial x}=A \quad \text { e } \quad \frac{\partial p}{\partial y}=B
$$

com constantes $A$ e $B$ dependentes das coordenadas do triângulo em questão e dadas pelas expressões (5.3) e (5.4).

Desta forma, a taxa de cisalhamento é também calculada para cada elemento triangular da malha empregada na discretização do domínio, por meio da derivação das expressões (3.5) e (3.6) para $v_{x}$ e $v_{y}$ resultando em:

$$
\dot{\gamma}=\frac{z}{\eta}\|\nabla p\|=\frac{z}{\eta} \sqrt{A^{2}+B^{2}}
$$

onde $\eta$ é descrita por um dos modelos de viscosidade newtoniana generalizada apresentados na Secção 2.9. Devido ao fato da viscosidade também depender da taxa de cisa- 
lhamento, esta expressão não linear é resolvida iterativamente aplicando-se o método de Newton (Isaacson e Keller, 1966). Para o caso de um fluido de Cross, a expressão (2.52) deve ser substituída na Equação (5.13) para definir a função $G$ :

$$
G(\dot{\gamma})=\dot{\gamma}-\frac{z}{\eta(\dot{\gamma})}\|\nabla p\|
$$

fornecendo:

$$
G(\dot{\gamma})=\dot{\gamma}-\frac{z}{\eta_{0}}\|\nabla p\|\left[1+\left(\frac{\eta_{0}}{\tau^{*}} \dot{\gamma}\right)^{1-n}\right]
$$

$\mathrm{e}$

$$
G^{\prime}(\dot{\gamma})=1+(n-1)\|\nabla p\| \frac{z}{\eta_{0}}\left(\frac{\eta_{0}}{\tau^{*}}\right)^{1-n} \dot{\gamma}^{-n}
$$

Note que a taxa de cisalhamento e, conseqüentemente, a função $G$ e sua derivada $G^{\prime}$ dependem de $z$ e, portanto, devem ser avaliadas em cada uma das camadas presentes na discretização da direção transversal do molde, isto é, ao longo da espessura. Obtidos os valores da taxa de cisalhamento e da viscosidade em cada uma das $N_{z}$ camadas, os valores da viscosidade a cada uma destas camadas pode então ser utilizado na integração numérica da expressão (3.4) para obter o valor da fluidez para cada um dos triângulos da malha.

\subsection{Solução da equação 2D da temperatura usando método semi lagrangeano}

O modelo completo para a simulação do escoamento de um fluido viscoso dentro da cavidade de um molde fino apresenta uma equação bidimensional para a pressão, uma equação tridimensional para a temperatura e uma estratégia para o avanço da superfície livre do fluido. No Capítulo 2 foram apresentadas as equações governantes para a fase de preenchimento de um molde em sua formulação original, enquanto a Seção 2.7 foi inteiramente dedicada à formulação de um modelo simplificado para a temperatura do fluido. Neste capítulo, a estratégia numérica escolhida para a solução deste modelo bidimensional da temperatura, baseada em um esquema semi lagrangeano, é apresentada.

\subsubsection{O método semi lagrangeano e a equação da temperatura}

A estratégia escolhida para calcular as contribuições do campo bidimensional de temperatura é um método semi lagrangeano (Phillips e Williams, 2001a,b, Xiu e Karniadakis, 2001). A idéia básica desse método é acompanhar uma partícula de fluido durante sua trajetória ao longo da malha definida sobre o escoamento. Para isso, escreve-se a equação tridimensional da temperatura (3.2) em termos da derivada material:

$$
\frac{D T}{D t}=f \quad \text { onde } \quad f=\frac{1}{\rho c_{p}}\left(\eta \dot{\gamma}^{2}+k \frac{\partial^{2} T}{\partial z^{2}}\right)
$$

Utilizando, então, o referencial lagrangeano, a derivada material $\frac{D T}{D t}$ pode ser apro- 
ximada por:

$$
\frac{T\left(p_{a}, t+\delta t\right)-T\left(p_{a}, t\right)}{\delta t}=f
$$

onde $p_{a}$ é uma partícula arbitrária de fluido.

Escolhendo a partícula que ocupa a posição $\mathbf{x}$ de um vértice de triângulo da malha no tempo $t+\delta t$ e escrevendo essa expressão em termos das coordenadas $\mathbf{x}=(x, y)$, tem-se:

$$
T(\mathbf{x}, t+\delta t)=T(\mathbf{x}-d \mathbf{x}, t)+\delta t f
$$

onde $d \mathbf{x}=\mathbf{v} \delta t$. Note que $\mathbf{x}$ é a posição ocupada no tempo $t+\delta t$ por uma partícula de fluido que ocupava a posição $\mathbf{x}-d \mathbf{x}$ no tempo $t$.

Considerando uma aproximação linear para $T$ no triângulo que contém $\mathbf{x}$, então $T(\mathbf{x}-d \mathbf{x}, t)$ pode ser aproximado usando uma expansão em série de Taylor truncada, como segue:

$$
T(\mathbf{x}-d \mathbf{x}, t) \approx T(\mathbf{x}, t)-d \mathbf{x} \cdot \nabla T(\mathbf{x}, t) .
$$

Substituindo a expressão para $d \mathbf{x}$ em na Equação (5.18) e depois esta em (5.17), obtém-se:

$$
T(\mathbf{x}, t+\delta t)=T(\mathbf{x}, t)-\delta t \mathbf{v} \cdot \nabla T(\mathbf{x}, t)+\delta t f,
$$

onde $\nabla T$ é calculado sobre o triângulo que contém a partícula $p_{a}$ no tempo $t$ e $\mathbf{v}$ é a velocidade no vértice. Por simplicidade de notação, considere $T=T(\mathbf{x}, t)$. Tem-se:

$$
T(t+\delta t)=T-\delta t \mathbf{v} \cdot \nabla T+\delta t f
$$

A Equação (5.20) é uma expressão para a temperatura tridimensional escrita segundo o referencial semi lagrangeano. Lembrando que a formulação bidimensional para a temperatura é obtida ao integrar a Equação (5.20) ao longo da espessura (veja a Seção 2.7), tem-se que a equação bidimensional da temperatura segundo o referencial semi lagrangeano é dada por:

$$
\begin{aligned}
\bar{T}(t+\delta t) & =\bar{T}-\delta t\left[\overline{\mathbf{v} \cdot \nabla T}+\frac{1}{\rho c_{p}}\left(\overline{\eta \dot{\gamma}^{2}}+\overline{k \frac{\partial^{2} T}{\partial z^{2}}}\right)\right] \\
& =\bar{T}+\delta t\left[-\frac{6}{5}(\overline{\mathbf{v}} \cdot \nabla \bar{T})+\frac{1}{\rho c_{p}}\left(\frac{3}{5 h^{2}}\|\overline{\mathbf{v}}\|^{2}\left(2 \eta_{c}+3 \eta_{w}\right)-\frac{3 k}{h^{2}}\left(\bar{T}-T_{w}\right)\right)\right],
\end{aligned}
$$

onde $\overline{\mathbf{v}}$ é o valor médio da velocidade, cujas componentes são dadas pelas Equações (3.4) e (3.5), $\eta_{c}$ e $\eta_{w}$ são os valores da viscosidade na linha central e na parede da cavidade do molde, respectivamente; e $T_{w}$ é a temperatura na parede do molde.

Para a solução numérica da Equação (5.21), os termos provenientes da dissipação viscosa e da condução são tratados como termos fonte, e a discretização do termo convectivo é apresentada a seguir.

Para o cálculo de $\nabla \bar{T}$, é necessário utilizar interpolação linear para $\bar{T}$ dentro dos 
triângulos da malha. Neste caso procede-se de maneira análoga aos passos seguidos na Seção 5.2 para a aproximação do gradiente de pressão.

Considerando o triângulo $i-j-j^{*}$ descrito na Figura 5.3 e sendo conhecidos os valores de $\bar{T}$ nos seus vértices, é possível escrever a temperatura dentro do triângulo por meio de interpolação linear:

$$
\bar{T}=A_{T} x+B_{T} y+C_{T}
$$

$\operatorname{com} A_{T}, B_{T}$ e $C_{T}$ dados por:

$$
\begin{gathered}
A_{T}=\frac{\left[\left(y_{j}-y_{j^{*}}\right) \bar{T}_{i}+\left(y_{j^{*}}-y_{i}\right) \bar{T}_{j}+\left(y_{i}-y_{j}\right) \bar{T}_{j^{*}}\right]}{D_{T}}, \\
B_{T}=\frac{\left[\left(x_{j^{*}}-x_{j}\right) \bar{T}_{i}+\left(x_{i}-x_{j^{*}}\right) \bar{T}_{j}+\left(x_{j}-x_{i}\right) \bar{T}_{j^{*}}\right]}{D_{T}}, \\
C_{T}=\frac{\left[\left(x_{j} y_{j^{*}}-x_{j^{*}} y_{j}\right) \bar{T}_{i}+\left(x_{j^{*}} y_{i}-x_{i} y_{j^{*}}\right) \bar{T}_{j}+\left(x_{i} y_{j}-x_{j} y_{i}\right) \bar{T}_{j^{*}}\right]}{D_{T}},
\end{gathered}
$$

$\operatorname{com} D_{T}=\left(x_{i} y_{j}+x_{j} y_{j^{*}}+x_{j^{*}} y_{i}-y_{i} x_{j}-y_{j} x_{j^{*}}-y_{j^{*}} x_{i}\right)$.

Desta forma, é possível obter as derivadas parciais de $\bar{T}$ com relação a $x$ e $y$ fazendo:

$$
\frac{\partial \bar{T}}{\partial x}=A_{T} \quad \text { e } \quad \frac{\partial \bar{T}}{\partial y}=B_{T}
$$

A escolha do valor da velocidade para efetuar o produto $\mathbf{v} \cdot \nabla \bar{T}$, para cada triângulo, é feita da seguinte maneira:

1. Para cada triângulo:

(a) Calcula-se $\frac{\partial \bar{T}}{\partial x}$ e $\frac{\partial \bar{T}}{\partial y}$ segundo a Equação (5.26);

2. Para cada vértice do triângulo verifica-se se alguma partícula $p_{a}$ se originou deste elemento no tempo $t$ realizando os seguintes passos:

(a) Calcula-se o produto vetorial e o produto interno entre o vetor velocidade no triângulo e os vetores que compõem as arestas incidentes àquele vértice;

(b) Se esses dois produtos vetoriais tiverem sinais trocados, e se os dois produtos internos são negativos, então a partícula $p_{a}$ pertence àquele triângulo e portanto, realiza-se o produto $\mathbf{v} \cdot \nabla \bar{T}$ com esse valor da velocidade e armazena-se o resultado no vértice relativo à coordenada $\mathbf{x}$.

Finalmente, a temperatura é avaliada no passo de tempo $n+1$ utilizando a seguinte estratégia: os termos referentes à convecção e à dissipação são avaliados no tempo $n$ e o termo referente à condução é avaliado no tempo $n+1$. A expressão resultante é dada por:

$$
\bar{T}^{n+1}=\bar{T}+\delta t\left[-\frac{6}{5}(\overline{\mathbf{v}} \cdot \nabla \bar{T})+\frac{1}{\rho c_{p}}\left(\frac{3}{5 h^{2}}\|\overline{\mathbf{v}}\|^{2}\left(2 \eta_{c}+3 \eta_{w}\right)-\frac{3 k}{h^{2}}\left(\bar{T}^{n+1}-T_{w}\right)\right)\right]
$$


ou seja:

$$
\bar{T}^{n+1}=\frac{1}{1+\frac{3 k \delta t}{h^{2} \rho c_{p}}}\left(\bar{T}+\delta t\left[-\frac{6}{5}(\overline{\mathbf{v}} \cdot \nabla \bar{T})+\frac{3}{\rho c_{p} h^{2}}\left(\frac{1}{5}\|\overline{\mathbf{v}}\|^{2}\left(2 \eta_{c}+3 \eta_{w}\right)+k T_{w}\right)\right]\right),
$$

onde os índices $n$ no lado direito da equação foram omitidos por simplicidade de notação.

\subsection{Avanço da superfície livre usando meshless FT}

O método Front-Tracking (FT) é uma técnica para identificação, representação e avanço da superfície livre de escoamentos de fluidos baseada na utilização de um conjunto de pontos conectados que se movem com a velocidade do fluido. Em geral, a velocidade do fluido, juntamente com outras variáveis do escoamento, é calculada em uma malha computacional fixa no espaço, fazendo-se necessário utilizar interpolações para a troca de informações entre a malha e a superfície livre. Por causa da conectividade dos pontos, mudanças topológicas na superfície livre, como coalescência e separação de fluxo, são fenômenos com difícil representação e implementação em métodos FT. Nesse sentido, a utilização da adaptação meshless do FT permite evitar essa significativa desvantagem.

$\mathrm{Na}$ abordagem descrita neste trabalho, uma estratégia FT é combinada com uma construção local meshless na região próxima à superfície livre na qual há fluido. Com a abordagem proposta, os pontos representando a superfície livre não são conectados e as mudanças topológicas são convenientemente acomodadas por uma estrutura de dados que identifica localmente agrupamentos (clusters) unidimensionais de pontos.

\subsubsection{Agrupamento de pontos da superfície livre}

Em métodos FT a superfície livre é modelada por um conjunto de pontos que se movem com velocidade local da frente da superfície. Por este motivo, a distribuição de pontos pode mudar rapidamente durante a simulação, e a estratégia adotada para rastrear a superfície livre deve ser capaz de lidar com ambas inserção e remoção de pontos, de forma a preservar a qualidade da frente.

Este aspecto do algoritmo envolve uma pesquisa espacial local adjacente ao movimento da frente de fluido. Os elementos triangulares da malha fixa que contém os pontos da frente devem ser marcados adequadamente. Em seguida, para cada ponto $P$ da frente de fluido é associado um raio que define uma vizinhança de $P$, sendo possível determinar também o vizinho mais próximo de $P$, denotado por $N_{P}$. Lembrando que o conjunto de pontos representando a superfície livre se move sobre uma malha fixa no espaço, tem-se que, num dado momento, $P$ é interior a um triângulo da malha. $\mathrm{O}$ raio do ponto $P$ é então calculado a partir da média dos comprimentos das arestas deste triângulo.

Tendo sido estabelecidos os raios e as vizinhanças para cada ponto $P$ representando a superfície livre, o segmento formado por $P$ e seu vizinho mais próximo $N_{P}$ é usado como referência para o cálculo dos ângulos entre $P$ e seus demais vizinhos. Os ângulos 
são usados para compor um ou dois agrupamentos (clusters) unidimensionais (Jain et. al., 1999), de acordo com a seguinte regra: ângulos menores do que um limiar, $\varepsilon$, indicam que os vizinhos de $P$ devem ser agrupados em um mesmo cluster; caso contrário, eles são agrupados em dois clusters.

A Figura 5.4 ilustra o agrupamento dos pontos em um único cluster: o ângulo $N_{P} P N_{1} \mathrm{e}$ o ângulo $N_{P} P N_{2}$ são pequenos, indicando que os pontos $N_{P}, N_{1}$ e $N_{2}$ devem ser agrupados no mesmo conjunto de pontos. Em contrapartida, na Figura 5.5 é ilustrado o agrupamento dos vizinhos do ponto $P$ em dois clusters: um, referente ao ângulo menor, contendo os pontos $N_{P}, N_{1}$ e $N_{2}$ e outro referente ao ângulo maior, contendo os pontos $N_{3}$ e $N_{4}$.

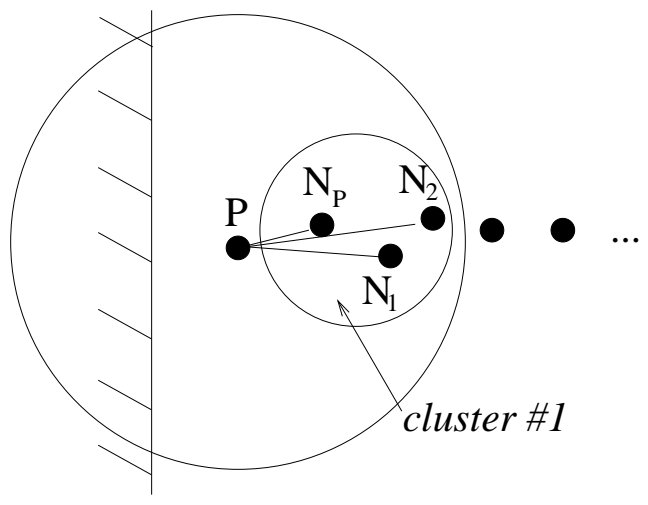

Figura 5.4: Os ângulos $N_{P} P N_{1}$ e $N_{P} P N_{1}$ são pequenos implicando na formação de um único cluster.

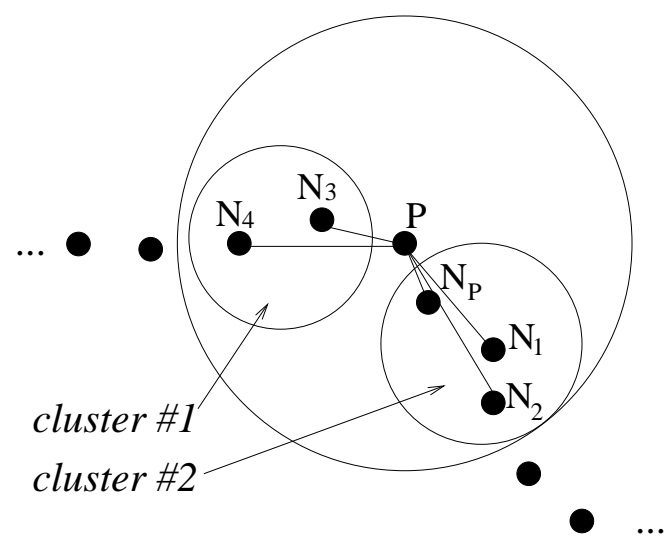

Figura 5.5: Os ângulos $N_{P} P N_{1}$ e $N_{P} P N_{2}$ são pequenos, mas os ângulos $N_{P} P N_{3}$ e $N_{P} P N_{4}$ não são, implicando na formação de dois clusters.

Se um ponto $P$ dá origem a apenas um cluster tem-se que $P$ é uma fronteira da superfície livre, enquanto a presença de dois clusters indica que $P$ está no interior da frente e essa informação define a estratégia de inserção.

\subsubsection{Inserção e remoção de pontos na superfície livre}

Existem basicamente duas estratégias de inserção de pontos na superfície livre: inserção no interior da superfície livre e inserção em uma de suas extremidades (fronteiras). 
No caso de inserção em uma das extremidades da superfície livre, o algoritmo tenta inserir um novo ponto $N_{O}$ na direção oposta ao vetor formado do ponto de fronteira $P$ até o seu vizinho mais próximo $N_{P}$. A distância entre $P$ e este novo ponto é determinada como sendo igual à metade da distância de $P$ a $N_{P}$.

Três possíveis situações podem ocorrer e são descritas a seguir. Se o ponto $N_{O}$ está fora do domínio, então por motivos triviais não é incluído na atualização da frente (Figura 5.6). Além disso, se a distância entre o novo ponto $N_{O}$ e $P$ é menor que um limiar pré-definido, $\varepsilon$, o novo ponto não é adicionado, conforme ilustrado na Figura 5.7.

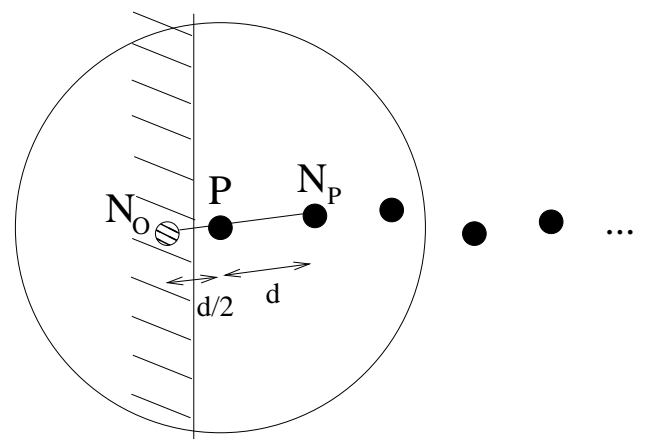

Figura 5.6: Procedimento de inserção para pontos de fronteira: o método tenta inserir um novo ponto $N_{O}$ na direção oposta à do vetor formado de $P$ a $N_{P}$. A inserção não é realizada porque o novo ponto está fora do domínio.

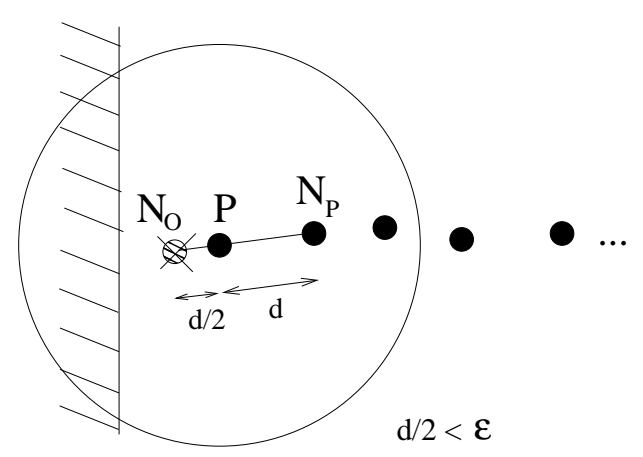

Figura 5.7: Procedimento de inserção para pontos de fronteira: o método tenta inserir um novo ponto $N_{O}$ na direção oposta à do vetor formado de $P$ a $N_{P}$. A inserção não é realizada porque a distância entre $P$ e $N_{O}$ é menor que uma tolerância $\varepsilon$ pré-definida.

Se $N_{O}$ não está fora do domínio, e nem muito perto de $P$, ele será acrescentado à frente e marcado como uma nova fronteira da superfície livre, conforme ilustrado na Figura 5.8.

Em caso de inserção de um novo ponto $N_{B}$ no interior da superfície livre, o algoritmo tenta inserir $N_{B}$ na metade da distância entre $P$ e seu vizinho mais próximo pertencente a cada um dos clusters da vizinhança de $P$.

Neste caso, duas situações podem ocorrer durante a tentativa de inserção em cada cluster: se a distância de $P$ ao seu vizinho mais próximo $N_{P}$, em cada cluster, é maior do que a metade do raio da circunferência que determina a vizinhança de $P$, e é maior que 


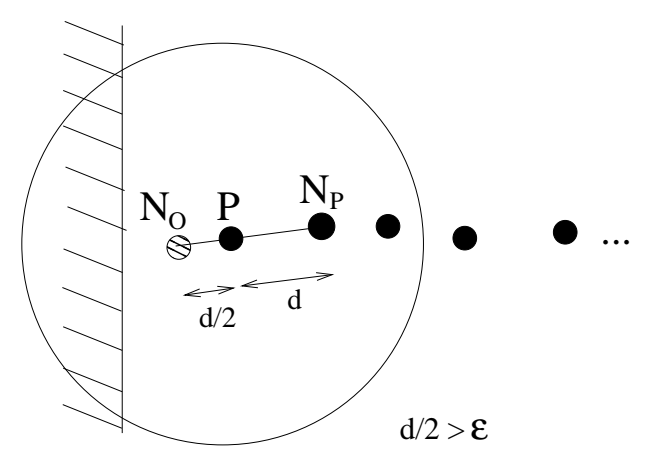

Figura 5.8: Procedimento de inserção para pontos de fronteira: o método tenta inserir um novo ponto $N_{O}$ na direção oposta à do vetor formado de $P$ a $N_{P}$. A inserção é realizada com sucesso.

o limiar pré-estabelecido $\varepsilon$, então o novo ponto $N_{B}$ é inserido entre $P$ e o seu vizinho. A Figura 5.9 ilustra a inserção realizada com sucesso em um dos clusters de $P$.

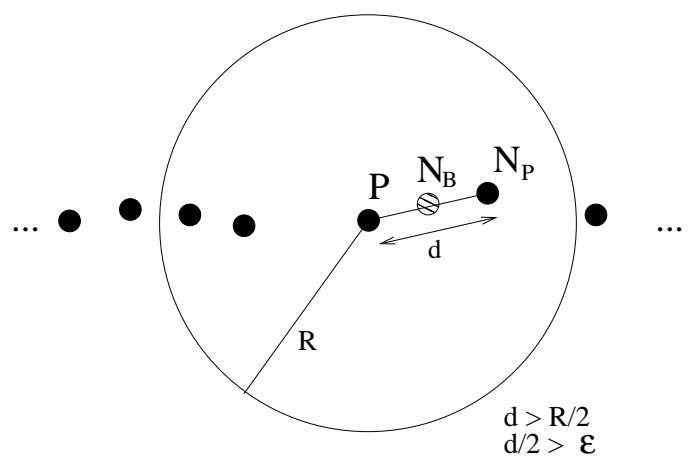

Figura 5.9: Procedimento de inserção de pontos no interior da superfície livre: se a distância entre $P$ e seu vizinho mais próximo $N_{P}$ é maior que metade do raio da circunferência centrada em $P$ e maior do que $\varepsilon$ então o método insere um novo ponto $N_{B}$ entre os pontos $P$ e $N_{P}$

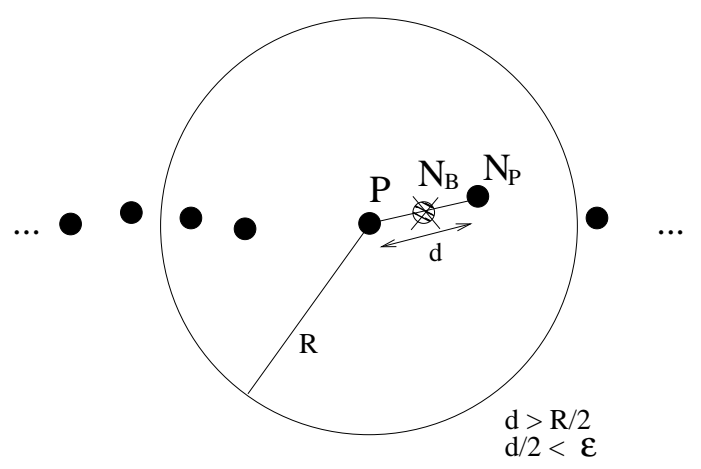

Figura 5.10: Procedimento de inserção de pontos no interior da superfície livre: se a distância entre $P$ e seu vizinho mais próximo $N_{P}$ é maior que metade do raio da circunferência centrada em $P$ e do que $\varepsilon$ então o método insere um novo ponto $N_{B}$ entre os pontos $P$ e $N_{P}$. Inserção não realizada porque o segundo critério não é satisfeito.

Em contrapartida, se a distância entre $P$ e $N_{P}$ é maior que a metade do raio, mas não é maior que o limiar pré-definido, o ponto $N_{B}$ não é inserido. Esta situação é exemplificada na Figura 5.10. 
O procedimento de remoção de pontos é realizado se a distância do ponto $P$ ao seu vizinho mais próximo $N_{P}$ é menor do que uma tolerância pré-definida, e de modo a não violar o procedimento de inserção de pontos interiores previamente descrito.

\subsubsection{Marcação dos triângulos da malha}

Conforme mencionado no início desta seção, o conjunto de pontos representando a superfície livre se move com a velocidade do fluido sobre uma malha que é utilizada para a discretização das variáveis do escoamento, como por exemplo a pressão e a própria velocidade do fluido. Desta forma, faz-se necessário o uso de interpolações entre a malha e o conjunto de pontos de modo a proporcionar troca de informações entre a malha e a lista de pontos representando a superfície livre.

Adicionalmente, a parte da malha representando a região do molde já invadida por fluido deve ser adequadamente marcada. Para este fim, uma variável escalar $\phi$ é associada a cada vértice dos triângulos da malha não estruturada representando um fator de preenchimento do volume de controle associado a este vértice. À variável $\phi$ podem estar associados três valores diferentes: 0 , se o volume de controle encontra-se vazio de fluido; 1 se o volume de controle está cheio de fluido e 0,5 se o volume de controle está parcialmente cheio de fluido. Este último caso ocorre em volumes de controle que compartilham triângulos que apresentam vértices com valores para $\phi$ iguais a 1 e 0 . A Figura 5.11 ilustra a marcação da variável $\phi$ durante o avanço da superfície livre.

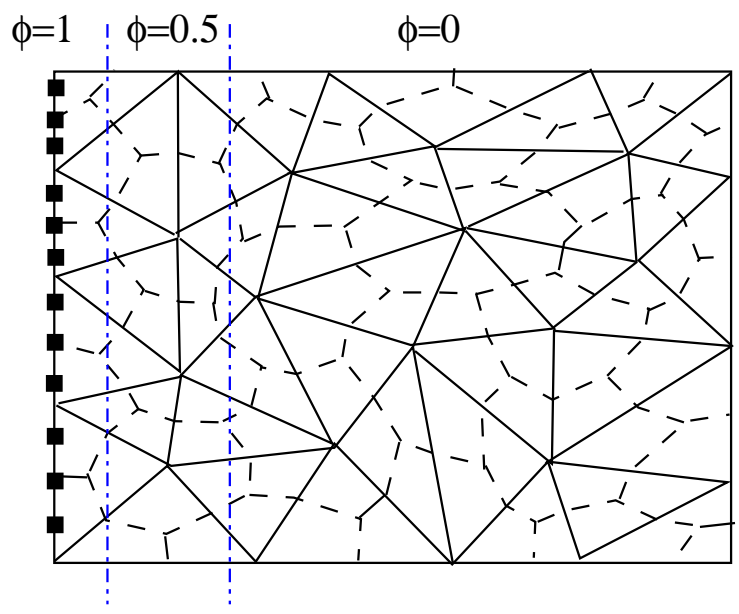

(a) Início do preenchimento

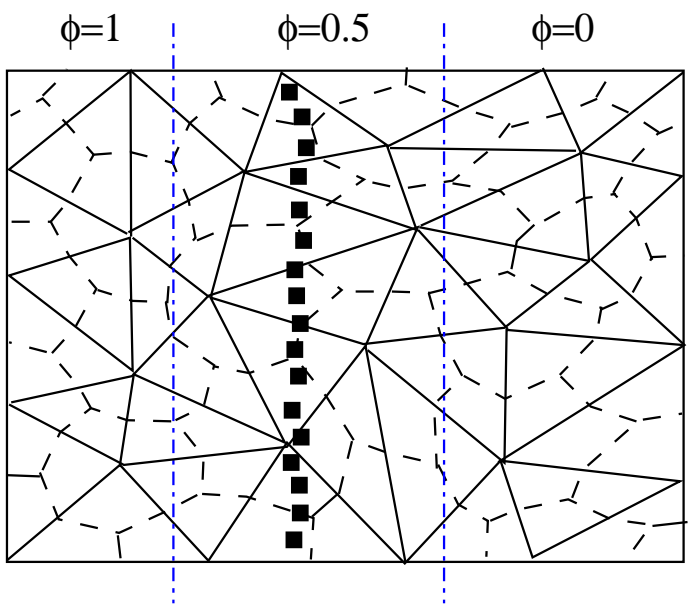

(b) Durante o preenchimento

Figura 5.11: Marcação dos vértices/volumes de controle durante o preenchimento de um molde. Vértices centros de volumes de controle cuja estrela (demais triângulos que compõem tal volume) apresentam vértices com $\phi=0$ e $\phi=1$ são marcados com $\phi=0,5$.

\subsubsection{Restrição no avanço temporal}

A estratégia VOF adotada para o avanço da superfície livre descrita na Seção 4.3 apresenta uma restrição no avanço temporal: o passo no tempo é determinado de tal 
maneira que apenas um volume de controle seja preenchido por iteração. Esta restrição é imposta de modo a evitar difusão numérica. Em contrapartida, na estratégia FT utilizada neste capítulo, tal restrição não se aplica.

Neste trabalho, uma estratégia semelhante à condição CFL (Courant et. al., 1967) é adotada de modo a simplificar o procedimento de marcação de células, descrito na seção anterior, e a controlar o avanço da superfície livre. Durante o preenchimento do molde, espera-se que antes de um vértice da malha ser marcado como cheio, ele tenha sido marcado como parcialmente cheio. Em outras palavras, o status de um vértice da malha deve mudar obedecendo sempre a ordem: vazio $(\phi=0)$, parcialmente cheio $(\phi=0.5)$, indicando a presença da superfície livre, e finalmente, cheio $(\phi=1)$. Esta propriedade deve ser verdadeira para todos os vértices da malha, com exceção daqueles pertencentes à região de injeção de fluido.

De modo a garantir tal comportamento, impõe-se que a superfície livre não avance mais do que uma camada de triângulos da malha, em cada passo temporal, fazendo:

$$
\left.\delta t\right|_{P} \leq \frac{R_{P}}{\left\|\mathbf{v}_{P}\right\|}
$$

onde $R_{P}$ é o raio associado ao ponto $P$ da superfície livre, sendo determinado como a média aritmética das arestas do triângulo da malha que contém $P$. A velocidade $\mathbf{v}_{P}$ é calculada por meio de duas médias: a primeira delas armazena nos vértices do triângulo $\triangle_{P}$ que contém $P$ a média aritmética da velocidade do fluido nos triângulos na estrela de $\triangle_{P}$ ponderada pela área de cada triângulo; a segunda delas atribui ao ponto $P$ da superfície livre a média das três velocidades nos vértices de $\triangle_{P}$ ponderadas pelas coordenadas baricêntricas de $P$ no triângulo $\triangle_{P}$. Finalmente, o passo no tempo $\delta t$ é calculado para todos os pontos $P$ da superfície livre e o menor deles é escolhido para o avanço temporal.

\subsection{Algoritmo}

O Algoritmo 2 calcula a solução do modelo matemático para a fase de preenchimento do processo de moldagem por injeção, fornecendo uma aproximação para o campo de pressão, o campo de velocidades, o campo bidimensional de temperatura e o avanço da superfície livre do fluido conforme o preenchimento é realizado. O campo de pressão é obtido por meio do uso do método CVFEM, o campo de temperatura é obtido por meio de um método semi lagrangeano e a superfície livre é avançada segundo a adaptação meshless do método FT.

O algoritmo utiliza a estratégia de desacoplamento descrita no Capítulo 3, tendo seus principais passos do algoritmo identificados linha a linha e sua ação descrita em seguida.

Na linha 3, a estratégia de injeção de fluido é escolhida: pressão ou velocidade prescrita. Na linha 4, a superfície livre do fluido é iniciada como sendo o conjunto de pontos sobre as arestas dos triângulos da malha marcadas como região de injeção de fluido: insere-se 


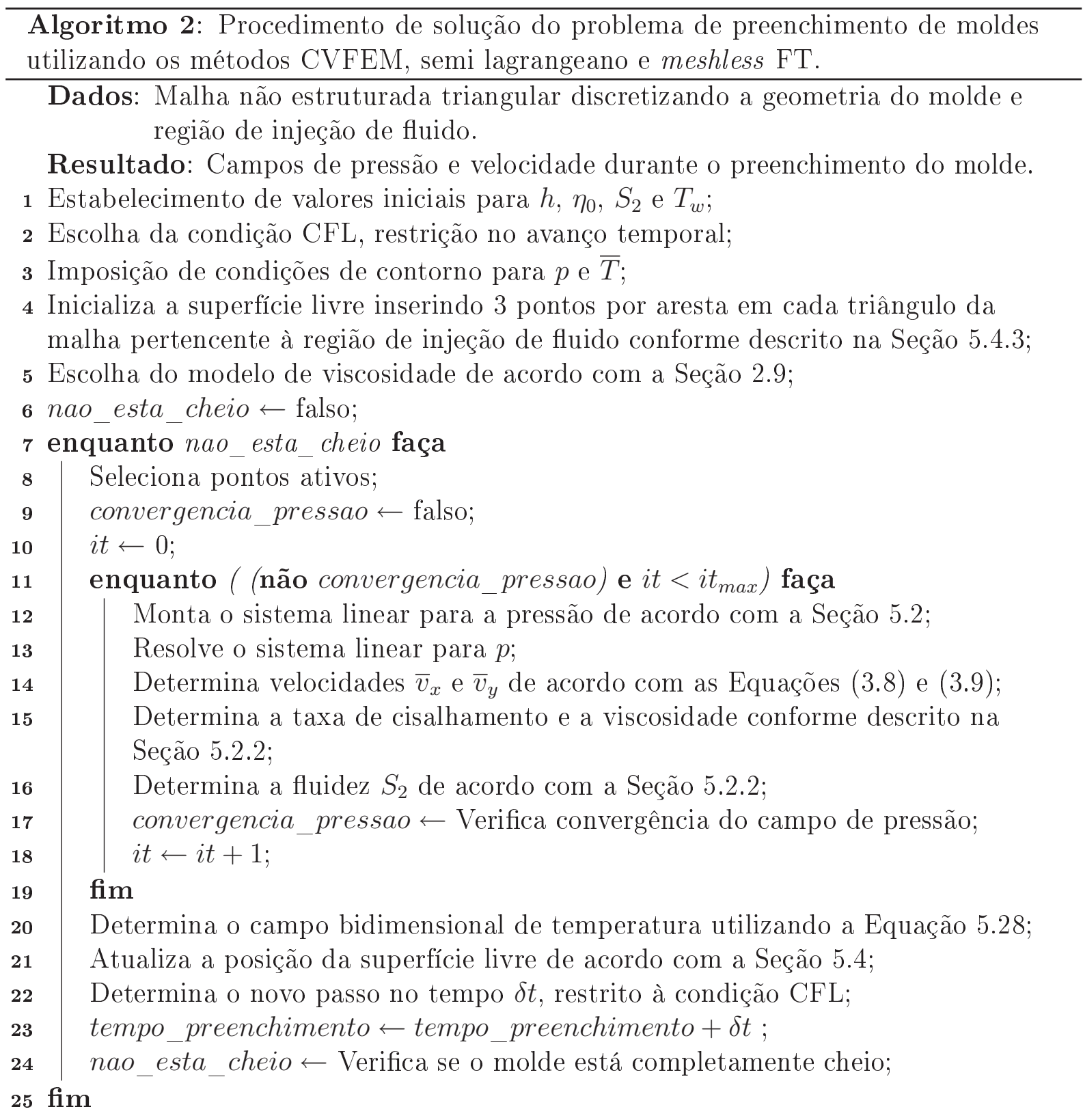

três pontos por aresta no conjunto de pontos que representará a posição da superfície livre durante o escoamento. A linha 7 define o bloco de repetição responsável pelo avanço temporal da simulação: o bloco de repetição é realizado enquanto houver pelo menos um ponto $j$ tendo $\phi_{j}<1$. A linha 8 atualiza o subconjunto de pontos ativos conforme a superfície livre do escoamento se move: pontos inativos são ou vazios de fluido ou pontos da região de injeção no caso do preenchimento utilizando pressão prescrita, e não participam dos cálculos. A linha 11 ilustra o bloco de repetição para a convergência da pressão utilizando o método das aproximações sucessivas. A linha 12 realiza a montagem do sistema linear para a equação de Hele-Shaw utilizando as Equações (5.7) e (5.8) conforme descrito na Seção 5.2. Na linha 20 o algoritmo realiza o cálculo do campo bidimensional de temperatura de acordo com a Seção 5.3. A linha 21 é responsável pela utilização do 
método FT para o avanço da superfície livre e seu procedimento é apresentado em maiores detalhes no Algoritmo 3.

O Algoritmo 3 é responsável pelo avanço da superfície livre propriamente dito. Este procedimento é iniciado considerando como dados de entrada as velocidades médias $\bar{v}_{x} \mathrm{e}$ $\bar{v}_{y}$ de cada triângulo da malha, dadas pelas Equações (3.8) e (3.9) e calculadas na linha 14 do Algoritmo 2.

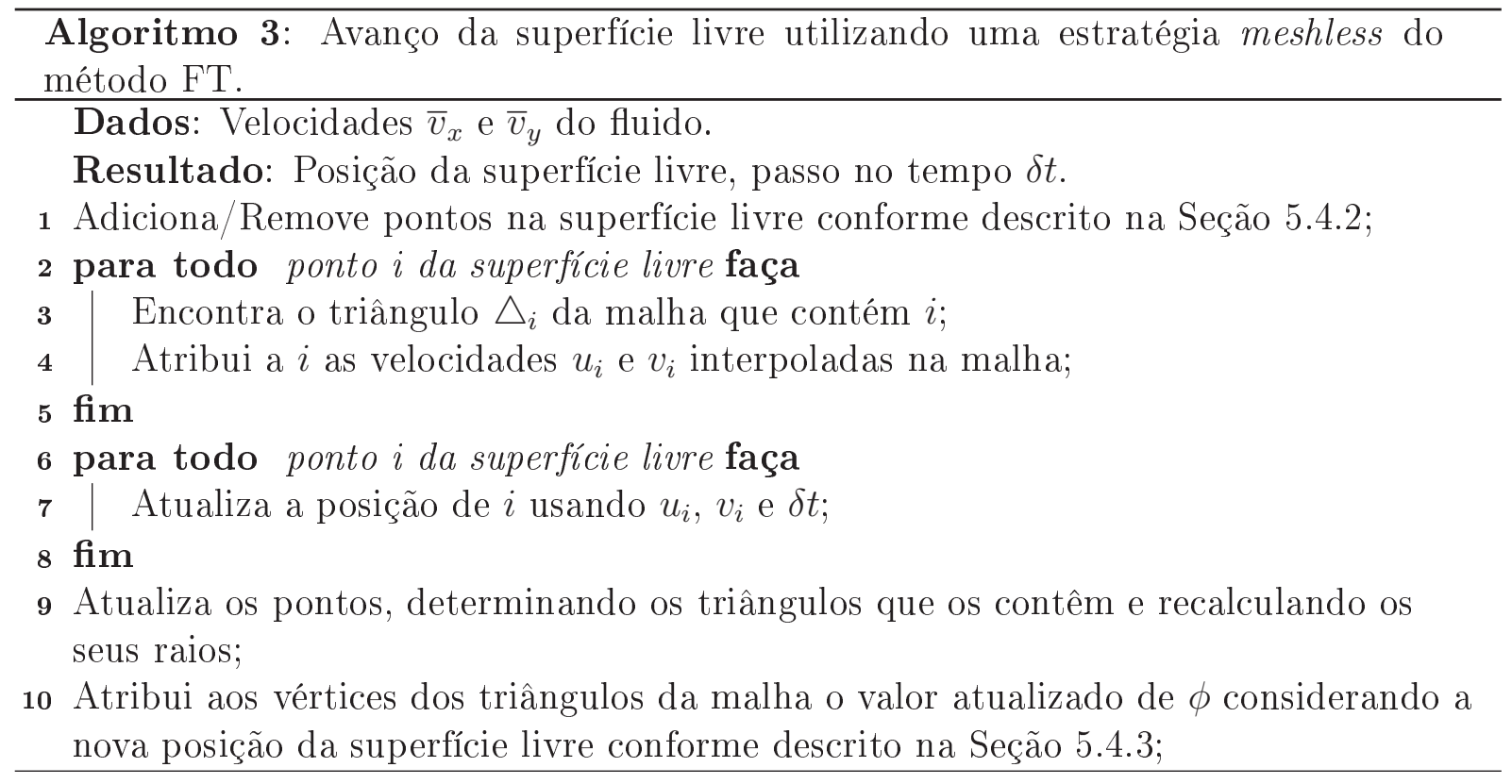

Na linha 1 é chamado o procedimento que executa a inserção e a remoção de pontos utilizando os critérios descritos na Seção 5.4.3. Em seguida, para cada ponto $i$ da superfície livre é calculada a velocidade com a qual $i$ será movido adentro do molde. Para tanto, na linha 3 é encontrado o triângulo $\triangle_{i}$ que contém $i$. Na linha 4 , as velocidades $\overline{\mathbf{v}}_{j}$ dos triângulos na estrela de $\triangle_{i}$ são interpoladas e armazenadas nos vértices de $\triangle_{i}$, e, finalmente a velocidade com a qual o ponto $i$ é movido é dada pelas velocidades nos vértices de $\triangle_{i}$ ponderadas pelas coordenadas baricêntricas de $\triangle_{i}$. Na linha 6 é definido o bloco de repetição responsável pela atualização da posição dos pontos representando a superfície livre. A linha 9 é responsável pela atualização dos pontos representando a superfície livre: são encontrados os triângulos que contém cada um dos pontos, os raios de cada ponto são determinados e os clusters são recalculados. Finalmente, na linha 10, o valor de $\phi$ é atualizado: triângulos que contêm pelo menos um vértice com $\phi=1$ passa a ter demais vértices com $\phi=0.5$.

\subsection{Verificações do método proposto}

Os resultados das simulações para vários problemas testes são apresentados considerando escoamento isotérmico e não isotérmico de fluidos newtonianos e não newtonianos em distintas condições de escoamento e geometrias de molde. Na próxima seção, a equação de Hele-Shaw é discretizada utilizando a estratégia CVFEM descrita na Seção 5.2, e 
a ordem de convergência do método é analisada comparando uma solução analítica com a solução fornecida pelo método utilizando malhas sucessivamente mais refinadas.

Nas seções subseqüentes são realizados diversos testes de modo a verificar a capacidade do método em fornecer simulações numéricas corretas. No primeiro deles, a pressão na região de injeção resultante pelo preenchimento do molde utilizando velocidade de injeção prescrita é comparada no caso de um fluido newtoniano e de um fluido de Cross com os resultados fornecidos por um outro método.

Em seguida, o uso de malhas sucessivamente mais refinadas é aplicado de modo a investigar a convergência do método no que diz respeito ao tempo correto de preenchimento do molde, usando velocidade de injeção prescrita. A qualidade do campo bidimensional de temperatura fornecido pelo método também é investigada.

Finalmente, os resultados fornecidos pelo presente método são comparados com resultados encontrados na literatura, em caso do preenchimento isotérmico de um molde retangular com um canal de entrada utilizando um fluido newtoniano e considerando-se velocidade de injeção prescrita.

\subsubsection{Solução da equação da pressão por CVFEM}

Este caso teste tem por objetivo estimar a qualidade dos resultados obtidos utilizando-se o método CVFEM para a solução da equação de Hele-Shaw. Para tanto, uma solução numérica obtida pelo método proposto é comparada com uma solução analítica em diferentes malhas, com o intuito de estimar com que taxa o erro cometido pela aproximação numérica decai com o refinamento da malha.

Desta forma, considere a equação de Laplace:

$$
\nabla^{2} p=0
$$

Este seria o caso, por exemplo, do escoamento de um fluido newtoniano, onde tem-se que a fluidez $S_{2}$ é constante. A Equação (5.30) definida num retângulo $\Omega=(0, \pi) \times(0, \pi)$ e sujeita às seguintes condições de contorno:

$$
\begin{array}{ll}
p(0, y)=p(\pi, y)=\operatorname{sen}(y), & 0 \leq y \leq \pi, \\
p(x, 0)=p(x, \pi)=\operatorname{sen}(x), & 0 \leq x \leq \pi,
\end{array}
$$

apresenta solução analítica $u$ conhecida em $\Omega$ dada por (Iório, 1991):

$$
u(x, y)=\frac{\operatorname{senh}(\pi-x) \operatorname{sen}(y)+\operatorname{senh}(x) \operatorname{sen}(y)+\operatorname{sen}(x) \operatorname{senh}(\pi-y)+\operatorname{sen}(x) \operatorname{senh}(y)}{\operatorname{senh}(\pi)} .
$$

Sabe-se que a diferença entre a solução analítica e as soluções calculadas pelo método implementado para um dado conjunto de pontos é o erro cometido pela aproximação. Além disso, o decaimento do erro cometido com o refinamento das malhas utilizadas na aproximação numérica ilustra a ordem de convergência do método. 
Com a solução analítica e a solução numérica conhecidas, é possível calcular a ordem de convergência $q$ do método numérico apresentado fazendo:

$$
q=\frac{\log \left(\frac{L_{k+1}}{L_{k}}\right)}{\log \left(\frac{h_{k+1}}{h_{k}}\right)},
$$

onde $L_{k}$ refere-se ao erro cometido na malha refinada e $L_{k+1}$ na malha grossa. Similarmente, $h_{k}$ e $h_{k+1}$ são medidas locais da malha, como por exemplo uma média dos comprimentos das arestas dos triângulos das malhas, ou a maior aresta. As malhas são construídas utilizando um gerador de malhas Delaunay denominado Easymesh (Niceno, 2001) e apresentam 250, 500, 1000 e 2000 vértices/volumes de controle.

Para este caso teste, a medida de erro utilizada é a norma $L_{2}$ e $h$ é tomado como uma média das arestas em cada malha. Os erros cometidos considerando-se tais malhas são listados na Tabela 5.1.

Tabela 5.1: Erro cometido na solução da Equação (5.30) segundo a norma $L_{2}$, considerando-se diversas malhas triangulares não estruturadas.

\begin{tabular}{ccc}
\hline \hline Vértices da malha & $h(m)$ & $L_{2}$ \\
\hline 100 & $3,5736 \times 10^{-1}$ & $3,0686 \times 10^{-3}$ \\
200 & $2,5056 \times 10^{-1}$ & $8,1128 \times 10^{-4}$ \\
400 & $1,7454 \times 10^{-1}$ & $4,6289 \times 10^{-4}$ \\
800 & $1,2278 \times 10^{-1}$ & $1,6828 \times 10^{-4}$ \\
1600 & $8,5751 \times 10^{-2}$ & $6,5030 \times 10^{-5}$ \\
3200 & $6,0436 \times 10^{-2}$ & $3,4106 \times 10^{-5}$ \\
\hline
\end{tabular}

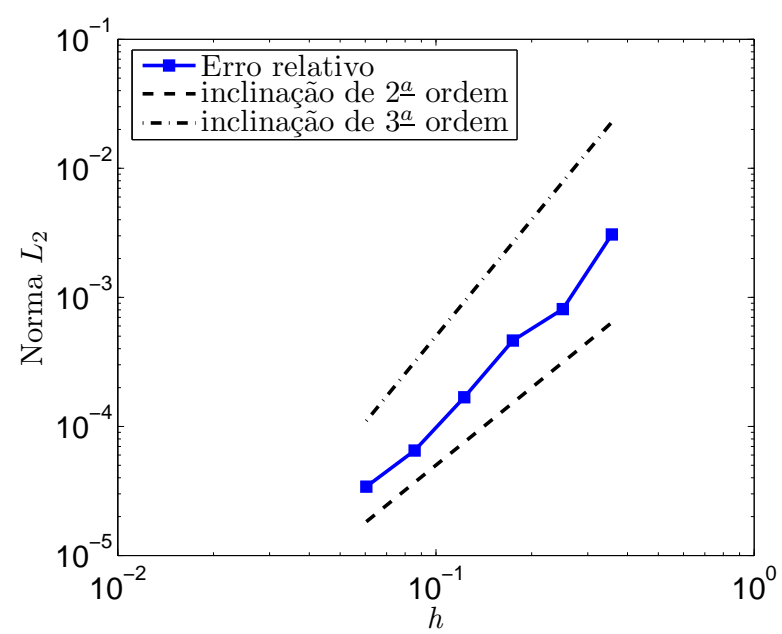

Figura 5.12: Norma $L_{2}$ do erro cometido na aproximação da equação de Laplace.

A Figura 5.12 ilustra que a ordem de convergência do método é aproximadamente quadrática já que em escala logarítmica um esquema de primeira ordem apresenta inclinação um, um esquema de segunda ordem apresenta inclinação dois, e assim por diante. 


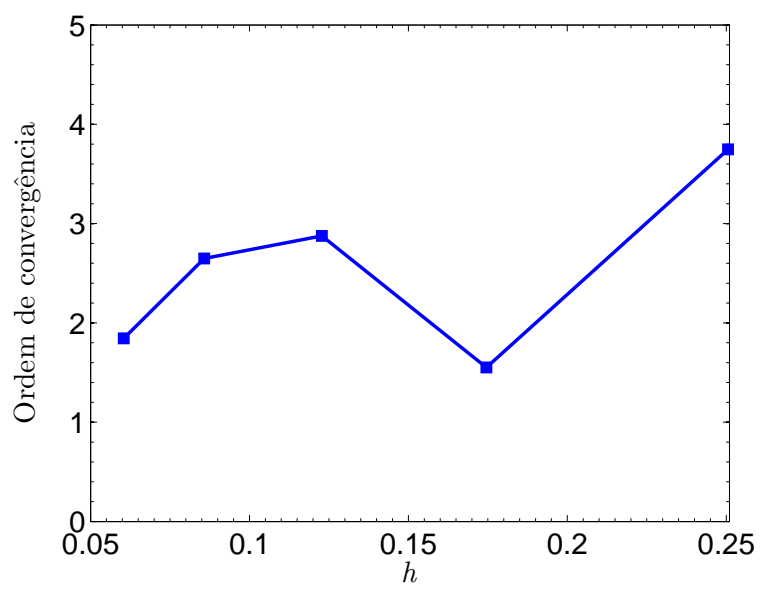

Figura 5.13: Ordem de convergência $q$ do método proposto.

A variação da ordem de convergência, obtida utilizando a Equação (5.33) e os valores de $h$ e $L_{2}$ para cada uma das malhas apresentadas na Tabela 5.1, é ilustrada na Figura 5.13.

\subsubsection{Escoamento em um canal retangular}

Nesta seção, três testes são realizados de modo a investigar a confiabilidade dos resultados fornecidos pelo presente método durante o preenchimento de um molde retangular simples ilustrado na Figura 5.14.

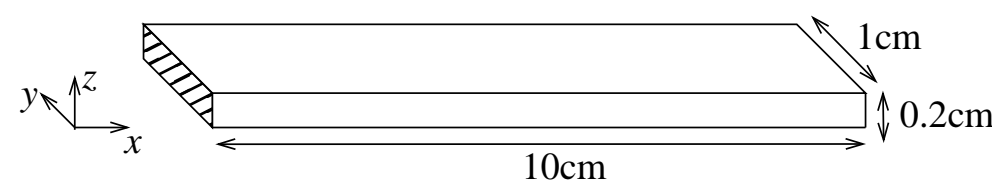

Figura 5.14: Dimensões do canal e região de injeção (área hachurada).

No primeiro teste, a pressão na região de injeção é comparada com a solução obtida pelo método de Estacio e Mangiavacchi (2007) considerando dois modelos de viscosidade. No segundo, a malha não estruturada triangular utilizada para a discretização é refinada sucessivamente de modo que o erro cometido na predição do tempo de preenchimento do molde, como um indicativo de conservação de massa pelo método proposto, seja investigado. No último teste, a qualidade do campo bidimensional de temperatura fornecido pelo método é investigada quando comparada com uma solução analítica.

\subsubsection{Pressão de injeção na entrada de fluido}

Neste caso, a simulação numérica do preenchimento do molde descrito na Figura 5.14 é conduzida considerando-se o método proposto e o método completamente baseado em malhas de Estacio e Mangiavacchi (2007) considerando o fluido ora como sendo newtoniano $\left(\eta_{0}=4 \times 10^{6} \mathrm{Pas}\right.$ ), ora como sendo de Cross (veja Seção 2.9). A estratégia de injeção de fluido é tomada como sendo velocidade horizontal prescrita $v_{\text {inj }}=2,5 \times 10^{-2} \mathrm{~m} / \mathrm{s}$, 
A malha não estruturada triangular utilizada para discretizar o molde apresenta 862 triângulos e 498 volumes de controle, tendo sido gerada pelo Easymesh (Niceno, 2001). A direção transversal do molde é dividida em $N_{z}=5$ camadas.

A pressão na região de injeção obtida por ambos os métodos é ilustrada na Figura 5.15 considerando um fluido newtoniano e na Figura 5.16 considerando um fluido de Cross.

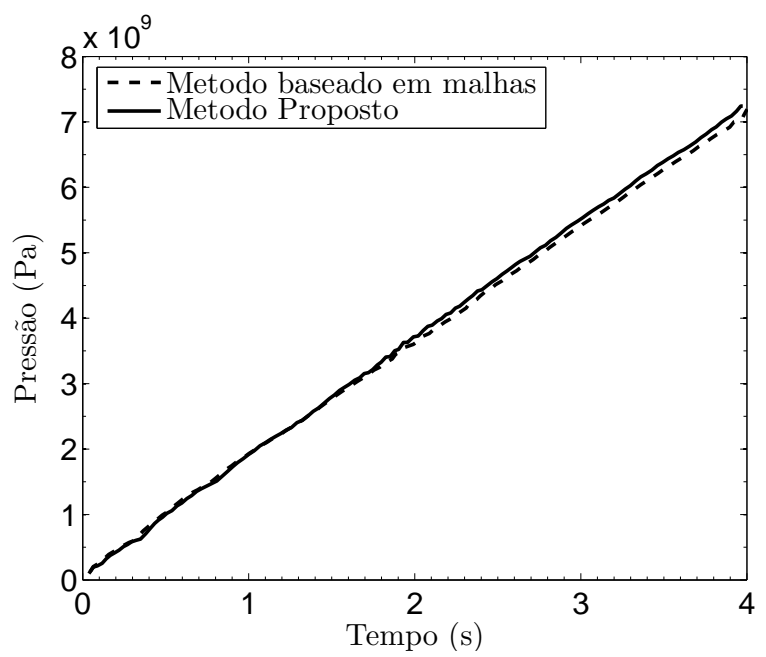

Figura 5.15: Comparação dos perfis da pressão na região de injeção durante o preenchimento do molde. Valores obtidos pelo método proposto e pelo método baseado em malhas de Estacio e Mangiavacchi (2007) considerando um fluido newtoniano com $\eta_{0}=4 \times 10^{6} \mathrm{Pas}$.

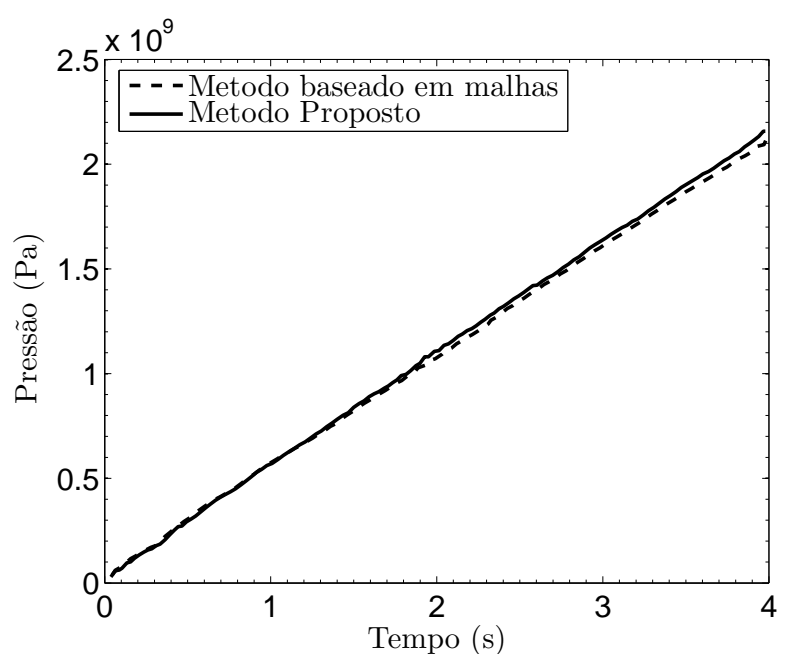

Figura 5.16: Comparação dos perfis da pressão na região de injeção durante o preenchimento do molde. Valores obtidos pelo método proposto e pelo método baseado em malhas de Estacio e Mangiavacchi (2007) considerando um fluido de Cross com parâmetros descritos na Tabela 2.1 da Seção 2.9.

Os resultados apresentados nas Figuras 5.15 e 5.16 ilustram a capacidade do método em prever corretamente a pressão na região de injeção durante o preenchimento do molde utilizando velocidade de injeção prescrita, quando compara-se os resultados com aqueles 
obtidos pelo método baseado em malhas. Além disso, considerando a velocidade de injeção escolhida, tem-se que um valor médio da taxa de cisalhamento deste escoamento, é dado por $\dot{\gamma}_{\text {med }}=\frac{v_{\text {inj }}}{h}=1,25 \times 10^{1} \mathrm{~s}^{-1}$. A esta taxa de cisalhamento, o fluido de Cross apresenta menor viscosidade que o fluido newtoniano, conforme ilustrado na Figura 2.3, e portanto a pressão resultante na região de injeção para um fluido de Cross é menor que a pressão para um fluido newtoniano. Este comportamento é corretamente predito pelo método proposto, e também pode ser observado nas Figuras 5.15 e 5.16.

\subsubsection{Comparação do tempo de preenchimento}

O tempo necessário para o preenchimento de um molde de volume $V$ a uma dada velocidade de injeção fixa $v_{\text {inj }}$ pode ser calculado por meio de conservação de massa da seguinte maneira:

$$
t=\frac{V}{A v_{\text {inj }}},
$$

onde $A$ é a área da região de injeção de fluido. Desta forma, considerando-se a geometria do molde ilustrado na Figura 5.14 e a velocidade de injeção prescrita escolhida, $v_{\text {inj }}=$ $2,5 \times 10^{-2} \mathrm{~m} / \mathrm{s}$, tem-se pela Equação (5.34) que o tempo necessário para o completo preenchimento do molde é de 4 segundos. Nessa seção, o erro cometido pela aproximação numérica na predição do tempo de preenchimento é investigado por meio do uso de quatro malhas sucessivamente mais refinadas, com 250, 500, 1000 e 2000 vértices/volumes de controle.

Lembrando que a ordem de convergência $q$ do método numérico é sinônima da taxa com que o erro decai com o refinamento da malha, pode-se novamente utilizar a Equação (5.33) para investigar a performance do método proposto. Nesse caso teste, a medida de erro utilizada é o erro relativo e $h$ é tomado como uma média das arestas da malha. Os erros cometidos considerando-se tais malhas são listados na Tabela 5.2.

Tabela 5.2: Erro relativo cometido na predição do tempo de preenchimento. Valores obtidos considerando-se diversas malhas triangulares não estruturadas.

\begin{tabular}{ccccc}
\hline \hline Vértices & Passos no tempo & $h(m)$ & Tempo $(s)$ & Erro Relativo (\%) \\
\hline 250 & 177 & $2,55 \times 10^{-3}$ & 3,9649 & 0,877 \\
500 & 268 & $1,63 \times 10^{-3}$ & 3,9751 & 0,622 \\
1000 & 388 & $1,13 \times 10^{-3}$ & 3,9883 & 0,292 \\
2000 & 578 & $7,91 \times 10^{-4}$ & 3,9931 & 0,172 \\
\hline
\end{tabular}

As Figuras 5.17 e 5.18 ilustram a ordem de convergência do método, indicando que a precisão do método é aproximadamente linear.

A Tabela 5.2 apresenta também a quantidade de passos no tempo necessária para o completo preechimento do molde, utilizando o método proposto. Na malha mais refinada, contendo 2000 vértices de triângulos e fazendo $\mathrm{CFL}=0,25$, a simulação é realizada 


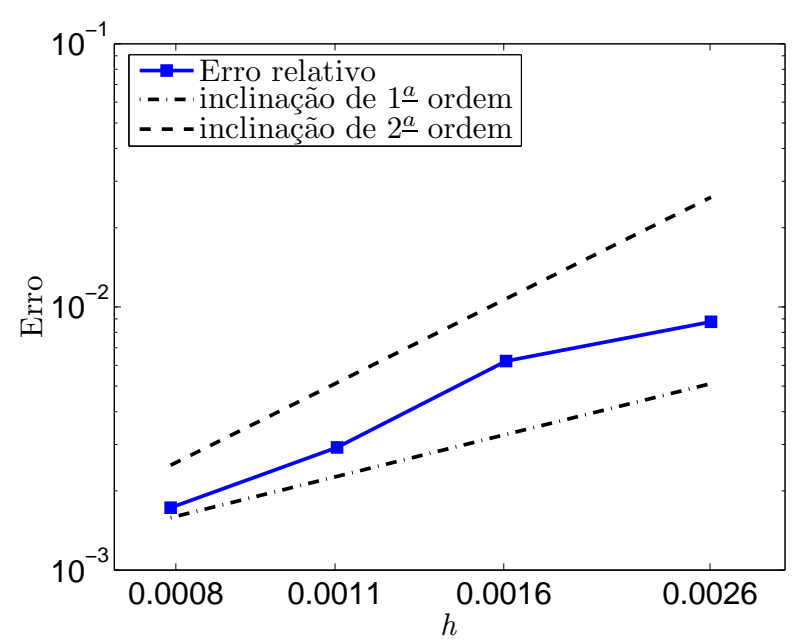

Figura 5.17: Erro relativo cometido pelo método proposto ao predizer o tempo de preenchimento do molde descrito na Figura 5.14.

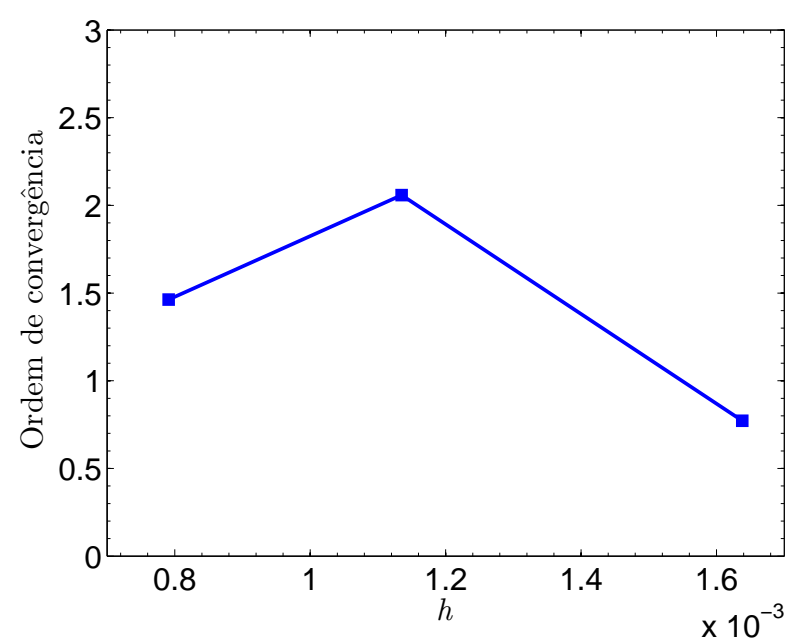

Figura 5.18: Ordem de convergência do método proposto. Valores ilustram que a ordem de convergência é aproximadamente linear.

utilizando apenas 578 passos no tempo, enquanto o método de Estacio e Mangiavacchi (2007) realizaria tal simulação em 2000 passos. Esse resultado ilustra o ganho no tempo de processamento ao se utilizar a estratégia proposta, que continua fornecendo resultados satisfatórios.

\subsubsection{Distribuição bidimensional de temperatura}

A equação da temperatura é composta por termos de convecção, difusão e condução. Dentre eles, o termo convectivo é o que mais representa dificuldades quanto à discretização numérica e está presente em ambas formulações bidimensional e tridimensional para a temperatura. Nessa seção será validada a discretização deste termo na equação bidimensional, utilizando um referencial semi lagrangeano.

Neste caso teste, a qualidade da aproximação numérica do campo bidimensional de temperatura é investigada considerando o escoamento não isotérmico do molde descrito na Figura 5.14. A solução obtida pelo método proposto utilizando quatro malhas suces- 
sivamente mais refinadas $(250,500,1000$ e 2000 volumes de controle) é comparada com uma solução analítica.

Com este objetivo, o fluido é injetado adentro da cavidade do molde com velocidade de injeção prescrita $v_{\text {inj }}=1 \times 10^{-2} \mathrm{~m} / \mathrm{s}$, a uma temperatura de $T_{\text {inj }}=513 \mathrm{~K}$. A temperatura do molde é considerada como sendo $T_{w}=313 \mathrm{~K}$. Adicionalmente, fluido é considerado newtoniano com viscosidade $\eta_{0}=4 \times 10^{6} \mathrm{~Pa} \mathrm{~s}$, densidade $\rho=1000 \mathrm{~kg} / \mathrm{m}^{3}$, condutividade térmica $k=0,18 \mathrm{~W} / \mathrm{mK}$ e calor específico $c_{p}=1900 \mathrm{~J} / \mathrm{kg} \mathrm{K}$.

Para construir uma expressão para a solução analítica para a distribuição bidimensional de temperatura no molde em questão, uma formulação euleriana é considerada. Desta forma, a temperatura $\bar{T}(\mathbf{x}, t)$, onde $\mathbf{x}=(x, y)$, pode ser escrita como $\bar{T}(\xi, t)$, com $\mathbf{x}=\mathbf{x}(\xi)$.

O vetor posição $\mathbf{x}(\xi)$ é dado por:

$$
\mathbf{x}(\xi)=\xi+v_{\text {inj }} t
$$

onde $v_{\text {inj }}$ é a velocidade de injeção do fluido e $t$ é o tempo.

A Equação (3.3), para os valores de $\bar{T}$, dada por:

$$
\frac{D \bar{T}}{D t}=\frac{1}{\rho c_{p}}\left(\frac{3}{5 h^{2}}\|\overline{\mathbf{v}}\|^{2}\left(2 \eta_{c}+3 \eta_{w}\right)+\frac{3 k}{h^{2}}\left(\bar{T}-T_{w}\right)\right),
$$

pode ser reescrita considerando $\xi$ e viscosidade constantes como:

$$
\left.\frac{d \bar{T}}{d t}\right|_{\xi \text { constante }}=\frac{1}{\rho c_{p}}\left(\frac{3 \eta_{0}}{h^{2}}\|\overline{\mathbf{v}}\|^{2}+\frac{3 k}{h^{2}}\left(\bar{T}-T_{w}\right)\right) .
$$

Considerando que a componente da velocidade na direção-y seja nula, é possível reescrever a Equação (5.37) e obter:

$$
\begin{aligned}
\left.\frac{d \bar{T}}{d t}\right|_{\xi \text { constante }} & =\frac{1}{\rho c_{p}}\left(\frac{3 \eta_{0}}{h^{2}} \bar{v}_{x}^{2}+\frac{3 k}{h^{2}} T_{w}\right)+\frac{3 k}{h^{2} \rho c_{p}} \bar{T} \\
& =c_{0}+c_{1} \bar{T} .
\end{aligned}
$$

A Equação (5.38) é uma equação diferencial ordinária da forma

$$
\bar{T}^{\prime}-c_{1} \bar{T}-c_{0}=0
$$

e admite solução analítica, dada por (Boyce e DiPrima, 1969):

$$
\bar{T}=\mathrm{e}^{-c_{1} x} \int^{x} \mathrm{e}^{c_{1} t} d t+c \mathrm{e}^{-c_{1} x}=\frac{c_{0}}{c_{1}}+c \mathrm{e}^{-c_{1} x}
$$

Lembrando que em $x=0$, tem-se $T=T_{\text {inj }}$, então a Equação (5.40) é escrita como:

$$
\bar{T}=\frac{c_{0}}{c_{1}}+T_{\text {inj }} \mathrm{e}^{-c_{1} x}
$$


Simulando o escoamento com características descritas no início desta Seção, e conhecendo a solução analítica para esse escoamento, é possível comparar as soluções obtidas e avaliar, mais uma vez, a precisão do método numérico desenvolvido, agora para o cálculo da temperatura.

Conforme apresentado em seção anterior, tem-se que a ordem de convergência $q$ do método numérico é sinônima da taxa com que o erro decai com o refinamento da malha. Desta forma, pode-se utilizar a Equação (5.33) para investigar a performance do método proposto com relação à distribuição de temperatura. Nesse caso teste, a medida de erro utilizada é a norma $L_{2}$ e $h$ é tomado como uma média das arestas da malha. Os erros cometidos considerando-se distintas malhas sucessivamente refinadas são listados na Tabela 5.3.

Tabela 5.3: Erro cometido na solução da equação da temperatura segundo a norma $L_{2}$, considerando-se diversas malhas triangulares não estruturadas.

\begin{tabular}{ccc}
\hline \hline Vértices & $h(m)$ & $L_{2}$ \\
\hline 250 & $2,55 \times 10^{-3}$ & $3,3332 \times 10^{-4}$ \\
500 & $1,63 \times 10^{-3}$ & $1,7796 \times 10^{-4}$ \\
1000 & $1,13 \times 10^{-3}$ & $1,1411 \times 10^{-4}$ \\
2000 & $7,91 \times 10^{-4}$ & $6,7066 \times 10^{-5}$ \\
\hline
\end{tabular}

A Figura 5.19 ilustra que a ordem de convergência do método é aproximadamente linear. Os valores obtidos para a ordem de convergência do método considerando as malhas apresentadas são ilustrados na Figura 5.20.

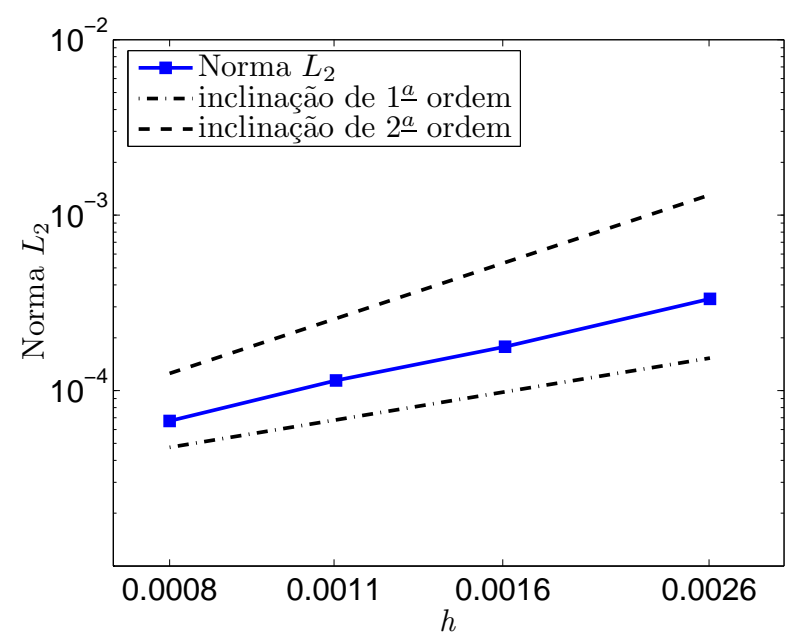

Figura 5.19: Erro relativo cometido pelo método proposto ao predizer o campo bidimensional de temperatura ao final do preenchimento do molde descrito na Figura 5.14.

\subsubsection{Escoamento em um molde com um canal de entrada}

Neste caso teste, os resultados alcançados pelo presente método são comparados com os apresentados no trabalho de Chang e Yang (2001) para o caso do escoamento isotérmico 


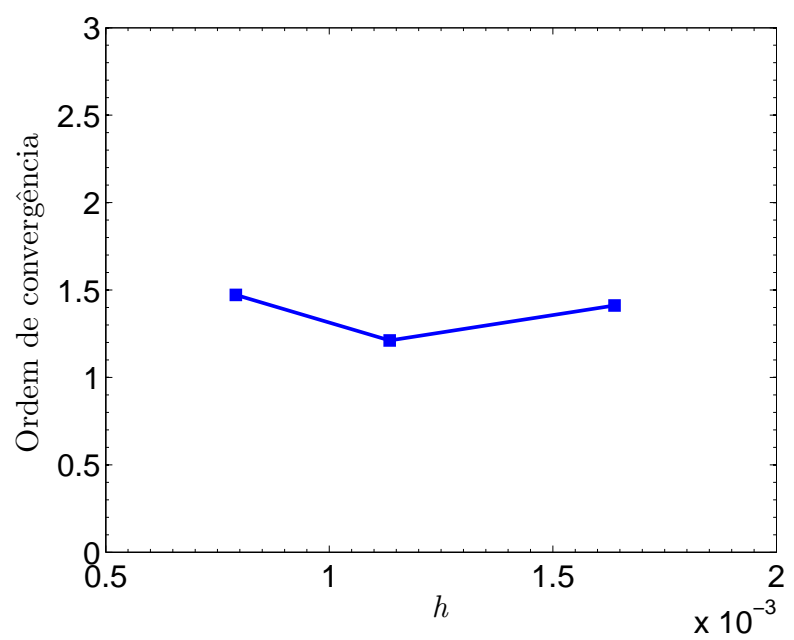

Figura 5.20: Ordem de convergência do método proposto. Valores ilustram que a ordem de convergência é aproximadamente linear.

de um fluido newtoniano em um molde retangular com um canal de entrada. O objetivo é verificar a capacidade do método em predizer corretamente ambas pressão na região de injeção e posição da superfície livre.

As dimensões do molde são ilustradas na Figura 5.21. A malha não estruturada triangular utilizada para discretizar o molde apresenta 1207 triângulos e 657 volumes de controle, tendo sido gerada pelo Easymesh (Niceno, 2001). A direção transversal do molde é dividida em $N_{z}=5$ camadas.

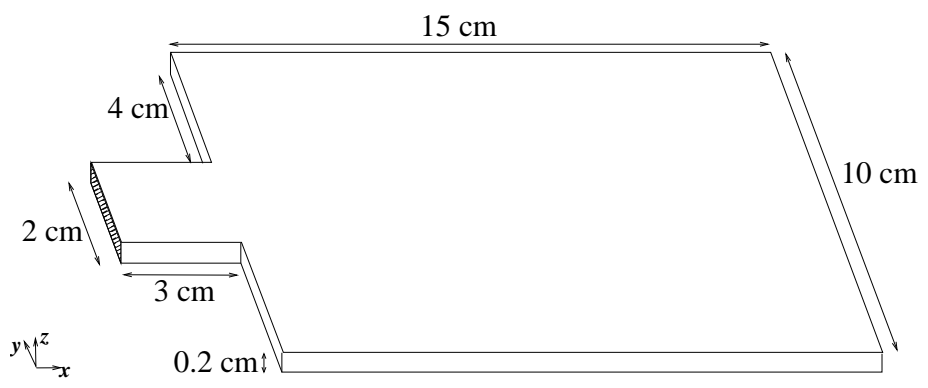

Figura 5.21: Molde retangular com um canal de entrada. A região de injeção é representada como a área hachurada na figura.

O molde descrito na Figura 5.21 é preenchido por um fluido newtoniano $\left(\eta_{0}=10^{4} \mathrm{~Pa} s\right)$ de tal modo que o tempo total de preenchimento seja 2 segundos. Pela Equação (5.34), tem-se que a velocidade com a qual o fluido deve ser injetado é $v_{\text {inj }}=3,9 \times 10^{-1} \mathrm{~m} / \mathrm{s}$.

A Figura 5.22 apresenta uma comparação dos perfis da pressão na região de injeção obtidos pelo método proposto e pelo método de Chang e Yang (2001) nas condições de escoamento descritas anteriormente. Pode-se observar a concordância entre os resultados obtidos por ambos os métodos.

A Figura 5.23 ilustra a posição da superfície livre em seis diferentes etapas do preenchimento do molde. A linha preta representa a superfície livre do fluido: o volume do molde localizado à esquerda da linha preta está cheio de fluido enquanto o volume do 


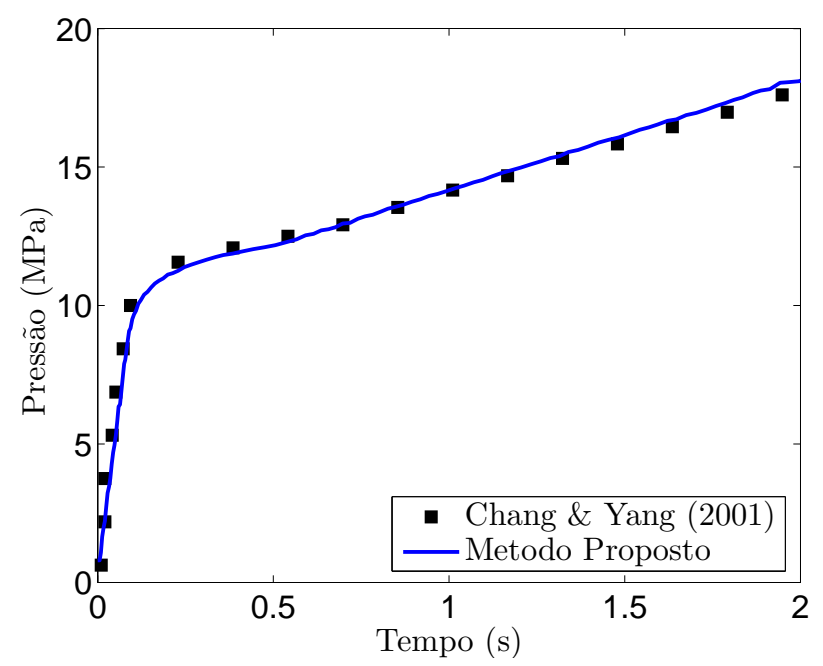

Figura 5.22: Comparação do perfil da pressão na região de injeção de fluido obtido pelo método proposto com o resultado de Chang e Yang (2001) durante o preenchimento do molde descrito na Figura 5.21.

molde localizado à direita da linha ainda encontra-se vazio. A posição da superfície livre predita pelo presente método está de acordo com os resultados obtidos pelo método de Chang e Yang (2001), apresentados na Figura 5.24.

\subsection{Resultados}

Tendo sido realizados diversos testes de modo a verificar a capacidade do método em prever corretas pressão de injeção, distribuição de temperatura e posição da superfície livre ao decorrer do preenchimento de moldes, conclui-se que o método proposto combinando idéias do método CVFEM com uma estratégia semi lagrangeana e uma adaptação meshless do método FT aplicados à solução numérica do preenchimento de moldes fornece resultados confiáveis.

Nesta seção, um caso teste representativo é apresentado referente ao preenchimento de um molde de geometria complexa, empregando-se poliestireno, cujo comportamento é determinado pelo modelo de viscosidade de Cross (2.52) descrito na Seção 2.9.

A geometria utilizada neste caso teste corresponde a um molde retangular com diversos obstáculos interiores, representando uma régua de desenhar, conforme ilustrado na Figura 5.25. A malha não estruturada triangular correspondente apresenta 2647 triângulos e 1435 volumes de controle, tendo sido gerada pelo Easymesh (Niceno, 2001).

O tempo necessário para preencher completamente o volume do molde considerando a taxa de injeção dada é de 2,01 segundos. As Figuras 5.26, 5.27 e 5.28 apresentam o campo de distribuição de pressão, de temperatura e a posição da superfície livre, respectivamente, em tempos intermediários dados por $t=0,20,0,40,0,90,1,41,1,81$ e 1,97 segundos.

Nesta simulação, é possível observar que a temperatura do fluido é mais alta nas proximidades dos obstáculos, como pode ser facilmente observado na Figura 5.27. Este 


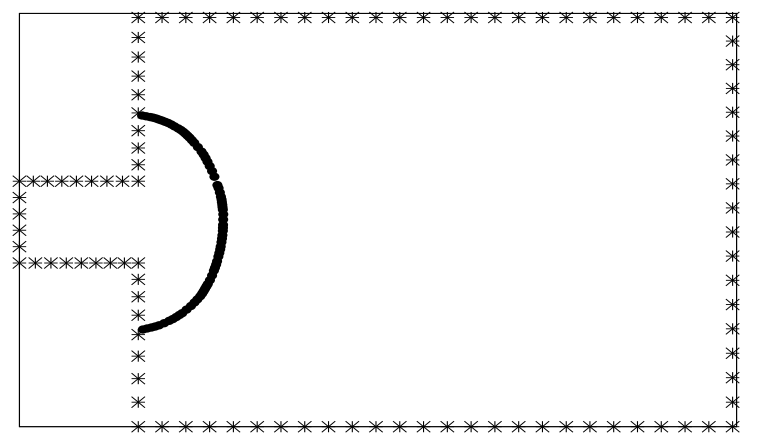

(a) $10 \%$ preenchido

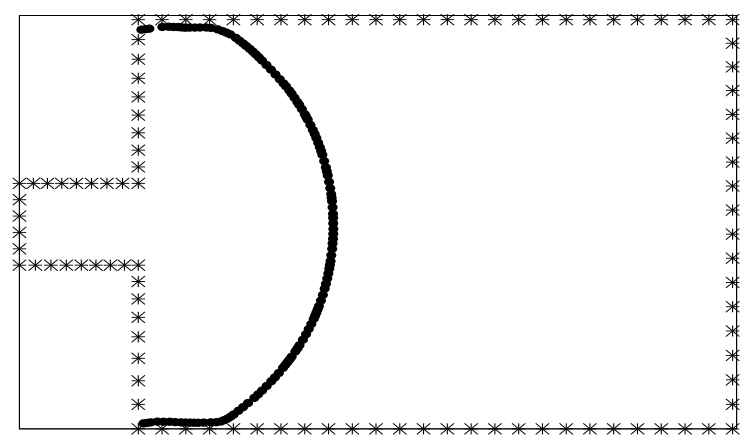

(c) $30 \%$ preenchido

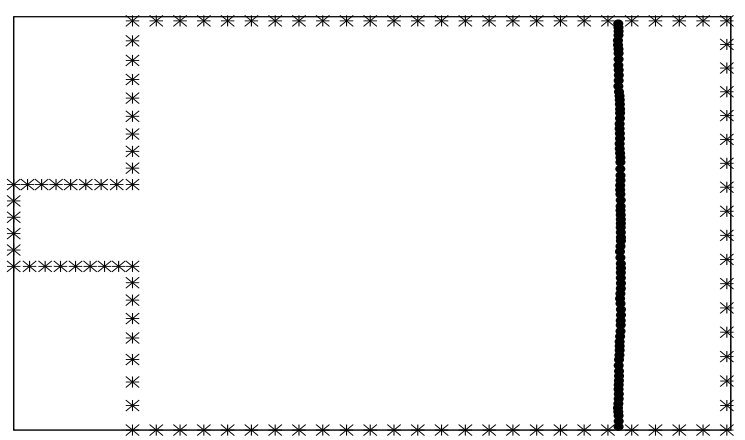

(e) $85 \%$ preenchido

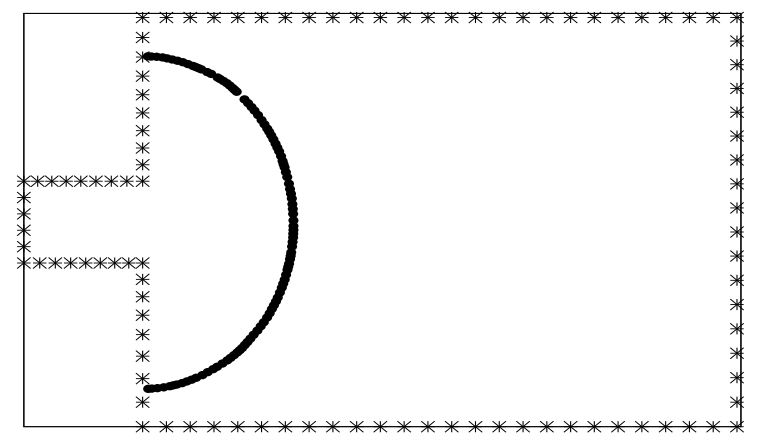

(b) $20 \%$ preenchido

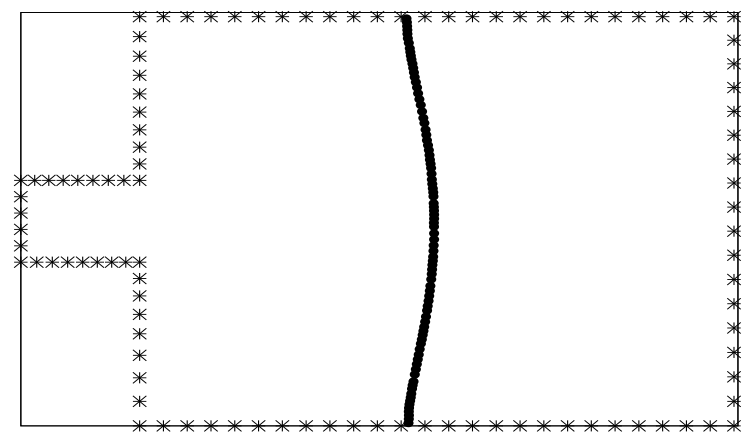

(d) $50 \%$ preenchido

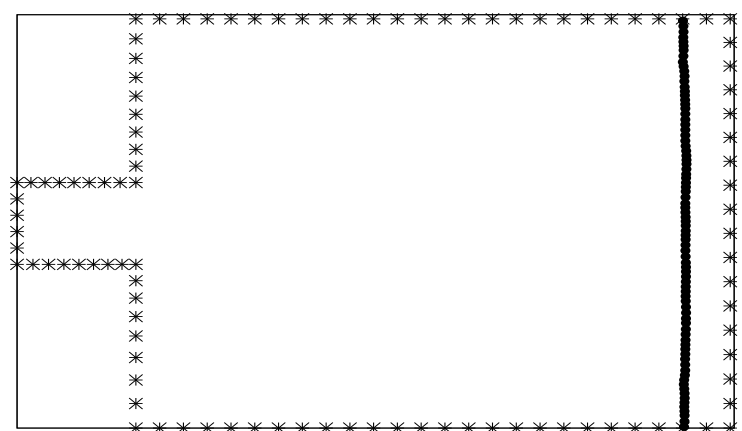

(f) $95 \%$ preenchido

Figura 5.23: Diversas etapas do avanço da superfície livre durante o preenchimento do molde descrito na Figura 5.21. Os resultados obtidos via método proposto estão de acordo com aqueles apresentados no trabalho de Chang e Yang (2001).

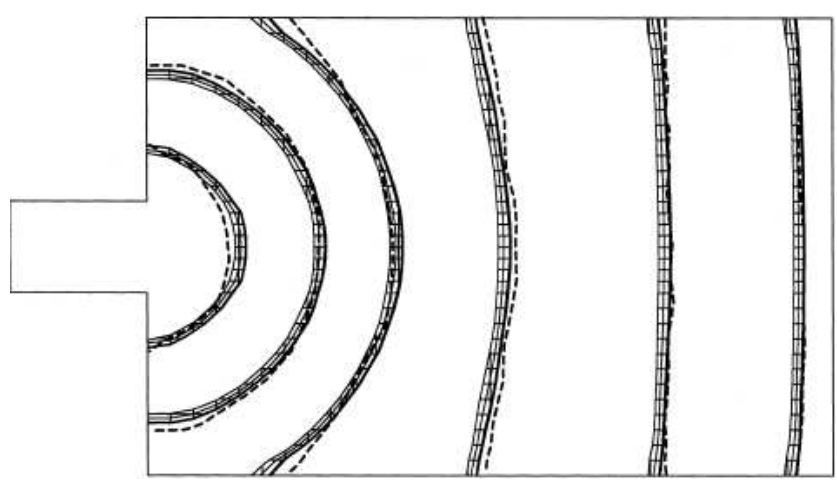

Figura 5.24: Resultados de Chang e Yang (2001). A linha tracejada representa as posições da superfície livre durante o preenchimento utilizando um modelo $2^{1} / 2 \mathrm{D}$, enquanto a malha representa um modelo 3D. 


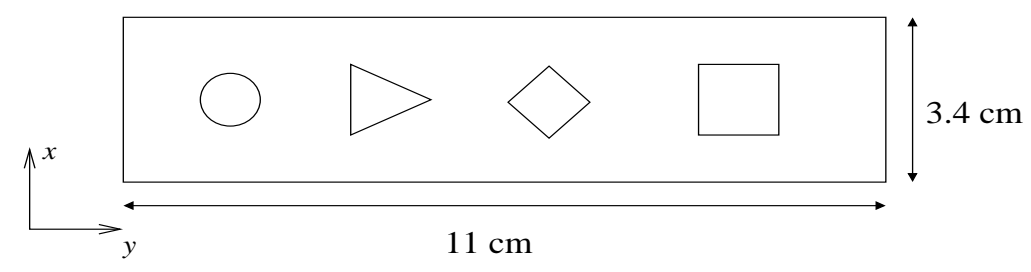

(a) vista superior

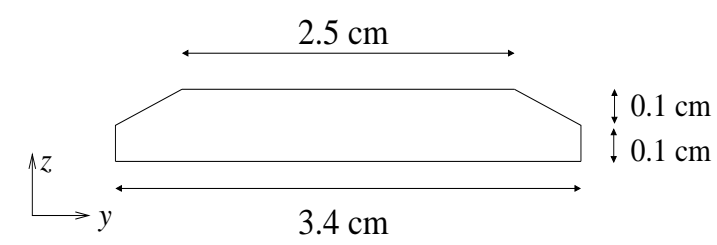

(b) vista lateral

Figura 5.25: Dimensões do molde e inserções (obstáculos interiores).

efeito, devido ao aquecimento viscoso (cisalhamento), é esperado em preenchimentos realizados com altas taxas de injeção (Subbiah et. al., 1989) e é adequadamente predito pelo método proposto. Neste caso, a solução da equação da temperatura com alta precisão é importante, uma vez que este aquecimento afeta a viscosidade do polímero, e por sua vez afeta a velocidade do escoamento. Conseqüentemente, a posição da superfície livre e a distribuição de pressão também são afetadas (Ahn e Carey, 2007).

Além disso, observa-se também a capacidade do presente modelo de lidar adequadamente com a divisão e coalescência da superfície livre do fluido durante o processo de

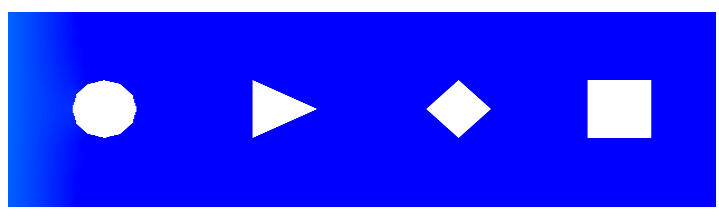

(a) $10 \%$ preenchido

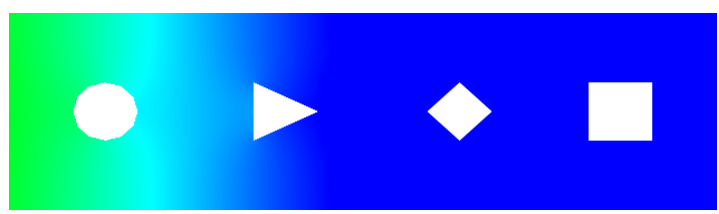

(c) $45 \%$ preenchido

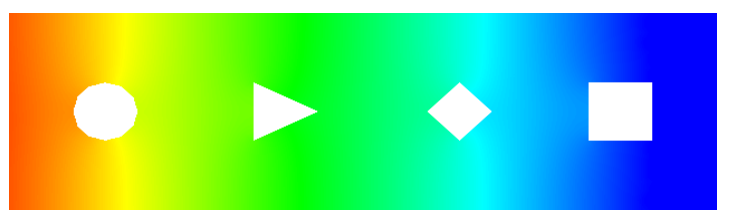

(e) $90 \%$ preenchido

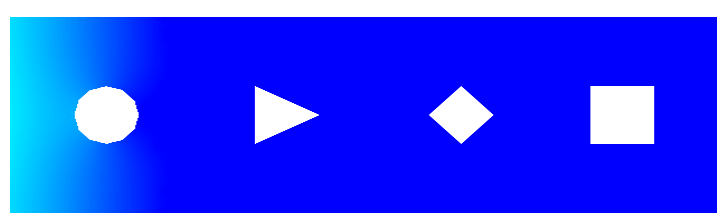

(b) $20 \%$ preenchido

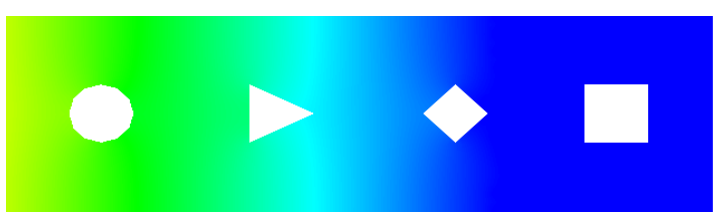

(d) $70 \%$ preenchido

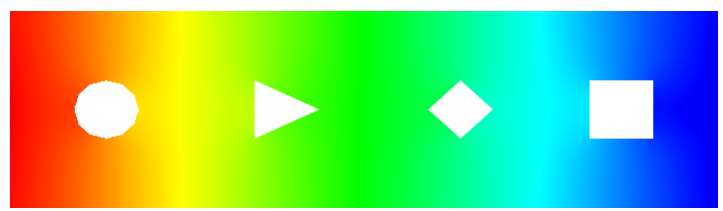

(f) $98 \%$ preenchido

$$
0.000
$$

Figura 5.26: Evolução da distribuição da pressão dentro do molde apresentado na Figura 5.25 representando uma régua de desenhar. 


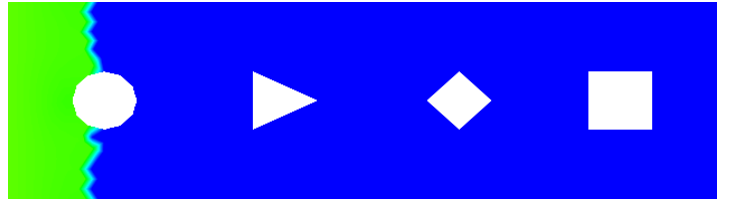

(a) $10 \%$ preenchido

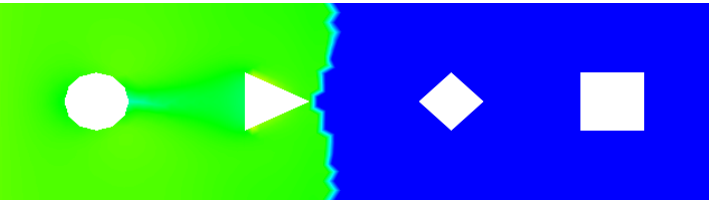

(c) $45 \%$ preenchido

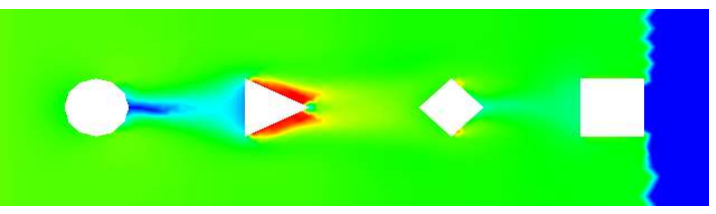

(e) $90 \%$ preenchido

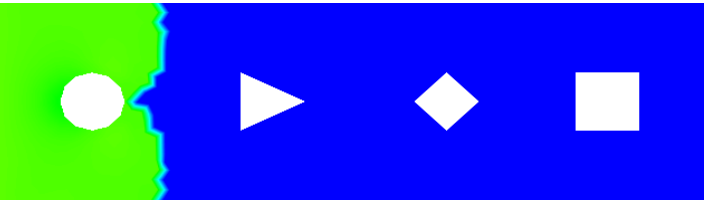

(b) $20 \%$ preenchido

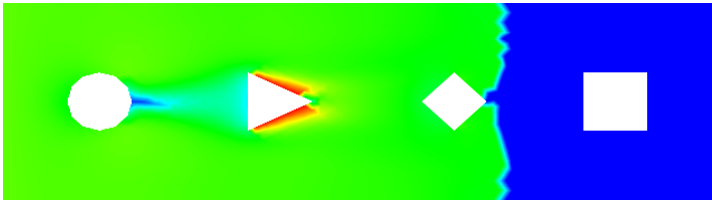

(d) $70 \%$ preenchido

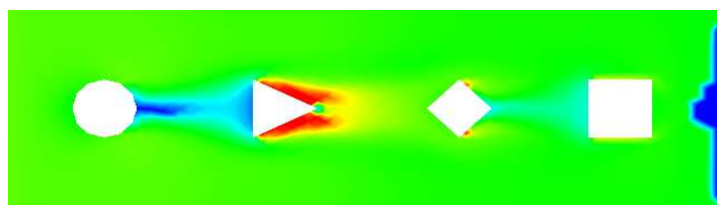

(f) $98 \%$ preenchido

500.

511.

522.

Figura 5.27: Evolução da distribuição bidimensional da temperatura durante o preenchimento do molde.

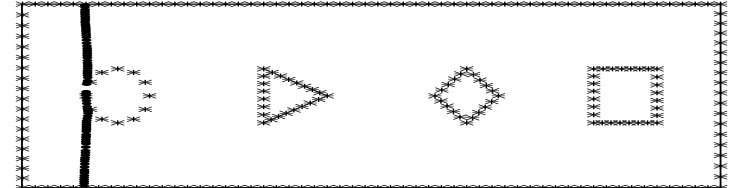

(a) $10 \%$ preenchido

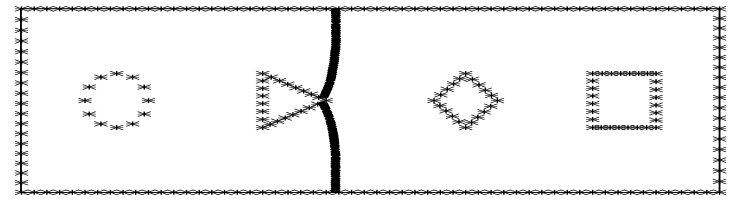

(c) $45 \%$ preenchido

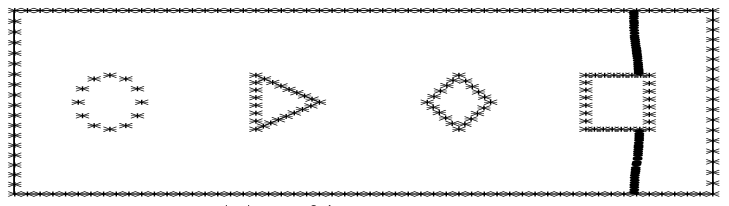

(e) $90 \%$ preenchido

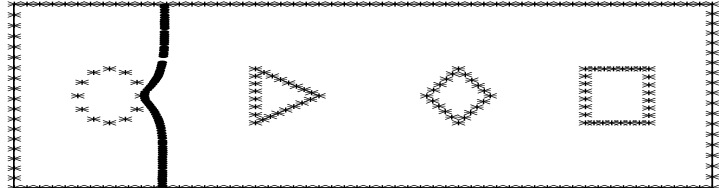

(b) $20 \%$ preenchido

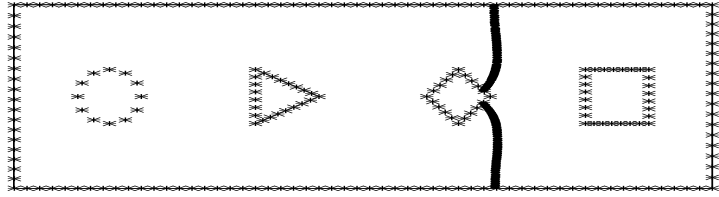

(d) $70 \%$ preenchido

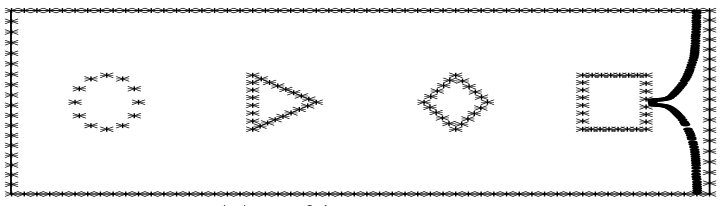

(f) $98 \%$ preenchido

Figura 5.28: Avanço da superfície livre do fluido.

preenchimento de moldes, adicionando e removendo partículas que representam a frente do fluido sempre que necessário. A caracterização deste efeito é também essencial para garantir a qualidade final da peça moldada, já que as regiões em que ocorrem a coalescência de duas ou mais frentes de fluido correspondem às áreas mais frágeis da peça produzida.

Conforme apresentado nas seções anteriores, o perfil da pressão e a posição da superfície-livre de fluido fornecidos pelo método proposto são quantitativamente semelhantes àqueles obtidos quando o esquema VOF de Estacio e Mangiavacchi (2007) é utilizado para 
rastrear a posição da superfície livre. Contudo, a implementação VOF requer 1415 iterações realizadas em $8 \mathrm{~min} 48 \mathrm{~s}$ em um processador Intel Xeon Quad-Core 3.2GHz com 4GB de memória RAM, enquanto o método apresentado, juntamente com condição CFL $=0.5$, requer apenas 127 iterações que demoram, ao total, 3min 7s para serem executadas.

\subsection{Comentários}

Neste capítulo um novo esquema para a simulação do preenchimento da cavidade de um molde foi apresentado. Esse esquema inclui um modelo bidimensional para a equação da pressão de um fluido newtoniano generalizado. A estratégia de discretização envolve malhas descrevendo o domínio computacional para a obtenção das variáveis do escoamento, e um conjunto de pontos que se movem sobre a malha representando o avanço do fluido adentro da cavidade do molde.

Testes numéricos foram conduzidos para o caso de escoamentos isotérmicos e não isotérmicos de fluidos newtonianos e não newtonianos. Primeiramente, a precisão do algoritmo responsável pela solução numérica da equação de Hele-Shaw foi investigado (Seção 5.6.1).

Na seqüência, os estudos mostraram a capacidade do método em fornecer perfis dcorretos e pressão na região de injeção de fluido por meio de velocidade prescrita tanto no caso de fluidos newtonianos quanto no caso de fluidos não newtonianos (Seções 5.6.2.1 e 5.6.3). Adicionalmente, a taxa com que o erro cometido na predição do tempo de preenchimento decai também foi investigada na Seção 5.6.2.2, e a qualidade do campo de temperatura fornecido pelo método foi investigada na Seção 5.6.2.3.

A estratégia adotada para predizer a posição da superfície livre, que é baseada somente no movimento dos pontos, demonstrou-se ser consistente e precisa. O método mostrou-se capaz de lidar com a divisão e coalescência de fluidos, simulando o preenchimento em menos iterações que outro método baseado em malhas, e portanto, apresentando menor custo computacional, mas mantendo a qualidade da solução encontrada.

Os estudos referentes a essa abordagem de solução das equações governantes da fase de preenchimento de um molde resultaram em um artigo publicado em periódico internacional (Estacio et. al., 2008). 


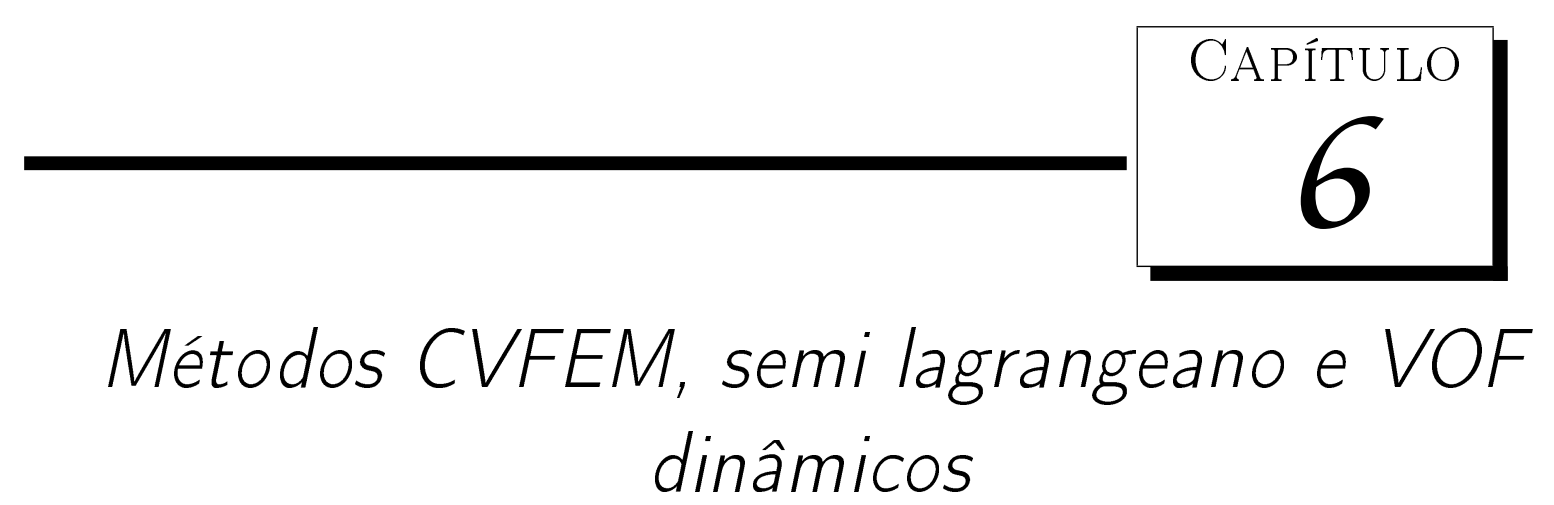

Neste capítulo um método tipo CVFEM é utilizado de maneira dinâmica e aplicado à solução da equação de Hele-Shaw juntamente com estratégias igualmente dinâmicas do método semi lagrangeano utilizada para aproximar o campo bidimensional de temperatura e do método VOF para avançar da superfície livre do fluido. Com este objetivo, uma malha dinâmica de elementos ativos e inativos é criada a partir do conjunto de pontos: volumes de controle locais são criados dinamicamente a partir de pontos ativos. Testes referentes à performance do método implementado e à qualidade da solução obtida são apresentados.

\subsection{Considerações iniciais}

Diversas estratégias têm sido desenvolvidas para simular numericamente o processo de moldagem por injeção fazendo uso de algum tipo de malha, ou, equivalentemente de uma estrutura de dados de modo a discretizar as equações governantes via elementos finitos, volumes finitos ou outros métodos de discretização local; exemplo de estratégias deste tipo são os trabalhos de Subbiah et. al. (1989), Holm e Langtangen (1999), Jiang et. al. (2007), Zhou e Li (2001), Zhou e Turing (2006), Estacio e Mangiavacchi (2007).

No presente trabalho, um conjunto de pontos é usado de modo a representar numericamente a geometria do molde e malhas computacionais são construídas local e dinamicamente para a solução das equações governantes para a pressão e temperatura na região do molde invadida por fluido (um subconjunto de pontos ativos da malha dinâmica).

Um método de volumes finitos é aplicado para a solução da equação de Hele-Shaw segundo os passos de Baliga e Patankar (1980, 1983) apresentados na Seção 5.2. A equação governante para o campo de temperatura bidimensional é resolvida utilizando uma estratégia semi lagrangeana (Phillips e Williams, 2001a,b, Xiu e Karniadakis, 2001) análoga àquela apresentada na Seção 5.3. Finalmente, a equação governante para a posição 
da superfície livre pode ser vista como um método do tipo VOF local (Hirt e Nichols, 1981) que usa uma abordagem de células ativas localizadas em uma camada da frente de fluido em movimento. Um modelo de camadas ao longo da espessura do molde é também utilizado para acomodar os efeitos de cisalhamento devido ao uso de modelos de viscosidade newtoniana generalizada, comumente empregados em processos de moldagem por injeção (Carey e Chow, 2003, Myers, 2005). Os passos seguidos para o desacoplamento das equações estão descritos no Capítulo 3.

\subsection{Construção dinâmica dos volumes de controle}

Conforme o próprio nome sugere, em métodos meshless não há malhas nas discretizações, mas apenas partículas definindo tanto o interior quanto o contorno do domínio no qual as equações em questão devem ser resolvidas.

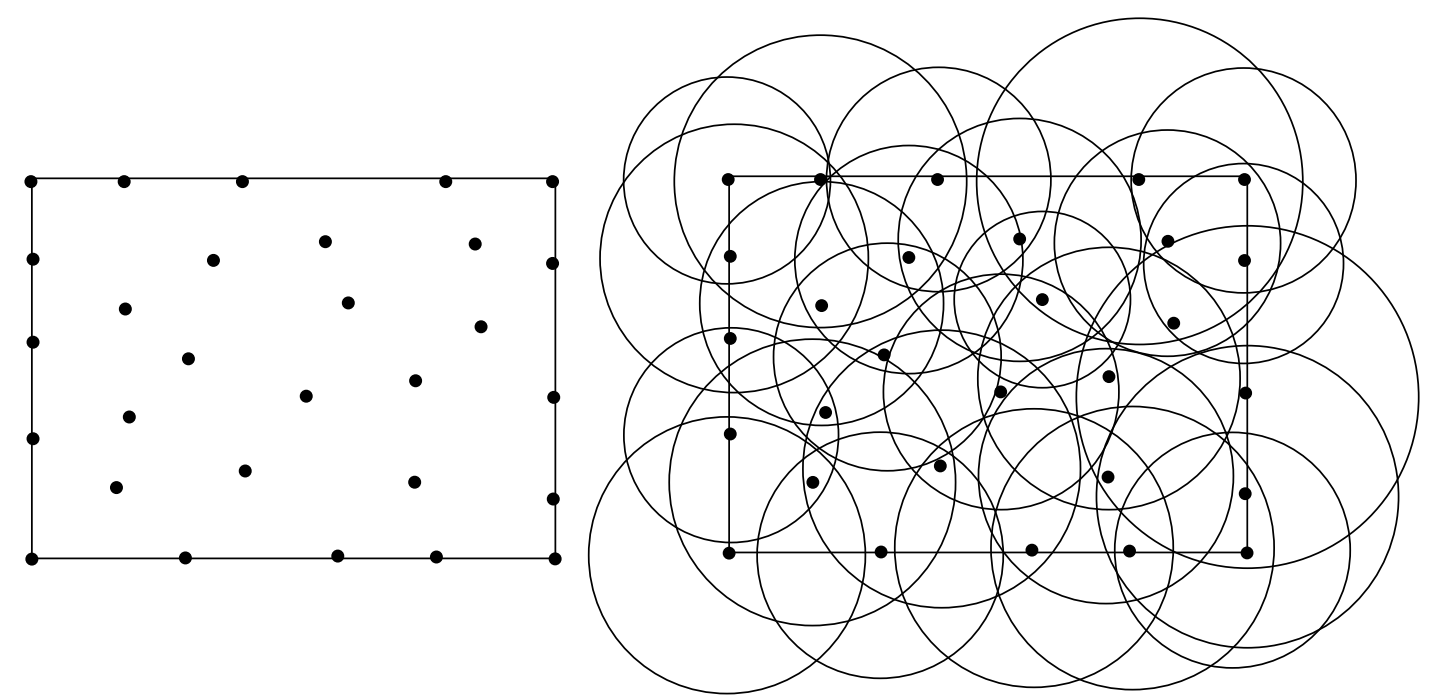

Figura 6.1: Pontos utilizados em aproximações meshless e raios associados a cada ponto, cobrindo todo o domínio.

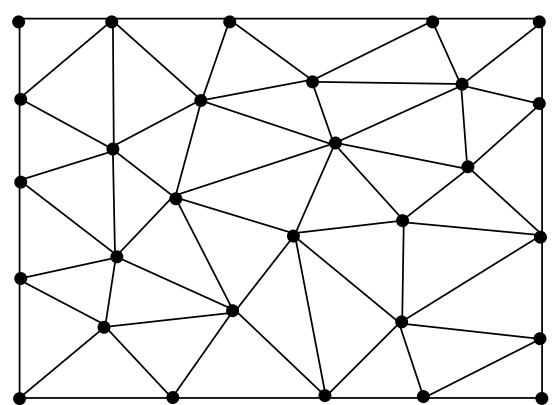

(a) Malha triangular

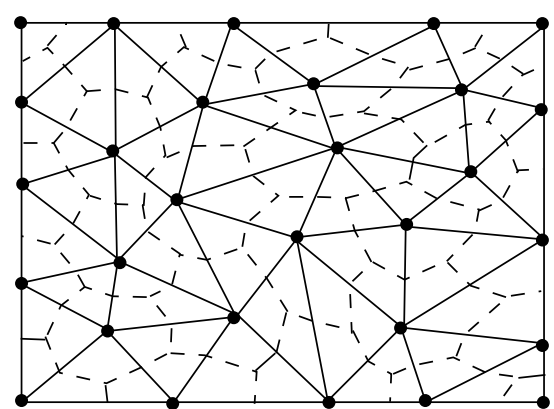

(b) Malha e volumes de controle

Figura 6.2: Malha não estruturada triangular e volumes de controle associados.

A Figura 6.1 ilustra um exemplo de pontos definindo ambos domínio e seu contorno, usados em aproximações meshless, em contraposição à malha e aos volumes ilustrados na Figura 6.2. Uma prática comum em métodos meshless é associar um raio a cada ponto onde serão realizados os cálculos da propriedade envolvida (Li e Liu, 2002, Chen e 
Liu, 2004). Este raio estabelece relações de vizinhança entre um determinado ponto e os restantes representando o domínio.

A Figura 6.3 ilustra um caso representativo de um ponto $i$ do domínio, seu raio associado e respectivos vizinhos $j$ de acordo com esse raio. Um ponto $j$ é vizinho de um ponto $i$ se $d(i, j)<R_{i}$, onde $d$ representa a função distância, normalmente tomada como a norma euleriana, e $R_{i}$ é o raio associado ao ponto $i$. Os diversos pontos representando o domínio podem apresentar raios associados diferentes; além disso, o raio associado a cada ponto pode ser alterado de modo a aumentar o número de vizinhos deste ponto.

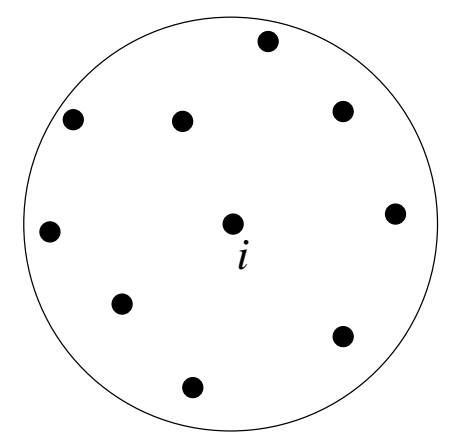

Figura 6.3: Disco centrado no ponto $i$ contendo um subconjunto de pontos vizinhos a $i$, segundo um raio pré-determinado $R_{i}$.

No presente trabalho, uma triangulação local dos pontos em cada disco é construída para servir de suporte para a construção dos volumes de controle, obtidos ao conectar o centro geométrico dos triângulos com o ponto médio dos lados, como no caso usual do CVFEM descrito no Capítulo 5. Como para cada ponto $i$ é conhecido somente o seu raio, pode-se associar a $i$ um volume de controle virtual dinâmico utilizando apenas os pontos $j$ vizinhos a $i$. Para tanto, é necessário ordenar tais pontos considerando-se o ângulo formado entre eles e $i$, com relação a um vetor de referência $t$, pertencente ao plano que contém (ou aproxima) os pontos, conforme ilustrado na Figura 6.4.

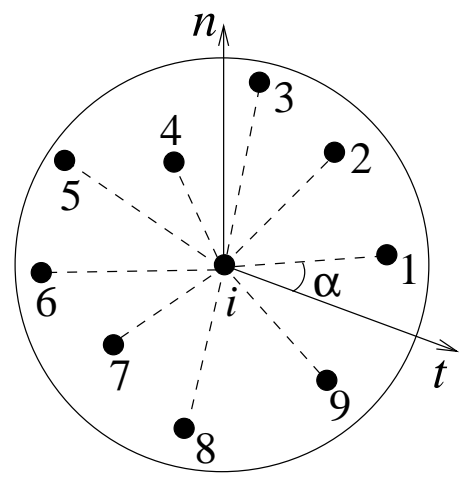

Figura 6.4: Pontos vizinhos à $i$, ordenados. $t$ é um vetor de referência pertencente ao plano definido pelos pontos, e $n$ é o vetor normal a este plano.

Para a construção dos volumes de controle dinâmicos mostra-se mais uma vez apropriado o método das medianas, já que ele faz uso apenas de informações geométricas, como o 
ponto médio entre dois pontos e o centro geométrico (centróide) entre três pontos. O método das medianas é empregado após a ordenação dos pontos vizinhos a $i$. Por exemplo, na Figura 6.5 os pontos $a$ e $c$ são valores médios dos segmentos $i 1$ e $i 2$, respectivamente, e o ponto 0 é o centro geométrico do triângulo $i-1-2$.

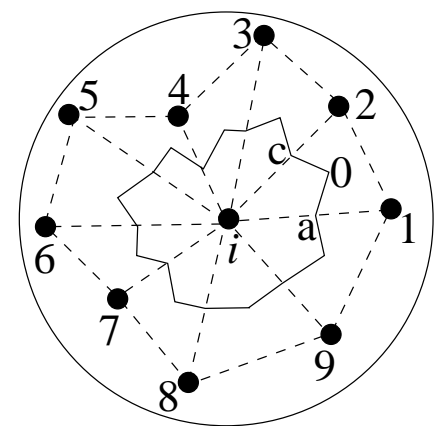

Figura 6.5: A triangulação define um caminho local e o volume de controle dinâmico é determinado pelo método das medianas.

Volumes de controle dinâmicos são então definidos dinamicamente para todos os pontos $i$ sobre os quais a equação de Hele-Shaw será aproximada, isto é, em pontos em que há fluido. Em seguida, a equação de Hele-Shaw pode ser aproximada na maneira usual aplicando o método CVFEM tradicional, conforme descrito sucintamente na seção a seguir.

\subsection{Solução da equação de Hele-Shaw por CVFEM dinâmico}

A equação de Hele-Shaw (3.1) para a pressão pode ser convenientemente escrita da forma divergente:

$$
\nabla \cdot \mathbf{J}=0
$$

com o vetor fluxo dado por $\mathbf{J}=-S_{2} \nabla p$.

Aplicando o teorema de Gauss, a propriedade de conservação associada em um volume arbitrário $V$ satisfaz:

$$
\int_{V} \nabla \cdot \mathbf{J} d V=\int_{S} \mathbf{J} \cdot \mathbf{n} d S=0
$$

onde $S$ é a fronteira de $V$ e $\mathbf{n}$ é um vetor unitário normal a $S$ e que aponta para fora.

No caso discreto, esta relação no volume arbitrário $V$ do domínio é substituída pela aproximação dimensional finita obtida ao restringir $V$ ao conjunto finito de volumes de controle para um conjunto de pontos específico.

Por exemplo, considere um volume finito $V_{i}$ associado com o ponto $i$ e seja $j$ denotando os vizinhos adjacentes de $i$; e, para fins de simplicidade de notação, $j^{*}=(j+1) \bmod N$, onde $N$ é o número de vizinhos do ponto $i$. Correspondentemente, na Figura $6.5, N=9$ e os pontos $j=1, \ldots, N$ estão associados ao ponto $i$. Assumindo uma distribuição linear para pressão nos triângulos $i-j-j^{*}$, a contribuição para o ponto $i$ proveniente do contorno 
$a 0 c$ para o cálculo da integral de superfície dentro do triângulo $i-j$ - $j^{*}$ tem a forma:

$$
\int_{a}^{0} \mathbf{J} \cdot \mathbf{n} d S+\int_{0}^{c} \mathbf{J} \cdot \mathbf{n} d S=C_{i} p_{i}+C_{j} p_{j}+C_{j^{*}} p_{j^{*}}
$$

onde, para $k=i, j, j^{*}, p_{k}$ são os valores da pressão nos vértices e os coeficientes $C_{k}$ dependem de $S_{2}$ (que é assumido constante sobre o elemento triangular em um determinado tempo) e das coordenadas destes vértices:

$$
\begin{aligned}
C_{i} & =\frac{S_{2}}{D}\left[\left(y_{a}-y_{c}\right)\left(y_{j}-y_{j^{*}}\right)+\left(x_{a}-x_{c}\right)\left(x_{j}-x_{j^{*}}\right)\right], \\
C_{j} & =\frac{S_{2}}{D}\left[\left(y_{a}-y_{c}\right)\left(y_{j^{*}}-y_{i}\right)+\left(x_{a}-x_{c}\right)\left(x_{j^{*}}-x_{i}\right)\right], \\
C_{j^{*}} & =\frac{S_{2}}{D}\left[\left(y_{a}-y_{c}\right)\left(y_{i}-y_{j}\right)+\left(x_{a}-x_{c}\right)\left(x_{i}-x_{j}\right)\right], \\
D & =\left(x_{i} y_{j}+x_{j} y_{j^{*}}+x_{j^{*}} y_{i}-y_{i} x_{j}-y_{j} x_{j^{*}}-y_{j^{*}} x_{i}\right) .
\end{aligned}
$$

Após a inclusão das contribuições relativas a outros elementos para o ponto $i$, obtém-se a equação nodal completa. O sistema linear resultante pode ser resolvido iterativamente pelo método dos Gradientes Conjugados, que requer repetidas operações de produto matriz-vetor (matvec) e produto interno. As operações mais caras, do tipo matvec, podem ser realizadas ponto a ponto na presente formulação proporcionando economia de armazenamento, similar às estratégias de elemento-por-elemento e aresta-por-aresta descritas para aproximações por elementos finitos nos trabalhos de Carey e Jiang (1986), Coutinho et. al. (2006). Pré-condicionamento diagonal também pode ser implementado neste esquema (Carey e Jiang, 1987, Bridson e Greif, 2006).

\subsubsection{Cálculo da fluidez}

Embora a estratégia de solução da equação de Hele-Shaw usando CVFEM dinâmico apresentada neste capítulo seja bastante semelhante àquela descrita no Capítulo 5, na abordagem proposta não há malhas ou estruturas de dados associadas à discretização, e portanto, a fluidez que seria armazenada para cada triângulo da malha no caso citado, é armazenada em cada ponto da discretização.

Para tanto, os valores da viscosidade e da taxa de cisalhamento são calculados de maneira análoga aos passos descritos na Seção 5.2.2 para cada elemento triangular gerado dinamicamente, mas têm seus valores armazenados nos vértices dos triângulos, como uma média ponderada pela área dos mesmos. Tendo sido aproximados os valores para a viscosidade e a taxa de cisalhamento nos vértices destes triângulos, isto é, em cada ponto que representa a geometria do molde, a fluidez é então obtida neste ponto por meio de integração numérica ao longo da espessura do molde.

Vale salientar que no caso dos modelos de Carreau e de Cross, a viscosidade depende da taxa de cisalhamento, que por sua vez, depende novamente da viscosidade. A presença de não-linearidade no cálculo da viscosidade/taxa de cisalhamento nesses modelos impõe 
o uso de uma estratégia de solução de equações não-lineares, e a estratégia escolhida é o método de Newton. Porém, nos modelos de Power-law e de Ellis não há necessidade da utilização do método de Newton para a obtenção dos valores da taxa de cisalhamento e da viscosidade, e estas grandezas podem ser calculadas explicitamente.

Este fato ocorre em qualquer uma das abordagens numéricas escolhidas para a solução das equações governantes para a fase de preenchimento de moldes (descritas nos Capítu$\operatorname{los} 4,5$ e 6), já que se trata de uma característica intrínseca do modelo de viscosidade, e não da estratégia adotada para a solução da equação da pressão e para o avanço da superfície livre.

No caso do modelo de Power-law, é possível substituir a expressão para a taxa de cisalhamento (3.7) no modelo propriamente dito (2.51) e vice-e-versa, resultando em:

$$
\eta=K \dot{\gamma}^{n-1}=K^{\frac{1}{n}}(z\|\nabla p\|)^{1-\frac{1}{n}}
$$

e também:

$$
\dot{\gamma}=\frac{z}{\eta}\|\nabla p\|=\left(\frac{z}{K}\|\nabla p\|\right)^{\frac{1}{n}}
$$

onde $K$ é uma constante que depende do fluido.

No caso do modelo de Ellis, a viscosidade é escrita em termos da tensão de cisalhamento $\tau$ :

$$
\tau=\eta(\dot{\gamma}) \dot{\gamma}=z\|\nabla p\|
$$

e portanto a viscosidade de Ellis (2.54) pode ser calculada usando:

$$
\frac{1}{\eta}=\frac{1}{\eta_{0}}\left(1+\left|\frac{z\|\nabla p\|}{\tau_{1 / 2}}\right|^{n-1}\right) .
$$

Finalmente, a expressão para a fluidez pode ser avaliada por meio de integração numérica ao longo da espessura do molde usando os valores da viscosidade em cada uma das $N_{z}$ camadas que discretiza, a direção transversal do molde, funcionando como pontos de integração.

\subsection{Solução da equação 2D da temperatura via mé- todo semi lagrangeano dinâmico}

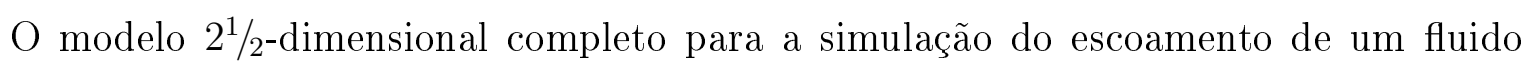
viscoso dentro da cavidade de um molde fino é formado por uma equação bidimensional para a pressão, uma equação tridimensional para a temperatura e uma estratégia para o avanço da superfície livre. Neste trabalho, um modelo bidimensional simplificado para o campo de temperatura é desenvolvido, e a estratégia numérica escolhida para a solução deste modelo segue os passos daquela apresentada na Seção 5.3, baseada em um esquema semi lagrangeano, é novamente apresentada.

A idéia básica do método semi lagrangeano é acompanhar uma partícula de fluido 
durante sua trajetória ao longo da malha definida sobre o escoamento (Phillips e Williams, 2001a,b, Xiu e Karniadakis, 2001). Para obter tal formulação, parte-se da equação tridimensional da temperatura (3.3) em termos da derivada material, e aplica-se a Definição 1, conforme o procedimento da Seção 5.3. O modelo resultante para a equação bidimensional da temperatura, escrita segundo o referencial semi lagrangeano, é dado por:

$$
\bar{T}(t+\delta t)=\bar{T}+\delta t\left[-\frac{6}{5}(\overline{\mathbf{v}} \cdot \nabla \bar{T})+\frac{1}{\rho c_{p}}\left(\frac{3}{5 h^{2}}\|\overline{\mathbf{v}}\|^{2}\left(2 \eta_{c}+3 \eta_{w}\right)-\frac{3 k}{h^{2}}\left(\bar{T}-T_{w}\right)\right)\right],
$$

onde $\overline{\mathbf{v}}$ é o valor médio da velocidade, cujas componentes são dadas pelas Equações (3.8) e (3.9), $\eta_{c}$ e $\eta_{w}$ são os valores da viscosidade na linha central e na parede da cavidade do molde, respectivamente; e $T_{w}$ é a temperatura da parede do molde.

Para a solução numérica da Equação (6.4), os termos provenientes da dissipação viscosa e da condução são tratados como termos fonte. Para a discretização do termo convectivo, é necessário o uso de interpolação linear para a temperatura dentro do triângulo em questão e os passos, análogos aos seguidos na Seção 5.2 para a aproximação do gradiente de pressão, são descritos a seguir.

Considerando o triângulo $i-j-j^{*}$ descrito na Figura 6.5 e sendo conhecidos os valores de $\bar{T}$ nos seus vértices, é possível escrever a temperatura dentro do triângulo por meio de interpolação linear:

$$
\bar{T}=A_{T} x+B_{T} y+C_{T}
$$

com $A_{T}, B_{T}$ e $C_{T}$ dados pelas expressões (5.23), (5.24), e (5.25).

Desta forma, é possível obter as derivadas parciais de $\bar{T}$ com relação a $x$ e $y$ fazendo:

$$
\frac{\partial \bar{T}}{\partial x}=A_{T} \quad \text { e } \quad \frac{\partial \bar{T}}{\partial y}=B_{T} .
$$

A escolha do valor da velocidade para efetuar o produto $\mathbf{v} \cdot \nabla \bar{T}$, para cada triângulo, é feita da seguinte maneira:

1. Para cada triângulo: calcula-se $\frac{\partial \bar{T}}{\partial x}$ e $\frac{\partial \bar{T}}{\partial y}$ segundo a Equação (6.6);

2. Para cada vértice do triângulo verifica-se se alguma partícula de fluido se originou deste elemento no tempo $t$ realizando os seguintes passos:

(a) Calcula-se o produto vetorial e o produto interno entre o vetor velocidade no triângulo e os vetores que compõem as arestas incidentes àquele vértice;

(b) Se esses dois produtos vetoriais tiverem sinais trocados, e se os dois produtos internos são negativos, então a partícula de fluido pertence àquele triângulo e portanto, realiza-se o produto $\mathbf{v} \cdot \nabla \bar{T}$ com esse valor da velocidade e armazena-se $\mathrm{o}$ resultado no vértice relativo à coordenada $\mathbf{x}$. 
Finalmente, a temperatura é avaliada no passo de tempo $n+1$ utilizando a seguinte estratégia: os termos referentes à convecção e à dissipação são avaliados no tempo $n$ e o termo referente à condução é avaliado no tempo $n+1$. A expressão resultante é dada por:

$$
\bar{T}^{n+1}=\frac{1}{1+\frac{3 k \delta t}{h^{2} \rho c_{p}}}\left(\bar{T}+\delta t\left[-\frac{6}{5}(\overline{\mathbf{v}} \cdot \nabla \bar{T})+\frac{3}{\rho c_{p} h^{2}}\left(\frac{1}{5}\|\overline{\mathbf{v}}\|^{2}\left(2 \eta_{c}+3 \eta_{w}\right)+k T_{w}\right)\right]\right) .
$$

onde os índices $n$ no lado direito da equação foram omitidos por simplicidade de notação.

É importante ressaltar que os triângulos utilizados para a aproximação da equação de transporte (6.7) são dinamicamente construídos segundo os passos descritos na Seção 6.2.

\subsection{Avanço da superfície livre usando VOF dinâmico}

Nesta seção, uma adaptação dinâmica da técnica VOF (Hirt e Nichols, 1981) é utilizada para a identificação e o avanço da superfície livre do fluido. Com esta finalidade, uma variável escalar $\phi$ é introduzida por meio de uma equação de transporte para governar o avanço do fluido adentro da cavidade do molde.

Nesse contexto, $\phi$ pode ser interpretada como um "fator de preenchimento", sendo igual a 1 nos pontos do conjunto de pontos cujos volumes de controles virtuais associados encontram-se completamente cheio de fluido e igual a 0 se o volume virtual associado ao ponto ainda encontra-se vazio. Valores intermediários de $\phi$ representam a superfície livre do fluido, pois os volumes correspondentes encontram-se parcialmente cheios de fluido (Hirt e Nichols, 1981, Shin e Lee, 2000).

O transporte de $\phi$ é modelado pela equação:

$$
\frac{\partial \phi h}{\partial t}+\nabla \cdot(\overline{\mathbf{v}} \phi h)=0
$$

onde $\overline{\mathbf{v}}$ é a velocidade média do fluido descrita pelas Equações (3.8) e (3.9) e $h$ é a espessura do molde.

Uma vez que a superfície livre está se movendo sobre o conjunto de pontos que definem o molde, uma abordagem local para atualizar a posição da frente de fluido envolve volumes de controle nesta região. Os volumes de controle utilizados para a aproximação da equação de transporte (6.8) são dinamicamente construídos somente para os pontos apresentando $0<\phi<1$, isto é, pontos que ainda serão preenchidos completamente.

Esta abordagem é apresentada na Figura 6.6: a Figura 6.6(a) mostra o conjunto de pontos representando o domínio computacional, a posição da superfície livre e um ponto $i$ localizado na superfície livre. A Figura 6.6(b) isola o disco de raio pré-determinado para o ponto $i$ definindo uma vizinhança e a Figura 6.6(c) ilustra um volume de controle dinamicamente criado para o ponto $i$.

Diversas abordagens têm sido usadas para discretizar a Equação (6.8). A abordagem 


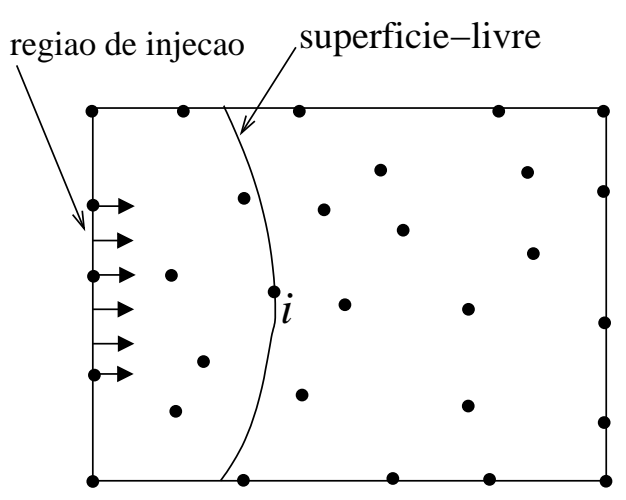

(a)

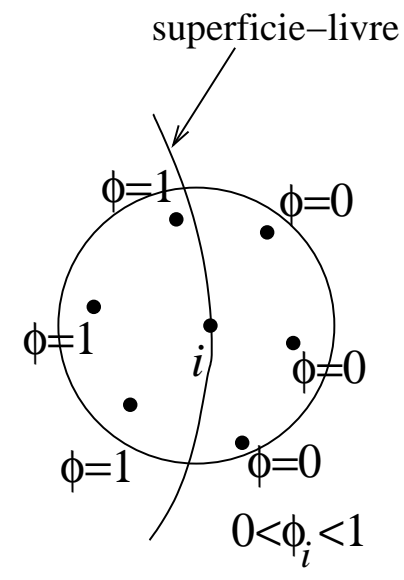

(b)

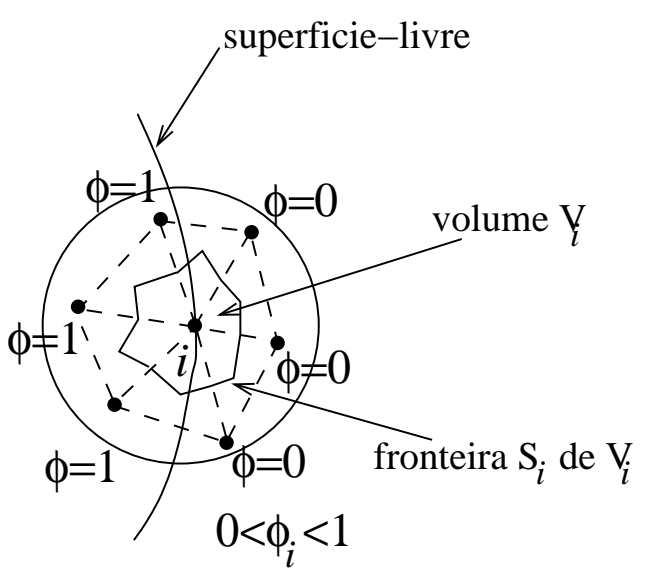

(c)

Figura 6.6: Determinação do volume local $V_{i}$ e fronteira $S_{i}$ associados ao ponto $i$ localizado na superfície livre do fluido. Somente pontos cheios de fluido, isto é, pontos apresentando $\phi=1$, são usados na aproximação da equação de transporte para $\phi$.

utilizada nesta seção considera a forma integral conservativa:

$$
\int_{V}\left(\frac{\partial \phi h}{\partial t}+\nabla \cdot(\overline{\mathbf{v}} \phi h)\right) d V=0
$$

Aplicando o teorema de Gauss, tem-se:

$$
\frac{\partial}{\partial t} \int_{V} \phi h d V+\int_{S} \phi h \overline{\mathbf{v}} \cdot \mathbf{n} d S=0
$$

onde $S$ é a fronteira de um volume arbitrário $V$ e $\mathbf{n}$ é um vetor unitário normal a $S$.

Agora, considere um volume finito virtual parcialmente cheio $V_{i}$ associado com o ponto $i$, isto é, $0<\phi_{i}<1$. Seja $j$ denotando os vizinhos adjacentes a $i$; e por simplicidade de notação, seja $j^{*}=(j+1) \bmod N$, onde $N$ é a quantidade de vizinhos do ponto $i$. Por exemplo, na Figura $6.5, N=9$ e os pontos $j=1, \ldots, N$ estão associados ao ponto $i$. Para o volume finito $V_{i}$, a Equação (6.9) se torna:

$$
\frac{\partial}{\partial t} \int_{V_{i}} \phi h d V=-\int_{S_{i}} \phi h \overline{\mathbf{v}} \cdot \mathbf{n} d S .
$$


Uma vez que ambos $\phi$ e $h$ são tomados como constantes dentro do volume $V_{i}$, o lado esquerdo da Equação (6.10) é simplificado, resultando em:

$$
h_{i} V_{i} \frac{\partial \phi_{i}}{\partial t}=-\int_{S_{i}} \phi h \overline{\mathbf{v}} \cdot \mathbf{n} d S,
$$

onde as contribuições da integral de superfície estão associadas a vizinhos cheios. Por exemplo, as integrais de superfície ao longo dos segmentos $a 0$ e $0 c$ entre os vizinhos $j$ e $j^{*}$ do ponto $i$ na Figura 6.5 são dadas por:

$$
\begin{gathered}
\int_{a}^{0} \phi h \overline{\mathbf{v}} \cdot \mathbf{n} d S=\Phi_{j} h_{j} \bar{v}_{x}\left(y_{0}-y_{a}\right)+\Phi_{j} h_{j} \bar{v}_{y}\left(x_{a}-x_{0}\right), \\
\int_{0}^{c} \phi h \overline{\mathbf{v}} \cdot \mathbf{n} d S=\Phi_{j^{*}} h_{j^{*}} \bar{v}_{x}\left(y_{c}-y_{0}\right)+\Phi_{j^{*}} h_{j^{*}} \bar{v}_{y}\left(x_{0}-x_{c}\right),
\end{gathered}
$$

onde $\Phi_{j}$ é o valor médio de $\phi_{j}$ na interface $a 0$. Assumindo que o fator de preenchimento na frente da superfície é íngreme e paralelo a $a 0, \Phi_{j}=1$ se $\phi_{j}=1$ e $\Phi_{j}=0$ se $\phi_{j} \neq 1$. Analogamente, considerando que o fator de preenchimento é íngreme e paralelo a $0 c$, tem-se neste segmento que $\Phi_{j}=1$ se $\phi_{j}=1$ e $\Phi_{j}=0$ caso contrário.

Lembrando que o ponto 0 é o centróide do triângulo $i$ - $j$ - $j^{*}$, as Equações (6.12) e (6.13) podem ser rearranjadas de maneira que o lado direito da Equação (6.11), restrita ao triângulo $i-j-j^{*}$, seja reduzido a:

$$
\int_{S_{i}} \phi h \overline{\mathbf{v}} \cdot \mathbf{n} d S=\left(E_{i j^{*} j} \Phi_{j}+E_{i j j^{*}} \Phi_{j^{*}}\right)
$$

onde $E_{i j^{*} j}$ e $E_{i j j^{*}}$ dependem das coordenadas dos pontos e das velocidades médias associadas correspondentes:

$$
\begin{aligned}
& E_{i j^{*} j}=-\frac{h_{j}}{6}\left[\bar{v}_{x}\left(y_{i}-2 y_{j^{*}}+y_{j}\right)-\bar{v}_{y}\left(x_{i}-2 x_{j^{*}}+x_{j}\right)\right] \\
& E_{i j j^{*}}=\frac{h_{j^{*}}}{6}\left[\bar{v}_{x}\left(y_{i}-2 y_{j}+y_{j^{*}}\right)-\bar{v}_{y}\left(x_{i}-2 x_{j}+x_{j^{*}}\right)\right] .
\end{aligned}
$$

As Equações (6.12) e (6.13), e correspondentes coeficientes $E$, devem ser calculadas para todos os triângulos na estrela do ponto $i$. Em outras palavras, todo vizinho $j$ do ponto $i$ cujo $\Phi_{j}=1$ contribui para o aumento do fator de preenchimento do ponto $i$. A Equação (6.11) fica:

$$
\frac{\partial \phi_{i}}{\partial t}=-\frac{1}{h_{i} V_{i}} \sum_{j=1}^{N}\left(E_{i j^{*} j} \Phi_{j}+E_{i j j^{*}} \Phi_{j^{*}}\right) .
$$

Introduzindo um esquema do tipo Euler explícito com incremento temporal $\delta t$, a fórmula para a atualização de $\phi$ durante o preenchimento do molde é dada por:

$$
\phi_{i}^{n+1}=\phi_{i}^{n}-\frac{\delta t}{h_{i} V_{i}} \sum_{j=1}^{N}\left(E_{i j^{*} j} \Phi_{j}+E_{i j j^{*}} \Phi_{j^{*}}\right) .
$$


Os resultados do cálculo acima podem ser usados para determinar o passo no tempo necessário para preencher o volume de controle associado com cada ponto $i$ que apresenta $0 \leq \phi_{i}<1$ :

$$
\left.\delta t_{\text {preench }}\right|_{i}=-\frac{\left(1-\phi_{i}^{n}\right) h_{i} V_{i}}{\sum_{j=1}^{N}\left(E_{i j^{*} j} \Phi_{j}+E_{i j j^{*}} \Phi_{j^{*}}\right)} .
$$

Escolhendo $\delta t$ como sendo o menor valor de $\left.\delta t_{\text {preench }}\right|_{i}$ fornece o passo no tempo com o qual apenas um volume de controle é preenchido, ao mesmo tempo que nenhum volume de controle é preenchido excessivamente. O incremento temporal $\delta t$ é calculado a cada passo de tempo da simulação por causa da mudança do fator de preenchimento de cada volume de controle e também porque volumes de controle apresentam tamanhos diferentes (Estacio e Mangiavacchi, 2007). Esta estratégia resulta em um esquema com difusão numérica controlada quando comparada com outras abordagens VOF (Hirt e Nichols, 1981), e é utilizada para o avanço da superfície livre deste trabalho.

\subsection{Algoritmo}

O Algoritmo 4 apresentado a seguir calcula a solução do modelo matemático para a fase de preenchimento do processo de moldagem por injeção, fornecendo uma aproximação para o campo de pressão, o campo de velocidades, o de temperatura bidimensional e o avanço da superfície livre do fluido conforme o preenchimento é realizado, utilizando a estratégia de desacoplamento descrita no Capítulo 3 e as abordagens dinâmicas dos métodos CVFEM, semi lagrangeano e VOF descritas no início deste capítulo. Os principais passos do algoritmo são identificados linha a linha e sua ação é descrita em seguida.

Na linha 2, a estratégia de injeção de fluido é escolhida: pressão ou velocidade prescrita. Na linha 4, um raio é associado a cada ponto $i$ na discretização, definindo os vizinhos de $i$. A linha 6 define o bloco de repetição responsável pelo avanço temporal da simulação: como a abordagem proposta utiliza o método VOF com uma restrição no passo de tempo de modo que apenas um volume associado a um ponto do domínio seja preenchido a cada passo no tempo, o bloco de repetição é realizado enquanto houver pelo menos um ponto $j$ tendo $\phi_{j}<1$. A linha 7 atualiza o subconjunto de pontos ativos conforme a superfície livre do escoamento se move: pontos inativos são ou vazios de fluido ou pontos da região de injeção no caso do preenchimento utilizando pressão prescrita, e não participam dos cálculos. A linha 10 ilustra o bloco de repetição para a convergência da pressão utilizando o método das aproximações sucessivas. A linha 11 realiza a montagem do sistema linear para a equação de Hele-Shaw utilizando as equações (6.2) e (6.3) e é apresentado em detalhes no Algoritmo 5. As linhas 13-15 chamam os procedimentos para calcular, respectivamente, as velocidades médias, segundo as Equações (3.8) e (3.9), a viscosidade do fluido de acordo com a descrição apresentada na Seção 6.3.1 e utilizando um dos modelos apresentados na Seção 2.9, e a fluidez, por meio de integração numérica ao longo da espessura do molde, cuja aproximação também está descrita na Seção 6.3.1. Na 


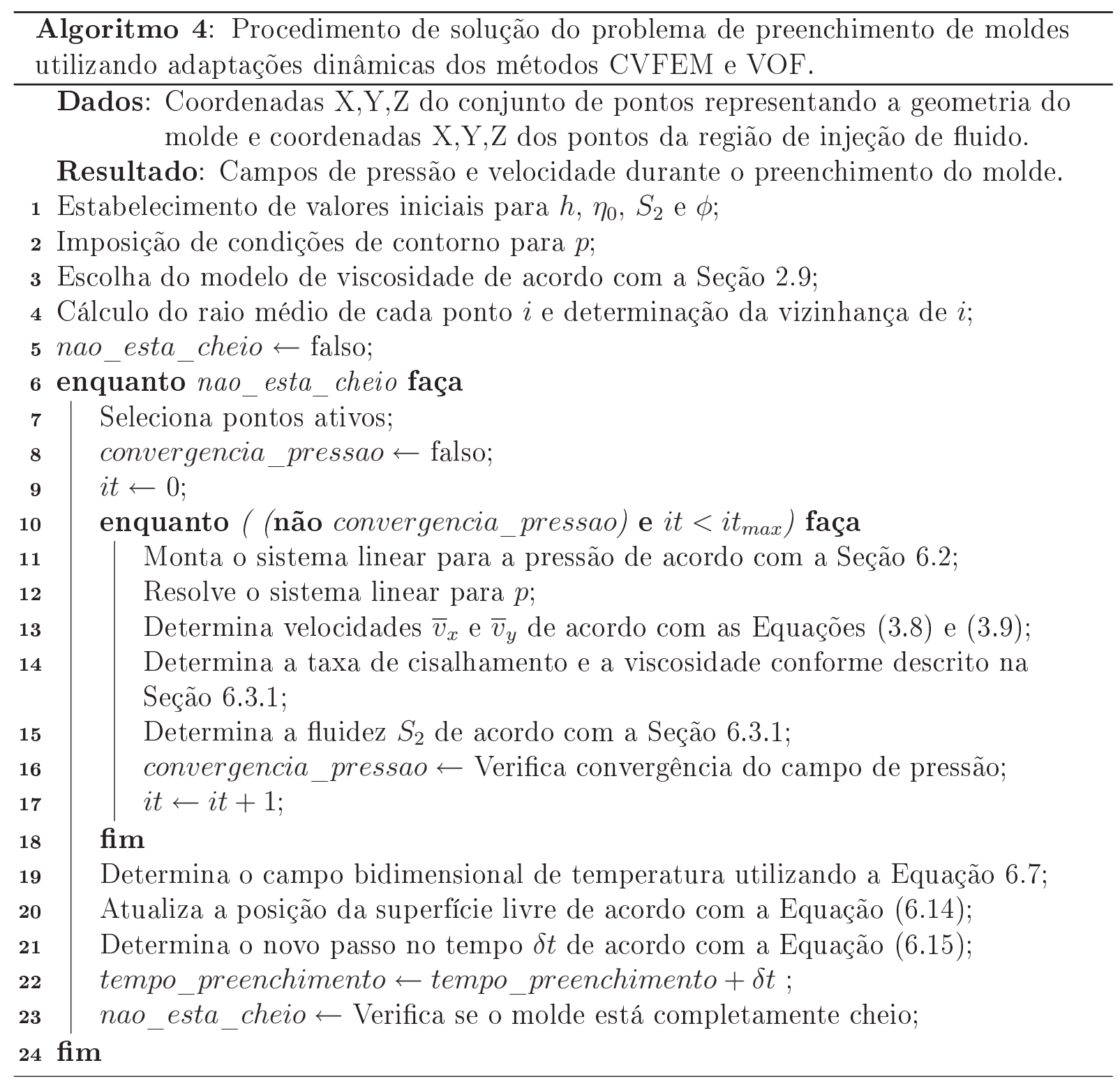

linha 19, o algoritmo realiza o cálculo do campo bidimensional de temperatura de acordo os passos descritos na Seção 6.4. Finalmente, a linha 20 é responsável pela utilização do método VOF dinâmico descrito na Seção 6.5 para o avanço da superfície livre e cálculo do novo passo no tempo (linha 21).

No Algoritmo 5, o bloco de repetição definido na linha 1 é responsável pela montagem (assemble) da matriz $A$ para todos os pontos usados na discretização. Esta matriz é usada para formar uma sub-matriz, $K$, contendo apenas as contribuições dos pontos ativos. A linha 2 seleciona os vizinhos $j$ do ponto $i$ para construir dinamicamente os volumes finitos locais. Os vizinhos de $i$ são ordenados de acordo com o ângulo formando pelo ponto $j$ ao ponto $i$ e um vetor de referência $t$, como descrito na linha 8. Depois que os ângulos são ordenados, um novo vetor $n b \_s$ é criado para armazenar a ordem dos vizinhos de $i$ de acordo com estes ângulos e é usado para compor o volume finito no qual o CVFEM é aplicado. O bloco de repetição definido na linha 9 é responsável pela aplicação do 


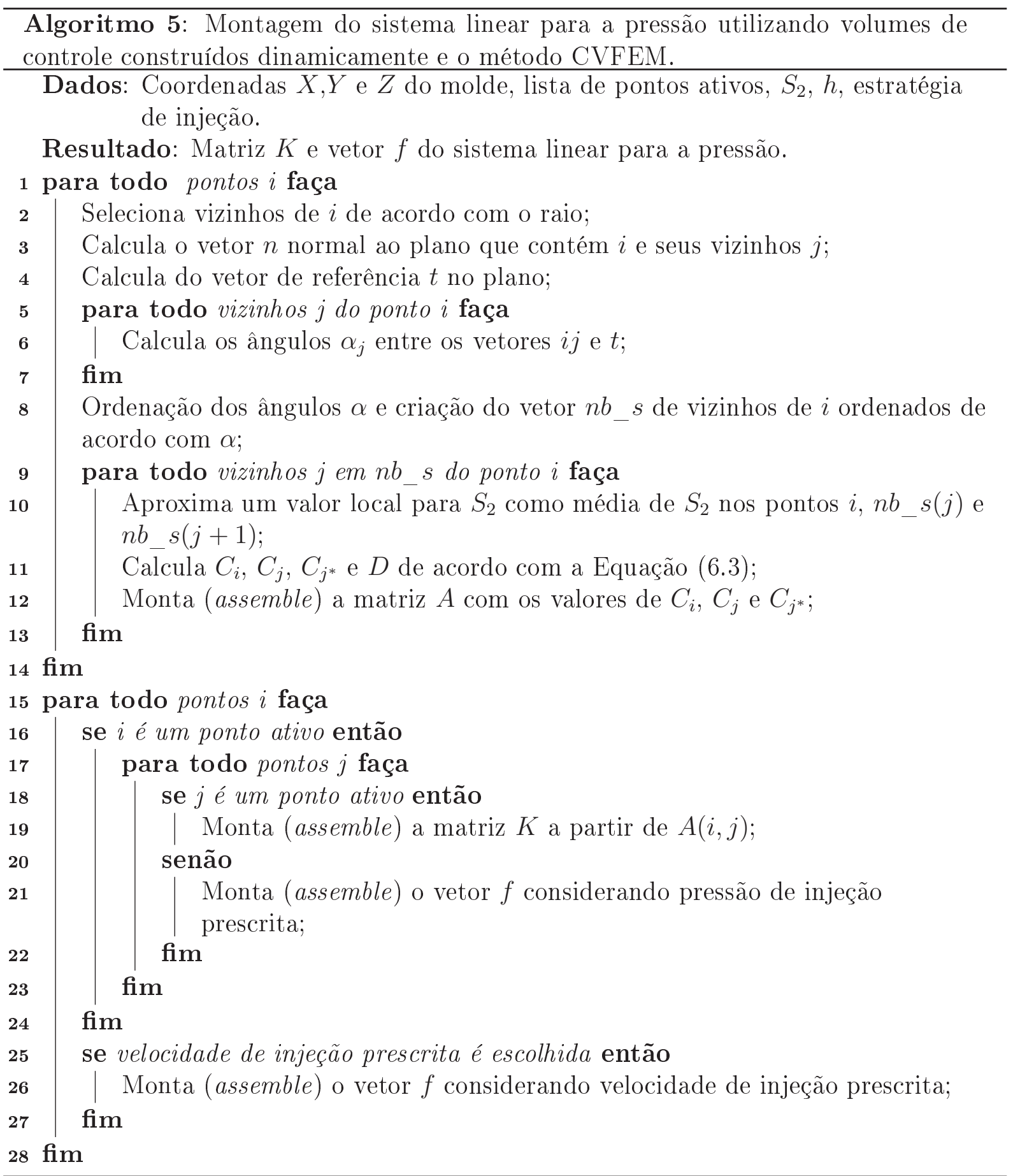

CVFEM de acordo com as Equações (6.2) e (6.3). A segunda parte do algoritmo lida com a montagem da matriz e do vetor considerando apenas os pontos ativos. Na linha 19 a submatriz $K$ é formada considerando somente as contribuições dos pontos ativos a partir da matriz geral $A$; na linha 21 , o vetor $f$ é montado para o caso de pressão de injeção prescrita. Finalmente, a linha 25 monta o vetor $f$ no caso de velocidade prescrita. 


\subsection{Verificações do método proposto}

Os resultados das simulações para vários problemas testes são apresentados considerando escoamento isotérmico e não-isotérmico de fluidos newtonianos e não newtonianos em distintas condições de escoamento e geometrias de molde.

Observação: O conjunto de pontos utilizados neste trabalho apresenta uma distribuição de pontos relativamente eqüidistante: os pontos são vértices de uma malha triangular gerada pelo Easymesh (Niceno, 2001). Entretanto, durante a simulação, somente as coordenadas dos vértices dos triângulos são consideradas. Nenhuma informação da malha, ou equivalentemente, informação sobre a conectividade entre os vértices dos triângulos, arestas ou faces, é empregada no presente trabalho. A informação da malha é estritamente utilizada durante o pós-processamento para propósito de visualização dos resultados alcançados.

\subsubsection{Comparação do tempo de preenchimento}

O tempo necessário para o preenchimento de um molde de volume $V$ a uma dada velocidade de injeção fixa $v_{\text {inj }}$ pode ser calculado por meio de conservação de massa da seguinte maneira:

$$
t=\frac{V}{A v_{\text {inj }}},
$$

onde $A$ é a área da região de injeção de fluido. Esta fórmula fornece uma ferramenta para testar o algoritmo responsável por atualizar a posição da frente de fluido e também para avaliar a preservação de massa do esquema, de maneira mais geral. Outros tipos de verificações são necessários e serão realizados nas seções subseqüentes.

O tempo exato de preenchimento do molde de geometria quadrangular bastante simples, ilustrado na Figura 6.7, com velocidade prescrita na região de injeção $v_{\text {inj }}=10^{-1} \mathrm{~m} / \mathrm{s}$ é comparado com os resultados fornecidos pelas simulações considerando quatro conjuntos distintos de pontos definindo a geometria e o interior do molde, contendo, respectivamente, 100, 400, 800 e 1600 pontos.

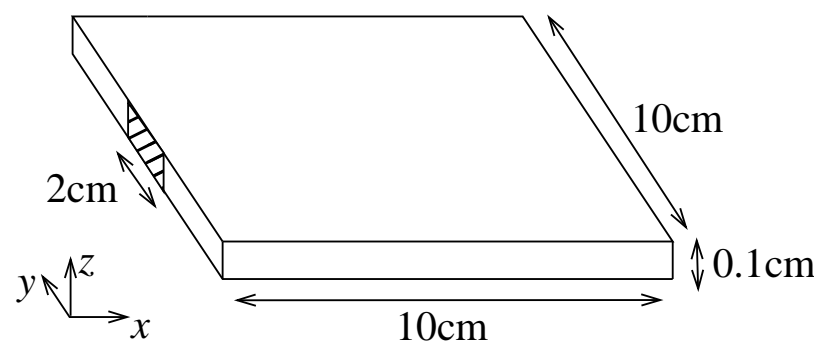

Figura 6.7: Dimensões do molde e região de injeção de fluido (área hachurada).

A diferença entre o tempo exato necessário para o preenchimento do molde e os tempos de preenchimento fornecidos pela simulação para cada um dos conjuntos de pontos é o erro cometido em cada caso. Uma medida deste erro pode ser comparada de maneira a 
estimar a taxa de decaimento do erro cometido nas simulações. Em escala logarítmica, a inclinação da reta do erro cometido como função da quantidade de pontos utilizada na discretização é análoga à taxa de convergência do método numérico (Roy, 2005). Assim, a ordem de convergência $q$ do método numérico apresentado é dada por:

$$
q=\frac{\log \left(\frac{L_{k+1}}{L_{k}}\right)}{\log \left(\frac{h_{k+1}}{h_{k}}\right)},
$$

onde $L_{k}$ refere-se ao erro cometido no conjunto com maior quantidade de pontos (refinado) e $L_{k+1}$ no conjunto com menor quantidade de pontos. Similarmente, $h_{k}$ e $h_{k+1}$ são diâmetros médios locais calculados nos respectivos conjuntos de pontos. O diâmetro médio local de um conjunto de $N$ pontos relativamente bem distribuídos em um domínio $\Omega$ de comprimento característico $l$ é definido por:

$$
h=\frac{l}{\sqrt{N}} .
$$

Neste caso teste, o tempo exato para o total preenchimento do molde é 5 segundos, enquanto o método proposto fornece 4,92, 4,96, 4,97 e 4,98 s considerando conjuntos de 100, 400, 800 e 1600 pontos, respectivamente. A medida do erro cometido pelo método proposto é analisada considerando o erro relativo cometido entre a solução exata e a numérica. De modo a calcular os diâmetros locais para cada um dos conjuntos de pontos, o comprimento característico do molde é escolhido como sendo $l=10^{-1} \mathrm{~m}$. A Tabela 6.1 apresenta os dados empregados na análise e o erro relativo encontrado em cada caso.

Tabela 6.1: Dados empregados no estudo da convergência do método e erro relativo cometido na aproximação (\%).

\begin{tabular}{cccc}
\hline \hline Pontos & $h(m)$ & Tempo $(s)$ & Erro Relativo $(\%)$ \\
\hline 100 & $1 \times 10^{-2}$ & 4,921433 & 1,572 \\
400 & $5 \times 10^{-3}$ & 4,965268 & 0,694 \\
800 & $3,5 \times 10^{-3}$ & 4,976287 & 0,474 \\
1600 & $2,5 \times 10^{-3}$ & 4,986197 & 0,276 \\
\hline
\end{tabular}

A Figura 6.8 ilustra que a ordem de convergência do método é aproximadamente linear. Os valores obtidos considerando os conjuntos de pontos citados são apresentados na Figura 6.9.

\subsubsection{Escoamento em um canal retangular}

Condições de contorno típicas para o problema isotérmico de Hele-Shaw são pressão ou velocidade de injeção prescrita. Como resultado do preenchimento do molde com velocidade de injeção prescrita, é esperado um aumento da pressão na região de injeção de fluido conforme o molde vai sendo preenchido. Além disso, ao longo do escoamento, 


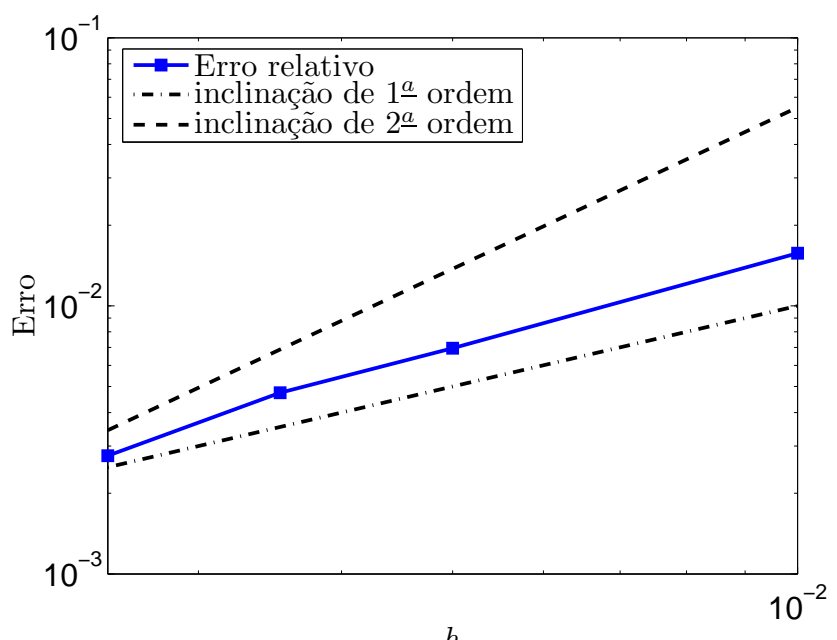

Figura 6.8: Erro relativo cometido pelo método proposto ao predizer o tempo de preenchimento do molde descrito na Figura 6.7.

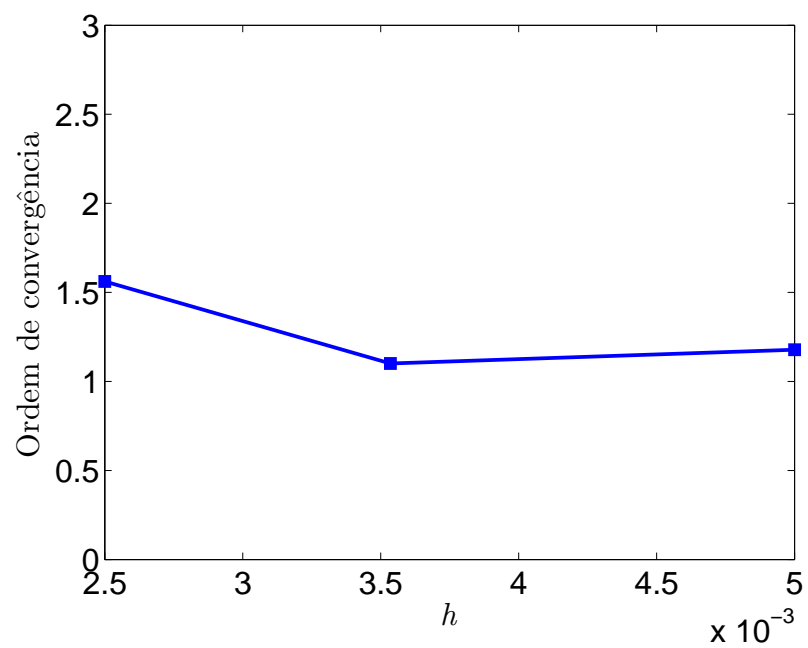

Figura 6.9: Ordem de convergência do método proposto. Valores ilustram que a ordem de convergência é aproximadamente linear.

espera-se que o fluido esfrie gradativamente. Nessa seção, a performance do método proposto é investigada tanto com relação à pressão resultante na região de injeção, quando o molde está parcialmente cheio, quanto com relação à distribuição de temperatura, ao final do preenchimento do molde.

Em ambos os casos, a estratégia de injeção de fluido é tomada como sendo velocidade horizontal prescrita $v_{\text {inj }}$ e a geometria do molde é descrita na Figura 6.10.

\subsubsection{Pressão de injeção}

Nesta seção, a pressão resultante na região de injeção de fluido, quando o molde encontra-se parcialmente cheio, é comparada com uma solução analítica obtida sob as mesmas condições de escoamento. O conjunto de pontos representando a geometria do molde (fronteira e interior) contém 498 pontos. Como as dimensões do molde não variam na direção- $x$, e as condições de contorno nas paredes finas do molde são de escorregamento 


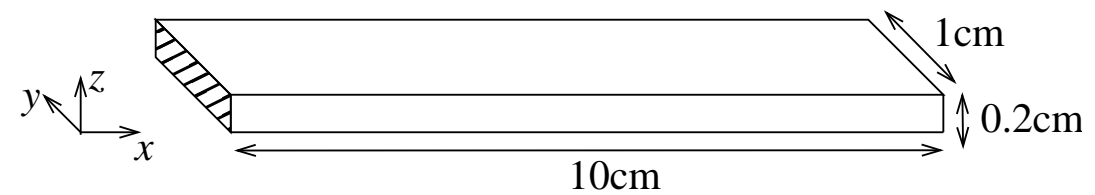

Figura 6.10: Dimensões do molde em formato de canal e região de injeção de fluido (área hachurada).

(slip) tem-se:

$$
\frac{\partial \bar{v}_{x}}{\partial y}=0 \quad \text { e } \quad \bar{v}_{y}=0
$$

e a solução para este problema é simplesmente:

$$
\bar{v}_{x}=v_{\text {inj }} \quad \text { e } \quad \bar{v}_{y}=0
$$

para todo o canal, sendo que a frente de fluido avança como um plano perpendicular ao eixo- $x$, movendo com velocidade $v_{\text {inj }}$. A distribuição de pressão no canal é obtida por meio das Equações (3.8) e (3.9), resultando em:

$$
\frac{\partial p}{\partial x}=-\frac{h}{S_{2}} v_{\text {inj }} \quad \text { e } \quad \frac{\partial p}{\partial y}=0,
$$

onde as expressões para as velocidades $\bar{v}_{x}$ e $\bar{v}_{y}$ da Equação (6.19) foram aplicadas. Desta forma a distribuição de pressão é dada por:

$$
p=p_{\text {inj }}-\frac{h}{S_{2}} v_{\text {inj }} x
$$

Lembrando que na superfície livre $x=\delta l$ e $p=p_{0}$, onde $\delta l$ é o deslocamento da superfície livre e $p_{0}$ é a pressão atmosférica, obtém-se:

$$
p_{\mathrm{inj}}=p_{0}+v_{\mathrm{inj}} \delta l \frac{h}{S_{2}} .
$$

A Equação (6.20) é uma expressão analítica para a distribuição de pressão dentro do molde e permite a verificação da confiabilidade dos resultados fornecidos pelo método proposto. Diversos testes são conduzidos considerando distintos modelos de viscosidade e diferentes valores de velocidade de injeção de maneira que o resultado alcançado pelo método para a pressão na região de injeção seja comparada com os valores fornecidos pela expressão analítica quando o molde encontra-se cheio pela metade, isto é, quando $\delta l=5 \times 10^{-2} \mathrm{~m}$.

No caso de fluidos newtonianos, a fluidez $S_{2}$ é constante e a pressão na região de injeção é calculada diretamente. Contudo, neste caso teste, considera-se o molde sendo preenchido também por poliestireno, cujo comportamento da viscosidade é reproduzido pelos modelos de viscosidade newtoniana generalizada e parâmetros descritos na Seção 2.9. Para os modelos de Carreau e de Cross, um método de solução de equações não-lineares é 
usado para calcular a taxa de cisalhamento e a viscosidade em cada uma das $N_{z}$ camadas que descrevem a direção transversal do molde, e o cálculo da fluidez é realizado em seguida, por integração numérica, conforme descrito na Seção 6.3.1.

Nas simulações apresentadas, quatro valores diferentes da taxa de cisalhamento média, $\dot{\gamma}_{\text {med }}=\frac{v_{\text {inj }}}{h}$, são considerados para cada modelo de viscosidade. Além disso, a integração numérica de $S_{2}$ é realizada considerando-se duas quantidades diferentes de camadas, $N_{z}$, de modo que o erro de discretização associado à integração numérica possa ser investigado e controlado.

Tabela 6.2: Pressão semi-analítica (em $\mathrm{Pa}$ ) na região de injeção do canal para vários modelos de viscosidades considerando quatro valores representativos da taxa de cisalhamento média do fluido $\dot{\gamma}_{\text {med }}$ Valores encontrados considerando o molde da Figura 6.10 preenchido pela metade e $N_{z}=1000$.

\begin{tabular}{ccccc}
\hline \hline Modelo & $10^{2}$ & $10^{0}$ & $10^{-2}$ & $10^{-4}$ \\
\hline Carreau & $1,1518 \times 10^{8}$ & $1,8252 \times 10^{7}$ & $2,3714 \times 10^{6}$ & $2,9999 \times 10^{4}$ \\
Cross & $6,4741 \times 10^{7}$ & $1,6613 \times 10^{7}$ & $1,8592 \times 10^{6}$ & $2,9343 \times 10^{4}$ \\
Ellis & $6,5470 \times 10^{7}$ & $1,5284 \times 10^{7}$ & $2,3185 \times 10^{6}$ & $2,9999 \times 10^{4}$ \\
Power-law & $9,5314 \times 10^{7}$ & $1,5815 \times 10^{7}$ & $2,6252 \times 10^{6}$ & $4,3567 \times 10^{5}$ \\
newtoniano & $3 \times 10^{10}$ & $3 \times 10^{8}$ & $3 \times 10^{6}$ & $3 \times 10^{4}$ \\
\hline
\end{tabular}

A Tabela 6.2 apresenta a solução semi-analítica para a pressão na região de injeção ao considerar cada um dos modelos de viscosidade usando quatro diferentes valores da taxa de cisalhamento, quando o molde está cheio pela metade. Para a solução semi-analítica, a viscosidade e a fluidez são aproximadas numericamente ao longo da direção transversal do molde considerando $N_{z}=1000$ camadas. A Tabela 6.3 ilustra o erro relativo cometido pelo método, para cada modelo de viscosidade a tais taxas de cisalhamento, considerando 5 e 100 camadas, respectivamente, na discretização da direção transversal do molde.

Pode-se observar que o erro cometido é menor considerando $N_{z}=100$ camadas e é associado principalmente à discretização espacial. Por outro lado, o erro cometido considerando $N_{z}=5$ inclui ambos os erros devidos à discretização espacial e à integração numérica. Entretanto, o tempo médio de processamento é pelo menos oito vezes menor quando $N_{z}=5$ do que quando $N_{z}=100$, para todos os modelos de viscosidade, com exceção do modelo newtoniano.

Perfis de velocidade para o caso de poliestireno fundido são ilustrados na Figura 6.11 em dois casos extremos da taxa de cisalhamento média descrita anteriormente. Para $\dot{\gamma}_{\text {med }}=10^{-4}$, a viscosidade se torna independente da taxa de cisalhamento, e os modelos de Carreau, Cross e Ellis exibem um comportamento newtoniano. Conseqüentemente, os perfis de velocidade destes modelos igualam-se à velocidade no caso newtoniano, e por isso não podem ser notados claramente na Figura 6.11a. O modelo de Power-law não prevê o comportamento newtoniano para baixos valores de taxa de cisalhamento e apresenta um 
Tabela 6.3: Erro relativo (em \%) na estimativa do valor da pressão na região de injeção considerando quatro valores distintos da taxa de cisalhamento média $\dot{\gamma}_{\text {med }}=\frac{v_{\text {inj }}}{h}$. A integração numérica de $S_{2}$ é realizada considerando 5 e 100 camadas na direção transversal do molde.

\begin{tabular}{cccccc}
\hline \hline Modelo & $N_{z}$ & $10^{2}$ & $10^{0}$ & $10^{-2}$ & $10^{-4}$ \\
\hline \multirow{2}{*}{ Carreau } & 5 & 1,7277 & 1,9614 & 3,0573 & 3,0068 \\
& 100 & 1,3891 & 1,1615 & 0,1180 & 0 \\
Cross & 5 & 2,1717 & 2,3114 & 2,7593 & 2,9990 \\
& 100 & 1,2697 & 1,0474 & 0,2743 & 0,0238 \\
Ellis & 5 & 2,0269 & 2,2115 & 3,0149 & 3,0068 \\
& 100 & 1,2800 & 1,0861 & 0,1293 & 0 \\
Power-law & 5 & 1,7553 & 1,7325 & 1,7713 & 1,9235 \\
& 100 & 1,3943 & 1,4164 & 1,3789 & 1,2188 \\
newtoniano & 5 & 3,0067 & 3,0067 & 3,0067 & 3,0067 \\
& 100 & 0,0033 & 0,0033 & 0,0033 & 0,0033 \\
\hline
\end{tabular}

perfil de velocidade mais achatado na região central.

Valores crescentes de taxas de cisalhamento conduzem à região de transição dos modelos de viscosidade para a região conhecida como assíntota "power-law" fazendo com que os perfis de velocidade fornecidos pelos modelos de Cross, Carreau e Ellis se achatem no centro, tornando-se similares ao perfil fornecido pelo modelo de Power-law, o que é facilmente observado quando $\dot{\gamma}_{\text {med }}=10^{2}$.

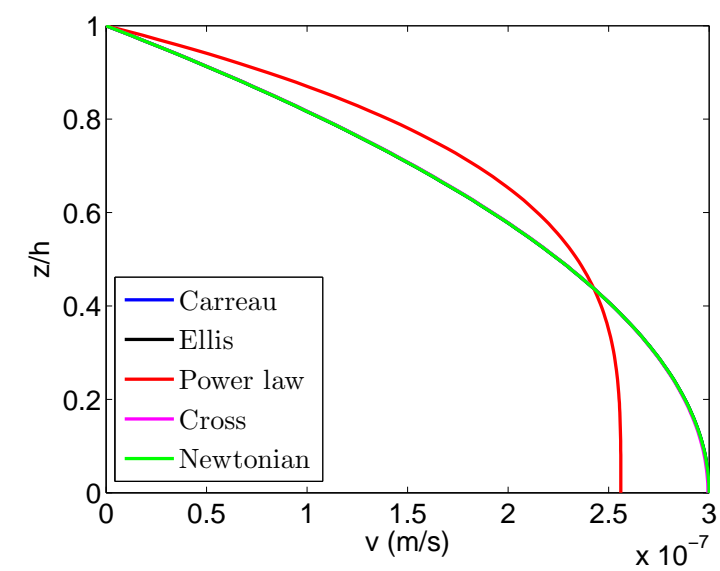

(a) $\dot{\gamma}_{\text {med }}=10^{-4}$

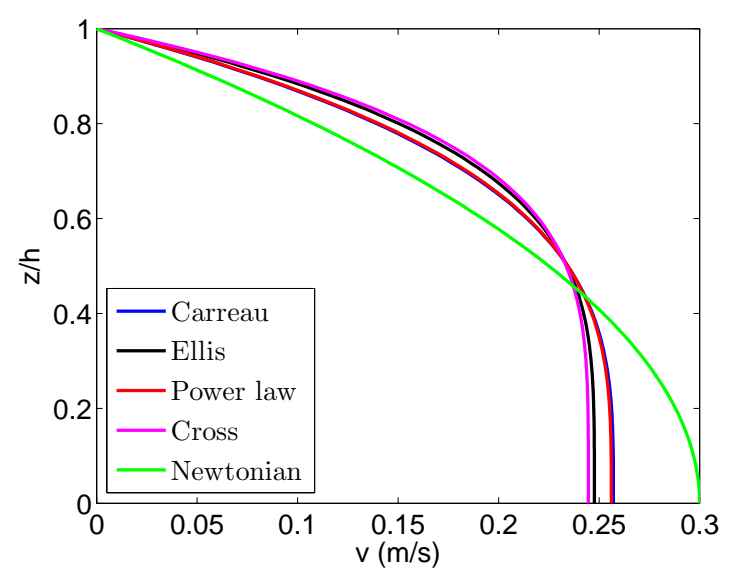

(b) $\dot{\gamma}_{\text {med }}=10^{2}$

Figura 6.11: Perfis de velocidade preditos para poliestireno usando vários modelos de viscosidade generalizada a dois valores médios da taxa de cisalhamento $\dot{\gamma}_{\text {med }}$.

O comportamento correspondente para a viscosidade é ilustrado na Figura 6.12: a baixas taxas de cisalhamento, os modelos de viscosidade generalizada, com exceção do modelo Power-law, exibem viscosidade newtoniana, enquanto a altas taxas de cisalhamento, os modelos tendem a representar o comportamento Power-law. 


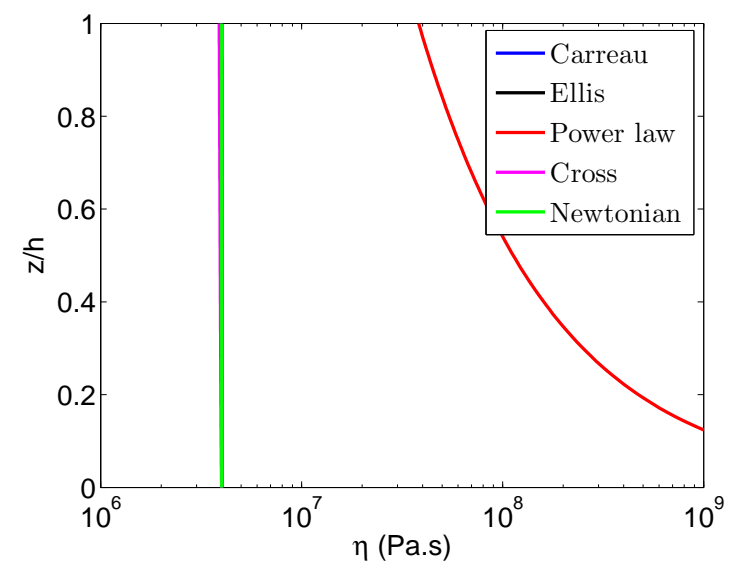

(a) $\dot{\gamma}_{\text {med }}=10^{-4}$

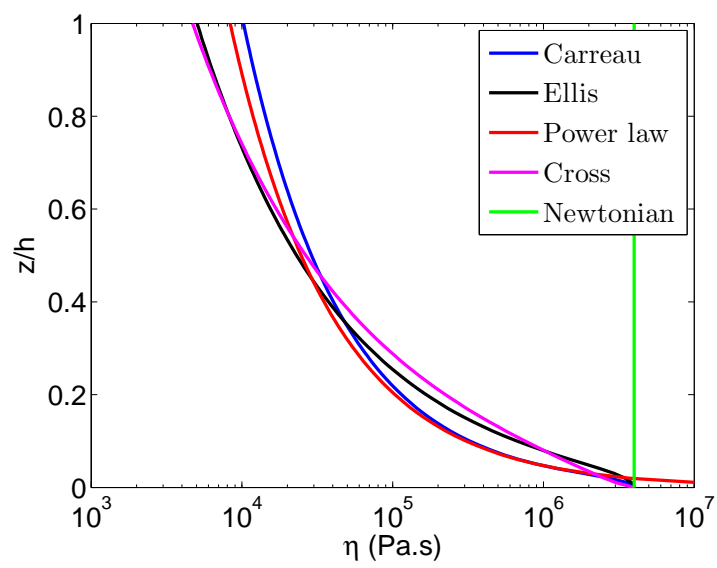

(b) $\dot{\gamma}_{\text {med }}=10^{2}$

Figura 6.12: Perfis de viscosidade preditos pelos modelos generalizados de viscosidade para o caso de poliestireno a dois valores médios da taxa de cisalhamento $\dot{\gamma}_{\text {med }}$.

\subsubsection{Distribuição de temperatura}

Este segundo teste é realizado de modo a investigar a confiabilidade dos resultados fornecidos pelo presente método durante o preenchimento do molde com relação à aproximação do campo de temperatura bidimensional. Neste caso, os resultados fornecidos pelo método, utilizando quatro conjunto de pontos distintos (100, 200, 400 e 800 pontos) representando a fronteira e o interior do molde, serão comparados com uma solução analítica.

Para construir uma expressão para a solução analítica para a distribuição bidimensional de temperatura no molde em questão, uma formulação euleriana é considerada. Além disso, o fluido é injetado adentro da cavidade do molde com velocidade de injeção prescrita $v_{\text {inj }}=1 \times 10^{-2} \mathrm{~m} / \mathrm{s}$, a uma temperatura de $T_{\text {inj }}=513 \mathrm{~K}$, enquanto a temperatura do molde é constante e igual a $T_{w}=313 \mathrm{~K}$. O fluido é considerado newtoniano com viscosidade $\eta_{0}=4 \times 10^{6} \mathrm{Pas}$, densidade $\rho=1000 \mathrm{~kg} / \mathrm{m}^{3}$, condutividade térmica $k=0,18 \mathrm{~W} / \mathrm{mK}$ e calor específico $c_{p}=2100 \mathrm{~J} / \mathrm{kg} \mathrm{K}$. O

Desta forma, a temperatura $\bar{T}(\mathbf{x}, t)$, onde $\mathbf{x}=(x, y)$, pode ser escrita como $\bar{T}(\xi, t)$, $\operatorname{com} \mathbf{x}=\mathbf{x}(\xi)$. O vetor posição $\mathbf{x}(\xi)$ é dado por:

$$
\mathbf{x}(\xi)=\xi+v_{\text {inj }} t
$$

onde $v_{\text {inj }}$ é a velocidade de injeção do fluido e $t$ é o tempo.

A Equação (3.3), para os valores de $\bar{T}$, dada por:

$$
\frac{D \bar{T}}{D t}=\frac{1}{\rho c_{p}}\left(\frac{3}{5 h^{2}}\|\overline{\mathbf{v}}\|^{2}\left(2 \eta_{c}+3 \eta_{w}\right)+\frac{3 k}{h^{2}}\left(\bar{T}-T_{w}\right)\right),
$$


pode ser reescrita considerando $\xi$ e viscosidade constantes como:

$$
\left.\frac{d \bar{T}}{d t}\right|_{\xi \text { constante }}=\frac{1}{\rho c_{p}}\left(\frac{3 \eta_{0}}{h^{2}}\|\overline{\mathbf{v}}\|^{2}+\frac{3 k}{h^{2}}\left(\bar{T}-T_{w}\right)\right) .
$$

Considerando $\bar{v}_{y}=0$ na Equação (6.23), obtém-se:

$$
\left.\frac{d \bar{T}}{d t}\right|_{\xi \text { constante }}=\frac{1}{\rho c_{p}}\left(\frac{3 \eta_{0}}{h^{2}} \bar{v}_{x}^{2}+\frac{3 k}{h^{2}} T_{w}\right)+\frac{3 k}{h^{2} \rho c_{p}} \bar{T}=c_{0}+c_{1} \bar{T},
$$

que é uma equação diferencial ordinária da forma:

$$
\bar{T}^{\prime}-c_{1} \bar{T}-c_{0}=0
$$

e admite solução analítica, dada por (Boyce e DiPrima, 1969):

$$
\bar{T}=\mathrm{e}^{-c_{1} x} \int^{x} \mathrm{e}^{c_{1} t} d t+c \mathrm{e}^{-c_{1} x}=\frac{c_{0}}{c_{1}}+c \mathrm{e}^{-c_{1} x}
$$

Lembrando que em $x=0$, tem-se $\bar{T}=T_{\text {inj }}$, então a Equação (6.26) é escrita como:

$$
\bar{T}=\frac{c_{0}}{c_{1}}+T_{\text {inj }} \mathrm{e}^{-c_{1} x}
$$

A Equação (6.27) é uma expressão analítica para a distribuição de temperatura dentro do molde e permite a verificação da confiabilidade dos resultados fornecidos pelo método proposto. A ordem de convergência $q$ no método com relação à aproximação do campo de temperatura é estimada por meio da Equação (6.17) tomando a norma $L_{2}$ como uma medida de erro e $h$ como o diâmetro médio local de cada conjunto de pontos, usando a Equação (6.18) $\operatorname{com} l=10^{-1} \mathrm{~m}$.

Os erros cometidos considerando-se distintas quantidades de pontos representando a a fronteira e o interior do molde são listados na Tabela 6.4. A Figura 6.13 ilustra que a ordem de convergência do método é aproximadamente linear.

Tabela 6.4: Erro cometido na solução da equação da temperatura segundo a norma $L_{2}$, considerando-se diversos conjuntos de pontos.

\begin{tabular}{ccc}
\hline \hline Pontos & $h(m)$ & $L_{2}$ \\
\hline 100 & $1,00 \times 10^{-2}$ & $1,4473 \times 10^{-1}$ \\
200 & $7,07 \times 10^{-3}$ & $9,0941 \times 10^{-2}$ \\
400 & $5,00 \times 10^{-3}$ & $5,8315 \times 10^{-2}$ \\
800 & $3,53 \times 10^{-3}$ & $4,0730 \times 10^{-2}$ \\
\hline
\end{tabular}




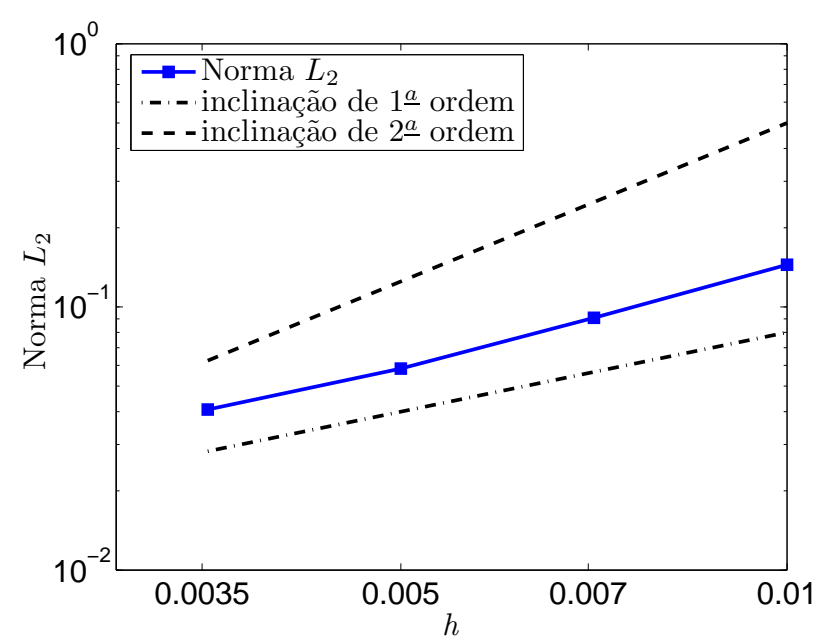

Figura 6.13: Norma $L_{2}$ do erro cometido pelo método proposto ao predizer o campo bidimensional de temperatura ao final do preenchimento do molde descrito na Figura 6.10.

\subsubsection{Escoamento em um molde com um canal de entrada e um obstáculo}

Neste caso teste, os resultados alcançados pelo presente método são comparados com os apresentados no trabalho de Chang e Yang (2001) para o caso do escoamento isotérmico de um fluido newtoniano em um molde retangular com um canal e entrada e um obstáculo (inserção). O objetivo é verificar a capacidade do método em predizer corretamente ambas pressão na região de injeção e posição da superfície livre.

As dimensões do molde são ilustradas na Figura 6.14. O conjunto de pontos descrevendo a fronteira e o interior do molde tem 608 pontos, e a direção transversal do molde é dividida em $N_{z}=5$ camadas.

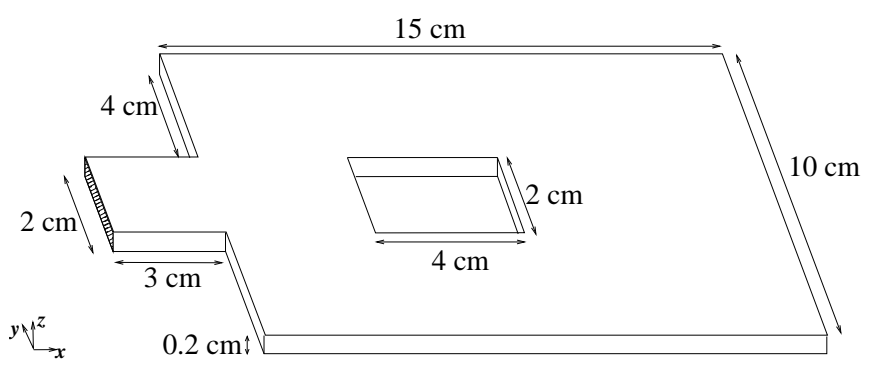

Figura 6.14: Molde retangular com um canal de entrada e uma inserção (buraco). A região de injeção é representada como a área hachurada na figura.

Os estudos conduzidos na Seção 6.7.2 mostram a capacidade do método em fornecer perfis de pressão corretos na região de injeção de fluido de um molde de geometria simples tanto para fluidos newtonianos quanto para não newtonianos, a vários valores de taxa de cisalhamento. Nesta seção, o objetivo é mostrar a capacidade do método em fornecer valores corretos para a pressão na região de injeção de fluidos em um molde de geometria mais complexa, usando valores altos e baixos da taxa de cisalhamento, e comparando, quando possível, com resultados encontrados na literatura. 


\subsubsection{Preenchimento à alta taxa de cisalhamento}

Na primeira parte desta seção, o molde descrito na Figura 6.14 é preenchido por um fluido newtoniano $\left(\eta_{0}=10^{4} \mathrm{Pas}\right)$ de tal modo que o tempo total de preenchimento seja 2 segundos. Desta forma, considerando-se a geometria do molde e o tempo de preenchimento escolhido, tem-se, pela Equação (6.16), que a velocidade com a qual o fluido deve ser injetado é $v_{\text {inj }}=3,7 \times 10^{-1} \mathrm{~m} / \mathrm{s}$. Nestas condições, o valor para a taxa de cisalhamento média do escoamento é dado por $\dot{\gamma}_{\text {med }}=1.85 \times 10^{2} \mathrm{~s}^{-1}$, o que é considerado alto.

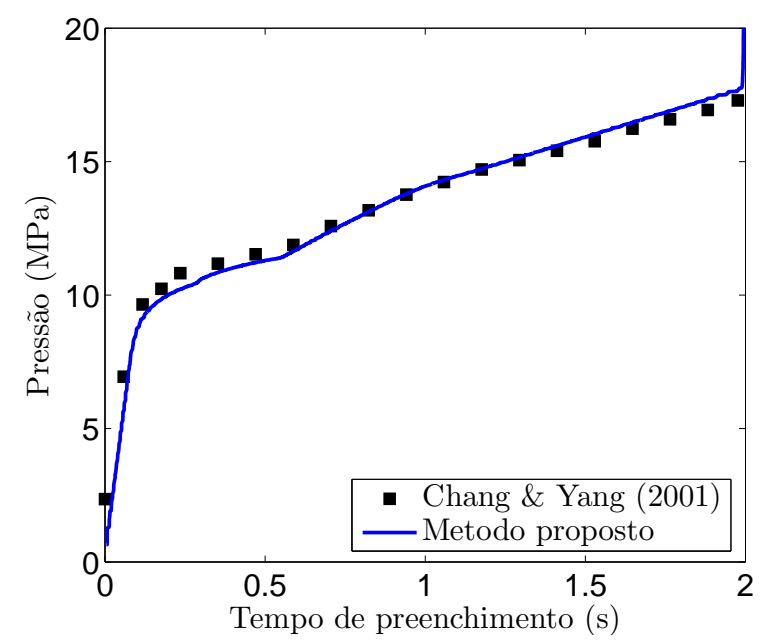

Figura 6.15: Comparação do perfil da pressão na região de injeção de fluido obtido pelo método proposto com o resultado de Chang e Yang (2001).

A Figura 6.15 apresenta uma comparação dos perfis da pressão na região de injeção obtidos pelo método proposto e pelo método de Chang e Yang (2001) nas condições de escoamento descritas anteriormente.

A Figura 6.16 ilustra a posição da superfície livre em seis diferentes etapas do preenchimento do molde. A linha preta representa a superfície livre do fluido: o volume do molde localizado à esquerda da linha preta está cheio de fluido enquanto o volume do molde localizado à direita da linha ainda encontra-se vazio. A posição da superfície livre predita pelo presente método está de acordo com os resultados apresentados por Chang e Yang (2001), apresentados na Figura 6.17.

O efeito de outros modelos de viscosidade na pressão na região de injeção é avaliado sob as mesmas condições de escoamento agora considerando poliestireno representado pelos modelos de Cross, Carreau, Ellis e Power-law, apresentados na Seção 2.9. O valor da pressão na região de injeção de fluido durante o preenchimento do molde para cada um dos modelos de viscosidade generalizada é ilustrado na Figura 6.18.

Os resultados ilustrados na Figura 6.18 exibem excelente concordância com o comportamento descrito na Figura 2.3 e também na Tabela 6.2 para este valor da taxa de cisalhamento. A taxas de cisalhamento mais altas, os modelos de Cross e Ellis produzem resultados semelhantes, apresentando menor viscosidade e, portanto, menor pressão, 


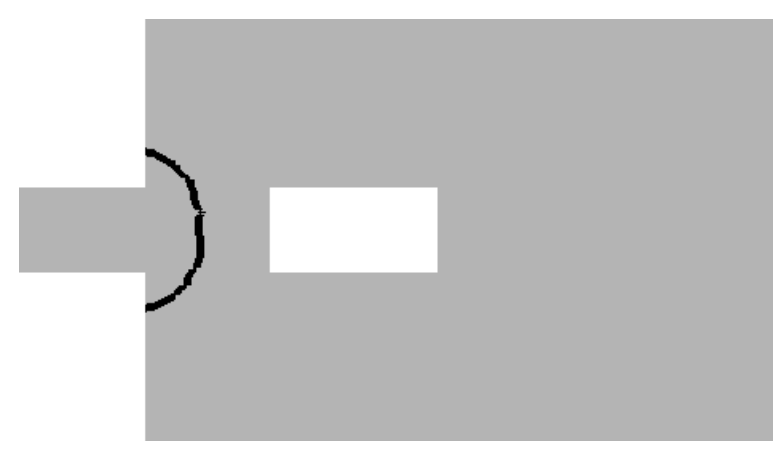

(a) $5 \%$ preenchido

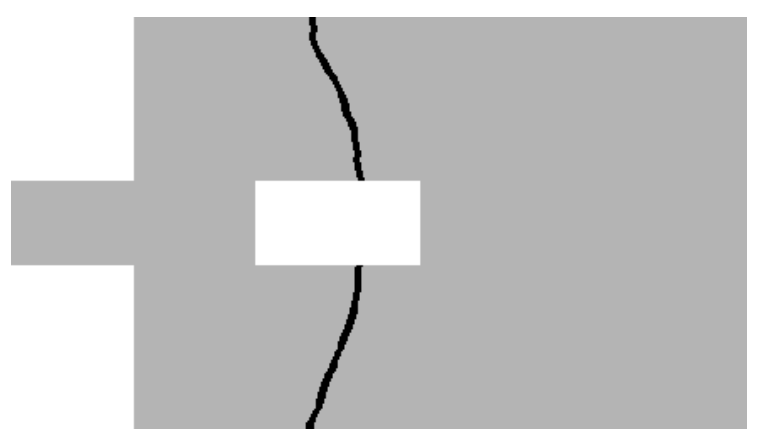

(c) $30 \%$ preenchido

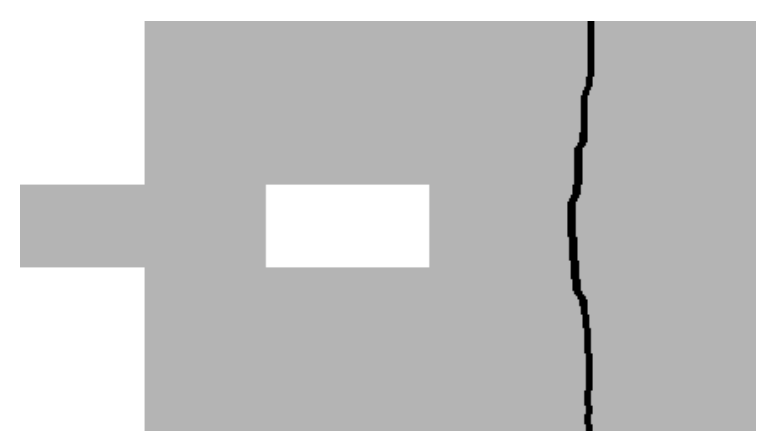

(e) $60 \%$ preenchido

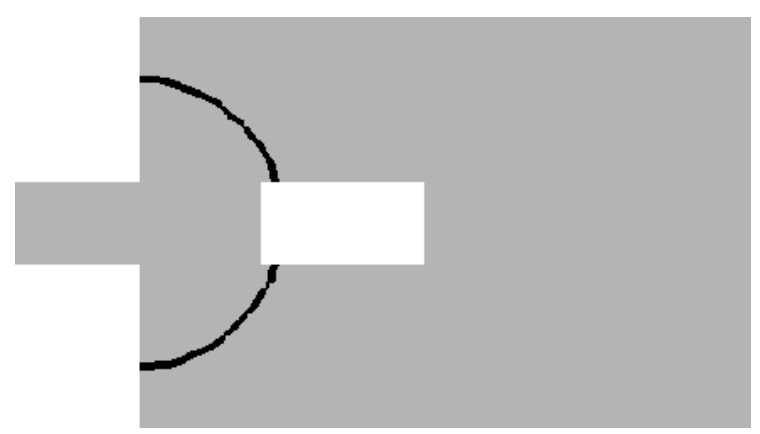

(b) $10 \%$ preenchido

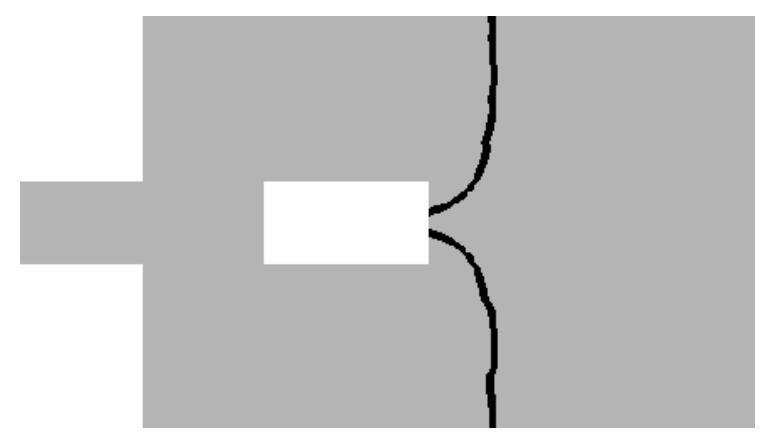

(d) $45 \%$ preenchido

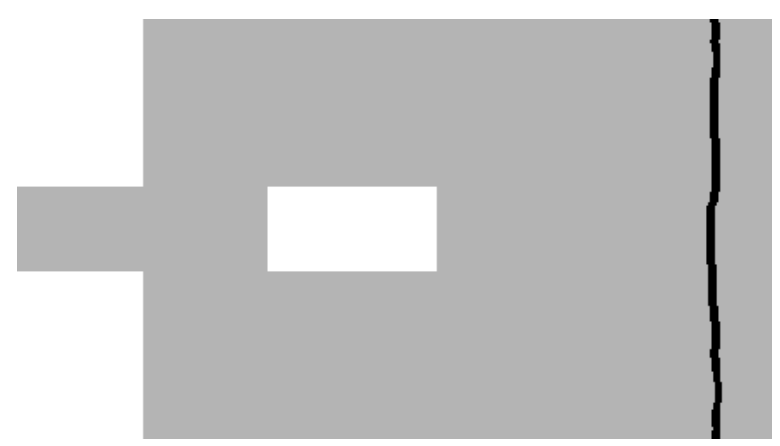

(f) $85 \%$ preenchido

Figura 6.16: Diversas etapas do avanço da superfície livre durante o preenchimento do molde descrito na Figura 6.14. Os resultados obtidos via método proposto estão de acordo com aqueles apresentados no trabalho de Chang e Yang (2001).

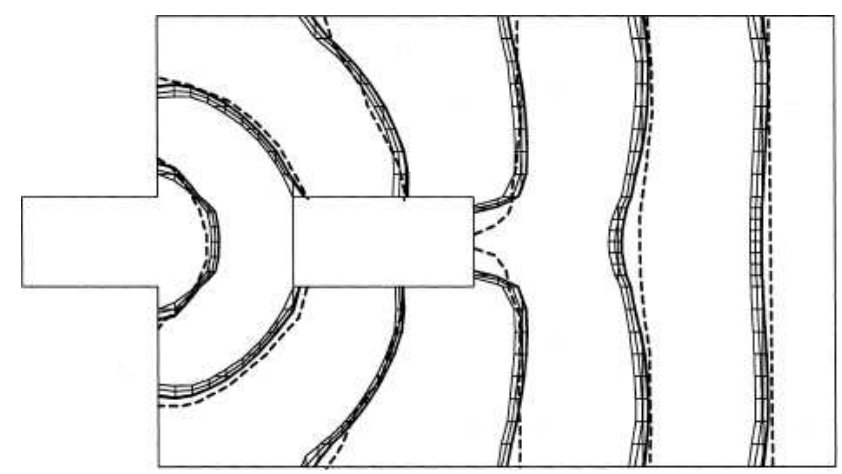

Figura 6.17: Resultados de Chang e Yang (2001). A linha tracejada representa as posições da superfície livre durante o preenchimento utilizando um modelo $2 \frac{1}{2} \mathrm{D}$, enquanto a a malha representa um modelo $3 \mathrm{D}$. 


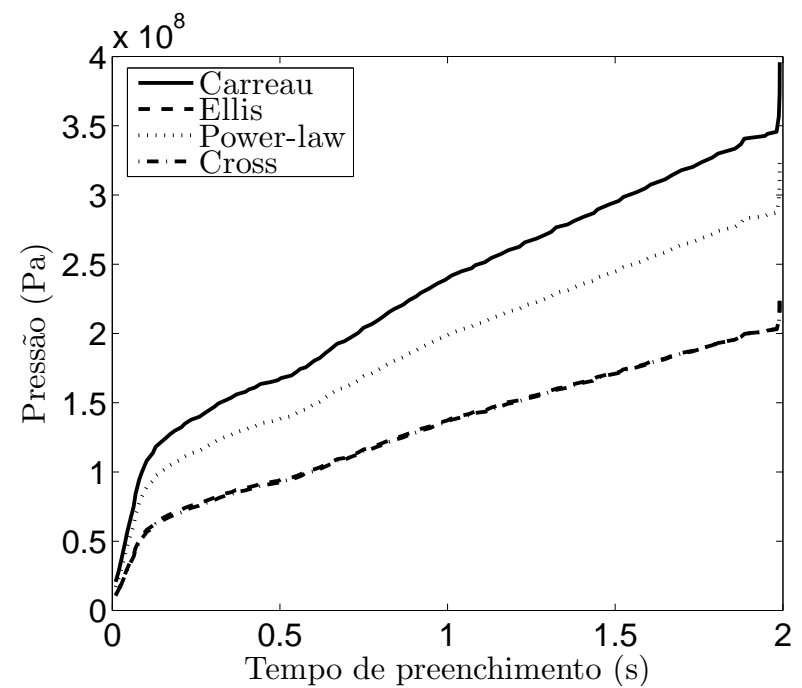

Figura 6.18: Perfil da pressão na região de injeção de poliestireno durante o preenchimento de um molde retangular com um canal de entrada e uma inserção usando diversos modelos de viscosidade e velocidade de injeção prescrita $v_{\text {inj }}=3,7 \times 10^{-1} \mathrm{~m} / \mathrm{s}$.

do que os resultados alcançados pelos modelos de Carreau e Power-law; e o modelo de Carreau apresenta os maiores valores para ambas pressão e viscosidade.

\subsubsection{Preenchimento à baixa taxa de cisalhamento}

Na última parte desta seção, o efeito dos diferentes modelos de viscosidade generalizada na pressão da região de injeção é considerada para o caso do preenchimento do molde à baixa taxa de cisalhamento utilizando poliestireno. Um valor representativo da taxa de cisalhamento média é tomado como $\dot{\gamma}_{\text {med }}=10^{-2} s^{-1}$ resultando em uma velocidade prescrita $v_{\text {inj }}=2 \times 10^{-5} \mathrm{~m} / \mathrm{s}$.

Apesar de valores de velocidade prescrita tão baixos quanto o utilizado nesta seção não sejam empregados na prática, este caso teste ilustra o capacidade do presente método em realizar corretamente a simulação, prevendo o comportamento dos modelos de viscosidade e destacando as diferenças e as similaridades entre tais modelos.

A Figura 6.19 apresenta a pressão obtida utilizando cada um dos modelos representando poliestireno. O tempo predito pela simulação para o completo preenchimento do molde é 36808, 61 s, enquanto o tempo exato obtido por meio da Equação (6.16) é $37000 s$, indicando um erro de apenas $0,51 \%$.

Pode-se observar que, como esperado, os modelos de Carreau e Ellis apresentam perfis de pressão muito semelhantes, enquanto o perfil da pressão predito pelo modelo de Cross apresenta valores mais baixos, e no caso do fluido Power-law o campo de pressão apresenta valores bastante maiores. No caso do modelo newtoniano, assume-se a viscosidade do fluido constante e dada por $\eta=4 \times 10^{6} \mathrm{Pas}$.

Voltando à Figura 2.3, tem-se que, à taxa de cisalhamento $\dot{\gamma}=10^{-2} \mathrm{~s}^{-1}$, os modelos de Ellis e Carreau exibem comportamentos semelhantes para a viscosidade e ambos 


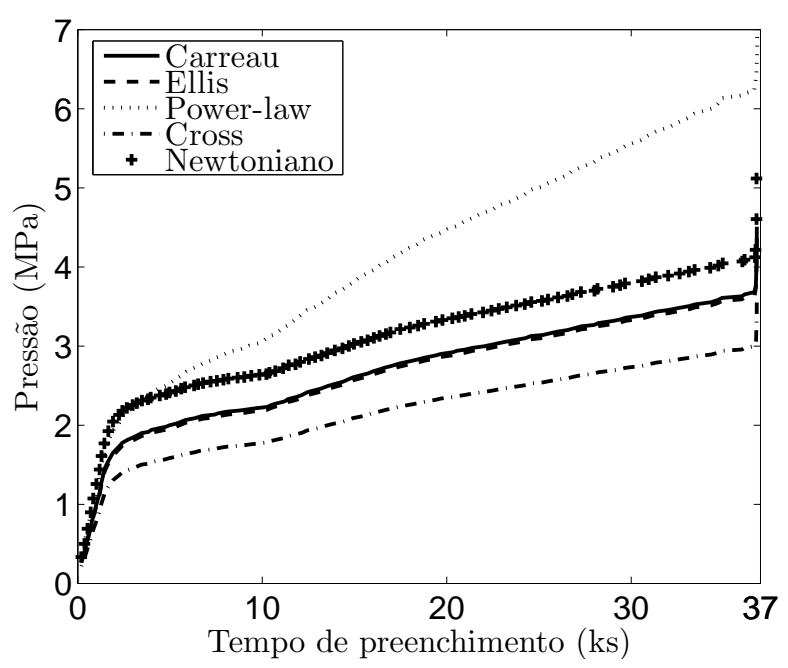

Figura 6.19: Perfil da pressão na região de injeção durante o preenchimento do molde retangular com um canal de entrada e uma inserção de poliestireno representado por diversos modelos de viscosidade e usando $v_{\text {inj }}=2 \times 10^{-5} \mathrm{~m} / \mathrm{s}$.

convergem para o platô newtoniano, enquanto o modelo de Cross exibe menores valores para a viscosidade, e o modelo de Power-law exibe valores maiores. Este comportamento esperado é claramente predito pelo método proposto, conforme ilustrado na Figura 6.19. Embora o uso de um valor tão baixo para a velocidade de injeção prescrita, resultando em um valor bastante baixo para a taxa de cisalhamento, não seja uma prática comum em processos de moldagem por injeção, este caso teste verifica a capacidade do método em lidar adequadamente com os diferentes modelos de viscosidade e em prever corretamente o comportamento do fluido em diferentes condições de escoamento.

\subsection{Resultados}

Tendo sido realizados diversos testes de modo a verificar a capacidade do método em prever corretas pressão de injeção e posição da superfície livre ao decorrer do preenchimento de moldes, conclui-se que o método proposto combinando idéias dos métodos CVFEM, semi lagrangeano e VOF dinâmicos para a solução das equações de Hele-Shaw, da temperatura e do avanço da superfície livre pode ser utilizado para a simulação numérica do problema físico em questão.

Nesta seção é apresentada a simulação do escoamento de um fluido adentro da cavidade de um molde de geometria complexa, similar à configuração de uma calculadora. A espessura do molde é constante e dada por $h=2 \times 10^{-3} \mathrm{~m}$ e uma visão do topo da geometria do molde e da região de injeção de fluido, representada por setas, é apresentada na Figura 6.20. O conjunto de pontos definindo as fronteiras e o interior do molde tem 2063 pontos e a direção transversal do molde é dividida em $N_{z}=5$ camadas.

Nesta simulação o fluido é representado pelo modelo de Cross de modo a ilustrar a capacidade do esquema numérico em lidar com várias situações de divisão da frente do 


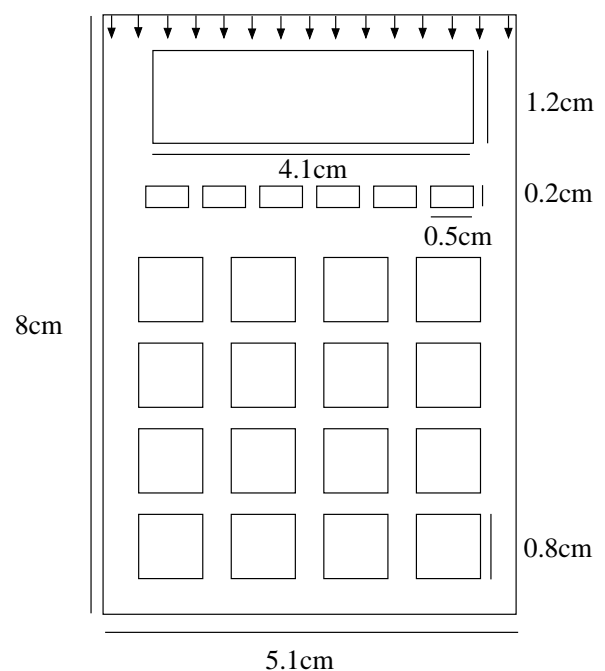

Figura 6.20: Visão do topo do molde e região de injeção de fluido representada por setas. A espessura do molde é constante e igual a $h=2 \times 10^{-3} \mathrm{~m}$.

fluido e posterior coalescência em um domínio multiplamente conectado. Além disso, os resultados para a pressão resultante na região de injeção de fluido e o tempo de preenchimento do molde são comparados com os resultados fornecidos pelo método baseado em malhas de Estacio e Mangiavacchi (2007) quando aplicado à solução do mesmo problema. O molde é preenchido utilizando velocidade de injeção prescrita $v_{\text {inj }}=1,25 \times 10^{-2} \mathrm{~m} / \mathrm{s}$.

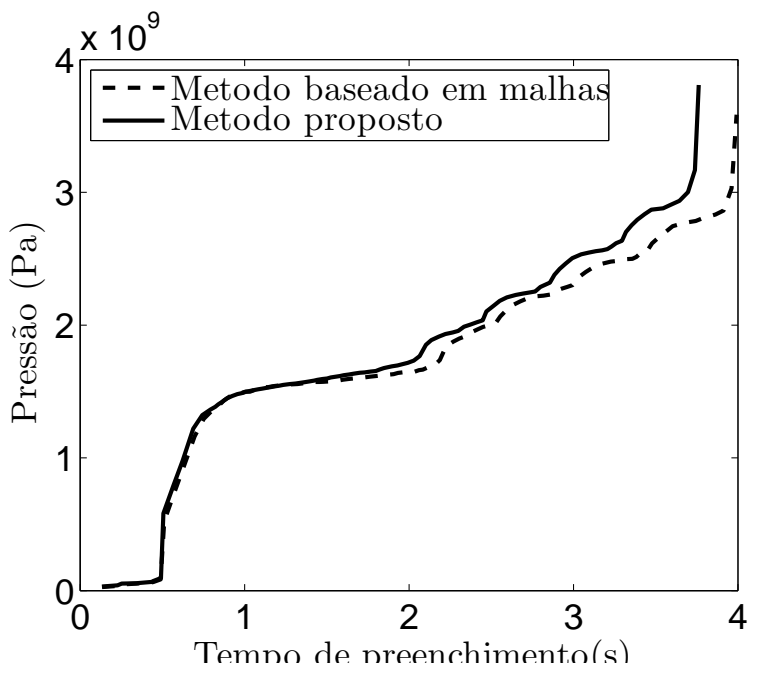

Figura 6.21: Comparação dos perfis da pressão na região de injeção durante o preenchimento do molde obtidos pelo método proposto e pelo método baseado em malhas de Estacio e Mangiavacchi (2007).

A Figura 6.21 apresenta uma comparação entre os valores para a pressão na região de injeção obtidos por ambos os métodos proposto e baseado em malhas. Pode-se observar que mesmo neste caso de fluido e geometria complexos, o método proposto fornece bons resultados numéricos. A Figura 6.22 apresenta a distribuição do campo de pressão dentro do molde em três momentos distintos da simulação, enquanto a Figura 6.23 apresenta a distribuição de temperatura bidimensional do fluido. 


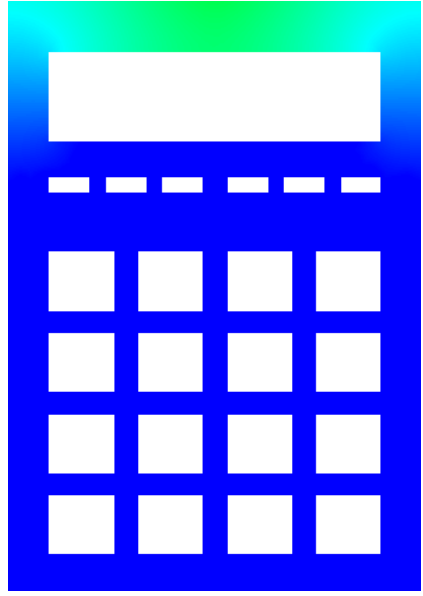

(a) $20 \%$ preenchido

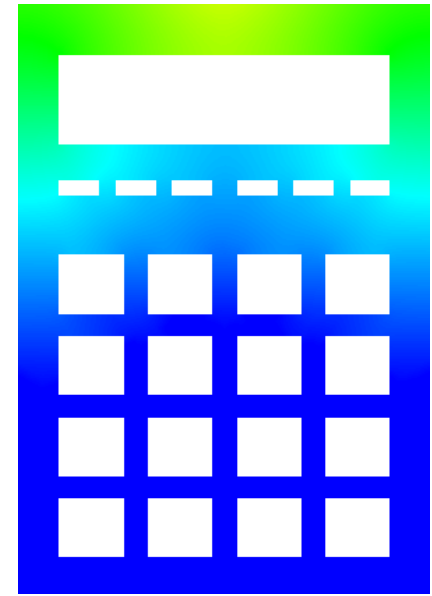

(b) $60 \%$ preenchido $3.59 e+007$

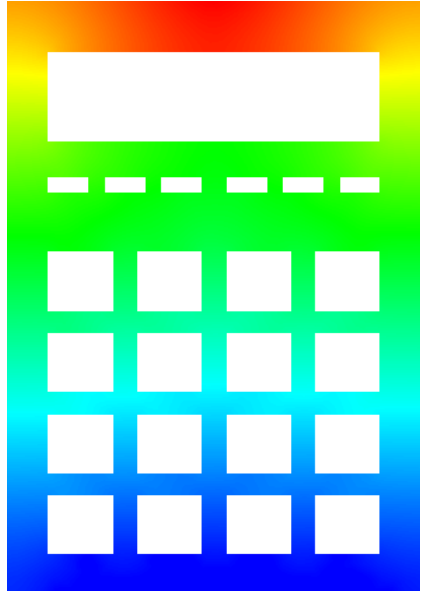

(c) $95 \%$ preenchido

0.000

Figura 6.22: Evolução do campo de pressão para o caso do molde sendo preenchido com velocidade de injeção constante e igual a $v_{\text {inj }}=1,25 \times 10^{-2} \mathrm{~m} / \mathrm{s}$.

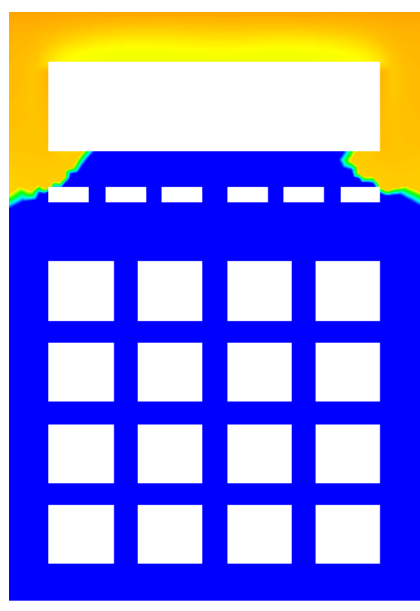

(a) $20 \%$ preenchido

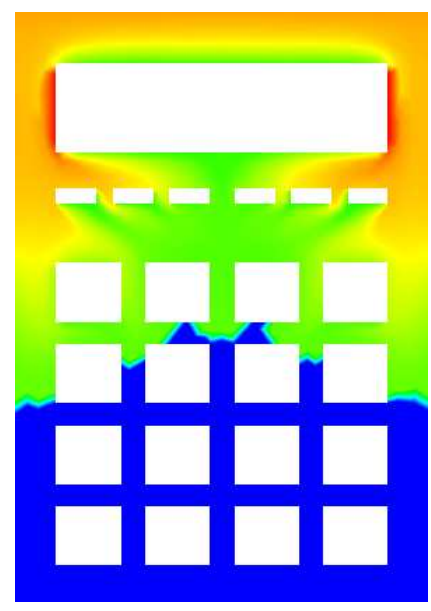

(b) $60 \%$ preenchido 488.

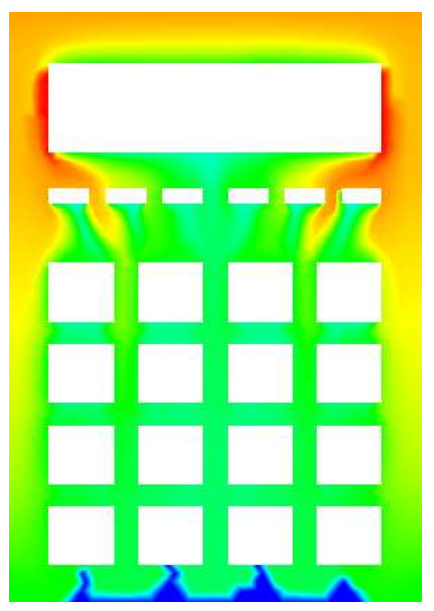

(c) $95 \%$ preenchido

450. 525.

Figura 6.23: Evolução do campo de temperatura bidimensional do fluido durante o preenchimento do molde. A temperatura do fluido no início da injeção é $T_{\text {inj }}=513 \mathrm{~K}$.

A Figura 6.24 ilustra a posição da superfície livre do fluido em quatro diferentes estágios do preenchimento predita por ambos os métodos: o método proposto neste trabalho (em branco) e o método baseado em malhas (em preto). Pode-se observar a excelente concordância entre os resultados alcançados nos dois casos: especialmente no início da simulação, a posição da superfície livre predita pelo método proposto é praticamente indiscernível daquela predita pelo método baseado em malhas. Finalmente, a Figura 6.25 apresenta em detalhes o avanço da superfície livre ao redor das inserções (obstáculos) durante o preenchimento.

Finalizando os resultados apresentados nesta seção, uma comparação do tempo de 
preenchimento é também realizada relativa à aproximação obtida pelo método baseado em malhas. Neste caso teste, de acordo com a Equação (6.16), o tempo esperado para o preenchimento do molde é $3,9278 \mathrm{~s}$, enquanto o método proposto fornece $3,8844 \mathrm{~s}$, resultando em um erro relativo de 1,10\%. O erro cometido pelo método baseado em malhas é de 1,60\%, o que ainda é comparável. Erros cometidos no tempo de preenchimento podem ser interpretados em termos de erros na conservação de massa, e o estudo referente ao aumento de pontos no conjunto de pontos representando a geometria do molde (análogo ao refinamento de malhas) apresentado na Seção 6.7.1 explora a taxa de convergência do método nesse contexto.

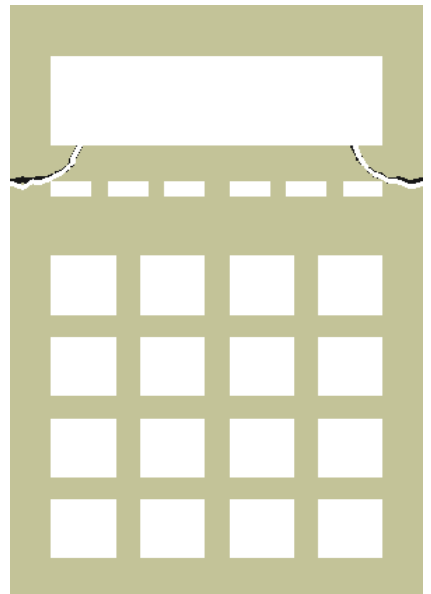

(a) $20 \%$ preenchido

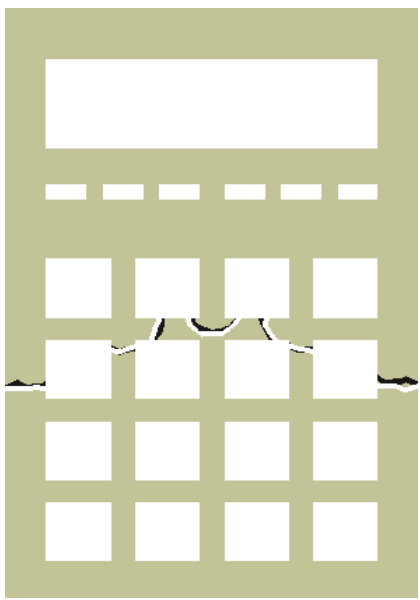

(b) $60 \%$ preenchido

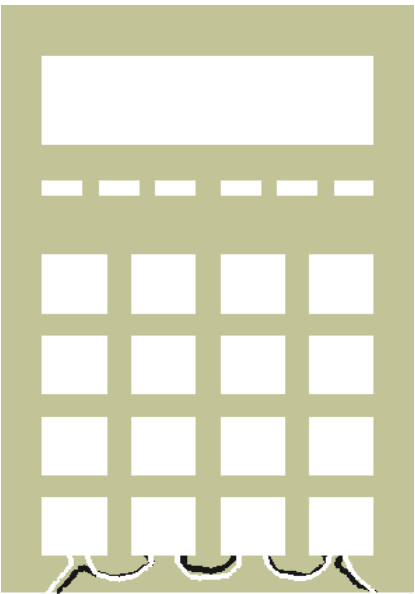

(c) $95 \%$ preenchido

Figura 6.24: Comparação entre a posição da superfície livre do fluido predita pelo método proposto (em branco) com a os resultados fornecidos por um método baseado em malhas.

\subsection{Comentários}

Neste capítulo, uma adaptação da técnica Control Volume Finite Element Method é empregada juntamente com a utilização de uma malha dinâmica para discretizar a equação de Hele-Shaw e fornecer o campo de pressão, ao mesmo tempo em que uma estratégia igualmente dinâmica do esquema Volume of Fluid é introduzida de modo a fornecer a posição da superfície livre durante o escoamento do fluido dentro da cavidade do molde que está sendo preenchido, e uma estratégia semi lagrangeana é utilizada para a obtenção do campo de temperatura.

O presente método pode ser considerado como uma nova abordagem para a aproximação numérica de processos descritos pelo modelo de Hele-Shaw. A estratégia de discretização envolve malhas construídas dinamicamente com células criadas a partir de um conjunto de pontos descrevendo o domínio computacional: volumes de controle dinâmicos são construídos dinamicamente para cada ponto ativo de modo a formar uma malha virtual dinâmica que se move com o avanço do fluido.

Vários testes numéricos são conduzidos para o caso do escoamento isotérmico de fluidos newtonianos e não newtonianos, além de um teste para o caso não isotérmico. Primeira- 

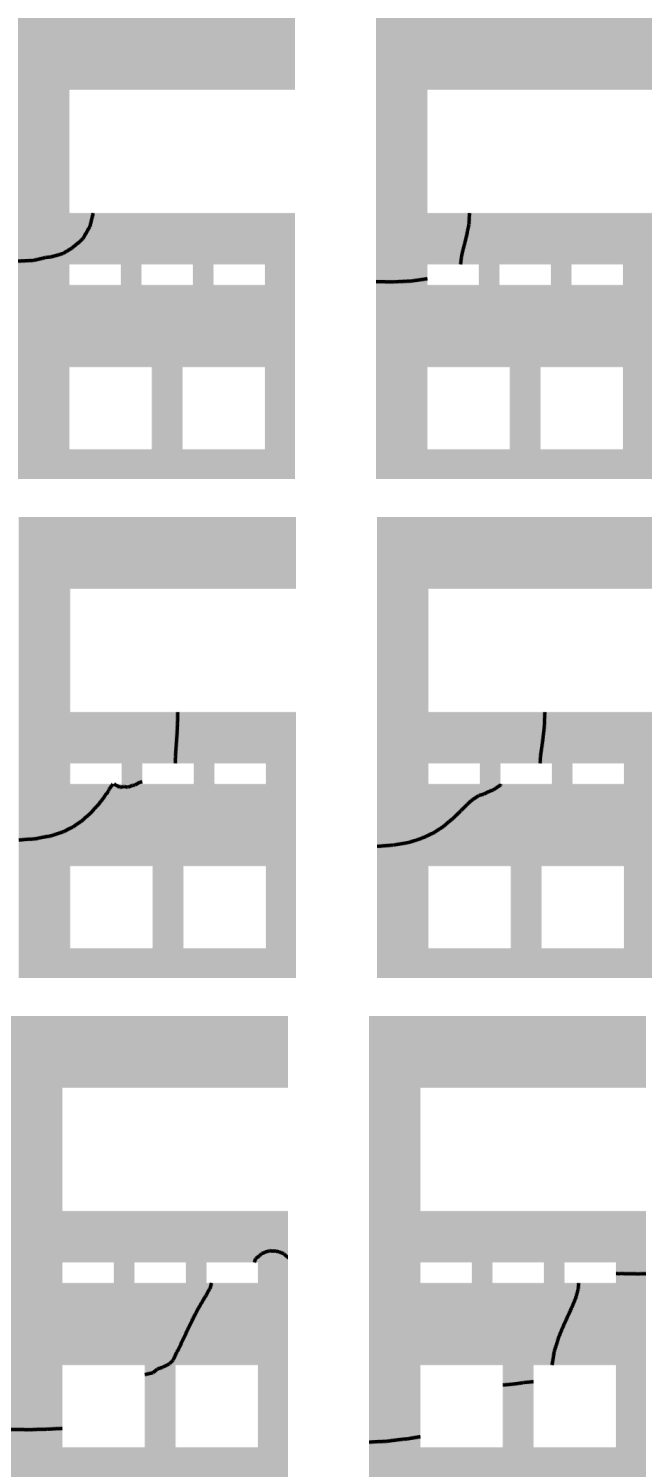
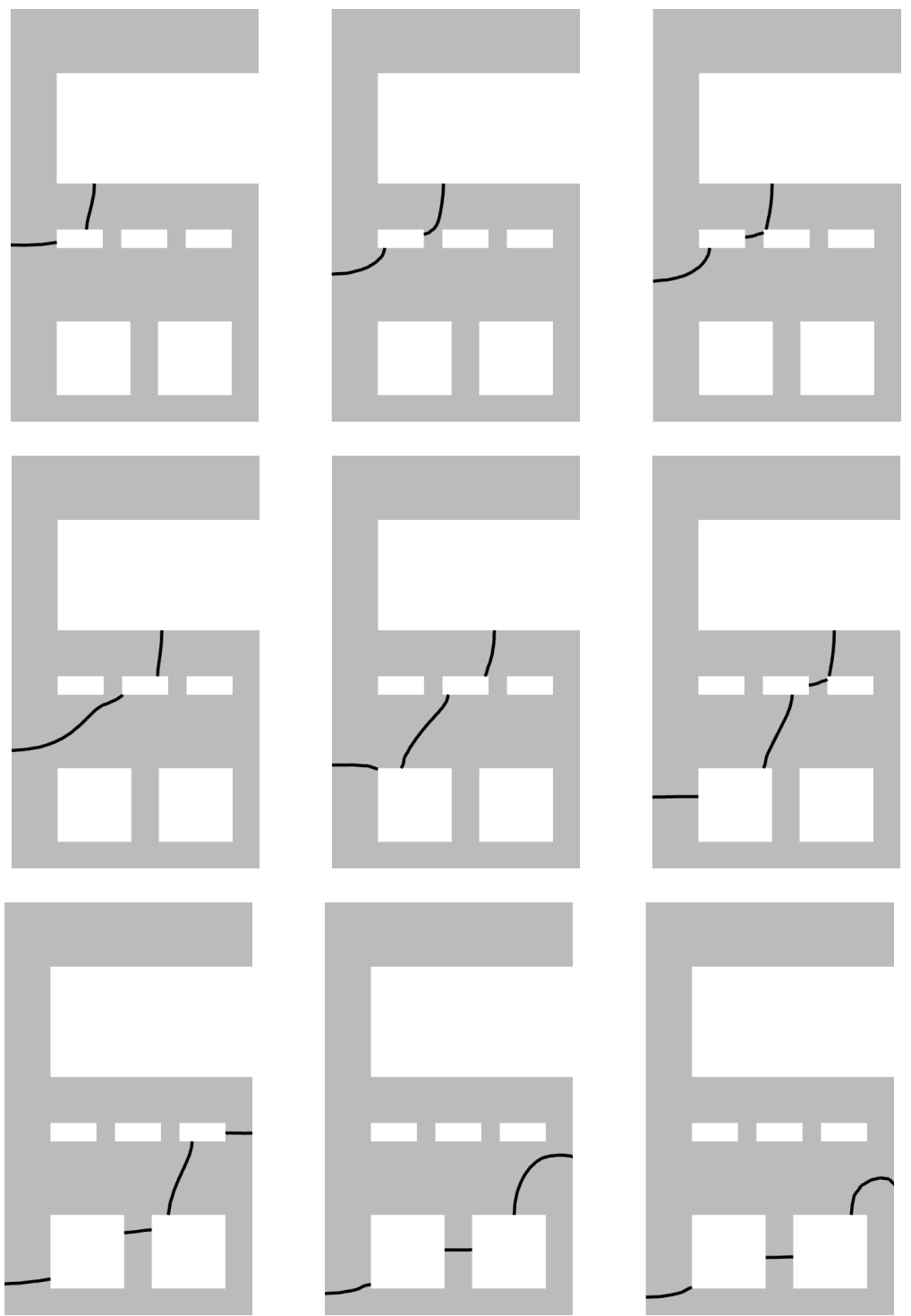

Figura 6.25: Detalhe do avanço da superfície livre do fluido ao redor de algumas das inserções presentes do molde da calculadora.

mente, a precisão do algoritmo responsável pelo avanço da frente de fluido é investigada juntamente com a precisão da conservação de massa de maneira geral, resultando em uma taxa de convergência aproximadamente linear (Seção 6.7.1). Na seqüência, os estudos mostraram a capacidade do método em fornecer perfis corretos de pressão na região de injeção de fluido por meio de velocidade prescrita tanto no caso da geometria do molde ser bem simples, quanto no caso do molde apresentar expansões e obstáculos (Seções 6.7.2 e 6.7.3) para o caso de fluidos newtonianos e não newtonianos, apresentando resultados em concomitância ora com resultados analíticos ora com resultados numéricos alcançados por outros autores. Finalmente, os resultados fornecidos pelo método proposto foram comparados com os resultados obtidos empregando-se um método baseado em malhas para o caso do escoamento de um fluido complexo em um molde de geometria complexa (Seção 6.8). Tais resultados indicam uma excelente conformidade com relação 
à pressão na região de injeção e à posição da superfície livre, mais uma vez explicitando a credibilidade do método proposto. Todos esses exemplos demonstram que o método proposto é de fato uma ferramente valiosa para a simulação da fase de preenchimento do processo de moldagem por injeção.

O estudo referente ao desenvolvimento inicial desta estratégia para solução das equações governantes da fase de preenchimento de um molde foi apresentado no 9th U.S. National Congress on Computational Mechanics e selecionado para a fase final da competição realizada entre os estudantes que apresentaram trabalhos (Estacio et. al., 2007b). Os estudos finais do trabalho referente à abordagem numérica adotada neste capítulo compõem um artigo submetido para um periódico internacional. 


\section{$-7$ \\ Comentários finais, contribuições e trabalhos futuros}

O objetivo deste projeto de doutorado foi desenvolver metodologias para a solução das equações governantes da fase de preenchimento de um processo de moldagem por injeção usando, pelo menos em alguma instância da solução numérica, pontos não organizados e a formulação de Hele-Shaw. Três diferentes abordagens foram apresentadas de maneira independente, tendo como característica comum o processo de desacoplamento das equações governantes.

A primeira abordagem, apresentada no Capítulo 4, baseia-se em uma estratégia euleriana do método SPH para a solução da equação de Hele-Shaw juntamente com uma abordagem dinâmica do método VOF para o avanço da superfície livre. Nesta estratégia, apenas pontos são utilizados para representar a fronteira e o interior dos moldes a serem preenchidos de fluido e o escoamento é considerado isotérmico. Diversos testes foram realizados e a confiabilidade do esquema proposto foi demonstrada. O método fornece campos de pressão e velocidade corretos, além de ser capaz de lidar com divisão e coalescência do fluido, sem a necessidade de utilização de malhas.

A segunda abordagem foi apresentada no Capítulo 5. Nesta estratégia, o uso de malhas é mantido para o cálculo das variáveis do escoamento (pressão, temperatura, dentre outras), mas apenas um conjunto de pontos é utilizado para o avanço da superfície livre do fluido. A estratégia de discretização adotada para o avanço da superfície livre demonstrou-se ser consistente e precisa, inclusive em situações de divisão e coalescência de fluido. Uma outra vantagem desta abordagem relaciona-se à possibilidade do método em simular o preenchimento do molde em menos iterações, e portanto, com maior rapidez computacional, sem que a qualidade dos resultados seja prejudicada.

A última abordagem proposta foi apresentada no Capítulo 6. Nela, uma adaptação da técnica CVFEM é empregada juntamente com a utilização de uma malha dinâmica 
para discretizar a equação de Hele-Shaw e fornecer o campo de pressão, ao mesmo tempo em que estratégias igualmente dinâmicas do esquema VOF e do método semi lagrangeano são usadas para a fornecer a posição da superfície livre e a distribuição de temperatura, durante preenchimento do molde. Nesta abordagem, uma malha é construída dinamicamente durante a simulação, utilizando apenas pontos ativos, isto é, pontos nos quais há fluido. Da mesma forma em que nos capítulos anteriores, vários testes numéricos são conduzidos de modo a investigar a precisão dos resultados fornecidos pelo método. Em todos eles, a performance do método proposto é excelente.

Dentre as três estratégias desenvolvidas, o método combinando FT e CVFEM baseado em malhas (Capítulo 5), é o método que fornece resultados em menor tempo computacional. A desvantagem deste método é a necessidade do uso de malhas para o cálculo das variáveis do escoamento e de uma estrutura da dados que realize operações de busca eficientemente, já que a cada passo no avanço temporal, é necessário encontrar quais triângulos contêm as partículas representando a superfície livre. Outra desvantagem desse método é que, em algumas situações (como no caso da superfície livre apresentar alta curvatura na frente de fluido) para que o método não falhe na identificação da quantidade de clusters, é necessário que a malha seja suficientemente refinada, de modo a diminuir o raio associado a cada partícula representando a superfície livre.

O método combinando idéias do SPH e VOF (Capítulo 4) mostrou-se bastante eficiente quando os pontos definindo o molde encontram-se uniformemente distribuídos, mas a performance diminui bastante quando tais pontos encontram-se desorganizados. Uma justificativa para a diminuição da qualidade dos resultados encontrados é a estimativa utilizada para o cálculo do volume associado em cada ponto e alternativas à estratégia atualmente utilizada devem ser encontradas.

Finalmente, o método combinando CVFEM e VOF dinâmicos (Capítulo 6) apresentou-se eficiente em todos os testes realizados, fornecendo resultados precisos mesmo no caso de fluidos mais complexos. Infelizmente, a necessidade da construção dinâmica e dinamicamente dos volumes de controle associados a cada ponto utilizado na discretização do domínio causa um aumento considerável no tempo da simulação.

De maneira geral, os estudos conduzidos nos capítulos citados anteriormente demonstram que as três abordagens propostas fornecem resultados precisos em diversas situações, como por exemplo, durante o preenchimento de moldes de geometrias arbitrárias, considerando duas estratégias de injeção de fluido, e diversos modelos de fluidos newtonianos generalizados além do caso mais simples newtoniano. Desta forma, elas podem ser vistas como ferramentas confiáveis para a simulação do preenchimento de moldes.

Dentre as três abordagens propostas, o método combinando idéais SPH e VOF é o que menos utiliza informações de malhas, sejam elas construídas dinamicamente ou não, e portanto se enquadra melhor dentro do contexto inicialmente proposto para esta pesquisa. Entretanto, a estimativa para o cálculo do raio médio, do volume e da área associados a 
cada partícula, descritos na seção para o avanço da superfície livre, é fortemente baseada na qualidade da distribuição dos pontos e necessita ser aprimorada. Além disso, uma alternativa ainda precisa ser encontrada para a aproximaçãp do termo convectivo presente na equação da temperatura, possibilitando a inclusão de efeitos térmicos nesta estratégia. A abordagem FT e CVFEM é a que apresenta simulações realizadas em menores tempos computacionais, e portanto poderia ser a estratégia recomendada para simulações do preenchimento de moldes. O ganho em velocidade computacional desta técnica está relacionado com o uso de malhas e, em diversas situações, a necessidade da malha para a simulação numérica é o maior obstáculo a ser superado. Desta forma, a metodologia combinando CVFEM e VOF, e sua estratégia de construção dinâmica de malhas, demonstra-se a mais promissora das técnicas desenvolvidas, pois constrói as malhas utilizando apenas informações geométricas dos pontos representando o domínio, e fornece resultados extremamente satisfatórios.

\subsection{Publicações originadas da tese}

Os estudos realizados durante o doutorado resultaram em um artigo em conferência internacional, dois artigos em congressos internacionais, um em periódico nacional e um em periódico internacional. Um último artigo encontra-se em preparação para possível publicação em periódico internacional.

São eles:

1. Estacio, K. C., Nonato, L.G., Mangiavacchi, N.. Solution of Hele-Shaw equation in surfaces defined by non organized points. XXVII Iberian Latin American Congress on Computational Methods in Engineering, Belém - PA, 2006 (Capítulo 4).

2. Estacio, K. C., Nonato, L.G., Mangiavacchi, N.. A meshless method for $2{ }^{1} / 2$ D mold filling simulations using point set surfaces. TEMA. Tendências em Matemática Aplicada e Computacional, 8:239-248, 2007 (Capítulo 4).

3. Estacio, K. C., Nonato, L. G., Mangiavacchi, N.. A meshless CVFEM method for mold filling simulations. Proceedings of ICFD2007 - Conference on Numerical Methods for Fluid Dynamics, Reading - UK, 2007 (Capítulo 5).

4. Estacio, K. C., Nonato, L. G., Mangiavacchi, N., Carey, G. F.. Combining CVFEM and meshless front tracking in Hele-Shaw mold filling simulation. International Journal for Numerical Methods in Fluids, 56(8): 1217-1223, 2008 (Capítulo 5).

5. Estacio, K. C., Nonato, L. G., Mangiavacchi, N., Carey, G. F.. Meshfree CVFEM for solving 2D flows in injection molding process. Proceedings of 9th U.S. National Congress on Computational Mechanics, San Francisco-CA, 2007 (Capítulo 6). 
6. Estacio, K. C., Mangiavacchi, N., Carey, G. F.. An unstructured CVFEM and moving interface algorithm for non-Newtonian Hele-Shaw flows in injection molding. International Journal of Heat and Fluid Flow. 2008. Em preparação (Capítulo 6).

\subsection{Trabalhos futuros}

Diversas sugestões para trabalhos futuros podem ser apresentadas. A mais natural delas é a inclusão de uma estratégia para a solução da equação tridimensional para a temperatura, de modo que o modelo $2^{1} / 2$-dimensional seja resolvido numericamente em sua completude. Em seguida, a escolha de outros modelos de viscosidade newtoniana generalizada, que apresentem dependência da temperatura, pode também ser incluída nos desenvolvimentos futuros, como por exemplo os modelos de Cross e de Carreau modificados com dependência de temperatura de Ahrrenius (Subbiah et. al., 1989, Chen et. al., 1998).

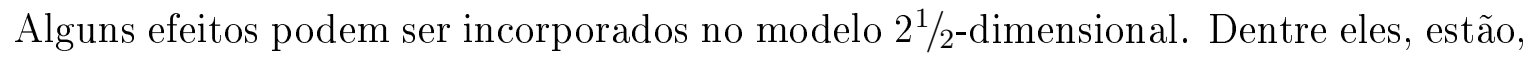
o efeito de chafariz, e os efeitos de resfriamento e solidificação do fluido. Efeitos de cristalização e reações químicas, podem ser modelados adicionando termos fontes apropriados na equação tridimensional da temperatura.

Adicionalmente, embora a comparação entre teoria e experimentos tenha mostrado que simulações baseadas em fluidos inelásticos possam ser realísticas, elasticidade é um outro aspecto importante e que pode ser eventualmente incorporado no modelo de discretização. Em simulações em que a curvatura local da frente de fluido é acentuada, os efeitos de tensão superficial se tornam importantes, e também podem ser adicionados ao modelo.

Finalmente, desenvolver uma interface mais amigável e flexível e que possibilite a importação de dados utilizados na indústria de plásticos também é uma das possibilidades de trabalhos futuros. 


\section{Referências Bibliográficas}

AbBassi, H.; Turki, S.; Ben Nasrallah, S. Interpolation functions in control volume finite element method. Computational Mechanics, vol. 30, no. 4, pgs. 3003-309, 2003.

Ahn, H.; CARey, G. F. An enhanced polygonal finite volume method for unstructured hybrid meshes. International Journal for Numerical Methods in Fluids, vol. 54, no. 1, pgs. 29-46, 2007.

Ammara, I.; Masson, C. Development of a fully coupled control-volume finite element method for the incompressible Navier-Stokes equations. International Journal for Numerical Methods in Fluids, vol. 44, no. 5, pgs. 621-644, 2004.

Amsden, A. A.; HARlOw, F. H. The SMAC method: a numerical technique for calculating incompressible fluid flow. Relatório técnico, Los Alamos Scientfic Laboratory, report LA, 4370, 1970.

Baliga, B. R.; PatankaR, S. V. A new finite element formulation for convection-diffusion problems. Numerical Heat Transfer, Part A: Applications, vol. 3, pgs. 393-409, 1980.

Baliga, B. R.; Patankar, S. V. A control volume finite-element method for two-dimensional fluid flow and heat transfer. Numerical Heat Transfer, Part A: Applications, 1983.

Belytschko, T.; Krongauz, Y.; Organ, D.; Fleming, M.; Krysl, P. Meshless methods: An overview and recent developments. Computer Methods in Applied Mechanics Engineering, vol. 139, pgs. 3-47, 1996.

Bernal, F.; Kindelan, M. RBF meshless modeling of non-Newtonian Hele-Shaw flow. Engineering analysis with boudary elements, vol. 31, pgs. 863-874, 2007.

Boyce, W. E.; DiPrima, R. C. Elementary differential equations and boundary value problems. 2 ed.. New York: John Wiley \& Sons, 1969. 
Bridson, R.; Greif, C. A multipreconditioned conjugate gradient algorithm. SIAM J. Matrix Anal. Appl, vol. 27, no. 4, pgs. 1056-1068, 2006.

Disponível em http://www.cs.ubc.ca/ greif/Papers/bg2006.pdf

CARey, G. F.; ChOw, S. S. Numerical approximation of generalized Newtonian fluids using Powell-Sabin-Heindl elements: I. theoretical estimates. International Journal for Numerical Methods in Fluids, vol. 41, pgs. 1085-1118, 2003.

Carey, G. F.; Jiang, B. N. Element by element linear and nonlinear solution schemes. Communications in Applied Numerical Methods, vol. 2, pgs. 145-153, 1986.

CArey, G. F.; Jiang, B. N. Nonlinear preconditioned conjugate gradient and least squares finite elements. Computer Methods in Applied Mechanics and Engineering, vol. 62, pgs. $145-154,1987$.

Carreau, P. Rheological equations from molecular network theories. Trans. Soc. Rheology, vol. 16, no. 1, pgs. 99-127, 1972.

Chang, R.-Y.; YAng, W.-H. Numerical simulation of mold filling in injection molding using a three-dimensional finite volume approach. International Journal for Numerical Methods in Fluids, vol. 37, pgs. 125-148, 2001.

Changyu, S.; Ming, Z.; Yuanxian, G. An improved algorithm for the simulation of injection-molding filling process. Journal of Reinforced Plastics and Composites, vol. 24, no. 7, pgs. 691-698, 2005.

Chen, J. S.; Liu, W. K. Meshless methods: recent advances and new applications. Computer Methods in Applied Mechanics and Engineering, vol. 193, no. 12-14, pgs. 933 - 1321, 2004.

Chen, S. C.; Chen, Y. C.; Cheng, N. T. Simulation of injection-compression mold-filling process. Int. Comm. Heat Mass Transfer., vol. 25, no. 7, pgs. 907-917, 1998.

Courant, R.; Friedrichs, K.; Lewy, H. On the partial difference equations of mathematical physics. IBM Journal, pgs. 215-234, english translation of the 1928 German original, 1967.

Coutinho, A. L. G. A.; Martins, M. A. D.; Sydenstricker, R. M.; Elias, R. N. Performance comparison of data-reordering algorithms for sparse matrix-vector multiplication in edge-based unstructured grid computations. International Journal for Numerical Methods in Engineering, vol. 66, pgs. 431-460, 2006.

Cross, M. M. Kinetic interpretation of non Newtonian flow. Journal of Colloid and Interface Science, vol. 33, pgs. 30-35, 1970. 
Cuadros-Vargas, A. J.; Nonato, L. G. Imesh: Quality mesh generation from images. Em: ECCOMAS - European Congress On Computational Methods in Applied Sciences and Engineering, Egmond aan Zee, Netherlands, 2006.

Duarte, C. A. M. A review of some meshless methods to solve partial differential equations. Relatório técnico 95-06, University of Texas, 1995.

Ellero, M. Smoothed particle dynamics methods for the simulation of viscoelastic fluids. Tese de doutorado, Technischen Universität Berlin, 2004.

Esmaeeli, A.; Tryggrason, G. Direct numerical simulations of bubbly flows. part 1: Low Reynolds number arrays. Journal of Fluid Mechanics, vol. 337, pgs. 313-345, 1998.

Estacio, K. C. Simulação do processo de moldagem por injeção 2d usando malhas não estruturadas. Dissertação de mestrado, Instituto de Ciências Matemáticas e de Computação da Universidade de São Paulo, São Carlos, 2004.

Estacio, K. C.; Mangiavacchi, N. Simplified model for mold filling simulations using CVFEM and unstructured meshes. Communications in Numerical Methods in Engineering, vol. 23, pgs. 345-361, 2007.

Estacio, K. C.; Nonato, L.; Mangiavacchi, N. Solution of Hele-Shaw equation in surfaces defined by non organized points. Em: XXVII CILAMCE - Iberian Latin American Congress on Computational Methods in Engineering, Belém - PA, 2006.

Estacio, K. C.; Nonato, L.; Mangiavacchi, N. A meshless method for $2^{1} / 2 \mathrm{D}$ mold filling simulations using point set surfaces. TEMA. Tendências em Matemática Aplicada e Computacional, vol. 8, pgs. 239-248, 2007a.

Estacio, K. C.; Nonato, L. G.; Mangiavacchi, N.; Carey, G. F. Meshfree CVFEM for solving $2 \mathrm{~d}$ flows in injection molding process. Em: Proceedings of 9th USNCCM - U.S. National Congress on Computational Mechanics, San Francisco-CA, $2007 \mathrm{~b}$.

Estacio, K. C.; Nonato, L. G.; Mangiavacchi, N.; Carey, G. F. Combining CVFEM and meshless front tracking in Hele-Shaw mold filling simulation. International Journal for Numerical Methods in Fluids, vol. 56, no. 8, pgs. 1217-1223, 2008.

Fries, T.-P.; Matthies, H. G. Classification and overview of meshfree methods. Relatório técnico, Technical University Braunschweig, Brunswick, Germany, 2004.

Gingold, R. A.; Monaghan, J. J. Smoothed particle hydrodynamics: theory and application to non-SPHerical stars. Mon. Roy. Astron. Soc., vol. 181, pgs. 375-389, 1977. 
Glimm, J.; Grove, J.; Lindquist, W. B.; McBryan, O.; Tryggvason, G. The bifurcation of tracked scalar waves. SIAM Journal of Computation, pgs. 61-79, 1988.

Glimm, J.; Grove, J. W.; Li, X. L.; M. Shyue, K.; Zeng, Y.; Zhang, Q. Three-dimensional front-tracking. SIAM Journal on Scientific Computing, vol. 19, pgs. 703-727, 1998.

Harlow, F. H.; WelCh, J. E. Numerical calculations of time-dependent viscous incompressible flow of fluid with a free surface. The Physic of Fluids, vol. 8, pgs. 2182-2189, 1967.

Hele-Shaw, H. S. On the motion of a viscous fluid between two parallel plates. Trans. Royal Inst. Nav. Archit., 1898.

Hieber, C. A.; Chiang, H. H. Some correlations involving the shear viscosity of polystyrene melts. Rheologica Acta, vol. 28, pgs. 321-332, 1989.

Hieber, C. A.; Shen, S. F. A finite-element/finite-difference simulation of the injection-molding filling process. Journal of Non-Newtonian Fluid Mechanics, vol. 7, pgs. $1-32,1980$.

Hirt, C. W.; Cook, J. L.; Butler, T. D. A Lagrangian method for calculating the dynamics of an incompressible fluid with free surface. Journal of Computational Physics, vol. 5, pgs. 103-124, 1970.

Hirt, C. W.; Nichols, B. D. Volume of fluid (VOF) method for the dynamics of free boundaries. Journal of Computational Physics, vol. 39, pgs. 201-225, 1981.

Holm, E.; Langtangen, H. A unified finite element model for the injection molding process. Computer Methods in Applied Mechanics and Engineering, vol. 178, pgs. 413-429, 1999.

Hyman, J. M. Numerical methods for tracking interfaces. Physica 12D, pgs. 396-407, 1984.

IsaACSOn, E.; Keller, H. B. Analysis of numerical methods. New York: Wiley, 1966.

IóRIO, V. M. EDP - um curso de graduação. Rio de Janeiro: Instituto de Matemática Pura e Aplicada - CNPq, 300 pgs., 1991.

Jain, A. K.; Murty, M. N.; Flynn, P. J. Data clustering: a review. ACM Computing Surveys, vol. 31, pgs. 264-323, 1999. 
JiAng, S.; WAng, Z.; Zhoub, G.; YAng, W. An implicit control-volume finite element method and its time step strategies for injection molding simulation. Computers and Chemical Engineering, vol. 31, pgs. 1407-1418, 2007.

Kamal, M. R.; KuO, Y.; DoAn, P. H. Injection molding behavior of thermoplastics in thin rectangular cavities. Polymer Engineering and Science, vol. 15, no. 12, pgs. 863-868, 1975.

Kennedy, P. Flow analysis of injection molds. New York: Hanser Publishers, 237 pgs., 1995.

KIM, S.-W.; TuRng, L.-S. Developments of three-dimensional computer-aided engineering simulation for injection moulding. Modelling Simul. Mater. Sci. Eng., vol. 12, pgs. S151-S173, 2004.

Li, S.; LiU, W. Meshfree and particle methods and their applications. Appl. Mech. Rev., vol. 55, pgs. 1-34, 2002.

Li, X.-Y.; Teng, S.-H.; Üngör, A. Point placement for meshless methods using SPHere packing and advancing front methods. Em: ICCES'00, Los Angeles, 2000, pgs. $20-25$.

LiU, G. R. Meshfree methods - moving beyond the finite element method. CRC Press, 2003.

LiU, G. R.; LiU, M. B. Smoothed particle hydrodynamics - a meshfree particle methods. Singapore: World Scientific Publisher Co. Pte. Ltd., 2003.

LuCY, N. B. A numerical approach to the testing of the frission hypothesis. The Astronomical Journal, vol. 82, pgs. 1013-1024, 1977.

Maliska, C. R. Transferência de calor e mecânica dos fluidos computacional - fundamentos e coordenadas generalizadas. Rio de Janeiro: LTC - Livros Técnicos e Científicos, 1995.

McKee, S.; Tomé, M. F.; Cuminato, J. A.; Castelo, A.; ; Ferreira, V. G. Recent advances in the marker and cell method. Archives in Computational Methods for Engineering, vol. 11, no. 2, pgs. 107-142, 2004.

Monaghan, J. J. Smoothed particle hydrodynamics. Annu. Rev. Astron. Astrophys., vol. 30, pgs. 543-574, 1992.

Myers, T. G. Application of non-Newtonian models to thin film flow. Physical Review E - Statistical, Nonlinear, and Soft Matter Physics, vol. 72 (6 Pt 2), pgs. 066302-1 066302-11, 2005. 
Niceno, B. Easymesh: a free two-dimensional quality mesh generator based on delaunay triangulation. Disponível em <http://www-dinma.univ.trieste.it/nirftc/research/easymesh/>, acessado em 9 de setembro de 2008, 2001.

Phillips, T. N.; Williams, A. J. Conservative semi-Lagrangian finite volume schemes. Numerical Methods for Partial Differential Equations, vol. 17, no. 4, pgs. 403-425, 2001a.

Phillips, T. N.; Williams, A. J. A semi-Lagrangian finite volume method for Newtonian contraction flows. SIAM Journal on Scientific Computing, vol. 22, no. 6, pgs. 2152-2177, 2001b.

RANSAu, S. Solution methods for incompressible viscous free surface flows: a literature review. Relatório técnico 3/2002, Norwegian University of Science and Technology, Trondheim, 2002.

REINER, M. Deformation, strain and flow: an elementary introduction to rheology. 3 ed.. London: H. K. Lewis, 1969.

Richardson, S. Hele-Shaw flows with a free boundary produced by the injection of fluid into a narrow channel. Journal of Fluid Mechanics, vol. 56, pgs. 609-618, 1972.

Roy, C. J. Review of code and solution verification procedures for computational simulation. Journal of Computational Physics, vol. 205, no. 1, pgs. 131-156, 2005.

ShaO, S.; Lo, E. Y. Incompressible SPH method for simulating Newtonian and non-Newtonian flows with a free surface. Advances in Water Resources, vol. 26, pgs. $787-800,2003$.

SHewCHuk, J. R. An introduction to the conjugate gradient method without the agonizing pain. Relatório técnico, School of Computer Science at Carnegie Mellon University, 1994.

Shin, S.; LeE, W. I. Finite element analysis of incompressible viscous flow with moving free surface by selective volume of fluid method. International Journal of Heat and Fluid Flow, vol. 21, no. 2, pgs. 197-206, 2000.

Silva, J. B. C.; MourA, L. F. M. A control-volume-finite-element method (CVFEM) for unsteady, incompressible, viscous fluid flows. Numerical Heat Transfer Part B Fundamentals, vol. 40, no. 1, pgs. 61-82, 2001.

Sousa, F. S.; Mangiavacchi, N.; Nonato, L. G.; Castelo, A. C.; Tomé, M. F.; Ferreira, V. G.; Cuminato, J. A.; MCKee, S. A front-tracking/front-capturing 
method for the simulation of 3d multi-fluid flows with free surfaces. Journal of Computational Physics, vol. 198, pgs. 469-499, 2004.

Subbiah, S.; Trafford, D. L.; GüÇERI, S. I. Non-isothermal flow of polymers into two-dimensional, thin cavity molds: a numerical grid generation approach. International Journal of Heat and Mass Transfer, vol. 32, no. 3, pgs. 415-434, 1989.

Sussman, M.; Smereka, P.; Osher, S. A level set approach for computing solutions of incompressible two-phase flow. Journal of Computational Physics, vol. 114, pgs. 146-159, 1994.

Tomé, M. F.; MCKeE, S. GENSMAC: A computational marker-and-cell method for free surface flows. Journal of Computational Physics, vol. 110, pgs. 171-186, 1994.

Tryggvason, G.; Bunner, B.; Esmaeeli, A.; Juric, D.; Al-Rawahi, N.; Tauber, W.; HAN, J.; NAS, S.; JAN, Y.-J. A front-tracking method for computations of multiphase flow. Journal of Computational Physics, vol. 160, pgs. 708-759, 2001.

TUCKer III, C. L. Computer modeling for polymer processing - fundamental. Computed Aided Engineering for Polymer Processing. Munich: Hanser Publishers, 1989.

Unverdi, S. O.; Tryggvason, G. A front-tracking method for viscous, incompressible, multi-fluid flows. Journal of Computational Physics, vol. 100, pgs. 25-37, 1992.

Verhoyen, O.; Dupret, F. A simplified method for introducing the Cross viscosity law in the numerical simulation of Hele-Shaw flow. Journal of Non-Newtonian Fluid Mechanics, vol. 74, pgs. 25-46, 1998.

Xiu, D.; Karniadakis, G. E. A semi-Lagrangian high-order method for navier-stokes equations. Journal of Computational Physics, vol. 172, pgs. 658-684, 2001.

Zhou, H.; LI, D. A numerical simulation of the filling stage in injection molding based on a surface model. Advances in Polymer Technology, vol. 20, no. 2, pgs. 125-131, 2001.

Zhou, J.; Turing, L.-S. Three-dimensional numerical simulation of injection molding filling with a finite-volume method and parallel computing. Advances in Polymer Technology, vol. 25, no. 4, pgs. 247-258, 2006. 


\section{APÊNDICE $\mathcal{A}$ \\ Análise dimensional das equações governantes}

Neste capítulo a ordem de magnitude dos termos nas equações governantes são estimados usando valores característicos das variáveis. Alguns valores apresentarão ordens de magnitude baixa quando comparados aos demais, podendo ser negligenciados e permitindo simplificações nas equações de conservação.

Os valores característicos para as variáveis do escoamento, descritos na Seção (2.4.1), são dados por $^{1}$ :

- Espessura da cavidade: $H=10^{-3} \mathrm{~m}$,

- Comprimento da cavidade: $L=H / \delta m$ onde $\delta=H / L<<1$,

- Velocidade do fundido: $\mathrm{v}_{0}=10^{-1} \mathrm{~m} / \mathrm{s}$,

- Pressão na cavidade: $p_{0}=10^{7} \mathrm{~N} / \mathrm{m}^{2}$,

- Viscosidade do fluido: $\eta_{0}=10^{4} \mathrm{Ns} / \mathrm{m}^{2}$,

- Expansividade: $\beta=10^{-3} K^{-1}$,

- Condutividade térmica do fluido: $k=10^{-1} \mathrm{~W} / \mathrm{mK}$,

- Densidade: $\rho=10^{3} \mathrm{~kg} / \mathrm{m}^{3}$,

- Diferença de temperatura entre o molde e o fluido: $T_{0}=10^{2} \mathrm{~K}$.

Usando esses valores típicos, as variáveis relevantes nas equações podem ser definidas em termos de variáveis adimensionais, como segue:

- Coordenada- $x: x=L x^{*}=H / \delta x^{*}$,

- Coordenada-y: $y=L y^{*}=H / \delta y^{*}$,

- Coordenada-z: $z=H z^{*}$,

- Tempo: $t=\left[L / \mathrm{v}_{0}\right] t^{*}=\left[H / \delta \mathrm{v}_{0}\right] t^{*}$,

- Componente $x$ da velocidade: $v_{x}=[L / T] v_{x}^{*}=\mathrm{v}_{0} v_{x}^{*}$,

- Componente $y$ da velocidade: $v_{y}=[L / T] v_{y}^{*}=\mathrm{v}_{0} v_{y}^{*}$,

- Componente $z$ da velocidade: $v_{z}=[H / T] v_{z}^{*}=\delta \mathrm{v}_{0} v_{z}^{*}$,

\footnotetext{
${ }^{1}$ Boshouwers, G. e van der Werf, J. apud Kennedy (1995), p. 63.
} 
- Pressão: $p=p_{0} p^{*}$,

- Viscosidade: $\eta=\eta_{0} \eta^{*}$,

- Diferença de temperatura: $\Delta T=T_{0} \Delta T^{*}$,

onde as quantidades marcadas com o asterisco $(*)$ são adimensionais e de ordem um.

As equações da continuidade, da quantidade de movimento e da temperatura para a fase de preenchimento serão analisadas e os termos de menor ordem de magnitude serão negligenciados.

\section{A.1 Equação da continuidade}

Conforme o apresentado na Seção (2.4.1), a equação da continuidade pode ser escrita em coordenadas cartesianas, como segue:

$$
\frac{\partial v_{x}}{\partial x}+\frac{\partial v_{y}}{\partial y}+\frac{\partial v_{z}}{\partial z}=0
$$

Usando os valores característicos das variáveis não-adimensionais dadas na seção anterior, tem-se que todos os termos tendo ordem de magnitude similar:

$$
\begin{aligned}
& O\left[\frac{\partial v_{x}}{\partial x}\right]=O\left[\frac{\mathrm{v}_{0}}{L}\right]=O\left[\frac{\delta \mathrm{v}_{0}}{H}\right]=O\left[\frac{10^{-1} \delta}{10^{-3}}\right]=O\left[10^{2} \delta\right] \\
& O\left[\frac{\partial v_{y}}{\partial y}\right]=O\left[10^{2} \delta\right] \\
& O\left[\frac{\partial v_{z}}{\partial z}\right]=O\left[10^{2} \delta\right]
\end{aligned}
$$

e, portanto, não é possível simplificar mais a equação.

\section{A.2 Equação da quantidade de movimento}

Neste seção, os termos de cada uma das componentes da equação da quantidade de movimento serão expandidos de modo a facilitar a análise dimensional.

\section{A.2.1 Análise dos termos da componente- $x$}

A equação da componente- $x$ da equação da quantidade de movimento, com seus termos expandidos e numerados é:

$$
\begin{aligned}
\underbrace{\rho \frac{\partial v_{x}}{\partial t}}_{(i)} & =\underbrace{\rho f_{x}}_{(i i)}-\underbrace{\frac{\partial p}{\partial x}}_{(i i i)}+\underbrace{\frac{\partial}{\partial x}\left(2 \eta \frac{\partial v_{x}}{\partial x}\right)}_{(i v)}+\underbrace{\frac{\partial}{\partial y}\left(\eta \frac{\partial v_{y}}{\partial x}\right)}_{(v)}+\underbrace{\frac{\partial}{\partial y}\left(\eta \frac{\partial v_{x}}{\partial y}\right)}_{(v i)} \\
& +\underbrace{\frac{\partial}{\partial z}\left(\eta \frac{\partial v_{x}}{\partial z}\right)}_{(v i i)}+\underbrace{\frac{\partial}{\partial z}\left(\eta \frac{\partial v_{z}}{\partial x}\right)}_{(v i i i)}-\underbrace{\rho\left(v_{x} \frac{\partial v_{x}}{\partial x}\right)}_{(i x)}-\underbrace{\rho\left(v_{y} \frac{\partial v_{x}}{\partial y}\right)}_{(x)}-\underbrace{\rho\left(v_{z} \frac{\partial v_{x}}{\partial z}\right)}_{(x i)} .
\end{aligned}
$$


Avaliando a ordem de magnitude de cada termo, tem-se:

Termo (i):

$$
O\left[\rho \frac{\partial v_{x}}{\partial t}\right]=O\left[\rho_{0} \frac{\mathrm{v}_{0}}{t}\right]=O\left[\rho_{0} \frac{\delta \mathrm{v}_{0}^{2}}{H}\right]=O\left[10^{3} \frac{10^{-2} \delta}{10^{-3}}\right]=O\left[10^{4} \delta\right] .
$$

Termo (ii):

$$
O\left[\rho g_{(x)}\right]=O\left[\rho_{0} g_{0}\right]=O\left[10^{3} 10\right]=O\left[10^{4}\right]
$$

Termo (iii):

$$
O\left[\frac{\partial p}{\partial x}\right]=O\left[\frac{p_{0}}{L}\right]=O\left[\frac{\delta p_{0}}{H}\right]=O\left[\frac{10^{7} \delta}{10^{-3}}\right]=O\left[10^{10} \delta\right]
$$

Termo (iv):

$$
O\left[\frac{\partial}{\partial x}\left(2 \eta \frac{\partial v_{x}}{\partial x}\right)\right]=O\left[\frac{1}{L}\left(\eta_{0} \frac{\mathrm{v}_{0}}{L}\right)\right]=O\left[\eta_{0} \frac{\delta^{2} \mathrm{v}_{0}}{H^{2}}\right]=O\left[10^{4} \frac{10^{-1} \delta^{2}}{10^{-6}}\right]=O\left[10^{9} \delta^{2}\right]
$$

Termo (v):

$$
O\left[\frac{\partial}{\partial y}\left(\eta \frac{\partial v_{y}}{\partial x}\right)\right]=O\left[\frac{1}{L}\left(\eta_{0} \frac{\mathrm{v}_{0}}{L}\right)\right]=O\left[\eta_{0} \frac{\delta^{2} \mathrm{v}_{0}}{H^{2}}\right]=O\left[10^{4} \frac{10^{-1} \delta^{2}}{10^{-6}}\right]=O\left[10^{9} \delta^{2}\right]
$$

Termo (vi):

$$
O\left[\frac{\partial}{\partial y}\left(\eta \frac{\partial v_{x}}{\partial y}\right)\right]=O\left[\frac{1}{L}\left(\eta_{0} \frac{\mathrm{v}_{0}}{L}\right)\right]=O\left[\eta_{0} \frac{\delta^{2} \mathrm{v}_{0}}{H^{2}}\right]=O\left[10^{4} \frac{10^{-1} \delta^{2}}{10^{-6}}\right]=O\left[10^{9} \delta^{2}\right]
$$

Termo (vii):

$$
O\left[\frac{\partial}{\partial z}\left(\eta \frac{\partial v_{x}}{\partial z}\right)\right]=O\left[\frac{1}{H}\left(\eta_{0} \frac{\mathrm{v}_{0}}{H}\right)\right]=O\left[\eta_{0} \frac{\mathrm{v}_{0}}{H^{2}}\right]=O\left[10^{4} \frac{10^{-1}}{10^{-6}}\right]=O\left[10^{9}\right] .
$$

Termo (viii):

$O\left[\frac{\partial}{\partial z}\left(\eta \frac{\partial v_{z}}{\partial x}\right)\right]=O\left[\frac{1}{H}\left(\eta_{0} \frac{\delta \mathrm{v}_{0}}{L}\right)\right]=O\left[\frac{1}{H} \eta_{0} \frac{\delta^{2} \mathrm{v}_{0}}{H}\right]=O\left[\frac{1}{10^{-3}} 10^{4} \frac{10^{-1} \delta^{2}}{10^{-3}}\right]=O\left[10^{9} \delta^{2}\right]$

Termo (ix):

$$
O\left[\rho v_{x} \frac{\partial v_{x}}{\partial x}\right]=O\left[\rho_{0} \mathrm{v}_{0} \frac{\mathrm{v}_{0}}{L}\right]=O\left[\rho_{0} \mathrm{v}_{0} \frac{\delta \mathrm{v}_{0}}{H}\right]=O\left[10^{3} 10^{-1} \frac{10^{-1} \delta}{10^{-3}}\right]=O\left[10^{4} \delta\right] .
$$

Termo (x):

$$
O\left[\rho v_{y} \frac{\partial v_{x}}{\partial y}\right]=O\left[\rho_{0} \mathrm{v}_{0} \frac{\mathrm{v}_{0}}{L}\right]=O\left[\rho_{0} \mathrm{v}_{0} \frac{\delta \mathrm{v}_{0}}{H}\right]=O\left[10^{3} 10^{-1} \frac{10^{-1} \delta}{10^{-3}}\right]=O\left[10^{4} \delta\right] .
$$


Termo (xi):

$$
O\left[\rho v_{z} \frac{\partial v_{x}}{\partial z}\right]=O\left[\rho_{0} \delta \mathrm{v}_{0} \frac{\mathrm{v}_{0}}{H}\right]=O\left[10^{3} 10^{-1} \frac{10^{-1} \delta}{10^{-3}}\right]=O\left[10^{4} \delta\right] .
$$

\section{A.2.2 Análise dos termos da componente-y}

A equação da componente- $y$ da equação da quantidade de movimento, com seus termos expandidos e numerados é:

$$
\begin{aligned}
\underbrace{\rho \frac{\partial v_{y}}{\partial t}}_{(i)} & =\underbrace{\rho f_{y}}_{(i i)}-\underbrace{\frac{\partial p}{\partial y}}_{(i i i)}+\underbrace{\frac{\partial}{\partial x}\left(\eta \frac{\partial v_{x}}{\partial y}\right)}_{(i v)}+\underbrace{\frac{\partial}{\partial x}\left(\eta \frac{\partial v_{y}}{\partial x}\right)}_{(v)}+\underbrace{\frac{\partial}{\partial y}\left(2 \eta \frac{\partial v_{y}}{\partial y}\right)}_{(v i)}+ \\
& +\underbrace{\frac{\partial}{\partial z}\left(\eta \frac{\partial v_{y}}{\partial z}\right)}_{(v i i)}+\underbrace{\frac{\partial}{\partial z}\left(\eta \frac{\partial v_{z}}{\partial y}\right)}_{(v i i i)}-\underbrace{\rho\left(v_{x} \frac{\partial v_{y}}{\partial x}\right)}_{(i x)}-\underbrace{\rho\left(v_{y} \frac{\partial v_{y}}{\partial y}\right)}_{(x)}-\underbrace{\rho\left(v_{z} \frac{\partial v_{y}}{\partial z}\right)}_{(x i)} .
\end{aligned}
$$

Comparando a componente-y da equação da quantidade de movimento (Equação (A.2)), com a componente- $x$ (Equação (A.3)), fica claro que as ordens de magnitude de seus termos são idênticas, e portanto a análise desta componente torna-se redundante.

\section{A.2.3 Análise dos termos da componente- $z$}

Expandindo a componente $z$ da equação da quantidade de movimento, tem-se:

$$
\begin{aligned}
\underbrace{\rho \frac{\partial v_{z}}{\partial t}}_{(i)} & =\underbrace{\rho f_{z}}_{(i i)}-\underbrace{\frac{\partial p}{\partial z}}_{(i i i)}+\underbrace{\frac{\partial}{\partial x}\left(\eta \frac{\partial v_{x}}{\partial z}\right)}_{(i v)}+\underbrace{\frac{\partial}{\partial x}\left(\eta \frac{\partial v_{z}}{\partial x}\right)}_{(v)}+\underbrace{\frac{\partial}{\partial y}\left(\eta \frac{\partial v_{y}}{\partial z}\right)}_{(v i)} \\
& +\underbrace{\frac{\partial}{\partial y}\left(\eta \frac{\partial v_{z}}{\partial y}\right)}_{(v i i)}+\underbrace{\frac{\partial}{\partial z}\left(2 \eta \frac{\partial v_{z}}{\partial z}\right)}_{(v i i i)}-\underbrace{\rho\left(v_{x} \frac{\partial v_{z}}{\partial x}\right)}_{(i x)}-\underbrace{\rho\left(v_{y} \frac{\partial v_{z}}{\partial y}\right)}_{(x)}-\underbrace{\rho\left(v_{z} \frac{\partial v_{z}}{\partial z}\right)}_{(x i)} .
\end{aligned}
$$

Avaliando cada termo na Equação (A.4), tem-se:

Termo (i):

$$
O\left[\rho \frac{\partial v_{z}}{\partial t}\right]=O\left[\rho_{0} \frac{\delta \mathrm{v}_{0}}{t_{0}}\right]=O\left[\rho_{0} \frac{\delta^{2} \mathrm{v}_{0}^{2}}{H}\right]=O\left[10^{3} \frac{\delta^{2} 10^{-2}}{10^{-3}}\right]=O\left[10^{4} \delta^{2}\right]
$$

Termo (ii):

$$
O\left[\rho g_{z}\right]=O\left[\rho_{0} g_{0}\right]=O\left[10^{3} 10\right]=O\left[10^{4}\right]
$$

Termo (iii):

$$
O\left[\frac{\partial p}{\partial z}\right]=O\left[\frac{p_{0}}{H}\right]=O\left[\frac{10^{7}}{10^{-3}}\right]=O\left[10^{10}\right]
$$


Termo (iv):

$$
\begin{aligned}
O\left[\frac{\partial}{\partial x}\left(\eta \frac{\partial v_{x}}{\partial z}\right)\right] & =O\left[\frac{1}{L}\left(\eta_{0} \frac{\mathrm{v}_{0}}{H}\right)\right]=O\left[\frac{\delta}{H}\left(\eta_{0} \frac{\mathrm{v}_{0}}{H}\right)\right]=O\left[\frac{\delta}{10^{-3}}\left(10^{4} \frac{10^{-1}}{10^{-3}}\right)\right] \\
& =O\left[10^{9} \delta\right]
\end{aligned}
$$

Termo (v):

$$
\begin{aligned}
O\left[\frac{\partial}{\partial x}\left(\eta \frac{\partial v_{z}}{\partial z}\right)\right] & =O\left[\frac{1}{L}\left(\eta_{0} \frac{\delta \mathrm{v}_{0}}{L}\right)\right]=O\left[\frac{\delta}{H}\left(\eta_{0} \frac{\delta^{2} \mathrm{v}_{0}}{H}\right)\right]=O\left[\frac{\delta}{10^{-3}}\left(10^{4} \frac{10^{-1} \delta^{3}}{10^{-3}}\right)\right] \\
& =O\left[10^{9} \delta^{3}\right]
\end{aligned}
$$

Termo (vi):

$$
\begin{aligned}
O\left[\frac{\partial}{\partial y}\left(\eta \frac{\partial v_{y}}{\partial z}\right)\right] & =O\left[\frac{1}{L}\left(\eta_{0} \frac{\mathrm{v}_{0}}{L}\right)\right]=O\left[\frac{\delta}{H}\left(\eta_{0} \frac{\mathrm{v}_{0}}{H}\right)\right]=O\left[\frac{\delta}{10^{-3}}\left(10^{4} \frac{10^{-1}}{10^{-3}}\right)\right] \\
& =O\left[10^{9} \delta\right]
\end{aligned}
$$

Termo (vii):

$$
\begin{aligned}
O\left[\frac{\partial}{\partial y}\left(\eta \frac{\partial v_{z}}{\partial y}\right)\right] & =O\left[\frac{1}{L}\left(\eta_{0} \frac{\delta \mathrm{v}_{0}}{L}\right)\right]=O\left[\frac{\delta}{H}\left(\eta_{0} \frac{\delta^{2} \mathrm{v}_{0}}{H}\right)\right] \\
& =O\left[\frac{\delta}{10^{-3}}\left(10^{4} \frac{10^{-1} \delta^{3}}{10^{-3}}\right)\right]=O\left[10^{9} \delta^{3}\right]
\end{aligned}
$$

Termo (viii):

$$
O\left[\frac{\partial}{\partial z}\left(2 \eta \frac{\partial v_{z}}{\partial z}\right)\right]=O\left[\frac{1}{H}\left(\eta_{0} \frac{\delta \mathrm{v}_{0}}{L}\right)\right]=O\left[\frac{1}{10^{-3}}\left(10^{4} \frac{10^{-1} \delta}{10^{-3}}\right)\right]=O\left[10^{9} \delta\right] .
$$

Termo (ix):

$$
O\left[\rho v_{x} \frac{\partial v_{z}}{\partial x}\right]=O\left[\rho_{0} \mathrm{v}_{0} \frac{\delta \mathrm{v}_{0}}{L}\right]=O\left[\rho_{0} \mathrm{v}_{0} \frac{\delta^{2} \mathrm{v}_{0}}{H}\right]=O\left[10^{3} 10^{-1} \frac{10^{-1} \delta^{2}}{10^{-3}}\right]=O\left[10^{4} \delta^{2}\right]
$$

Termo (x):

$$
O\left[\rho v_{y} \frac{\partial v_{z}}{\partial y}\right]=O\left[\rho_{0} \mathrm{v}_{0} \frac{\delta \mathrm{v}_{0}}{L}\right]=O\left[\rho_{0} \mathrm{v}_{0} \frac{\delta^{2} \mathrm{v}_{0}}{H}\right]=O\left[10^{3} 10^{-1} \frac{10^{-1} \delta^{2}}{10^{-3}}\right]=O\left[10^{4} \delta^{2}\right]
$$

Termo (xi):

$$
O\left[\rho v_{z} \frac{\partial v_{z}}{\partial z}\right]=O\left[\rho_{0} \delta \mathrm{v}_{0} \frac{\delta \mathrm{v}_{0}}{H}\right]=O\left[10^{3} \delta 10^{-1} \frac{10^{-1} \delta}{10^{-3}}\right]=O\left[10^{4} \delta^{2}\right] .
$$




\section{A.2.4 Equações resultantes}

Escrevendo convenientemente a ordem de magnitud sob cada um dos termos presentes nas Equações (A.2), (A.3) e (A.4), tem-se:

Componente- $x$ :

$$
\begin{aligned}
\underbrace{\rho \frac{\partial v_{x}}{\partial t}}_{10^{4} \delta} & =\underbrace{\rho f_{x}}_{10^{4}}-\underbrace{\frac{\partial p}{\partial x}}_{10^{10} \delta}+\underbrace{\frac{\partial}{\partial x}\left(2 \eta \frac{\partial v_{x}}{\partial x}\right)}_{10^{9} \delta^{2}}+\underbrace{\frac{\partial}{\partial y}\left(\eta \frac{\partial v_{y}}{\partial x}\right)}_{10^{9} \delta^{2}}+\underbrace{\frac{\partial}{\partial y}\left(\eta \frac{\partial v_{x}}{\partial y}\right)}_{10^{9} \delta^{2}} \\
& +\underbrace{\frac{\partial}{\partial z}\left(\eta \frac{\partial v_{x}}{\partial z}\right)}_{10^{9}}+\underbrace{\frac{\partial}{\partial z}\left(\eta \frac{\partial v_{z}}{\partial x}\right)}_{10^{9} \delta^{2}}-\underbrace{\rho\left(v_{x} \frac{\partial v_{x}}{\partial x}\right)}_{10^{4} \delta}-\underbrace{\rho\left(v_{y} \frac{\partial v_{x}}{\partial y}\right)}_{10^{4} \delta}-\underbrace{\rho\left(v_{z} \frac{\partial v_{x}}{\partial z}\right)}_{10^{4} \delta} .
\end{aligned}
$$

Componente-y:

$$
\begin{aligned}
\underbrace{\rho \frac{\partial v_{y}}{\partial t}}_{10^{4} \delta} & =\underbrace{\rho f_{y}}_{10^{4}}-\underbrace{\frac{\partial p}{\partial y}}_{10^{10} \delta}+\underbrace{\frac{\partial}{\partial x}\left(\eta \frac{\partial v_{x}}{\partial y}\right)}_{10^{9} \delta^{2}}+\underbrace{\frac{\partial}{\partial x}\left(\eta \frac{\partial v_{y}}{\partial x}\right)}_{10^{9} \delta^{2}}+\underbrace{\frac{\partial}{\partial y}\left(2 \eta \frac{\partial v_{y}}{\partial y}\right)}_{10^{9} \delta^{2}} \\
& +\underbrace{\frac{\partial}{\partial z}\left(\eta \frac{\partial v_{z}}{\partial y}\right)}_{10^{9} \delta^{2}}+\underbrace{\frac{\partial}{\partial z}\left(\eta \frac{\partial v_{y}}{\partial z}\right)}_{10^{9}}-\underbrace{\rho\left(v_{x} \frac{\partial v_{y}}{\partial x}\right)}_{10^{4} \delta}-\underbrace{\rho\left(v_{y} \frac{\partial v_{y}}{\partial y}\right)}_{10^{4} \delta}-\underbrace{\rho\left(v_{z} \frac{\partial v_{y}}{\partial z}\right)}_{10^{4} \delta}
\end{aligned}
$$

Componente- $z$ :

$$
\begin{aligned}
\underbrace{\rho \frac{\partial v_{z}}{\partial t}}_{10^{4} \delta} & =\underbrace{\rho f_{z}}_{10^{4}}-\underbrace{\frac{\partial p}{\partial z}}_{10^{10}}+\underbrace{\frac{\partial}{\partial x}\left(\eta \frac{\partial v_{x}}{\partial z}\right)}_{10^{9} \delta}+\underbrace{\frac{\partial}{\partial x}\left(\eta \frac{\partial v_{z}}{\partial x}\right)}_{10^{9} \delta^{3}}+\underbrace{\frac{\partial}{\partial y}\left(\eta \frac{\partial v_{y}}{\partial z}\right)}_{10^{9} \delta} \\
& +\underbrace{\frac{\partial}{\partial y}\left(\eta \frac{\partial v_{z}}{\partial y}\right)}_{10^{9} \delta^{3}}+\underbrace{\frac{\partial}{\partial z}\left(2 \eta \frac{\partial v_{z}}{\partial z}\right)}_{10^{9} \delta}-\underbrace{\rho\left(v_{x} \frac{\partial v_{z}}{\partial x}\right)}_{10^{4} \delta^{2}}-\underbrace{\rho\left(v_{y} \frac{\partial v_{z}}{\partial y}\right)}_{10^{4} \delta^{2}}-\underbrace{\rho\left(v_{z} \frac{\partial v_{z}}{\partial z}\right)}_{10^{4} \delta^{2}} .
\end{aligned}
$$

Como a maioria das peças moldadas por injeção são finas, espera-se $\delta$ muito menor do que um. Tipicamente, $\delta$ varia no intervalo $0,001<\delta<0,1$. Desta forma, os termos mais dominantes são o gradiente de pressão e as forças viscosas resultantes das derivadas na direção $z$.

Em particular, para $\delta=0,1$, forças gravitacionais e inerciais são, respectivamente, cinco e seis ordens de magnitude menores que os maiores termos. Desta forma, ignora-se todos os termos menores ou iguais a $10^{9} \delta$, e então, as equações para as componentes $x, y$ e $z$ da equação quantidade de movimento se tornam, respectivamente:

$$
\frac{\partial p}{\partial x}=\frac{\partial}{\partial z}\left(\eta \frac{\partial v_{x}}{\partial z}\right), \quad \frac{\partial p}{\partial y}=\frac{\partial}{\partial z}\left(\eta \frac{\partial v_{y}}{\partial z}\right) \quad \text { e } \quad \frac{\partial p}{\partial z}=0 .
$$




\section{A.3 Equação da temperatura}

A equação da energia para a fase de preenchimento, em termos de temperatura, pode ser escrita em coordenadas cartesianas e ter seus termos expandidos e enumerados, como segue:

$$
\begin{aligned}
\underbrace{\rho c_{p} \frac{\partial T}{\partial t}}_{(i)}+\underbrace{\rho c_{p} v_{x} \frac{\partial T}{\partial x}}_{(i i)} & +\underbrace{\rho c_{p} v_{y} \frac{\partial T}{\partial y}}_{(i i i)}+\underbrace{\rho c_{p} v_{z} \frac{\partial T}{\partial z}}_{(i v)}=\underbrace{\beta T \frac{\partial p}{\partial t}}_{(v)}+\underbrace{\beta T v_{x} \frac{\partial p}{\partial x}}_{(v i)}+ \\
& +\underbrace{\beta T v_{y} \frac{\partial p}{\partial y}}_{(v i i)}+\underbrace{\beta T v_{z} \frac{\partial p}{\partial z}}_{(v i i i)}+\underbrace{\eta \dot{\gamma}^{2}}_{(i x)}+\underbrace{k \frac{\partial^{2} T}{\partial x^{2}}}_{(x)}+\underbrace{k \frac{\partial^{2} T}{\partial y^{2}}}_{(x i)}+\underbrace{k \frac{\partial^{2} T}{\partial z^{2}}}_{(x i i)}
\end{aligned}
$$

Agora calcula-se se a ordem de magnitude de cada um dos termos:

Termo (i):

$$
O\left[\rho c_{p} \frac{\partial T}{\partial t}\right]=O\left[\rho_{0} c_{p_{0}} \frac{T_{0}}{t_{0}}\right]=O\left[\rho_{0} c_{p_{0}} \frac{\delta T_{0} \mathrm{v}_{0}}{H}\right]=O\left[10^{3} 10^{3} \frac{10^{2} 10^{-1} \delta}{10^{-3}}\right]=O\left[10^{10} \delta\right] .
$$

Termo (ii):

$O\left[\rho c_{p} v_{x} \frac{\partial T}{\partial x}\right]=O\left[\rho_{0} c_{p_{0}} \mathrm{v}_{0} \frac{T_{0}}{t_{0}}\right]=O\left[\rho_{0} c_{p_{0}} \mathrm{v}_{0} \frac{\delta T_{0}}{H}\right]=O\left[10^{3} 10^{3} 10^{-1} \frac{10^{2} \delta}{10^{-3}}\right]=O\left[10^{10} \delta\right]$.

Termo (iii):

$O\left[\rho c_{p} v_{y} \frac{\partial T}{\partial y}\right]=O\left[\rho_{0} c_{p_{0}} \mathrm{v}_{0} \frac{T_{0}}{t_{0}}\right]=O\left[\rho_{0} c_{p_{0}} \mathrm{v}_{0} \frac{\delta T_{0}}{H}\right]=O\left[10^{3} 10^{3} 10^{-1} \frac{10^{2} \delta}{10^{-3}}\right]=O\left[10^{10} \delta\right]$.

Termo (iv):

$$
\begin{aligned}
O\left[\rho c_{p} v_{z} \frac{\partial T}{\partial z}\right] & =O\left[\rho_{0} c_{p_{0}} \delta \mathrm{v}_{0} \frac{T_{0}}{H}\right]=O\left[\rho_{0} c_{p_{0}} \delta \mathrm{v}_{0} \frac{\delta T_{0}}{H}\right]=O\left[10^{3} 10^{3} \delta 10^{-1} \frac{10^{2}}{10^{-3}}\right] \\
& =O\left[10^{10} \delta\right] .
\end{aligned}
$$

Termo (v):

$$
O\left[\beta T \frac{\partial p}{\partial t}\right]=O\left[\beta_{0} T_{0} \frac{p_{0}}{t_{0}}\right]=O\left[\beta_{0} T_{0} \frac{p_{0} \delta \mathrm{v}_{0}}{H}\right]=O\left[10^{-3} 10^{2} \frac{10^{7} \delta 10^{-1}}{10^{-3}}\right]=O\left[10^{8} \delta\right] .
$$

Termo (vi):

$O\left[\beta T v_{x} \frac{\partial p}{\partial x}\right]=O\left[\beta_{0} T_{0} \mathrm{v}_{0} \frac{p_{0}}{L}\right]=O\left[\beta_{0} T_{0} \mathrm{v}_{0} \frac{\delta p_{0}}{H}\right]=O\left[10^{-3} 10^{2} 10^{-1} \frac{10^{7} \delta}{10^{-3}}\right]=O\left[10^{8} \delta\right]$.

Termo (vii):

$O\left[\beta T v_{y} \frac{\partial p}{\partial y}\right]=O\left[\beta_{0} T_{0} \mathrm{v}_{0} \frac{p_{0}}{L}\right]=O\left[\beta_{0} T_{0} \mathrm{v}_{0} \frac{\delta p_{0}}{H}\right]=O\left[10^{-3} 10^{2} 10^{-1} \frac{10^{7} \delta}{10^{-3}}\right]=O\left[10^{8} \delta\right]$. 
Termo (viii):

$$
O\left[\beta T v_{z} \frac{\partial p}{\partial z}\right]=O\left[\beta_{0} T_{0} \delta \mathrm{v}_{0} \frac{p_{0}}{H}\right]=O\left[10^{-3} 10^{2} \delta 10^{-1} \frac{10^{7}}{10^{-3}}\right]=O\left[10^{8} \delta\right]
$$

Termo (ix):

$$
O\left[\eta \dot{\gamma}^{2}\right]=O\left[\eta_{0}\left(\frac{\partial v_{x}}{\partial z}\right)^{2}+\left(\frac{\partial v_{y}}{\partial z}\right)^{2}\right]=O\left[\eta_{0}\left(\frac{\mathrm{v}_{0}}{H}\right)^{2}\right]=O\left[10^{4}\left(\frac{10^{-1}}{10^{-3}}\right)^{2}\right]=O\left[10^{8}\right]
$$

Termo (x):

$$
O\left[k \frac{\partial^{2} T}{\partial x^{2}}\right]=O\left[k_{0} \frac{T_{0}}{L^{2}}\right]=O\left[k_{0} \frac{T_{0} \delta^{2}}{H^{2}}\right]=O\left[10^{-1} \frac{10^{2} \delta^{2}}{10^{-6}}\right]=O\left[10^{7} \delta^{2}\right]
$$

Termo (xi):

$$
O\left[k \frac{\partial^{2} T}{\partial y^{2}}\right]=O\left[k_{0} \frac{T_{0}}{L^{2}}\right]=O\left[k_{0} \frac{T_{0} \delta^{2}}{H^{2}}\right]=O\left[10^{-1} \frac{10^{2} \delta^{2}}{10^{-6}}\right]=O\left[10^{7} \delta^{2}\right]
$$

Termo (xii):

$$
O\left[k \frac{\partial^{2} T}{\partial z^{2}}\right]=O\left[k_{0} \frac{T_{0}}{H^{2}}\right]=O\left[10^{-1} \frac{10^{2}}{10^{-6}}\right]=O\left[10^{7}\right]
$$

Escrevendo essas magnitudes abaixo dos seus respectivos termos, na Equação (A.5), obtém-se:

$$
\begin{aligned}
\underbrace{\rho c_{p} \frac{\partial T}{\partial t}}_{\left(10^{10} \delta\right)}+\underbrace{\rho c_{p} v_{x} \frac{\partial T}{\partial x}}_{\left(10^{10} \delta\right)} & +\underbrace{\rho c_{p} v_{y} \frac{\partial T}{\partial y}}_{\left(10^{10} \delta\right)}+\underbrace{\rho c_{p} v_{z} \frac{\partial T}{\partial z}}_{\left(10^{10} \delta\right)} \\
& =\underbrace{\beta T \frac{\partial p}{\partial t}}_{\left(10^{8} \delta\right)}+\underbrace{\beta T v_{x} \frac{\partial p}{\partial x}}_{\left(10^{8} \delta\right)}+\underbrace{\beta T v_{y} \frac{\partial p}{\partial y}}_{\left(10^{8} \delta\right)}+\underbrace{\beta T v_{z} \frac{\partial p}{\partial z}}_{\left(10^{8} \delta\right)} \\
& +\underbrace{\eta \dot{\gamma}^{2}}_{\left(10^{8}\right)}+\underbrace{k \frac{\partial^{2} T}{\partial x^{2}}}_{\left(10^{7} \delta^{2}\right)}+\underbrace{k \frac{\partial^{2} T}{\partial y^{2}}}_{\left(10^{7} \delta^{2}\right)}+\underbrace{k \frac{\partial^{2} T}{\partial z^{2}}}_{\left(10^{7}\right)}
\end{aligned}
$$

Pode-se, então, observar que os termos envolvendo variação de energia devido compressão e/ou expansão e condução nas direções $x$ e $y$ são de ordem de magnitude significativamente menor. Desta forma, estes termos são ignorados e obtém-se a seguinte equação de energia:

$$
\rho c_{p}\left(\frac{\partial T}{\partial t}+v_{x} \frac{\partial T}{\partial x}+v_{y} \frac{\partial T}{\partial y}+v_{z} \frac{\partial T}{\partial z}\right)=\eta \dot{\gamma^{2}}+k \frac{\partial^{2} T}{\partial z^{2}} .
$$

